\title{
WestVirginiaUniversity
}

THE RESEARCH REPOSITORY @ WVU

Graduate Theses, Dissertations, and Problem Reports

2006

\section{Phosphatidylinositol 3-kinase/Akt signaling pathway and angiogenesis}

\author{
Zongxian Cao \\ West Virginia University
}

Follow this and additional works at: https://researchrepository.wvu.edu/etd

\section{Recommended Citation}

Cao, Zongxian, "Phosphatidylinositol 3-kinase/Akt signaling pathway and angiogenesis" (2006). Graduate Theses, Dissertations, and Problem Reports. 4218.

https://researchrepository.wvu.edu/etd/4218

This Dissertation is protected by copyright and/or related rights. It has been brought to you by the The Research Repository @ WVU with permission from the rights-holder(s). You are free to use this Dissertation in any way that is permitted by the copyright and related rights legislation that applies to your use. For other uses you must obtain permission from the rights-holder(s) directly, unless additional rights are indicated by a Creative Commons license in the record and/ or on the work itself. This Dissertation has been accepted for inclusion in WVU Graduate Theses, Dissertations, and Problem Reports collection by an authorized administrator of The Research Repository @ WVU.

For more information, please contact researchrepository@mail.wvu.edu. 


\title{
Phosphatidylinositol 3-kinase/Akt Signaling Pathway and Angiogenesis
}

\author{
Zongxian Cao
}

\author{
Dissertation submitted to the \\ School of Medicine at West Virginia University \\ in partial fulfillment of the requirements \\ for the degree of \\ Doctor of Philosophy \\ in \\ Microbiology, Immunology, and Cell Biology
}

\author{
Bing-Hua Jiang, Ph.D., Chair \\ Daniel C. Flynn, Ph.D. \\ Nyles W. Charon, Ph.D. \\ Christopher F. Cuff, Ph.D. \\ Sharon L. Wenger, Ph.D. \\ Department of Microbiology, Immunology, and Cell Biology \\ Morgantown, West Virginia \\ 2006
}

Key Words: phosphatidylinositol 3-kinase (PI3K), Akt, p70S6K1, cyclooxgenase-2, HIF-1, VEGF, angiogenesis, ovarian cancer

Copyright 2006 Zongxian Cao 


\section{Abstract \\ Phosphatidylinositol 3-kinase (PI3K)/Akt Signaling Pathway and Angiogenesis}

\section{Zongxian Cao}

Angiogenesis, the formation of new blood vessels from preexisting ones, is tightly controlled under physiological conditions, and deregulated angiogenesis contributes to many pathological situations. This study investigates the role of PI3K/Akt pathway in both physiological and pathological angiogenesis. Angiopoietin-1 (Ang1) is an endothelial specific growth factor that plays a critical role in vessel maturation and stabilization during angiogenesis. We found that Ang1 potently induced p70S6K1 activation in human umbilical vein endothelial cells (HUVECs). p70S6K1 is a downstream target of PI3K, but its role in angiogenesis has not be defined. In the work shown in Chapter 2, p70S6K1 activity in HUVECs was modified by adenovirus-mediated gene transfer, and we provided first evidence that p70S6K1 is directly involved in Ang1-induced angiogenic endothelial responses, including cell migration, invasion, survival, and capillary morphogenesis. We also examined the effect and mechanisms of action of insulin-like growth factor-I (IGF-I) on the expression of cyclooxygenase-2 (COX-2), which is a crucial player in angiogenesis and tumorigenesis. In Chapter 3, we showed that IGF-I efficiently upregulated COX-2 expression in human ovarian cancer cells, which was differentially regulated by PI3K, MAPK, and PKC signaling pathways at transcriptional and/or post-transcriptional levels. In the study shown in Chapter 4, we selectively modulated PI3K/Akt signaling in either human microvascular endothelial cells or cancer cells, and examined the effects on tumor angiogenesis using a chimeric tumor model. We found that PI3K and Akt activities in both endothelial cells and tumor cells contributed to tumor growth and angiogenesis, suggesting that targeting PI3K/Akt signaling in both cellular compartments may be more effective for anti-cancer therapy. In Chapter 5, we demonstrated that resveratrol has a strong inhibitory effects on hypoxiainducible factor $1 \alpha$ (HIF-1 $\alpha$ ) and vascular endothelial growth factor (VEGF) expression in human ovarian cancer cells. The effects are associated with suppression of PI3K/Akt and MAPK pathways, interference with protein translational machinery, and enhancement of HIF-1 $\alpha$ protein degradation through the proteasome. This work provides a better understanding of the molecular basis of angiogenesis, which we hope may facilitate the identification of novel therapeutic targets in the future. 


\section{Acknowledgements}

First, I wish to thank the excellent Ph.D. program at the Department of Microbiology, Immunology, and Cell Biology. I very much value the coursework and the wonderful seminar series of the program, which exposed me to so many enlightening lectures and stimulating talks from so many knowledgeable and insightful faculties and invited scientists.

I would like to give my sincere thanks to my advisor Dr. Bing-Hua Jiang for the opportunity to undertake this dissertation research. I am grateful to my committee members-Dr. Daniel C. Flynn, Dr. Nyles W. Charon, Dr. Christopher F. Cuff, and Dr. Sharon L. Wenger. Thanks for their valuable time, kindly supports, and thoughtful suggestions. Without their supports, this dissertation would not have been completed.

For their help and friendship, I thank all the past and present members in Dr. Jiang's laboratory Jing Fang, Jenny Z. Zheng, Xiaosong Zhong, Chang Xia, Qiao Meng, Heath D. Skinner, Lesly A. Lopez, and Lingzhi Liu. I also thank all the fellow students in the department, especially Richard Bakker, Sarah Dodson, Malanie Sal, Suzanne Davis Clutter, Alex Rowe, and Ihtishaam Qazi for their friendly and helpful suggestions to improve my graduate seminar presentation.

Special thanks are extended to my English tutor and friend David R. Hopfer. I feel so fortunate to get to know David, a genuine American gentleman with amazing knowledge in English language and astute insights into the life and current society. I also thank many other friends for their encouragements and helpful opinions when things were not going well in my life.

Finally, and most importantly, I give my wholehearted thanks to my wife Huan Xu, my son Eric, and my daughter Emily. Without their love and support I can not imagine I would have made all of these. 


\section{Table of Contents}

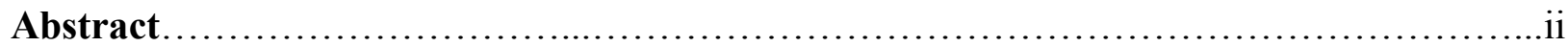

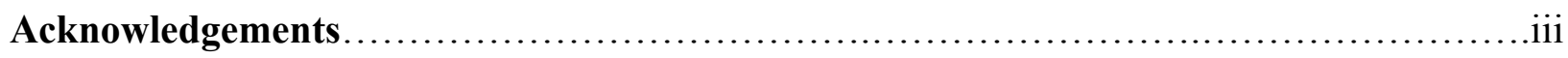

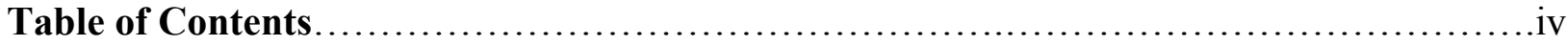

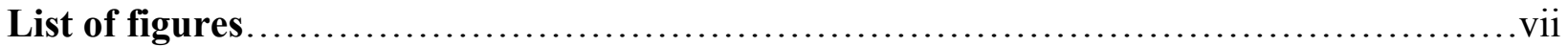

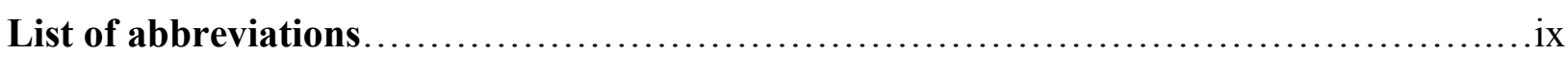

Chapter 1: Introduction and Literature Review ....................................

1. Phosphatidylinositiol 3-kinase (PI3K) /Akt signaling pathway.................................. 2

2. PI3K signaling and angiogenesis.............................................

2.1. Role of PI3K/Akt signaling in the induction of angiogenic factors................4

2.2. Role of $\mathrm{PI} 3 \mathrm{~K} /$ Akt signaling in endothelial responses to angiogenic factors..........5

2.2.1. Akt directly mediates the activation of endothelial nitric oxide synthase........6

2.2.2. Role of $\mathrm{PI} 3 \mathrm{~K} / \mathrm{Akt}$ signaling in VEGF-induced endothelial responses...........7

2.2.3. Role of PI3K/Akt signaling in angiopoietin-1-induced endothelial responses....7

3. Vascular endothelial growth factor, angiopoietin-1 and angiogenesis......................... 8

3.1. VEGF and angiogenesis............................................ 9

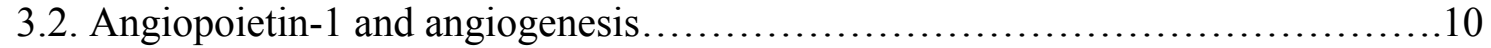

3.3. Complementary actions of VEGF and Ang1 in angiogenesis...................12

4. Role of cyclooxygenase- 2 in angiogenesis and human cancer.....................12

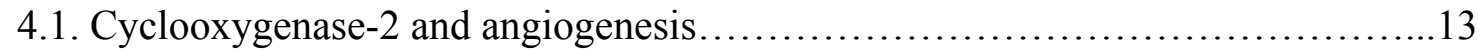

4.2. Cyclooxygenase-2 and human cancer......................................14

5. Anti-angiogenic therapy for cancer....................................... 15

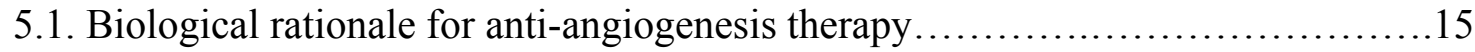

5.2. Approaches to interfere with tumor angiogenesis........................... 16

5.2.1. Monoclonal antibodies against VEGF protein or receptors.................. 17

5.2.2. VEGF receptor tyrosine kinase inhibitors............................. 17

5.2.3. Natural peptide inhibitors........................................... 18

5.2.4. Specific inhibitors of endothelial cell growth........................... 19

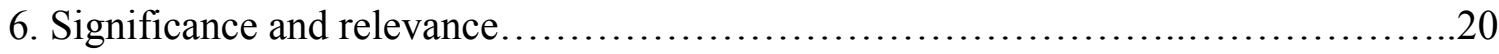

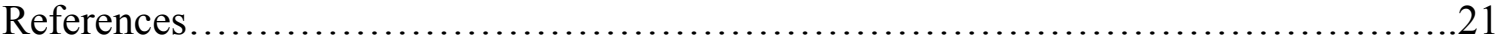




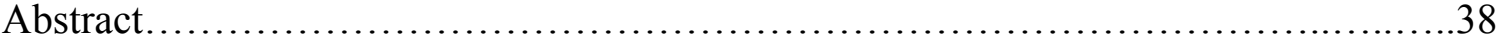

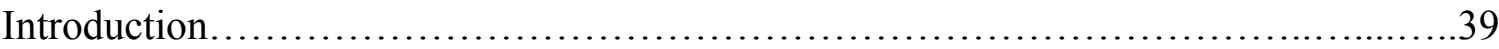

Materials and Methods............................................................40

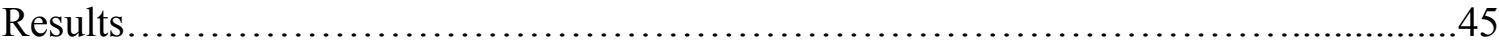

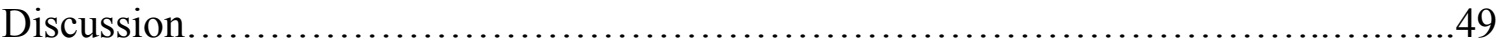

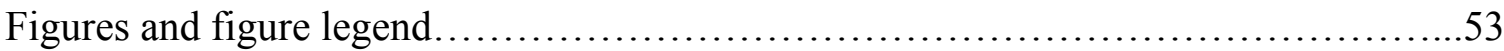

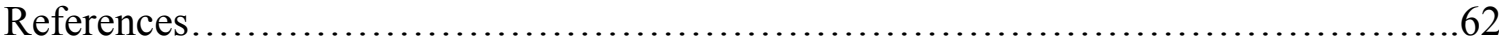

Chapter 3: Insulin-like growth factor-1 upregulates cyclooxygenase-2 expression via PI3K,

MAPK and PKC signaling pathways in human ovarian cancer cells.....................65

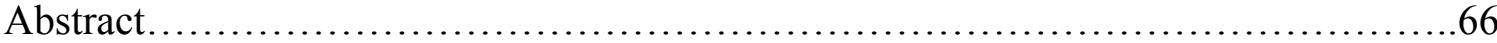

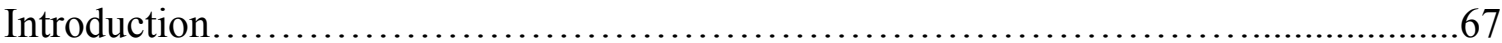

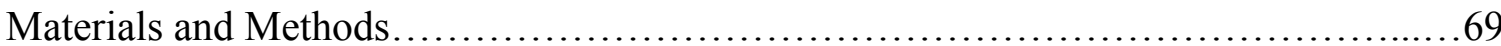

Results...................................................................... 73

Discussion.................................................................... 77

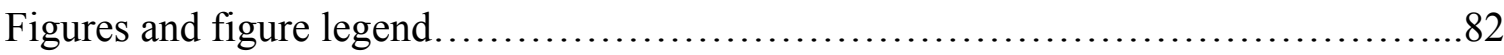

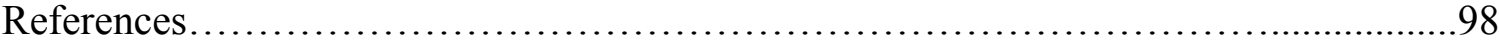

Chapter 4: Dual roles of PI3K/Akt signaling pathway in tumor-induced angiogenesis and

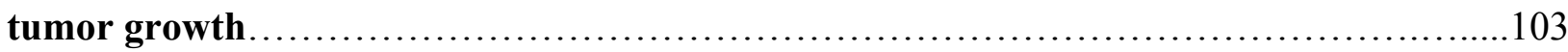

Abstract................................................................. 104

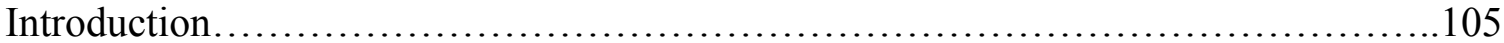

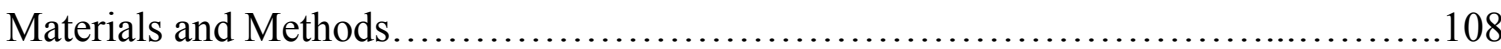

Results................................................................... 114

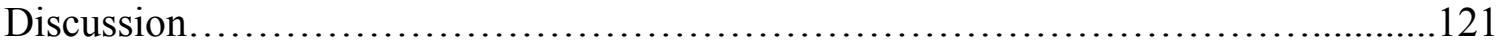

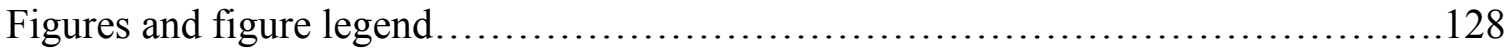

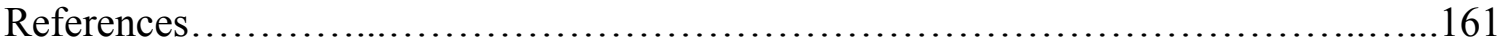

Chapter 5: trans-3,4,5'-Trihydroxystibene Inhibits Hypoxia-Inducible Factor $1 \alpha$ and Vascular Endothelial Growth Factor Expression in Human Ovarian Cancer Cells........165

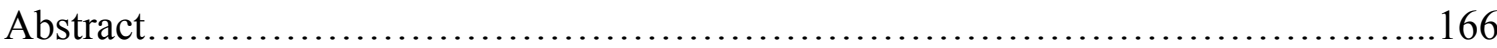

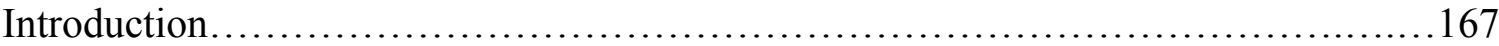

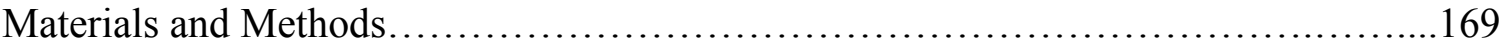




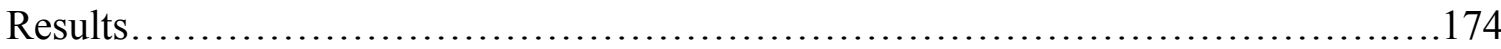

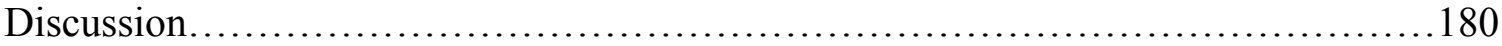

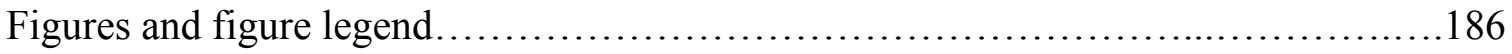

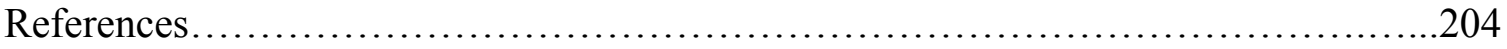

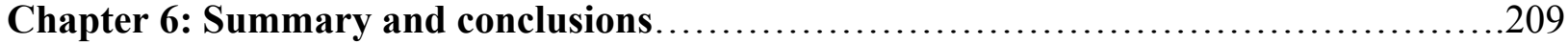

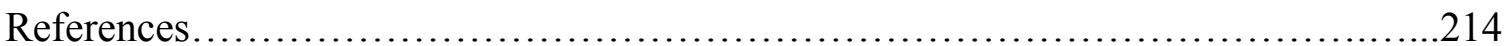

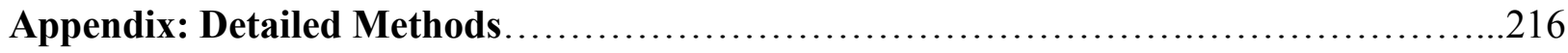

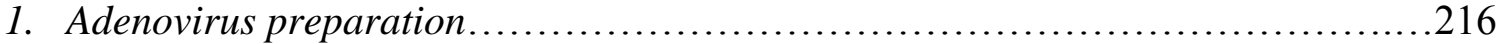

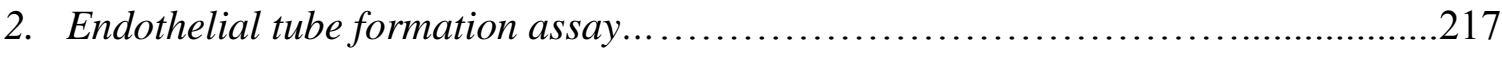

3. Biodegradable sponge fabrication........................................... 218

4. Survival surgery to co-transplant human endothelial and cancer cells in nude mice to

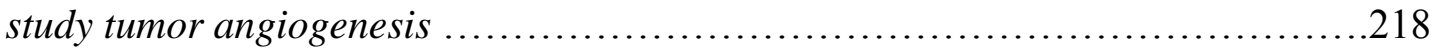

5. Co-transplantation of human endothelial and cancer cells in chicken chorioallantoic membrane (CAM) to study tumor angiogenesis.................................219

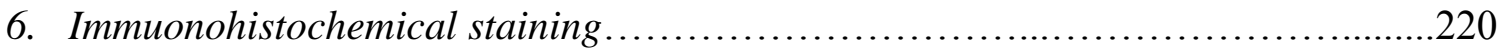

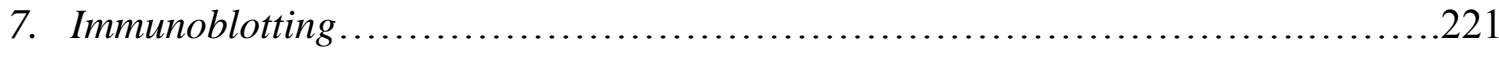

8. PKC kinase activity assay ..................................................222

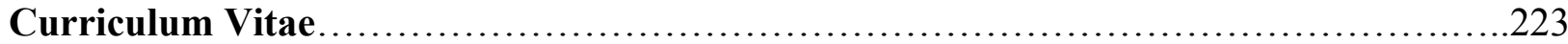




\section{List of Figures}

\section{Chapter 2}

Figure 1. Ang1 induces p70S6K1 activation in HUVECs .53

Figure 2. p70S6K1 regulates actin cytoskeleton remodeling and Ang1-induced cell migration .55

Figure 3. p70S6K1 regulates Ang1-mediated endothelial cell (EC) survival .................57

Figure 4. p70S6K1 modulates Ang1-induced EC invasion................................58

Figure 5. p70S6K1 modulates Ang1-induced EC tube formation............................60

\section{Chapter 3}

Figure 1. IGF-I upregulates COX-2 mRNA expression. ...............................82

Figure 2. IGF-I induces $\mathrm{COX}-2$ protein expression and $\mathrm{PGE}_{2}$ biosynthesis. ..................83

Figure 3. IGF-I treatment induces COX-2 transcriptional activation and mRNA stability........85

Figure 4. PI3K signaling is required for IGF-I-induced COX-2 expression..................88

Figure 5. IGF-I-induced COX-2 expression is dependent on MAPK activation...............91

Figure 6. PKC activity is important for IGF-I-induced COX-2 expression.....................94

Figure 7. Schematic representation of the mechanism by which IGF-I induces COX-2 expression in human ovarian cancer cells...................................97

\section{Chapter 4}

Figure 1. PI3K/Akt signaling in human microvascular endothelial cells (HMVEC) is critical for tumor conditioned medium-induced endothelial cell tube formation ................128

Figure 2. PI3K activity in human endothelial cells is important for tumor growth and tumor

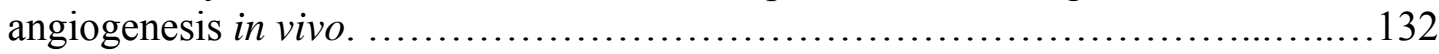

Figure 3. Modulation of Akt activity in human endothelial cells affects tumor growth and tumor induced-angiogenesis in vivo.

Figure 4. PI3K/Akt signaling regulates VEGF expression through HIF-1 $\alpha$ in human ovarian cancer cells; inhibition of PI3K or Akt activity in the cells inhibits tumor CM-induced EC tube formation.

Figure 5. Overexpression of PTEN or dominant-negative Akt in human ovarian cancer cells inhibits tumor growth and tumor-induced angiogenesis in vivo.

Figure 6. Conditioned medium collected from ovarian cancer cells stably expressing HIF-1 $\alpha$ and VEGF si-RNAs have reduced ability to induce EC tube formation .152 
Figure 7. Knockdown of HIF-1 $\alpha$ and VEGF expression in ovarian cancer cells inhibits tumor growth and angiogenesis in vivo.

Figure 8. Schematic representation of the dual roles of PI3K/Akt signaling in tumor-induced angiogenesis 160

\section{Chapter 5}

Figure 1. Resveratrol decreased HIF-1 $\alpha$ protein levels in A2780/CP70 and OVCAR-3 cells..186

Figure 2. Resveratrol inhibited serum-induced, insulin-induced, and IGF-1-induced HIF-1 $\alpha$

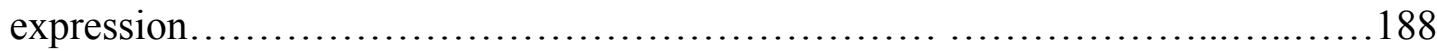

Figure 3. Effect of resveratrol on HIF-1 $\alpha$ mRNA levels......................................................190

Figure 4. Effect of resveratrol on VEGF mRNA expression in the cells.......................191

Figure 5. Effect of resveratrol on VEGF protein levels.....................................193

Figure 6. HIF-1 $\alpha$-mediated VEGF transcriptional activation in human ovarian cancer cells..195

Figure 7. Effect of resveratrol on AKT and MAPK activation.................................. 196

Figure 8. Effect of resveratrol on phosphorylation of p70S6K1, S6 ribosomal protein, 4E-BP1,

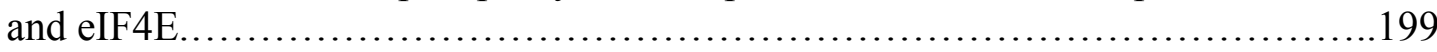

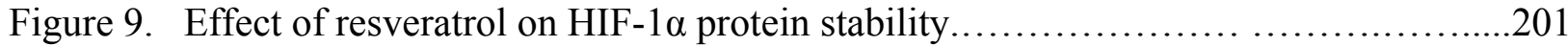

Figure 10. Resveratrol-induced HIF-1 $\alpha$ protein degradation is mediated by the proteasome

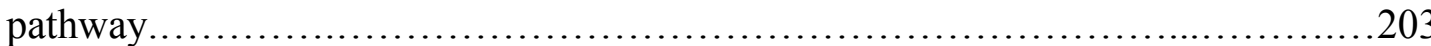




\section{List of Abbreviations}

Ang1

ARE

bFGF

CAM

$\mathrm{CEF}$

COX-2

EC

ECM

eNOS

HGF

HIF-1

HMVEC

HSP

HUVEC

IGF-I

IKK

IL-1 $\beta$

ILK

MAPK

MMP

mTOR

MVD

NO

NSAIDs

NSCLC

MOI

PA

PARP

PC

PI3K

PDK-1

$\mathrm{PGE}_{2}$

$\mathrm{PLA}_{2}$

RTK

Tie

TGF- $\beta 1$

TKRI

TSP-1

TXA2

3'-UTR

VEGF angiopoietin-1

AU-rich element

basic fibroblast growth factor

chicken chorioallantoic membrane

chicken embryo fibroblast

cyclooxygenase- 2

endothelial cell

extracellular matrix

endothelial nitric oxide synthase

hepatocyte growth factor

hypoxia-inducible factor 1

human microvascular endothelial cell

heat shock protein

human umbilical vein endothelial cell

insulin-like growth factor I

IкB kinase

interleukin $1 \beta$

integrin-linked kinase

mitogen-activated protein kinase

matrix metalloprotease

mammalian target of rapamycin

microvessel density

nitric oxide

nonsteroidal anti-inflammatory drugs

non-small cell lung cancer

multiplicity of infection

plasminagen activator

poly(ADP-ribose) polymerase

pericytes

phosphatidylinositol 3-kinase

phosphoinositide dependent kinase 1

prostaglandin $\mathrm{E}_{2}$

phospholipase $\mathrm{A}_{2}$

receptor tyrosine kinase

tyrosine kinase with immunoglobulin and epidermal growth factor

homology domain

Transforming growth factor $\beta 1$

tyrosine kinase receptor inhibitor

thrombospondin-1

thromboxane $\mathrm{A}_{2}$

3 '-untranslated region

vascular endothelial growth factor 


\section{Chapter 1}

Introduction and Literature Review 


\section{Phosphatidylinositiol 3-kinase (PI3K)/Akt signaling pathway}

Phosphatidylinositiol 3-kinase (PI3K) was initially found to form complexes with some viral oncoproteins such as v-Src and v-Ros, and attracted considerable scientific attention because of its involvement in malignant transformation (1-4). PI3K is a heterodimer composed of a regulatory subunit (p85) and a catalytic (p110) subunit, and appears to possess both lipid kinase and protein kinase activity (5;6). p85 subunit negatively regulates the catalytic activity of its associated p1 10 subunit, and this inhibition is alleviated by binding of the p85 SH2 domain to specific phosphotyrosine sequences generated by receptor or nonreceptor tyrosine kinases, and thereby leads to enzymatic activation of PI3K $(7 ; 8)$. GTP-associated Ras can directly bind to p110 catalytic subunit and stimulates the catalytic activity of PI3K (9). Upon activation, PI3K phosphorylates phosphatidylinositol at the 3'-OH of the inositol ring, producing phosphatidylinositol $(3,4,5)$ trisphosphate $\left(\mathrm{PIP}_{3}\right)$, which functions as lipid second messenger. The tumor suppressor PTEN is a phosphoinositide 3-phosphatase that specifically removes the phosphate group from the D3 position and thereby antagonizes the PI3K activity (10;11). A number of pleckstrin $(\mathrm{PH})$ domain-containing proteins, including the serine/thrionine kinase Akt, bind to $\mathrm{PIP}_{3}$ and are recruited to the inner surface of plasma membrane. $\mathrm{PIP}_{3}$ also recruits phosphoinositide dependent kinase 1 (PDK1) to the plasma membrane. Full activation of Akt requires phosphorylation of the T308 and S473 residues by PDK1 and a still controversial PDK2, respectively $(12 ; 13)$. Akt is the key downstream target of PI3K that transmits most, if not all, the signals from PI3K. A large number of Akt downstream effectors have been identified, such as Bad, caspase-9, Forkhead (FH) trsanscription factors, IкB kinases (IKKs), eNOS, BRCA1, mTOR, p70S6K1, GSK-3 $\beta$, IRS-1, Glut4, E2F, p21, MDM2, and hTERT (14;15). PI3K also 
directly affects cytoskeletal dynamics through activation of Rac and Rho GTPases (16;17). The activation of TEC family of tyrosine kinases (Btk, Itk, and Tec), which have an N-terminal PH domain, is also mediated by PI3K (18). Therefore, PI3K/Akt pathway has been emerging as one of the most important signal events involved in a variety of key cellular processes, including cell survival, cell proliferation, protein synthesis, glucose metabolism, and cell motility (19).

\section{PI3K signaling and angiogenesis}

Blood vessels are first formed by the process of vasculogenesis, which involves in situ differentiation of endothelial cells from mesodermal precursors and their organization into a primary vascular plexus. This primary capillary plexus is extended by a process called angiogenesis, in which new blood vessels are formed from the pre-existing vasculature (20). Vasculogenesis occurs only during early embryogenesis, whereas angiogenesis is required for the normal growth of both embryonic and postnatal tissues. Angiogenesis is a complex process, involving a high degree of spatial and temporal coordination between different cell types. Vascular endothelial cells play a pivotal role in new blood vessel formation. The process of angiogenesis requires that endothelial cells detach from pericytes (PC) and extracellular matrix (ECM); proliferate, migrate and form endothelial tubes; and recruit peri-endothelial supporting cells (pericytes for small capillaries; smooth muscle cells for larger vessels) to encase the endothelial tubes. Angiogenesis is crucial in many physiological processes, including embryonic development, female reproductive cycle, wound healing, tissue repair and organ regeneration. It also contributes to several pathological situations such as diabetic retinopathy, rheumatoid arthritis, and tumor progression and metastasis. 
The process of angiogenesis can be considered to have two phases: the induction and response phases. The former includes the production of angiogenic cytokines by host or/and tumor cells, and the latter refers to the functional responses of endothelial cells to these stimuli. PI3K signaling pathway appears to play a key role in both aspects of angiogenesis.

\section{1. Role of PI3K/Akt signaling in the induction of angiogenic factors}

Under physiological conditions, angiogenesis is tightly regulated through a local balance between angiogenic stimulators (e.g., VEGF, bFGF, TGF-beta, PDGF) and angiogenic inhibitors (e.g., thrombospondin-1 (TSP-1), tissue inhibitor of MMP-1, angiostatin, endostatin). The robust formation of new blood vessels in many pathological settings is due to either a decrease in levels of inhibitors, an increase in levels of inducers, or a combination of both (21). VEGF is the most powerful and selective angiogenic inducers. VEGF is expressed by many types of cells surrounding the area of angiogenesis, including the activated endothelial cells themselves. A majority of malignant tumors overexpress VEGF, and tumor cell-derived VEGF was considered to be the primary stimulus for tumor angiogenesis (22). One of the major stimuli for VEGF expression in tumor cells is intratumoral hypoxia, a characteristic property of advanced solid tumors, which is caused by the structural and functional abnormalities of the tumor microvasculature, rapid expansion of tumor mass, and tumor-associated anemia $(23 ; 24)$. Hypoxia induces VEGF expression primarily through the induction of hypoxia-inducible factor-1 (HIF-1) $(25 ; 26)$. HIF-1 is a heterodimeric transcriptional factor composed of HIF-1 $\alpha$ and HIF-1ß subunits (27). HIF-1 $\alpha$ is rapidly accumulated under hypoxia conditions due to the inhibition of ubiquitin-mediated degradation, and subsequently dimerizes with the constitutively expressed HIF-1 $\beta$, and activates transcription of target genes, including VEGF (23). HIF-1 $\alpha$ also regulates 
VEGF expression under normoxic conditions. Many growth factors and oncogenic proteins can induce HIF-1 $\alpha$-mediated VEGF expression in a PI3K/Akt-dependent manner (28-31). Forced expression of PI3K or Akt was shown to sufficiently induce VEGF expression in fibroblasts and endothelial cells (32). Consistently, it was found that loss of PTEN upregulates VEGF production in prostate cancer cells, and reintroduction of PTEN decreases VEGF production (33). The PI3K specific inhibitor LY294002 reduces both constitutive and hypoxia-induced VEGF expression in ovarian cancer cells (34). In addition, PI3K controls hepatocyte growth factor (HGF)-induced production of IL-8, which is another important angiogenic cytokine (35). In a mouse glioma tumor model, overexpression of PTEN suppresses tumor angiogenesis, which correlates with increased TSP-1 expression in the tumor cells (36). PTEN and PI3K inhibitor LY294002 were shown to be able to induce transactivation of p53 in glioma tumor cells, and systemic administration of LY294002 significantly decreases tumor-induced angiogenesis and tumor growth in vivo (37). A more recent study demonstrated that activation of integrin-linked kinase (ILK) resulted in HIF-1 $\alpha$-mediated VEGF expression in prostate cancer cells, which contributed to tumor growth and tumor angiogenesis in vivo (38).

\section{2. Role of PI3K/Akt signaling in endothelial responses to angiogenic factors}

Vascular endothelial cells play a central role during angiogenesis. A single layer of endothelial cells (termed endothelium) lines the lumen surface of mature capillaries. Basement membrane and a layer of cells called pericytes surround the endothelium and maintain the integrity of the vessels. Endothelial cells are the biological target of most angiogenic factors. Upon stimulation by angiogenic factors, endothelial cells become activated and secrete proteases that digest the basement membrane and break the cell-cell junctions between endothelial cells. 
The cells then migrate, proliferate and form sprouts towards the source of the angiogenic stimuli. Neighboring blind-ended sprouts then join together to form a capillary loop, which eventually matures into functional blood vessels. During the process of angiogenesis, the continuous presence of angiogenic factors is the prerequisite for endothelial cell proliferation, migration, survival, and differentiation into tube structures. The PI3K/Akt signaling pathway has been recognized as the key signaling event involved in the regulation of these angiogenic endothelial responses.

\section{2. 1. Akt directly mediates the activation of endothelial nitric oxide synthase (eNOS)}

It is well established that endothelial-derived nitric oxide (NO) plays an essential role in postnatal neovascularization $(39 ; 40)$. NO production in endothelial cells is catalyzed by endothelial nitric oxide synthase (eNOS). Akt was shown to phosphorylate eNOS at Ser1177, leading to a persistent, calcium-independent eNOS activation $(41 ; 42)$. The activity of eNOS is also regulated by subcellular localization and protein-protein interactions. eNOS has been shown to localize in caveolae and to interact with caveolin-1, which inhibits eNOS activity (43-45). eNOS was also shown to interact with heat shock protein 90 (Hsp90) upon stimulation with VEGF or shear stress, and this interaction enhances eNOS activity (46). Interestingly, Akt also interacts with Hsp90 upon stimulation and this interaction enhances Akt enzymatic activity (47). It was suggested that Hsp90 may serve as a scaffold protein for the efficient phosphorylation of eNOS by Akt at caveolae (48) 


\section{2. 2. Role of PI3K/Akt signaling in VEGF-induced endothelial responses}

Binding of growth factors to the cognate tyrosine kinase receptors represents the prototypical model of PI3K activation. As an endothelial-specific growth factor, VEGF binds to its receptor KDR and induces positive angiogenic responses. In cultured human umbilical vein endothelial cells (HUVECs), the p85 subunit of PI3K was shown to constitutively associate with KDR (49). VEGF induces phosphorylation of p85 and subsequent PI3K activation, which is required for VEGF-induced EC proliferation(49;50). VEGF/KDR-induced anti-apoptotic effect is also PI3K and Akt dependent (51;52). VEGF-induced EC migration was inhibited by overexpression of a dominant-negative Akt. Conversely, introduction of a constitutively active Akt initiated cell migration in the absence of VEGF (53). In an in vivo model, transduction of a dominant-negative Akt was shown to block VEGF-induced vascular permeability, whereas expression of an active form of Akt mimicked the effect of VEGF (54). Forced expression of PTEN in HUVECs inhibited VEGF-induced cell migration and proliferation. In contrast, expression of a dominant-negative PTEN enhanced VEGF-mediated cell migration, proliferation and tube formation (55). Interestingly, activation of PI3K/Akt signaling can in turn increase VEGF expression (56-58). It is plausible that VEGF-induced PI3K/Akt signaling mediates an autocrine expression of VEGF that amplifies VEGF functions.

\section{2. 3. Role of PI3K/Akt signaling in angiopoietin-1-induced endothelial responses}

Angiopoietin-1 (Ang1) was identified in 1996 as a ligand for receptor Tie2, which is expressed almost exclusively in endothelial cells $(59 ; 60)$. As an endothelial specific growth factor, Ang1 plays a very important role in angiogenesis. Ang1 is critical for vessel maturation and stabilization at the later stages of angiogenesis by recruiting mural cells to support the primitive 
endothelial tubes $(61 ; 62)$. Ang1 does not stimulate endothelial cell proliferation, rather it is a potent factor for endothelia cell survival (63-66), and can induce endothelial cell migration (67), sprouting (68;69), and tube formation (70-72). Binding of Ang1 to its receptor Tie2 activates PI3K /Akt signaling pathway (73). Tyrosine 1101 of $\mathrm{Tie}_{2}$ receptor was shown to associate with the p85 subunit of PI3K, inducing PI3K and Akt activation (74). PI3K/Akt signaling plays an essential role in Ang1/Tie2-induced angiogenic responses in endothelial cells, such as cell survival, migration, sprouting, and tube formation (75-80). The anti-apoptosis protein survivin has recently been shown

to regulate Ang1-mediated endothelial cell survival in a PI3K/Akt-dependent manner (81). In addition, PI3K/Akt pathway modulates Ang1-induced increased nitric oxide release and activation of matrix metalloproteinase-2 (MMP-2) in endothelial cells $(82 ; 83)$.

\section{Vascular endothelial growth factor, angiopoietin-1 and angiogenesis}

Many angiogenic factors such as bFGF, PDGF, and TGF-beta have profound effects in endothelial cells. However, such factors also act on other cells, and these nonspecific growth factors are not the ideal targets for the treatment of angiogenesis-related diseases. Vascular endothelial growth factor (VEGF) and angiopoietin-1 (Ang1) are the only growth factors proven to be specific for endothelial cells and are critical for angiogenesis both in vitro and in vivo. VEGF is absolutely required for the vascular morphogenesis during the early stages of blood vessel formation, whereas Ang1 is essential for vessel maturation and stabilization at the later stages of vascular development. VEGF and Ang1 have been shown to be useful in inducing functional neovascularization for therapeutic angiogenesis (84-86). 


\section{1. VEGF and angiogenesis}

VEGF was identified independently as vascular permeability factor (VPF) and vascular endothelial cell-specific growth factor in 1980 s $(87 ; 88)$. There are at least six isoforms of human VEGF resulting from alternative mRNA splicing, of which $\mathrm{VEGF}_{121}, \mathrm{VEGF}_{165}$ and $\mathrm{VEGF}_{189}$ are the three predominant variants (89). VEGF binds to endothelial cell-specific tyrosine kinase receptors, VEGFR-1 (Flt-1) and VEGFR-2 (KDR, also known as Flk-1 in mice). Although VEGFR-1 has the highest affinity for VEGF, VEGF binding does not activate the receptor and does not induce any positive endothelial cell responses (90). VEGFR-2 is tyrosinephosphorylated efficiently upon VEGF binding and mediates major positive signals from VEGF $(89 ; 90)$. The lack of significant cellular responses to VEGFR-1 stimulation has led to speculation that VEGFR-1 acts as a decoy receptor that sequesters VEGF from signaling through VEGFR-2 (89). VEGF 165 also binds to endothelial cell surface molecule neuropilin-1 (NRP1). NRP1 acts as a co-receptor for binding of $\mathrm{VEGF}_{165}$ to $\mathrm{KDR}$, increasing the affinity to about 10 fold, making $\mathrm{VEGF}_{165}$ the strongest signaling molecule among the VEGF subtypes (91). Extensive research over the last decade has elucidated the pivotal role of VEGF and its receptors in the regulation of angiogenesis. VEGF induces pronounced angiogenic responses in a variety of in vitro and in vivo models (92). VEGF has multiple effects on endothelial cells: it stimulates cell proliferation, migration, survival, activation of eNOS, release of matrix metalloproteinases (MMPs) and plasminagen activators (PAs) (92-94), all of these cellular events are critical for angiogenesis. Furthermore, targeted disruption of VEGF and its receptors results in murine embryonic lethality that correlated with remarkable vascular defects. VEGFR-2 knockout mice lack both endothelial cells and hematopoietic precursors, and die by embryonic day 8.5 (E8.5) due to lack of vasculogenesis and very low hematopoiesis (95). VEGFR-1 knockout mice also 
die around E8.5. However, these mice have normal hematopoietic progenitors and abundant endothelial cells but fail to assemble into tubes and functional vessels (96). Disruption of even a single VEGF allele results in mouse embryo death between days 11 and 12 due to abnormal vessel and blood island formation (97;98). The VEGF deficient mice have delayed endothelial differentiation and impaired endothelial cell sprouting and lumen formation, suggesting that VEGF is required for early vascular development $(97 ; 98)$. VEGF also plays an important role in tumor-induced angiogenesis. A majority of malignant tumor cells overexpress VEGF, and tumor cells-derived VEGF is believed to be the primary stimulus for tumor angiogenesis (22). Inhibition of VEGF function shows potent anti-tumor effects in experimental and clinical studies, and VEGF is therefore considered as one of the primary targets for anti-angiogenic therapy of cancer (99).

\section{2. Angiopoietin-1 and angiogenesis}

Receptor Tie1 (tyrosine kinase with immunoglobulin and epidermal growth factor homology domain) and Tie2 (also known as Tek) represent another family of receptor tyrosine kinases (RTKs) that are selectively expressed on vascular endothelial cells $(59 ; 60)$. So far, four ligands, Ang1 to Ang4, have been identified for Tie2 receptor, whereas Tie1 is still an orphan receptor $(100 ; 101)$. Ang1 and Ang2 are the best-characterized angiopoietins. They have similar binding affinities for Tie2, but only Ang1 induces Tie2 receptor activation (102). Tie2 knockout mice die around E9.5 10.5. In Tie2-/- mice, endothelial cells are present in normal numbers and can be assembled into tubes, but the vessels are immature, lacking branching networks and periendothelial supporting cells (103). Ang1 knockout mice have largely similar phenotypes $(103 ; 104)$. Mice overexpressing Ang2 have similar vascular defects to Ang1 and Tie2 knockout 
mice, supporting the idea that Ang2 is an antagonist for the Ang1/Tie2 system (102). In vitro studies showed that Ang1 has no effect on endothelial cell proliferation, rather it is a strong survival factor for endothelial cells (105-108). Ang1 is also involved in endothelial cell migration and sprouting to form tube-like structures in vitro $(109 ; 110)$. Ang1/Tie2 system seems to play a crucial role in recruitment of periendothelial cells (also termed mural cells) during angiogenesis. It has been recognized that interactions between endothelial cells (ECs) and mural cells (MCs) are critical for vessel stability and integrity maintenance: ECs and MCs form tight contacts by interdigitations and gap junctions; MCs inhibit EC proliferation and migration in part due to the activation of TGF- $\beta 1$; paracrine expression of VEGF and Ang1 is essential for vessel stability by providing continous survival signals to ECs $(62 ; 111 ; 112)$. Transgenic overexpression of Ang1 in vivo increases vascularization (113-115). Importantly, blood vessels induced by Ang1 are leakage-resistant (116). Ang1 has therapeutic potential for diseases with increased vascular leakage, e.g., diabetic retinopathy (117), and appears to be of benefit in inducing functional neovascularization when it is co-administered with VEGF (118-120).

The role of Ang1 in tumor angiogenesis is not clear. Expression levels of Ang1 vary among different tumor types (121). Interestingly, despite the stimulatory role in physiological angiogenesis, ectopic overexpression of Ang1 in several types of cancer cells decreases tumor angiogenesis in xenograft tumor models, suggesting an inhibitory role of Ang1 in tumor angiogenesis (121). By contrast, high levels of Ang2 are frequently detected in a variety of highly vascularized human tumors, and elevated Ang2 expression was shown to correlate with poor prognosis (121). It is believed that Ang2 plays an important role in the initiation of tumor angiogenesis. 


\section{3. Complementary actions of VEGF and Ang1 in angiogenesis}

There appears to be an elaborate collaboration between VEGF, Ang1 and Ang2 in the process of angiogenesis. In the absence of VEGF, Ang2 induces vessel regression by antagonizing Ang1/Tie2 signaling. In the presence of VEGF, however, Ang2 enhances angiogenesis presumably by blocking Ang1/Tie2 function and destabilizing the vascular structure and thereby exposing the endothelial cells to VEGF stimulation $(62 ; 111 ; 112)$. Blood vessels induced by VEGF are inherently leaky (122). In contrast, Ang1-induced blood vessels are leakage-resistant (123). Co-administration of Ang1 counteracts VEGF-induced hyperpermeability of blood vessels and augments VEGF-induced angiogenesis (124-126).

\section{Role of cyclooxygenase- 2 in angiogenesis and human cancer}

Cyclooxygenases (COXs) are the rate-limiting enzymes for prostaglandin (PG) biosynthesis. Three isoforms of cyclooxygenases have been identified so far, termed COX-1, COX-2, and COX-3. COX-1 is constitutively expressed in most human tissues, and appears to be responsible for the production of PGs that modulate physiological functions. COX-3 is a variant of COX-1 and is abundant in cerebral cortex (127). In contrast to COX-1, COX-2 is expressed at low or undetectable levels in most normal tissues, but can be rapidly induced by inflammatory stimuli $(128 ; 129)$. The first step of PG synthesis is hydrolysis of membrane phospholipids by phospholipase $\mathrm{A}_{2}\left(\mathrm{PLA}_{2}\right)$ to produce free arachidonic acid. COXs catalyze a reaction by which oxygen is inserted into arachidonic acid to form $\mathrm{PGG}_{2} . \mathrm{PGG}_{2}$ is an unstable intermediate and is rapidly converted to $\mathrm{PGH}_{2}$ by the peroxidase activity of COXs. Finally, several specific 
synthases/isomerases convert $\mathrm{PGH}_{2}$ into thromboxane $\mathrm{A}_{2}\left(\mathrm{TXA}_{2}\right)$ and a series of $\mathrm{PGs}\left(\mathrm{PGE}_{2}\right.$, $\mathrm{PGI}_{2}, \mathrm{PGD}_{2}$, etc.) (130-132). Prostaglandins mediate acute and chronic inflammation and have important homeostatic functions, e.g., the maintenance of gastric mucosal integrity. COXs are of particular clinical significance because they are the main target for nonsteroidal antiinflammatory drugs (NSAIDs) such as aspirin. Recently, a growing body of evidence suggests that COXs are also critically involved in the process of angiogenesis and the development and progression of human cancer.

\section{1. Cyclooxygenase-2 and angiogenesis}

Inflammatory stimuli can acutely induce COX-2 expression. It is known that many inflammatory mediators (e.g., IL-1ß, TNF- $\alpha$ ) are potent inducers for angiogenesis (133). Indeed, COX-2 was shown to play a pivotal role in angiogenesis at site of inflammation (134). Importantly, the classical angiogenic factor VEGF- and bFGF-induced angiogenesis appears to require the induction of COX-2 (135-137). The proangiogenic effects of COX-2 are mediated primarily by three products of arachidonic metabolism: $\mathrm{TXA}_{2}, \mathrm{PGE}_{2}$, and $\mathrm{PGI}_{2}$, which are involved in multiple key points of angiogenesis (138). Downstream proangiogenic actions of these eicosanoid products include: (a) production of vascular endothelial growth factor; (b) promotion of vascular sprouting, migration, and tube formation; (c) inhibition of endothelial cell apoptosis by stimulation of Bcl-2 or Akt activation; (d) induction of matrix metalloproteinases; and (e) activation of epidermal growth factor receptor-mediated angiogenesis. Recent studies indicated that COX-2 plays a critical role in tumor-induced angiogenesis as well (139). High levels of COX-2 were detected in the area of invading neovasculature of various human cancers (140). COX-2 overexpressing colon cancer cells produce large amounts of proangiogenic factors, 
including VEGF, bFGF, TGF- $\beta$, PDGF, and endothelin-1 (141). Furthermore, PGE2 can induce hypoxia-inducible factor-1 expression in human prostate cancer cells (142). The dual COX-1/-2 inhibitor diclofenac was shown to inhibit colorectal cancer growth via the suppression of angiogenesis (143). Also, tumors implanted in COX-2 (-/-) mice display a reduction in vascular density and tumor growth (144).

\section{2. Cyclooxygenase-2 and human cancer}

Multiple lines of evidence support that COX-2 plays a crucial role in tumor development and progression. Many human cancers produce higher levels of COX-2 and $\mathrm{PGE}_{2}$ than the normal tissues (145). Overexpression of COX-2 in human cancer is a consequence of deregulated transcriptional and posttranscriptional control $(146 ; 147)$. COX-2 expression can be induced by inflammatory cytokines and by growth factors as well as by activation of oncogenes and inactivation of tumor suppressor genes (148). Genetic studies showed that transgenic mice that overexpressed COX-2 in various types of tissues developed malignant tumors $(149 ; 150)$. Conversely, the development and growth of tumors were markedly retarded in COX-2 knockout mice $(151 ; 152)$. The role of COX-2 in carcinogenesis is further supported by recent experimental and clinical studies which demonstrated the effectiveness of selective COX-2 inhibitors in the prevention and treatment of human cancers $(153 ; 154)$. The biological effects of COX-2 are mediated by its prostanoid products that affect multiple mechanisms implicated in carcinogenesis. For example, $\mathrm{PGE}_{2}$ can stimulate cell proliferation and motility while inhibiting apoptosis and immune surveillance (155). Importantly, COX-2-derived prostanoids are critically involved in tumor angiogenesis as mentioned above. 


\section{Anti-angiogenic therapy for cancer}

It is a well established notion that solid tumor growth is angiogenesis dependent (156). The progression of tumors can be divided into two phases: the pre-vascular (avascular) and the vascular phase (157). Tumors may persist in situ for a long period of time (from months to years) in an avascular, quiescent status. In this phase, the size of the tumor usually does not exceed a few cubic millimeters because of the limited supply of nutrients and oxygen through passive diffusion from the host vasculature. Once a tumor switches to an angiogenic phenotype, the tumor grows rapidly and acquires an increased metastatic potential (157). After the recognition of angiogenesis being absolutely required for solid tumor expansion, it was hypothesized that the process of angiogenesis might be an attractive target for developing a novel anti-cancer strategy. To date, anti-angiogenesis therapy is being considered a very promising approach for cancer therapy based on the exciting results obtained from experimental animal models, and intense clinical trials are ongoing to evaluate and validate this novel therapeutic tool.

\section{1. Biological rationale for anti-angiogenesis therapy}

It has been recognized for a long time that tumor vessels are phenotypically different from normal vessels with respect to organization, structure and function $(158 ; 159)$. Tumor vasculature is structurally irregular and heterogeneous with arterovenous shunts, multiple loops, and spiral motifs $(158 ; 159)$. They are also very leaky and less efficient for oxygen delivery, leading to typical hypoxic characteristics (160). Importantly, tumor vessels are lined by actively dividing endothelial cells, which overexpress some specific molecules such as endoglin, E-selectin, endosialin, and VEGF receptors (161). Human tumor-derived endothelial cells show enhanced 
survival and proadhesive properties, and have increased angiogenic potential (162). The Akt activity was found to be up-regulated and PTEN expression was decreased in tumor-derived endothelial cells (162). The "activated" endothelial cells in tumor vessels are the primary target for anti-angiogenic therapy. Endothelial cells in normal vessels are quiescent under physiological conditions, and angiogenesis in adults is normally restricted. Therefore, the side effects of antiangiogenesis therapy is considered to be negligible (161). In addition, microvascular endothelial cells are genetically stable as compared to tumor cells $(163 ; 164)$, so the potential of drug resistance to anti-angiogenic therapy might be very low. Indeed, acquired resistance to antiangiogenesis drugs has not been clearly demonstrated in preclinical studies. Anti-angiogenic therapy presents several other advantages over conventional therapy: (i) Intratumoral endothelium overexpresses selective molecules that may be harnessed as more specific therapeutic targets; (ii) Endothelial cells are easily accessible from the circulation; (iii) Some anti-angiogenic compounds have synergistic effects when combined with cytotoxic drugs and radiation therapy (165).

\section{2. Approaches to interfere with tumor angiogenesis}

Anti-angiogenic agents can be divided into two classes: direct and indirect angiogenesis inhibitors (166). Direct inhibitors target tumor vascular endothelial cells, inhibiting their ability to proliferate, migrate, or survive in response to a spectrum of pro-angiogenic factors. Indirect angiogenesis inhibitors inhibit the tumor production of pro-angiogenic factors or block the expression of its receptor on endothelial cells. More and more anti-angiogenic compounds are available for clinical evaluation in cancer patients, and many of these drugs target the VEGF pathway. Actually, the VEGF system is considered to be the primary target for anti-angiogenic 
therapy of cancer. There are multiple possible strategies to inhibit VEGF function, including the use of monoclonal antibodies against VEGF protein or receptors, VEGF receptor tyrosine kinase inhibitors (TKRIs) and VEGF receptor targeted ribozymes. Other therapeutic targets include matrix metalloproteinase inhibitors (MMPIs), and natural inhibitors, such as endostatin, angiostatin, and thromobspondin-1 (TSP-1).

\section{2. 1. Monoclonal antibodies against VEGF protein or receptors}

Bevacizumab (Avastin ${ }^{\circledR}$; Genentech, Inc.) is a humanized monoclonal antibody directed against VEGF-A. It has been tested in phase I studies in combination with chemotherapy with a good safety profile $(167 ; 168)$. In phase II studies, the combination of bevacizumab and chemotherapy resulted in an increased response rate and prolonged progression-free survival in metastatic colon cancer, stage IIIB-IV non-small cell lung cancer (NSCLC), and advanced breast cancer $(161 ; 169)$. Several phase III studies of bevacizumab treatment combined with chemotherapy are ongoing, and the results for the treatment of colorectal cancer are quite promising. Monoclonal antibodies against the extracellular domain of VEGF receptor have also been developed, and shown effectiveness in inhibiting tumor growth in animal models (170). So far, no clinical data are available for these VEGF receptor neutralizing antibodies.

\section{2. 2. VEGF receptor tyrosine kinase inhibitors}

Another class of angiogenesis inhibitors currently under development is the smallmolecules that inhibit VEGF receptor tyrosine kinase. Semaxanib(SU5416) is an inhibitor of VEGF-R2 (KDR), VEGF-R1 (Flt) and c-kit (171). SU5416 inhibits growth and metastasis of lung, colon, breast, prostate cancers, melanoma, glioma and sarcoma xenografts (172-174). In a Phase I clinical trial for patients with gastrointestinal, breast, or lung cancer, a weekly scheduled 
dose of SU5416 showed signs of clinical benefit as defined by tumor regression or disease stabilization for at least 12 weeks (175). The most common serious drug-related toxicity was headache, often associated with nausea and vomiting (175). However, in a randomized phase II study, no significant disease-modifying effects of SU5416 were observed in prostate cancer patients (176). In a phase III study of 737 untreated metastatic colorectal cancer patients, SU5416 resulted in severe toxicity, and showed no improvement in response rate, time to progression, and overall survival (161). Therefore, SU5416 was not recommended for additional study in cancer patients. Vatalanib (PTK787/ZK-222584) is a potent inhibitor of VEGFR-1 and VEGFR-2 with good oral bioavailability (177). Phase II/III trials with vatalanib (PTK787) in colorectal cancer are ongoing. ZD6474 is another oral compound that inhibits VEGFR-2, VEGFR-3, and EGFR (178). Clinical evaluation of ZD6474 is still in early phases for cancer patients refractory to conventional treatments.

Another strategy to block VEGF function is the administration of soluble VEGF receptors. A soluble VEGF receptor was constructed by fusing the entire extracellular domain of murine flk-1 to a six-histidine tag at the C-terminus (ExFlk.6His) (179). In vitro, recombinant ExFlk.6His protein binds VEGF with high affinity, blocks the receptor activation, and inhibited VEGF-induced endothelial cell migration and proliferation. In vivo, ExFlk.6His potently inhibited corneal neovascularization induced by conditioned media prepared from a rat mammary carcinoma cell line (179).

\section{2. 3. Natural peptide inhibitors of angiogenesis}

Angiostatin and endostatin are potent endogenous inhibitors of angiogenesis. Angiostatin is a $38-\mathrm{kD}$ of plasminogen fragment generated by proteolytic cleavage. This circulating inhibitor of angiogenesis interacts with vascular endothelial cells through at least 3 potential receptors: 
ATP synthase, angiomotin and $\alpha v \beta 3$ integrin (180). Angiostatin inhibits endothelial growth in vitro, and angiogenesis in vivo, and induces tumor dormancy in both primary and metastatic tumors in mice $(181 ; 182)$. Endostatin is a $20 \mathrm{kD}$ C-terminal fragment of collagen XVIII by the action of elastase and other proteases (183). Endostatin specifically inhibits endothelial proliferation, and induces endothelial cell apoptosis more potently than angiostatin (184). Endostatin also acts on endothelial precursor cells that contribute to the de novo vessel formation in tumors (185). Results from phase I studies are available for both agents, and have shown no drug related toxicity.

\section{2. 4. Specific inhibitors of endothelial cell growth}

One of the first compounds identified to specifically inhibit endothelial cell growth was O-chloroacetylcarbamoyl fumagillol or AGM-1470/TNP-470, an analog of the fungus-derived antibiotic fumagillin (186). TNP-470 was found to prevent endothelial cells from entering $\mathrm{G}_{1}$ phase of the cell cycle, and thereby decreasing cell proliferation (187). TNP-470 inhibits both tumor growth and metastasis in animal models $(186 ; 188)$. Mild toxicity and high incidence of apparent prolonged progression-free survival were reported in phase I/II clinical studies (189). Several other endogenous molecules were found to directly inhibit endothelial cell growth, including thrombospondin-1, platelet factor-4, and interferon-inducible protein-10 (189).

Some other novel approaches are emerging to interfere with tumor blood supply. Tumor vasculature targeting aims to block tumor blood flow by a direct damage of endothelium within the tumor, without affecting normal endothelium (190). This approach requires an absolutely specific marker for tumor vasculature, and a variety of potential target candidates are under investigation (191). 


\section{Significance and relevance}

Angiogenesis is a complex process that is tightly controlled by pro- and anti-angiogenic factors, and involves the interaction and coordination between different cell types within the host microenvironment. Deregulated angiogenesis contributes to many pathological situations including tumor progression and metastasis. The proposed studies in this dissertation are expected to provide better understanding of the molecular mechanisms of angiogenesis, which would be of benefit for the development of novel strategies for anti-angiogenic therapy. 


\section{References}

1. Sugimoto Y, Whitman M, Cantley LC, Erikson RL. Evidence that the Rous sarcoma virus transforming gene product phosphorylates phosphatidylinositol and diacylglycerol. Proc Natl Acad Sci U S A 1984 Apr;81(7):2117-21.

2. Macara IG, Marinetti GV, Balduzzi PC. Transforming protein of avian sarcoma virus UR2 is associated with phosphatidylinositol kinase activity: possible role in tumorigenesis. Proc Natl Acad Sci U S A 1984 May;81(9):2728-32.

3. Cantley LC, Auger KR, Carpenter C, Duckworth B, Graziani A, Kapeller R, et al. Oncogenes and signal transduction. Cell 1991 Jan 25;64(2):281-302.

4. Chang HW, Aoki M, Fruman D, Auger KR, Bellacosa A, Tsichlis PN, et al. Transformation of chicken cells by the gene encoding the catalytic subunit of PI 3-kinase. Science 1997 Jun 20;276(5320):1848-50.

5. Carpenter CL, Duckworth BC, Auger KR, Cohen B, Schaffhausen BS, Cantley LC. Purification and characterization of phosphoinositide 3-kinase from rat liver. J Biol Chem 1990 Nov 15;265(32):19704-11.

6. Dhand R, Hiles I, Panayotou G, Roche S, Fry MJ, Gout I, et al. PI 3-kinase is a dual specificity enzyme: autoregulation by an intrinsic protein-serine kinase activity. EMBO J 1994 Feb 1;13(3):522-33.

7. Kodaki T, Woscholski R, Hallberg B, Rodriguez-Viciana P, Downward J, Parker PJ. The activation of phosphatidylinositol 3-kinase by Ras. Curr Biol 1994 Sep 1;4(9):798-806.

8. Cantrell DA. Phosphoinositide 3-kinase signalling pathways. J Cell Sci 2001 Apr;114(Pt 8):1439-45.

9. Rodriguez-Viciana P, Warne PH, Dhand R, Vanhaesebroeck B, Gout I, Fry MJ, et al. Phosphatidylinositol-3-OH kinase as a direct target of Ras. Nature 1994 Aug $18 ; 370(6490): 527-32$.

10. Wu X, Senechal K, Neshat MS, Whang YE, Sawyers CL. The PTEN/MMAC1 tumor suppressor phosphatase functions as a negative regulator of the phosphoinositide 3kinase/Akt pathway. PNAS 1998 Dec 22;95(26):15587-91.

11. Maehama T, Dixon JE. The Tumor Suppressor, PTEN/MMAC1, Dephosphorylates the Lipid Second Messenger, Phosphatidylinositol 3,4,5-Trisphosphate. J Biol Chem 1998 May 29;273(22):13375-8.

12. Anderson KE, Coadwell J, Stephens LR, Hawkins PT. Translocation of PDK-1 to the plasma membrane is important in allowing PDK-1 to activate protein kinase B. Current Biology 1998 Jun 4;8(12):684-91. 
13. Downward J. Mechanisms and consequences of activation of protein kinase B/Akt. Curr Opin Cell Biol 1998 Apr;10(2):262-7.

14. Vanhaesebroeck B, Alessi DR. The PI3K-PDK1 connection: more than just a road to PKB. Biochem J 2000 Mar 15;346 Pt 3:561-76.

15. Coffer PJ, Jin J, Woodgett JR. Protein kinase B (c-Akt): a multifunctional mediator of phosphatidylinositol 3-kinase activation. Biochem J 1998 Oct 1;335 ( Pt 1):1-13.

16. Arrieumerlou C, Donnadieu E, Brennan P, Keryer G, Bismuth G, Cantrell D, et al. Involvement of phosphoinositide 3-kinase and Rac in membrane ruffling induced by IL-2 in T cells. Eur J Immunol 1998 Jun;28(6):1877-85.

17. Reif K, Nobes CD, Thomas G, Hall A, Cantrell DA. Phosphatidylinositol 3-kinase signals activate a selective subset of Rac/Rho-dependent effector pathways. Curr Biol 1996 Nov 1;6(11):1445-55.

18. Cantrell DA. Phosphoinositide 3-kinase signalling pathways. Journal of Cell Science 2001 Apr 15;114(8):1439-45.

19. Coelho CM, Leevers SJ. Do growth and cell division rates determine cell size in multicellular organisms? J Cell Sci 2000 Sep;113 ( Pt 17):2927-34.

20. Risau W. Mechanisms of angiogenesis. Nature 1997 Apr 17;386(6626):671-4.

21. Bouck N, Stellmach V, Hsu SC. How tumors become angiogenic. Adv Cancer Res 1996;69:135-74.

22. Ferrara N, Davis-Smyth T. The biology of vascular endothelial growth factor. Endocr Rev 1997 Feb;18(1):4-25.

23. Harris AL. Hypoxia--a key regulatory factor in tumour growth. Nat Rev Cancer 2002 Jan;2(1):38-47.

24. Vaupel P, Thews O, Hoeckel M. Treatment resistance of solid tumors: role of hypoxia and anemia. Med Oncol 2001;18(4):243-59.

25. Forsythe JA, Jiang BH, Iyer NV, Agani F, Leung SW, Koos RD, et al. Activation of vascular endothelial growth factor gene transcription by hypoxia-inducible factor 1 . Mol Cell Biol 1996;16(9):4604-13.

26. Carmeliet P, Dor Y, Herbert JM, Fukumura D, Brusselmans K, Dewerchin M, et al. Role of HIF-1 [alpha] in hypoxiamediated apoptosis, cell proliferation and tumour angiogenesis. Nature 1998 Jul 30;394(6692):485-90.

27. Jiang BH, Rue E, Wang GL, Roe R, Semenza GL. Dimerization, DNA binding, and transactivation properties of hypoxia-inducible factor 1. The Journal Of Biological Chemistry 1996 Jul 26;271(30):17771-8. 
28. Laughner E, Taghavi P, Chiles K, Mahon PC, Semenza GL. HER2 (neu) signaling increases the rate of hypoxia-inducible factor lalpha (HIF-1alpha) synthesis: novel mechanism for HIF-1-mediated vascular endothelial growth factor expression. Mol Cell Biol 2001 Jun;21(12):3995-4004.

29. Zelzer E, Levy Y, Kahana C, Shilo BZ, Rubinstein M, Cohen B. Insulin induces transcription of target genes through the hypoxia-inducible factor HIF-1alpha/ARNT. EMBO J 1998 Sep 1;17(17):5085-94.

30. Zhong H, Chiles K, Feldser D, Laughner E, Hanrahan C, Georgescu MM, et al. Modulation of hypoxia-inducible factor 1alpha expression by the epidermal growth factor/phosphatidylinositol 3-kinase/PTEN/AKT/FRAP pathway in human prostate cancer cells: implications for tumor angiogenesis and therapeutics. Cancer Res $2000 \mathrm{Mar}$ $15 ; 60(6): 1541-5$.

31. Jiang BH, Jiang G, Zheng JZ, Lu Z, Hunter T, Vogt PK. Phosphatidylinositol 3-kinase signaling controls levels of hypoxia-inducible factor 1. Cell Growth Differ 2001 Jul;12(7):363-9.

32. Jiang BH, Zheng JZ, Aoki M, Vogt PK. Phosphatidylinositol 3-kinase signaling mediates angiogenesis and expression of vascular endothelial growth factor in endothelial cells. PNAS 2000 Feb 15;97(4):1749-53.

33. Koul D, Shen R, Garyali A, Ke LD, Liu TJ, Yung WK. MMAC/PTEN tumor suppressor gene regulates vascular endothelial growth factor-mediated angiogenesis in prostate cancer. Int J Oncol 2002 Sep;21(3):469-75.

34. Zhang L, Yang N, Katsaros D, Huang W, Park JW, Fracchioli S, et al. The oncogene phosphatidylinositol 3'-kinase catalytic subunit alpha promotes angiogenesis via vascular endothelial growth factor in ovarian carcinoma. Cancer Res 2003 Jul 15;63(14):4225-31.

35. Dong G, Chen Z, Li ZY, Yeh NT, Bancroft CC, Van WC. Hepatocyte growth factor/scatter factor-induced activation of MEK and PI3K signal pathways contributes to expression of proangiogenic cytokines interleukin-8 and vascular endothelial growth factor in head and neck squamous cell carcinoma. Cancer Res 2001 Aug 1;61(15):5911-8.

36. Wen S, Stolarov J, Myers MP, Su JD, Wigler MH, Tonks NK, et al. PTEN controls tumor-induced angiogenesis. Proc Natl Acad Sci U S A 2001 Apr 10;98(8):4622-7.

37. Su JD, Mayo LD, Donner DB, Durden DL. PTEN and phosphatidylinositol 3'-kinase inhibitors up-regulate p53 and block tumor-induced angiogenesis: evidence for an effect on the tumor and endothelial compartment. Cancer Res 2003 Jul 1;63(13):3585-92.

38. Tan C, Cruet-Hennequart S, Troussard A, Fazli L, Costello P, Sutton K, et al. Regulation of tumor angiogenesis by integrin-linked kinase (ILK). Cancer Cell 2004 Jan;5(1):79-90. 
39. Papapetropoulos A, Garcia-Cardena G, Madri JA, Sessa WC. Nitric Oxide Production Contributes to the Angiogenic Properties of Vascular Endothelial Growth Factor in Human Endothelial Cells. J Clin Invest 1997 Dec 15;100(12):3131-9.

40. Murohara T, Asahara T, Silver M, Bauters C, Masuda H, Kalka C, et al. Nitric Oxide Synthase Modulates Angiogenesis in Response to Tissue Ischemia. J Clin Invest 1998 Jun 1;101(11):2567-78.

41. Dimmeler S, Fleming I, Fisslthaler B, Hermann C, Busse R, Zeiher AM. Activation of nitric oxide synthase in endothelial cells by Akt-dependent phosphorylation. Nature 1999 Jun 10;399(6736):601-5.

42. Fulton D, Gratton JP, McCabe TJ, Fontana J, Fujio Y, Walsh K, et al. Regulation of endothelium-derived nitric oxide production by the protein kinase Akt. Nature 1999 Jun 10;399(6736):597-601.

43. Garcia-Cardena G, Oh P, Liu J, Schnitzer JE, Sessa WC. Targeting of nitric oxide synthase to endothelial cell caveolae via palmitoylation: Implications for nitric oxide signaling. PNAS 1996 Jun 25;93(13):6448-53.

44. Ju H, Zou R, Venema VJ, Venema RC. Direct Interaction of Endothelial Nitric-oxide Synthase and Caveolin-1 Inhibits Synthase Activity. J Biol Chem 1997 Jul $25 ; 272(30): 18522-5$.

45. Feron O, Belhassen L, Kobzik L, Smith TW, Kelly RA, Michel T. Endothelial Nitric Oxide Synthase Targeting to Caveolae. SPECIFIC INTERACTIONS WITH CAVEOLIN ISOFORMS IN CARDIAC MYOCYTES AND ENDOTHELIAL CELLS. J Biol Chem 1996 Sep 13;271(37):22810-4.

46. Garcia-Cardena G, Fan R, Shah V, Sorrentino R, Cirino G, Papapetropoulos A, et al. Dynamic activation of endothelial nitric oxide synthase by Hsp90. Nature 1998 Apr 23;392(6678):821-4.

47. Sato S, Fujita N, Tsuruo T. Modulation of Akt kinase activity by binding to Hsp90. PNAS 2000 Sep 26;97(20):10832-7.

48. Fontana J, Fulton D, Chen Y, Fairchild TA, McCabe TJ, Fujita N, et al. Domain Mapping Studies Reveal That the M Domain of hsp90 Serves as a Molecular Scaffold to Regulate Akt-Dependent Phosphorylation of Endothelial Nitric Oxide Synthase and NO Release. Circ Res 2002 May 3;90(8):866-73.

49. Thakker GD, Hajjar DP, Muller WA, Rosengart TK. The role of phosphatidylinositol 3kinase in vascular endothelial growth factor signaling. J Biol Chem 1999 Apr 9;274(15):10002-7.

50. Yu Y, Sato JD. MAP kinases, phosphatidylinositol 3-kinase, and p70 S6 kinase mediate the mitogenic response of human endothelial cells to vascular endothelial growth factor. $\mathrm{J}$ Cell Physiol 1999 Feb;178(2):235-46. 
51. Gerber HP, McMurtrey A, Kowalski J, Yan M, Keyt BA, Dixit V, et al. Vascular endothelial growth factor regulates endothelial cell survival through the phosphatidylinositol 3'-kinase/Akt signal transduction pathway. Requirement for Flk1/KDR activation. J Biol Chem 1998 Nov 13;273(46):30336-43.

52. Gratton JP, Morales-Ruiz M, Kureishi Y, Fulton D, Walsh K, Sessa WC. Akt Downregulation of p38 Signaling Provides a Novel Mechanism of Vascular Endothelial Growth Factor-mediated Cytoprotection in Endothelial Cells. J Biol Chem 2001 Aug 3;276(32):30359-65.

53. Morales-Ruiz M, Fulton D, Sowa G, Languino LR, Fujio Y, Walsh K, et al. Vascular Endothelial Growth Factor-Stimulated Actin Reorganization and Migration of Endothelial Cells Is Regulated via the Serine/Threonine Kinase Akt. Circ Res 2000 Apr 28;86(8):892-6.

54. Six I, Kureishi Y, Luo Z, Walsh K. Akt signaling mediates VEGF/VPF vascular permeability in vivo. FEBS Lett 2002 Dec 4;532(1-2):67-9.

55. Huang J, Kontos CD. PTEN Modulates Vascular Endothelial Growth Factor-Mediated Signaling and Angiogenic Effects. J Biol Chem 2002 Mar 22;277(13):10760-6.

56. Jiang BH, Zheng JZ, Aoki M, Vogt PK. Phosphatidylinositol 3-kinase signaling mediates angiogenesis and expression of vascular endothelial growth factor in endothelial cells. PNAS 2000 Feb 15;97(4):1749-53.

57. Zhong H, Chiles K, Feldser D, Laughner E, Hanrahan C, Georgescu MM, et al. Modulation of Hypoxia-inducible Factor $1\{\{$ alpha $\}\}$ Expression by the Epidermal Growth Factor/Phosphatidylinositol 3-Kinase/PTEN/AKT/FRAP Pathway in Human Prostate Cancer Cells: Implications for Tumor Angiogenesis and Therapeutics. Cancer Research 2000 Mar 1;60(6):1541-5.

58. Gleadle JM, Ratcliffe PJ. Induction of Hypoxia-Inducible Factor-1, Erythropoietin, Vascular Endothelial Growth Factor, and Glucose Transporter-1 by Hypoxia: Evidence Against a Regulatory Role for Src Kinase. Blood 1997 Jan 15;89(2):503-9.

59. Davis S, Aldrich TH, Jones PF, Acheson A, Compton DL, Jain V, et al. Isolation of angiopoietin-1, a ligand for the TIE2 receptor, by secretion-trap expression cloning. Cell 1996 Dec 27;87(7):1161-9.

60. Sato TN, Tozawa Y, Deutsch U, Wolburg-Buchholz K, Fujiwara Y, Gendron-Maguire M, et al. Distinct roles of the receptor tyrosine kinases Tie-1 and Tie-2 in blood vessel formation. Nature 1995 Jul 6;376(6535):70-4.

61. Suri C, Jones PF, Patan S, Bartunkova S, Maisonpierre PC, Davis S, et al. Requisite role of angiopoietin-1, a ligand for the TIE2 receptor, during embryonic angiogenesis. Cell 1996 Dec 27;87(7):1171-80. 
62. Hanahan D. Signaling vascular morphogenesis and maintenance. Science 1997 Jul 4;277(5322):48-50.

63. Kwak HJ, So JN, Lee SJ, Kim I, Koh GY. Angiopoietin-1 is an apoptosis survival factor for endothelial cells. FEBS Lett 1999 Apr 9;448(2-3):249-53.

64. Papapetropoulos A, Garcia-Cardena G, Dengler TJ, Maisonpierre PC, Yancopoulos GD, Sessa WC. Direct actions of angiopoietin-1 on human endothelium: evidence for network stabilization, cell survival, and interaction with other angiogenic growth factors. Lab Invest $1999 \mathrm{Feb} ; 79(2): 213-23$.

65. Kim I, Kim HG, So JN, Kim JH, Kwak HJ, Koh GY. Angiopoietin-1 regulates endothelial cell survival through the phosphatidylinositol 3'-Kinase/Akt signal transduction pathway. Circ Res 2000 Jan 7;86(1):24-9.

66. Kwak HJ, Lee SJ, Lee YH, Ryu CH, Koh KN, Choi HY, et al. Angiopoietin-1 inhibits irradiation- and mannitol-induced apoptosis in endothelial cells. Circulation 2000 May 16;101(19):2317-24.

67. Witzenbichler B, Maisonpierre PC, Jones P, Yancopoulos GD, Isner JM. Chemotactic properties of angiopoietin-1 and -2, ligands for the endothelial-specific receptor tyrosine kinase Tie2. J Biol Chem 1998 Jul 17;273(29):18514-21.

68. Koblizek TI, Weiss C, Yancopoulos GD, Deutsch U, Risau W. Angiopoietin-1 induces sprouting angiogenesis in vitro. Curr Biol 1998 Apr 23;8(9):529-32.

69. Kim I, Kim HG, Moon SO, Chae SW, So JN, Koh KN, et al. Angiopoietin-1 induces endothelial cell sprouting through the activation of focal adhesion kinase and plasmin secretion. Circ Res 2000 May 12;86(9):952-9.

70. Papapetropoulos A, Garcia-Cardena G, Dengler TJ, Maisonpierre PC, Yancopoulos GD, Sessa WC. Direct actions of angiopoietin-1 on human endothelium: evidence for network stabilization, cell survival, and interaction with other angiogenic growth factors. Lab Invest $1999 \mathrm{Feb} ; 79(2): 213-23$.

71. Hayes AJ, Huang WQ, Mallah J, Yang D, Lippman ME, Li LY. Angiopoietin-1 and its receptor Tie-2 participate in the regulation of capillary-like tubule formation and survival of endothelial cells. Microvasc Res 1999 Nov;58(3):224-37.

72. Babaei S, Teichert-Kuliszewska K, Zhang Q, Jones N, Dumont DJ, Stewart DJ. Angiogenic actions of angiopoietin-1 require endothelium-derived nitric oxide. Am J Pathol 2003 Jun;162(6):1927-36.

73. Kontos CD, Stauffer TP, Yang WP, York JD, Huang L, Blanar MA, et al. Tyrosine 1101 of Tie2 is the major site of association of p85 and is required for activation of phosphatidylinositol 3-kinase and Akt. Mol Cell Biol 1998 Jul;18(7):4131-40. 
74. Kontos CD, Stauffer TP, Yang WP, York JD, Huang L, Blanar MA, et al. Tyrosine 1101áof Tie2 Is the Major Site of Association of p85 and Is Required for Activation of Phosphatidylinositol 3-Kinase and Akt. Mol Cell Biol 1998 Jul 1;18(7):4131-40.

75. Babaei S, Teichert-Kuliszewska K, Zhang Q, Jones N, Dumont DJ, Stewart DJ. Angiogenic actions of angiopoietin-1 require endothelium-derived nitric oxide. Am J Pathol 2003 Jun;162(6):1927-36.

76. Kim I, Kim HG, So JN, Kim JH, Kwak HJ, Koh GY. Angiopoietin-1 regulates endothelial cell survival through the phosphatidylinositol 3'-Kinase/Akt signal transduction pathway. Circ Res 2000 Jan 7;86(1):24-9.

77. Kim I, Kim HG, Moon SO, Chae SW, So JN, Koh KN, et al. Angiopoietin-1 induces endothelial cell sprouting through the activation of focal adhesion kinase and plasmin secretion. Circ Res 2000 May 12;86(9):952-9.

78. Jones N, Master Z, Jones J, Bouchard D, Gunji Y, Sasaki H, et al. Identification of Tek/Tie2 binding partners. Binding to a multifunctional docking site mediates cell survival and migration. J Biol Chem 1999 Oct 22;274(43):30896-905.

79. Harfouche R, Hassessian HM, Guo Y, Faivre V, Srikant CB, Yancopoulos GD, et al. Mechanisms which mediate the antiapoptotic effects of angiopoietin-1 on endothelial cells. Microvasc Res 2002 Jul;64(1):135-47.

80. Fujikawa K, de AS, I, Jain SK, Presman E, Christensen RA, Varticovski L. Role of PI 3kinase in angiopoietin-1-mediated migration and attachment-dependent survival of endothelial cells. Exp Cell Res 1999 Dec 15;253(2):663-72.

81. Papapetropoulos A, Fulton D, Mahboubi K, Kalb RG, O'Connor DS, Li F, et al. Angiopoietin-1 inhibits endothelial cell apoptosis via the Akt/survivin pathway. J Biol Chem 2000 Mar 31;275(13):9102-5.

82. Kim I, Kim HG, Moon SO, Chae SW, So JN, Koh KN, et al. Angiopoietin-1 induces endothelial cell sprouting through the activation of focal adhesion kinase and plasmin secretion. Circ Res 2000 May 12;86(9):952-9.

83. Babaei S, Teichert-Kuliszewska K, Zhang Q, Jones N, Dumont DJ, Stewart DJ. Angiogenic actions of angiopoietin-1 require endothelium-derived nitric oxide. Am J Pathol 2003 Jun;162(6):1927-36.

84. Chae JK, Kim I, Lim ST, Chung MJ, Kim WH, Kim HG, et al. Coadministration of angiopoietin-1 and vascular endothelial growth factor enhances collateral vascularization. Arterioscler Thromb Vasc Biol 2000 Dec;20(12):2573-8.

85. Thurston G, Rudge JS, Ioffe E, Zhou H, Ross L, Croll SD, et al. Angiopoietin-1 protects the adult vasculature against plasma leakage. Nat Med 2000 Apr;6(4):460-3. 
86. Arsic N, Zentilin L, Zacchigna S, Santoro D, Stanta G, Salvi A, et al. Induction of functional neovascularization by combined VEGF and angiopoietin-1 gene transfer using AAV vectors. Mol Ther 2003 Apr;7(4):450-9.

87. Senger DR, Galli SJ, Dvorak AM, Perruzzi CA, Harvey VS, Dvorak HF. Tumor cells secrete a vascular permeability factor that promotes accumulation of ascites fluid. Science 1983 Feb 25;219(4587):983-5.

88. Leung DW, Cachianes G, Kuang WJ, Goeddel DV, Ferrara N. Vascular endothelial growth factor is a secreted angiogenic mitogen. Science 1989 Dec 8;246(4935):1306-9.

89. Robinson CJ, Stringer SE. The splice variants of vascular endothelial growth factor (VEGF) and their receptors. Journal of Cell Science 2001 Mar 1;114(5):853-65.

90. Waltenberger J, Claesson-Welsh L, Siegbahn A, Shibuya M, Heldin CH. Different signal transduction properties of KDR and Flt1, two receptors for vascular endothelial growth factor. J Biol Chem 1994 Oct 28;269(43):26988-95.

91. Soker S, Takashima S, Miao HQ, Neufeld G, Klagsbrun M. Neuropilin-1 is expressed by endothelial and tumor cells as an isoform-specific receptor for vascular endothelial growth factor. Cell 1998 Mar 20;92(6):735-45.

92. Ferrara N. Vascular endothelial growth factor: molecular and biological aspects. Curr Top Microbiol Immunol 1999;237:1-30.

93. Carmeliet P, Collen D. Role of vascular endothelial growth factor and vascular endothelial growth factor receptors in vascular development. Curr Top Microbiol Immunol 1999;237:133-58.

94. Kimura H, Esumi H. Reciprocal regulation between nitric oxide and vascular endothelial growth factor in angiogenesis. Acta Biochim Pol 2003;50(1):49-59.

95. Shalaby F, Rossant J, Yamaguchi TP, Gertsenstein M, Wu XF, Breitman ML, et al. Failure of blood-island formation and vasculogenesis in Flk-1-deficient mice. Nature 1995 Jul 6;376(6535):62-6.

96. Fong GH, Rossant J, Gertsenstein M, Breitman ML. Role of the Flt-1 receptor tyrosine kinase in regulating the assembly of vascular endothelium. Nature $1995 \mathrm{Jul}$ 6;376(6535):66-70.

97. Ferrara N, Carver-Moore K, Chen H, Dowd M, Lu L, O'Shea KS, et al. Heterozygous embryonic lethality induced by targeted inactivation of the VEGF gene. Nature $1996 \mathrm{Apr}$ 4;380(6573):439-42.

98. Carmeliet P, Ferreira V, Breier G, Pollefeyt S, Kieckens L, Gertsenstein M, et al. Abnormal blood vessel development and lethality in embryos lacking a single VEGF allele. Nature 1996 Apr 4;380(6573):435-9. 
99. Longo R, Sarmiento R, Fanelli M, Capaccetti B, Gattuso D, Gasparini G. Antiangiogenic therapy: rationale, challenges and clinical studies. Angiogenesis 2002;5(4):237-56.

100. Koh GY, Kim I, Kwak HJ, Yun MJ, Leem JC. Biomedical significance of endothelial cell specific growth factor, angiopoietin. Exp Mol Med 2002 Mar 31;34(1):1-11.

101. Loughna S, Sato TN. Angiopoietin and Tie signaling pathways in vascular development. Matrix Biol 2001 Sep;20(5-6):319-25.

102. Maisonpierre PC, Suri C, Jones PF, Bartunkova S, Wiegand SJ, Radziejewski C, et al. Angiopoietin-2, a natural antagonist for Tie2 that disrupts in vivo angiogenesis. Science 1997 Jul 4;277(5322):55-60.

103. Sato TN, Tozawa Y, Deutsch U, Wolburg-Buchholz K, Fujiwara Y, Gendron-Maguire M, et al. Distinct roles of the receptor tyrosine kinases Tie-1 and Tie-2 in blood vessel formation. Nature $1995 \mathrm{Jul}$ 6;376(6535):70-4.

104. Suri C, Jones PF, Patan S, Bartunkova S, Maisonpierre PC, Davis S, et al. Requisite role of angiopoietin-1, a ligand for the TIE2 receptor, during embryonic angiogenesis. Cell 1996 Dec 27;87(7):1171-80.

105. Kwak HJ, So JN, Lee SJ, Kim I, Koh GY. Angiopoietin-1 is an apoptosis survival factor for endothelial cells. FEBS Lett 1999 Apr 9;448(2-3):249-53.

106. Papapetropoulos A, Garcia-Cardena G, Dengler TJ, Maisonpierre PC, Yancopoulos GD, Sessa WC. Direct actions of angiopoietin-1 on human endothelium: evidence for network stabilization, cell survival, and interaction with other angiogenic growth factors. Lab Invest $1999 \mathrm{Feb} ; 79(2): 213-23$.

107. Kim I, Kim HG, So JN, Kim JH, Kwak HJ, Koh GY. Angiopoietin-1 regulates endothelial cell survival through the phosphatidylinositol 3'-Kinase/Akt signal transduction pathway. Circ Res 2000 Jan 7;86(1):24-9.

108. Kwak HJ, Lee SJ, Lee YH, Ryu CH, Koh KN, Choi HY, et al. Angiopoietin-1 inhibits irradiation- and mannitol-induced apoptosis in endothelial cells. Circulation 2000 May 16;101(19):2317-24.

109. Hayes AJ, Huang WQ, Mallah J, Yang D, Lippman ME, Li LY. Angiopoietin-1 and its receptor Tie-2 participate in the regulation of capillary-like tubule formation and survival of endothelial cells. Microvasc Res 1999 Nov;58(3):224-37.

110. Koblizek TI, Weiss C, Yancopoulos GD, Deutsch U, Risau W. Angiopoietin-1 induces sprouting angiogenesis in vitro. Curr Biol 1998 Apr 23;8(9):529-32.

111. Ramsauer M, D'Amore PA. Getting Tie(2)d up in angiogenesis. J Clin Invest 2002 Dec $1 ; 110(11): 1615-7$. 
112. Lauren J, Gunji Y, Alitalo K. Is Angiopoietin-2 Necessary for the Initiation of Tumor Angiogenesis? Am J Pathol 1998 Nov 1;153(5):1333-9.

113. Shyu KG, Manor O, Magner M, Yancopoulos GD, Isner JM. Direct intramuscular injection of plasmid DNA encoding angiopoietin-1 but not angiopoietin-2 augments revascularization in the rabbit ischemic hindlimb. Circulation 1998 Nov 10;98(19):20817.

114. Suri C, McClain J, Thurston G, McDonald DM, Zhou H, Oldmixon EH, et al. Increased vascularization in mice overexpressing angiopoietin-1. Science 1998 Oct 16;282(5388):468-71.

115. Thurston G, Suri C, Smith K, McClain J, Sato TN, Yancopoulos GD, et al. Leakageresistant blood vessels in mice transgenically overexpressing angiopoietin-1. Science 1999 Dec 24;286(5449):2511-4.

116. Thurston G, Suri C, Smith K, McClain J, Sato TN, Yancopoulos GD, et al. Leakageresistant blood vessels in mice transgenically overexpressing angiopoietin-1. Science 1999 Dec 24;286(5449):2511-4.

117. Joussen AM, Poulaki V, Tsujikawa A, Qin W, Qaum T, Xu Q, et al. Suppression of diabetic retinopathy with angiopoietin-1. Am J Pathol 2002 May;160(5):1683-93.

118. Chae JK, Kim I, Lim ST, Chung MJ, Kim WH, Kim HG, et al. Coadministration of angiopoietin-1 and vascular endothelial growth factor enhances collateral vascularization. Arterioscler Thromb Vasc Biol 2000 Dec;20(12):2573-8.

119. Thurston G, Rudge JS, Ioffe E, Zhou H, Ross L, Croll SD, et al. Angiopoietin-1 protects the adult vasculature against plasma leakage. Nat Med 2000 Apr;6(4):460-3.

120. Arsic N, Zentilin L, Zacchigna S, Santoro D, Stanta G, Salvi A, et al. Induction of functional neovascularization by combined VEGF and angiopoietin-1 gene transfer using AAV vectors. Mol Ther 2003 Apr;7(4):450-9.

121. Metheny-Barlow LJ, Li LY. The enigmatic role of angiopoietin-1 in tumor angiogenesis. Cell Res 2003 Oct;13(5):309-17.

122. Dvorak HF, Nagy JA, Feng D, Brown LF, Dvorak AM. Vascular permeability factor/vascular endothelial growth factor and the significance of microvascular hyperpermeability in angiogenesis. Curr Top Microbiol Immunol 1999;237:97-132.

123. Thurston G, Suri C, Smith K, McClain J, Sato TN, Yancopoulos GD, et al. Leakageresistant blood vessels in mice transgenically overexpressing angiopoietin-1. Science 1999 Dec 24;286(5449):2511-4.

124. Chae JK, Kim I, Lim ST, Chung MJ, Kim WH, Kim HG, et al. Coadministration of angiopoietin-1 and vascular endothelial growth factor enhances collateral vascularization. Arterioscler Thromb Vasc Biol 2000 Dec;20(12):2573-8. 
125. Thurston G, Rudge JS, Ioffe E, Zhou H, Ross L, Croll SD, et al. Angiopoietin-1 protects the adult vasculature against plasma leakage. Nat Med 2000 Apr;6(4):460-3.

126. Arsic N, Zentilin L, Zacchigna S, Santoro D, Stanta G, Salvi A, et al. Induction of functional neovascularization by combined VEGF and angiopoietin-1 gene transfer using AAV vectors. Mol Ther 2003 Apr;7(4):450-9.

127. Chandrasekharan NV, Dai H, Roos KLT, Evanson NK, Tomsik J, Elton TS, et al. From the Cover: COX-3, a cyclooxygenase-1 variant inhibited by acetaminophen and other analgesic/antipyretic drugs: Cloning, structure, and expression. PNAS 2002 Oct 15;99(21):13926-31.

128. Chun KS, Surh YJ. Signal transduction pathways regulating cyclooxygenase-2 expression: potential molecular targets for chemoprevention. Biochem Pharmacol 2004 Sep 15;68(6):1089-100.

129. Wendum D, Masliah J, Trugnan G, Flejou JF. Cyclooxygenase-2 and its role in colorectal cancer development. Virchows Arch 2004 Oct;445(4):327-33.

130. Dannenberg AJ, Subbaramaiah K. Targeting cyclooxygenase-2 in human neoplasia: rationale and promise. Cancer Cell 2003 Dec;4(6):431-6.

131. Wendum D, Masliah J, Trugnan G, Flejou JF. Cyclooxygenase-2 and its role in colorectal cancer development. Virchows Arch 2004 Oct;445(4):327-33.

132. Mitchell JA, Warner TD. Cyclo-oxygenase-2: pharmacology, physiology, biochemistry and relevance to NSAID therapy. 1999 Nov;128(6):1121-32.

133. KUWANO TAKA, NAKAO SHIN, YAMAMOTO HIDE, TSUNEYOSHI MASA, YAMAMOTO TOMO, KUWANO MICH, et al. Cyclooxygenase 2 is a key enzyme for inflammatory cytokine-induced angiogenesis. FASEB J 2004 Feb 1;18(2):300-10.

134. Fosslien E. Molecular Pathology of Cyclooxygenase-2 in Cancer-induced Angiogenesis. Ann Clin Lab Sci 2001 Oct 1;31(4):325-48.

135. MURPHY JF, FITZGERALD DJ. Vascular endothelial growth factor induces cyclooxygenase-dependent proliferation of endothelial cells via the VEGF-2 receptor. FASEB J 2001 Jul 1;15(9):1667-9.

136. Majima M, Isono M, Ikeda Y, Hayashi I, Hatanaka K, Harada Y, et al. Significant roles of inducible cyclooxygenase (COX)-2 in angiogenesis in rat sponge implants. Jpn J Pharmacol 1997 Oct;75(2):105-14.

137. Hernandez GL, Volpert OV, Iniguez MA, Lorenzo E, Martinez-Martinez S, Grau R, et al. Selective inhibition of vascular endothelial growth factor-mediated angiogenesis by cyclosporin A: roles of the nuclear factor of activated $\mathrm{T}$ cells and cyclooxygenase 2 . $\mathrm{J}$ Exp Med 2001 Mar 5;193(5):607-20. 
138. Gately S, Li WW. Multiple roles of COX-2 in tumor angiogenesis: a target for antiangiogenic therapy. Semin Oncol 2004 Apr;31(2 Suppl 7):2-11.

139. Prescott SM. Is cyclooxygenase-2 the alpha and the omega in cancer? J Clin Invest 2000 Jun 1;105(11):1511-3.

140. Leahy KM, Koki AT, Masferrer JL. Role of cyclooxygenases in angiogenesis. Curr Med Chem 2000 Nov;7(11):1163-70.

141. Tsujii M, Kawano S, Tsuji S, Sawaoka H, Hori M, DuBois RN. Cyclooxygenase regulates angiogenesis induced by colon cancer cells. Cell 1998 May 29;93(5):705-16.

142. Liu XH, Kirschenbaum A, Lu M, Yao S, Dosoretz A, Holland JF, et al. Prostaglandin E2 induces hypoxia-inducible factor-1alpha stabilization and nuclear localization in a human prostate cancer cell line. J Biol Chem 2002 Dec 20;277(51):50081-6.

143. Seed MP, Brown JR, Freemantle CN, Papworth JL, Colville-Nash PR, Willis D, et al. The inhibition of colon-26 adenocarcinoma development and angiogenesis by topical diclofenac in 2.5\% hyaluronan. Cancer Res 1997 May 1;57(9):1625-9.

144. Williams CS, Tsujii M, Reese J, Dey SK, DuBois RN. Host cyclooxygenase-2 modulates carcinoma growth. J Clin Invest 2000 Jun;105(11):1589-94.

145. Chun KS, Surh YJ. Signal transduction pathways regulating cyclooxygenase-2 expression: potential molecular targets for chemoprevention. Biochem Pharmacol 2004 Sep 15;68(6):1089-100.

146. Dixon DA. Regulation of COX-2 expression in human cancers. Prog Exp Tumor Res 2003;37:52-71.

147. Dannenberg AJ, Subbaramaiah K. Targeting cyclooxygenase-2 in human neoplasia: rationale and promise. Cancer Cell 2003 Dec;4(6):431-6.

148. Wendum D, Masliah J, Trugnan G, Flejou JF. Cyclooxygenase-2 and its role in colorectal cancer development. Virchows Arch 2004 Oct;445(4):327-33.

149. Dannenberg AJ, Subbaramaiah K. Targeting cyclooxygenase-2 in human neoplasia: rationale and promise. Cancer Cell 2003 Dec;4(6):431-6.

150. Chun KS, Surh YJ. Signal transduction pathways regulating cyclooxygenase-2 expression: potential molecular targets for chemoprevention. Biochem Pharmacol 2004 Sep 15;68(6):1089-100.

151. Dannenberg AJ, Subbaramaiah K. Targeting cyclooxygenase-2 in human neoplasia: rationale and promise. Cancer Cell 2003 Dec;4(6):431-6. 
152. Chun KS, Surh YJ. Signal transduction pathways regulating cyclooxygenase-2 expression: potential molecular targets for chemoprevention. Biochem Pharmacol 2004 Sep 15;68(6):1089-100.

153. Dannenberg AJ, Subbaramaiah K. Targeting cyclooxygenase-2 in human neoplasia: rationale and promise. Cancer Cell 2003 Dec;4(6):431-6.

154. Chun KS, Surh YJ. Signal transduction pathways regulating cyclooxygenase-2 expression: potential molecular targets for chemoprevention. Biochem Pharmacol 2004 Sep 15;68(6):1089-100.

155. Dannenberg AJ, Subbaramaiah K. Targeting cyclooxygenase-2 in human neoplasia: rationale and promise. Cancer Cell 2003 Dec;4(6):431-6.

156. Folkman J. What is the evidence that tumors are angiogenesis dependent? J Natl Cancer Inst 1990 Jan 3;82(1):4-6.

157. Hanahan D, Folkman J. Patterns and emerging mechanisms of the angiogenic switch during tumorigenesis. Cell 1996 Aug 9;86(3):353-64.

158. Dvorak HF. How Tumors Make Bad Blood Vessels and Stroma. Am J Pathol 2003 Jun $1 ; 162(6): 1747-57$.

159. Hammersen F, Endrich B, Messmer K. The fine structure of tumor blood vessels. I. Participation of non-endothelial cells in tumor angiogenesis. Int J Microcirc Clin Exp 1985;4(1):31-43.

160. Senger DR. Molecular framework for angiogenesis: a complex web of interactions between extravasated plasma proteins and endothelial cell proteins induced by angiogenic cytokines. Am J Pathol 1996 Jul;149(1):1-7.

161. Longo R, Sarmiento R, Fanelli M, Capaccetti B, Gattuso D, Gasparini G. Antiangiogenic therapy: rationale, challenges and clinical studies. Angiogenesis 2002;5(4):237-56.

162. BUSSOLATI BENE, DEAMBROSIS ILAR, RUSSO SIMO, DEREGIBUS MC, CAMUSSI GIOV. Altered angiogenesis and survival in human tumor-derived endothelial cells. FASEB J 2003 Jun 1;17(9):1159-61.

163. Kerbel RS. Inhibition of tumor angiogenesis as a strategy to circumvent acquired resistance to anti-cancer therapeutic agents. Bioessays 1991 Jan;13(1):31-6.

164. Rak J, Kerbel RS. Treating cancer by inhibiting angiogenesis: new hopes and potential pitfalls. Cancer Metastasis Rev 1996 Jun;15(2):231-6.

165. Kakeji Y, Teicher BA. Preclinical studies of the combination of angiogenic inhibitors with cytotoxic agents. Invest New Drugs 1997;15(1):39-48. 
166. Kerbel R, Folkman J. CLINICAL TRANSLATION OF ANGIOGENESIS INHIBITORS. Nat Rev Cancer 2002 Oct;2(10):727-39.

167. Margolin K, Gordon MS, Holmgren E, Gaudreault J, Novotny W, Fyfe G, et al. Phase Ib Trial of Intravenous Recombinant Humanized Monoclonal Antibody to Vascular Endothelial Growth Factor in Combination With Chemotherapy in Patients With Advanced Cancer: Pharmacologic and Long-Term Safety Data. J Clin Oncol 2001 Feb 1;19(3):851-6.

168. Gordon MS, Margolin K, Talpaz M, Sledge GW, Jr., Holmgren E, Benjamin R, et al. Phase I Safety and Pharmacokinetic Study of Recombinant Human Anti-Vascular Endothelial Growth Factor in Patients With Advanced Cancer. J Clin Oncol 2001 Feb 1;19(3):843-50.

169. Rosen LS. VEGF-Targeted Therapy: Therapeutic Potential and Recent Advances. Oncologist 2005 Jun 1;10(6):382-91.

170. Prewett M, Huber J, Li Y, Santiago A, O'Connor W, King K, et al. Antivascular endothelial growth factor receptor (fetal liver kinase 1) monoclonal antibody inhibits tumor angiogenesis and growth of several mouse and human tumors. Cancer Res 1999 Oct 15;59(20):5209-18.

171. Vajkoczy P, Menger MD, Vollmar B, Schilling L, Schmiedek P, Hirth KP, et al. Inhibition of tumor growth, angiogenesis, and microcirculation by the novel Flk-1 inhibitor SU5416 as assessed by intravital multi-fluorescence videomicroscopy. Neoplasia 1999 Apr;1(1):31-41.

172. Fong TA, Shawver LK, Sun L, Tang C, App H, Powell TJ, et al. SU5416 Is a Potent and Selective Inhibitor of the Vascular Endothelial Growth Factor Receptor (Flk-1/KDR) That Inhibits Tyrosine Kinase Catalysis, Tumor Vascularization, and Growth of Multiple Tumor Types. Cancer Research 1999 Jan 1;59(1):99-106.

173. Angelov L, Salhia B, Roncari L, McMahon G, Guha A. Inhibition of Angiogenesis by Blocking Activation of the Vascular Endothelial Growth Factor Receptor 2 Leads to Decreased Growth of Neurogenic Sarcomas. Cancer Research 1999 Nov 1;59(21):553641.

174. Shaheen RM, Davis DW, Liu W, Zebrowski BK, Wilson MR, Bucana CD, et al. Antiangiogenic Therapy Targeting the Tyrosine Kinase Receptor for Vascular Endothelial Growth Factor Receptor Inhibits the Growth of Colon Cancer Liver Metastasis and Induces Tumor and Endothelial Cell Apoptosis. Cancer Research 1999 Nov 1;59(21):5412-6.

175. Stopeck A, Sheldon M, Vahedian M, Cropp G, Gosalia R, Hannah A. Results of a Phase I Dose-escalating Study of the Antiangiogenic Agent, SU5416, in Patients with Advanced Malignancies. Clin Cancer Res 2002 Sep 1;8(9):2798-805. 
176. Stadler WM, Cao D, Vogelzang NJ, Ryan CW, Hoving K, Wright R, et al. A Randomized Phase II Trial of the Antiangiogenic Agent SU5416 in Hormone-Refractory Prostate Cancer. Clin Cancer Res 2004 May 15;10(10):3365-70.

177. Thomas AL, Morgan B, Drevs J, Unger C, Wiedenmann B, Vanhoefer U, et al. Vascular endothelial growth factor receptor tyrosine kinase inhibitors: PTK787/ZK 222584. Semin Oncol 2003 Jun;30(3 Suppl 6):32-8.

178. Wedge SR, Ogilvie DJ, Dukes M, Kendrew J, Chester R, Jackson JA, et al. ZD6474 Inhibits Vascular Endothelial Growth Factor Signaling, Angiogenesis, and Tumor Growth following Oral Administration. Cancer Research 2002 Aug 15;62(16):4645-55.

179. Lin P, Sankar S, Shan S, Dewhirst MW, Polverini PJ, Quinn TQ, et al. Inhibition of tumor growth by targeting tumor endothelium using a soluble vascular endothelial growth factor receptor. Cell Growth Differ 1998 Jan;9(1):49-58.

180. Wahl ML, Moser TL, Pizzo SV. Angiostatin and Anti-angiogenic Therapy in Human Disease. Recent Prog Horm Res 2004 Jan 1;59(1):73-104.

181. O'Reilly MS, Holmgren L, Shing Y, Chen C, Rosenthal RA, Moses M, et al. Angiostatin: a novel angiogenesis inhibitor that mediates the suppression of metastases by a Lewis lung carcinoma. Cell 1994 Oct 21;79(2):315-28.

182. O'Reilly MS, Holmgren L, Chen C, Folkman J. Angiostatin induces and sustains dormancy of human primary tumors in mice. Nat Med 1996 Jun;2(6):689-92.

183. Ferreras M, Felbor U, Lenhard T, Olsen BR, Delaisse J. Generation and degradation of human endostatin proteins by various proteinases. FEBS Lett 2000 Dec 15;486(3):247-51

184. O'Reilly MS, Boehm T, Shing Y, Fukai N, Vasios G, Lane WS, et al. Endostatin: an endogenous inhibitor of angiogenesis and tumor growth. Cell 1997 Jan 24;88(2):277-85.

185. Capillo M, Mancuso P, Gobbi A, Monestiroli S, Pruneri G, Dell'Agnola C, et al. Continuous Infusion of Endostatin Inhibits Differentiation, Mobilization, and Clonogenic Potential of Endothelial Cell Progenitors. Clin Cancer Res 2003 Jan 1;9(1):377-82.

186. Ingber D, Fujita T, Kishimoto S, Sudo K, Kanamaru T, Brem H, et al. Synthetic analogues of fumagillin that inhibit angiogenesis and suppress tumour growth. Nature 1990 Dec 6;348(6301):555-7.

187. Castronovo V, Belotti D. TNP-470 (AGM-1470): mechanisms of action and early clinical development. Eur J Cancer 1996 Dec;32A(14):2520-7.

188. Futami H, Iseki H, Egawa S, Koyama K, Yamaguchi K. Inhibition of lymphatic metastasis in a syngeneic rat fibrosarcoma model by an angiogenesis inhibitor, AGM1470. Invasion Metastasis 1996;16(2):73-82. 
189. Griffioen AW, Molema G. Angiogenesis: Potentials for Pharmacologic Intervention in the Treatment of Cancer, Cardiovascular Diseases, and Chronic Inflammation. Pharmacol Rev 2000 Jun 1;52(2):237-68.

190. Burrows FJ, Thorpe PE. Vascular targeting--a new approach to the therapy of solid tumors. Pharmacol Ther 1994 Oct;64(1):155-74.

191. Brekken RA, Li C, Kumar S. Strategies for vascular targeting in tumors. Int J Cancer 2002 Jul 10;100(2):123-30. 


\section{Chapter 2}

Modulation of Angiopoietin-1-induced Angiogenic Effects by p70S6K1 


\begin{abstract}
Angiopoietin-1 (Ang1) is an endothelial specific growth factor that is critical for vessel maturation and stabilization during angiogenesis. We found that Ang1 markedly induces the activation of p70S6K1 in human umbilical vein endothelial cells (HUVECs). p70S6K1 is a downstream target of PI3K signaling and has emerged as an important regulator of cell cycle progression and cell growth. However, little is known about the role of p70S6K1 in angiogenesis. Here, we showed that inhibition of endogenous p70S6K1 activity in HUVECs by adenovirusmediated overexpression of a dominant-negative p70S6K1 mutant (p70S6K-KD) caused remarkable changes in cell morphology, characterized by disruption of stress fiber formation, cell rounding, and loss of cell polarity and motile structures. Overexpression of p70S6K-KD completely blocked Ang1-induced cell migration. In contrast, expression of a constitutively active p70S6K1 (p70S6K-CA) enhanced Ang1-induced cell migration. Ang1 significantly reduced serum deprivation-induced cell death. p70S6K-KD completely abrogated the effect of Ang1 on cell viability, whereas p70S6K-CA enhanced Ang1-mediated cell survival. Ang1 treatment also significantly increased cell invasion through the Matrigel. Inhibition of p70S6K1 activity markedly reduced Ang1-induced cell invasion. Correlated with its effect on cell invasion, p70S6K1 also regulated Ang1-induced MMP-2 secretion and activation. Moreover, p70S6K-KD significantly inhibited endothelial tube formation, whereas cells transduced with p70S6K-CA form more tube structures in the presence or absence of Ang1. Taken together, this study provides evidence that p70S6K1 is directly involved in Ang1-mediated angiogenic responses, including endothelial cell migration, invasion, survival, and capillary morphogenesis, implying an important role of p70S6K1 in angiogenesis.
\end{abstract}




\section{Introduction}

Angiopoietin-1 (Ang1) is a ligand of the receptor tyrosine kinase Tie2, which is expressed predominantly on endothelial cells (ECs) $(1 ; 2)$. Gene knockout studies suggested that Ang1 is involved in the recruitment of mural cells to support the primitive endothelial tubes, thereby contributes to vessel maturation and stabilization at the later stages of angiogenesis (3). Ang1 does not stimulate EC proliferation (3), rather it is a potent factor for EC survival (4-7), and Ang1 can induce EC migration (8), sprouting $(9 ; 10)$, and tube formation $(5 ; 11 ; 12)$. Transgenic overexpression of Ang1 increases vascularization in vivo, and the blood vessels induced by Ang1 are leakage-resistant (13-15). Ang1 has therapeutic potential for diseases with increased vascular leakage, e.g., diabetic retinopathy (16), and appears to be of benefit in inducing functional neovascularization when it is co-administered with vascular endothelial growth factor (VEGF) to produce therapeutic angiogenesis (17-19).

Binding of Ang1 to its receptor Tie2 activates phosphatidylinositol 3-kinase (PI3K)/Akt signaling pathway (20). The PI3K/Akt signaling pathway has been recognized as the key signaling event of Tie2 activation to regulate the angiogenic functions of Ang1. PI3K/Akt signaling plays important roles in mediating Ang1-induced EC survival, migration, sprouting, and tube formation (6;10;12;21-23). The anti-apoptotic protein survivin has recently been shown to regulate Ang1-

mediated EC survival in a PI3K/Akt-dependent manner (24). In addition, PI3K/Akt pathway modulates nitric oxide release and activation of matrix metalloproteinase-2 (MMP-2) in human endothelial cells in response to Ang1 stimulation (10;12).

The $70 \mathrm{kD}$ ribosomal S6 kinase (p70S6K1) plays a critical role in the initiation of protein synthesis. p70S6K1 phosphorylates the S6 ribosomal protein and stimulates the translation of a 
subset of mRNAs with a 5'-oligopyrimidine tract that encode major components of the protein synthesis apparatus (25). p70S6K1 is activated by numerous mitogens, growth factors and hormones. Activation of p70S6K1 occurs through a complex series of phosphorylation events on several serine and threonine residues, which are mediated by PI3K, mTOR, and other kinases $(25 ; 26)$. In addition to S6 ribosomal protein, many other substrates or downstream effectors of p70S6K1 have been identified, and p70S6K1 has emerged as an important regulator of cell cycle progression, cell growth, and cell motility (25-27). However, the role of p70S6K1 in angiogenesis remains largely unclear. It is reported that VEGF induced a PI3K-dependent activation of p70S6K1, and that inactivation of p70S6K1 by rapamycin inhibited VEGFstimulated HUVEC proliferation (28). A more recent study suggested that the PDGFR $\alpha$ p70S6K1 signaling in mesenchymal cells might be a target for rapamycin to suppress tumor angiogenesis (29). In both studies, the pharmaceutical inhibitor rapamycin was utilized to inhibit p70S6K1 activity. However, the target of rapamycin is the serine/threonine kinase mTOR (mammalian target of rapamycin), which has other downstream effectors besides p70S6K1. In

the present study, we directly modified p70S6K1 activity in human endothelial cells using adenoviral vector-mediated gene transfer, and aimed to define the role of p70S6K1 in Ang1induced angiogenic responses in human endothelial cells.

\section{Materials and Methods}

\section{Cell Culture and Reagents}

HUVECs were cultured in MCDB131 medium (Sigma, St. Louis, MO) supplemented with 10\% fetal bovine serum (FBS), $15 \mu \mathrm{g} / \mathrm{ml}$ EC growth supplement (ECGS, Upstate, Lake Placid, NY), 1 
$\mathrm{ng} / \mathrm{ml} \mathrm{bFGF}, 10 \mathrm{ng} / \mathrm{ml} \mathrm{EGF}, 50 \mu \mathrm{g} / \mathrm{ml}$ heparin, $1 \mu \mathrm{g} / \mathrm{ml}$ hydrocortisone, 100 units $/ \mathrm{ml}$ penicillin, and $100 \mu \mathrm{g} / \mathrm{ml}$ streptomycin. The cells were maintained at $37^{\circ} \mathrm{C}$ and $5 \% \mathrm{CO}_{2}$ in a humid environment. Cells at 4-6 passage were used in this study.

Recombinant human Ang1 was purchased from R \& D Systems (Minneapolis, MN). LY294002, PD98059, and rapamycin were from Calbiochem (La Jolla, CA). Antibodies against phosphorylated S6 ribosomal protein (Ser235/236), phosphorylated p70S6K1 (Thr412/Ser424, and Thr389), total p70S6K1, phosphorylated Akt (Ser473), total Akt, phosphorylated Erk1/2 (Thr202/Tyr204), and HA tag were obtained from Cell Signaling Technology (Beverly, MA). Total Erk1/2 antibody was from Santa Cruz Biotechnology (Santa Cruz, CA). Antibody against $\beta$-actin was from Sigma (St. Louis, MO). Monoclonal antibody against poly(ADP-ribose) polymerase (PARP) was purchased from R \& D Systems (Minneapolis, MN). Growth factorreduced Matrigel was from BD Biosciences (San Jose, CA).

\section{Adenovirus Preparation and Cell Infection}

The construction of constitutively active p70S6K1 and kinase-dead p70S6K1 has been described previously (30). Recombinant adenoviruses were generated using the AdEasy system as previously described (31). A control virus carrying the green fluorescent protein (Ad-GFP) was derived from the same vector system. The virus stock was purified by cesium chloride gradient centrifugation. Viral titers were determined by using the BD Adeno- $\mathrm{X}^{\mathrm{TM}}$ Rapid Titer Kit (BD Biosciences Clontech, Mountain View, CA). 10 multiplicity of infection (MOI) was used for HUVEC infection, which consistently achieved more than $90 \%$ of transduction and no apparent cell toxicity was observed. 


\section{Western Blotting}

Cell lysates were fractionated by SDS-PAGE and transferred to nitrocellulose membranes (Schleicher \& Schuell Biosciences, Keene, NH). The Blots were incubated with appropriately diluted primary antibodies, followed by incubation with corresponding horseradish peroxidaseconjugated secondary antibody and visualized by enhanced chemiluminescence reagent (Pierce Biotechnology, Rockford, IL).

\section{Immunofluorescence Staining}

HUVECs were seeded onto glass coverslips and cultured in normal growth medium. Cells were fixed in $3.7 \%$ formaldehyde, washed in PBS, and permealized with $0.4 \%$ Triton-X100. Actin filaments were stained with TRITC-phalloidin diluted to 1:1000 in 3\% BSA in PBS. The coverslips were washed and mounted on slides with Fluormount (Fisher, Pittsburgh, PA). A Zeiss LSM 510 confocal microscope was used to capture the images.

\section{p70S6K1 Kinase Activity Assay}

In vitro p70S6K1 kinase assay was carried out using a S6 Kinase Assay Kit (Upstate biotechnology, Lake Placid, NY) according to the manufacturer's instructions. Briefly, p70S6K1 was precipitated from $200 \mu \mathrm{g}$ of cell lysates by a monoclonal anti-p70S6K1 antibody (49D7, Cell Signaling Technology, Beverly, MA). Immunoprecipitates were washed and then incubated at $30^{\circ} \mathrm{C}$ for $10 \mathrm{~min}$ in the kinase assay cocktail containing a substrate peptide and $10 \mu \mathrm{Ci}[\gamma$ $\left.{ }^{32} \mathrm{P}\right] \mathrm{dATP}$. The reaction was transferred onto a P81 phosphocellulose filter and the residual $[\gamma-$

${ }^{32} \mathrm{P}$ ]dATP was washed off. The radioactivity of the phosphorylated substrate bound to the filter was quantified by using a liquid scintillation counter. 


\section{Cell Migration Assay}

Migration of HUVECs was assayed using a $6.5 \mathrm{~mm}$ Transwell device with polycarbonate filters of $8.0 \mu \mathrm{M}$ pore size (Corning Incorporated, Corning, NY). Cells were trypsinized and resuspended in basal medium as $2.5 \times 10^{5}$ cells $/ \mathrm{ml}$ and $200 \mu \mathrm{l}$ of the cell suspension was added onto the upper chamber. Ang1 was added into the lower chamber as a chemotractant. The chamber was incubated at $37^{\circ} \mathrm{C}$ for $6 \mathrm{~h}$. The filter was carefully removed, and cells attached on the upper side were wiped off. The cells migrating through the filter to the lower side were fixed with methanol and stained with Diff-Quik solution.

\section{Cell Invasion Assay}

The in vitro cell invasion assay was performed using $\mathrm{BD}$ Biocoat ${ }^{\mathrm{TM}}$ Matrigel $^{\mathrm{TM}}$ invasion chamber with 6.5-mm diameter polycarbonate filters with $8.0 \mu \mathrm{m}$ pore size (BD Biosciences, San Jose, CA). HUVECs were resuspended at $5 \times 10^{5}$ cells $/ \mathrm{ml}$ in basal medium containing $1 \% \mathrm{FBS}$. Ang1 $(250 \mathrm{ng} / \mathrm{ml})$ or BSA was added into the cell suspension and $200 \mu \mathrm{l}$ of the cell suspension was loaded onto the upper chamber. The lower wells were filled with basal medium containing $1 \% \mathrm{FBS}$ with or without $250 \mathrm{ng} / \mathrm{ml}$ of Ang1. The chamber was incubated at $37^{\circ} \mathrm{C}$ for $24 \mathrm{~h}$. The Matrigel and nonmigrating cells on the upper surface of the filter were removed by wiping with a cotton swab, and the filter was then fixed with methanol and stained with Diff-Quik solution. Invasive activity was quantified by counting the cells that migrated to the lower side of the filter. 


\section{Gelatin Zymography Assay}

For MMP-2 zymography, equal aliquots of conditioned cell culture medium were separated in 9\% SDS-PAGE containing 0.1\% gelatin. Samples were prepared in a nonreducing loading buffer. After electrophoresis, SDS was removed by $2.5 \%$ Triton X-100 to renature gelatinases. The gels were washed in a buffer $(0.1 \mathrm{~mol} / \mathrm{L}$ Tris- $\mathrm{HCl}, \mathrm{pH} 8.0,0.5 \mathrm{~mol} / \mathrm{L} \mathrm{NaCl}, 2.5 \%$ Triton $\mathrm{X}-100)$, and were then incubated at $37^{\circ} \mathrm{C}$ for $24 \mathrm{~h}$ in a reaction buffer $(50 \mathrm{mmol} / \mathrm{L}$ Tris-HCl, $\mathrm{pH} 8.0,20$ $\mathrm{mmol} / \mathrm{L} \mathrm{CaCl}_{2}$ ). The gels were stained with $0.25 \%$ Coomassie Blue $\mathrm{R} 250$, followed by destaining in a buffer containing $10 \%$ methanol and $10 \%$ acetic acid.

\section{Cell Survival Assay}

HUVECs were seeded in triplicate at the density of $1 \times 10^{5}$ cells per well in 6 -well plates. Cells were infected with adenovirus vectors for $24 \mathrm{~h}$ in normal growth medium, then washed with $1 \times$ PBS and incubated in serum-free medium with or without $250 \mathrm{ng} / \mathrm{ml} \mathrm{Ang1.} \mathrm{After} 24 \mathrm{~h}$, cell viability was determined by trypan blue dye exclusion. Viable cells were counted on a hemocytometer.

\section{Tube Formation Assay}

HUVECs were infected with adenovirus vectors for $24 \mathrm{~h}$, serum-starved and then trypsinized and resuspended in basal medium containing $0.5 \%$ FBS. Cells $\left(1 \times 10^{4}\right.$ cells per well $)$ were plated in triplicate wells of 96-well plates pre-coated with growth factor-reduced Matrigel. The cells were incubated for $16 \mathrm{~h}$ at $37^{\circ} \mathrm{C}$, and tubule structures were photographed by phase-contrast microscopy using an Olympus IX-71 microscope $(100 \times$ magnification $)$ connected to a digital 
camera. Total tube length per field was measured using the Olympus MicroSuite ${ }^{\mathrm{TM}}$ Basic program.

\section{Statistical Analysis}

All results were expressed as the mean $\pm \mathrm{SD}$. Statistical analysis was performed using the onetailed Student's $t$ test (two sample, unequal variance) or one-way ANOVA (Tukey's honestly significance difference test was used for post-hoc comparisons). Significance level was set at $\mathrm{p}<0.05$. SPSS software (SPSS ${ }^{\circledR}$ for Windows Student Version, SPSS Inc., Chicago, IL, USA) was used for all statistical analyses.

\section{Results}

\section{Ang1 Induces p70S6K1 Activation through PI3K and MAPK Signaling Pathways}

To determine whether Ang1 induces p70S6K1 activation, we examined the effects of Ang1 on the phosphorylation of p70S6K1 at Thr421/Ser424 and Thr389 residues, which are critical phosphorylation sites for maximal activation of p70S6K1. Ang1 significantly induced p70S6K1 phosphorylation, which was blocked by LY294002, rapamycin, or PD98509 (Figure 1A). We also examined the effect of Ang1 on the phosphorylation of S6 ribosomal protein, which is an endogenous substrate of p70S6K1. Stimulation of serum-starved HUVECs with recombinant Ang1 led to a marked increase in S6 ribosomal protein phosphorylation (Figure 1A). Ang1induced phosphorylation of S6 ribosomal protein was inhibited by PI3K inhibitor LY294002, mTOR inhibitor rapamycin, or MAPK inhibitor PD98509 (Figure 1A). Ang1 stimulation caused dramatic increases in Akt and ERK1/2 MAPK phosphorylation that were specifically inhibited 
by LY294002 and PD98509, respectively (Figure 1A). These data demonstrate that Ang1 stimulates p70S6K1 activation via PI3K and MAPK signaling cascades in HUVECs.

\section{p70S6K1 modulates Actin Cytoskeleton Remodeling and Ang1-mediated EC Migration}

To study the role of p70S6K1 in Ang1-mediated angiogenic effects, we altered p70S6K1 activity in HUVECs by adenovirus-mediated expression of either a constitutively active p70S6K 1 mutant (p70S6K-CA) or a catalytically inactive mutant (p70S6K-KD). Ang1 treatment significantly stimulated p70S6K1 kinase activity in HUVECs (Figure 1B). Overexpression of p70S6K-KD blocked Ang1-induced p70S6K1 activation, indicating that p70S6K-KD functions dominantnegatively in the cells. In contrast, transduction of p70S6K-CA resulted in marked increases in p70S6K1 activity even in unstimulated cells (Figure 1B). After adenoviral infection, we noticed pronounced morphologic changes of the cells. The cells transduced with p70S6K-KD were relatively larger in size and became rounded up, whereas cells transduced with p70S6K-CA or Ad-GFP did not show apparent morphologic changes as observed under phase-contrast microscope (Figure 2A). The distinct changes in cell morphology prompted us to examine the alterations in cell cytoskeleton. We found that, in untransduced HUVECs, bundled actin stress fibers were formed throughout the cells, both lamelipodia and philopodia structures were apparent, and the cells were polarized (Figure 2B). Infection of the cells with Ad-GFP or Adp70S6K-CA did not cause significant changes in actin cytoskeleton architecture (Figure 2B). In contrast, cells infected with Ad-p70S6K-KD displayed remarkable morphological changes, characterized by disruption of stress fiber formation, cell rounding, and loss of cell polarity and motile structures (Figure 2B). These results suggested that p70S6K1 may be important for cell migration. To test this hypothesis, we performed transwell cell migration assay using a modified 
Boyden chamber system. As previously documented, Ang1 treatment significantly increased EC migration (Figure 2C). Overexpression of p70S6K-KD completely blocked Ang1-induced cell migration, whereas expression of p70S6K-CA enhanced both basal and Ang1-induced cell migration (Figure 3C). Taken together, these results indicate that p70S6K1 modulates the cytoskeletal architecture of endothelial cells and controls Ang1-mediated cell migration.

\section{Role of p70S6K1 in Ang1-mediated EC Survival}

Compelling evidence indicates that $\mathrm{EC}$ apoptosis plays a major regulatory role in angiogenesis (32). Ang1 has been shown to have strong antiapoptotic effect on ECs (4-7;11). Mechanistically, the anti-apoptotic effect of Ang1 is dependent on PI3K/Akt signaling pathway (6;24). We have shown that Ang1-induced p70S6K1 activation is downstream of PI3K/Akt signaling (Figure 1). In addition, p70S6K1 was shown to regulate cell survival in rat fibroblasts (33). Therefore, we hypothesized that p70S6K1 might be involved in the regulation of Ang1-mediated EC survival. To test this, we performed a cell viability assay in HUVECs cultured in serum-free medium for 24 h. Consistent with previous studies, Ang1 treatment significantly reduced cell death induced by serum deprivation (Figure 3A). Overexpression of p70S6K-KD completely abolished the cytoprotective effect of Ang1, whereas p70S6K-CA enhanced cell survival (Figure 3A). To further confirm the effect of p70S6K1 on cell apoptosis, we evaluated PARP cleavage in HUVECs upon serum deprivation. PARP is a substrate of caspases, and cleaved PARP fragments mediate the apoptotic effects (34). In control groups, Ang1 treatment inhibited serum deprivation-induced PARP cleavage (Figure 3B). Overexpression of p70S6K-KD increased PARP cleavage and reduced Ang1-mediated cell survival. In contrast, very low levels of cleaved PARP were detected in cells overexpressing p70S6K-CA either with or without Ang1 treatment 
(Figure 3B). These results indicate that p70S6K1 is downstream of Ang1 to modulate the antiapoptotic effects.

\section{p70S6K1 Regulates EC Invasion and MMP-2 Activation Induced by Ang1}

EC invasion, the ability of ECs to degrade and penetrate the basement membrane and the extracellular matrix, is critical for angiogenesis. To determine whether Ang1 regulates EC invasion, we performed cell invasion assay using a Matrigel-coated transwell system. Ang1 treatment significantly increased invasion of HUVECs through the Matrigel (Figure 4A). Inhibition of p70S6K1 activity by overexpressing p70S6K-KD significantly reduced cell invasion both at basal level and after Ang1 treatment (Figure 4A). In contrast, transduction of the cells with the empty vector or p70S6K-CA did not significantly alter Ang1-induced EC invasion (Figure 4A).

Matrix metalloproteinases (MMPs) are important for degradation of extracellular matrix components during cell invasion, and ECs can synthesize and release MMPs, especially MMP-2 (35;36). Here, we performed gelatin zymography assay to determine whether p70S6K1 modulates the secretion and activation of MMP-2 in ECs. We found that Ang1 treatment resulted in marked increases in both proMMP-2 and active MMP-2 secretion in HUVECs (Figure 4B). Expression of p70S6K-KD dramatically inhibited both basal level and Ang1-induced MMP-2 secretion and activation, whereas p70S6K-CA did not exhibit significant effect (Figure 4B). These results indicate that p70S6K1 is necessary for Ang1-induced MMP-2 secretion and activation, which might be an underlying mechanism for the involvement of p70S6K1 in Ang1mediated EC invasion. 


\section{p70S6K1 Controls Ang1-induced endothelial cell tube formation}

We have demonstrated that p70S6K1 is important for Ang1-induced EC migration, survival, and invasion, which are critical cellular events for angiogenesis. We next evaluated the effect of p70S6K1 in Ang1-induced EC differentiation into capillary structures by performing endothelial tube formation assay in Matrigel, which is a commonly-used in vitro assay to study angiogenesis. HUVECs were infected with adenoviruses and then seeded on growth factor-reduced Matrigel and treated with or without Ang1. Within $16 \mathrm{~h}$, the cells formed an organized network of tubelike structures, and this effect was enhanced by Ang1 treatment (Figure 5). Overexpression of p70S6K-KD significantly inhibited EC tube formation in the absence or presence of Ang1 (Figure 5). Conversely, the cells infected with p70S6K-CA formed more tube structures, and the ability of Ang1 to induce EC tube formation was further enhanced by expression of p70S6K-CA (Figure 5). These data indicate that p70S6K1 activation is important for Ang1-induced EC capillary morphogenesis.

\section{Discussion}

This study examined the regulation and functional significance of p70S6K1 in ECs in response to Ang1 stimulation. We showed that p70S6K1 is directly involved in the regulation of Ang1mediated EC migration, survival, invasion, and capillary morphogenesis, implying an important role of p70S6K1 in angiogenesis.

This study revealed that $\mathrm{p} 70 \mathrm{~S} 6 \mathrm{~K} 1$ modulates the reorganization of actin cytoskeleton and EC migration induced by Ang1. Our results were consistent with recent observations that p70S6K1 plays a role in actin filament remodeling and cell motility in other cultured cells 
$(25 ; 37)$. The mechanisms by which p70S6K1 controls cell migration remain unclear. The remarkable effects of p70S6K1 on actin cytoskeleton remodeling and EC migration suggest that p70S6K1 may modulate the activities of Rho family small GTPases, which are key regulators of cell motility (38). In addition, p70S6K1 has been found to colocalize with actin cytoskeleton and the leading edges of motile cells (25). Therefore, it was speculated that p70S6K1 may enhance localized synthesis of key protein regulators of the motility structures (25).

EC survival is important for angiogenesis and vessel integrity (32). Ang1 is a strong antiapoptotic factor for ECs $(4 ; 5 ; 11)$. In the present study, we demonstrated that p70S6K1 plays an important role in controlling Ang1-mediated EC survival. The effect of Ang1 on cell survival is dependent on the PI3K/Akt signaling pathway $(6 ; 24)$. We have shown that Ang1-induced p70S6K1 activation is downstream of PI3K/Akt signaling. Therefore, p70S6K1 appears to act downstream of PI3K/Akt pathway to transmit Ang1-induced survival signal. Other Akt-regulated proteins, such as $\mathrm{BAD}$, eNOS, and survivin, have been shown to be important for the cytoprotective effects of many angiogenic factors including Ang1 (32). The mechanisms by which p70S6K1 regulates Ang1-mediated EC survival are unknown. p70S6K1 might modulate cell survival by acting closely with the above-mentioned Akt downstream proteins. Indeed, a recent study reported that p70S6K1 is capable of phosphorylating and inactivating the proapoptotic protein $\mathrm{BAD}$, and thereby promotes cell survival (33). The precise mechanisms by which p70S6K1 controls Ang1-mediated EC survival remain to be elucidated.

EC sprouting is a critical initial step in angiogenesis (39). Ang1 has been shown to be a potent inducer for EC sprouting in vitro $(9 ; 10)$, suggesting that Ang1 may directly regulate EC invasion because EC sprouting requires the migratory and invasive activities of EC. Here, we demonstrated that Ang1 treatment indeed significantly increased EC invasion in an in vitro 
invasion assay. We further showed that p70S6K1 plays an important role in Ang1-induced EC invasion. Previous work showed that Ang1 was able to stimulate MMP-2 secretion by ECs (10). Here, we found that activation of p70S6K1 is essential for Ang1-induced MMP-2 secretion and activation, which may be responsible for its involvement in Ang1-mediated EC invasion. The detailed mechanisms by which p70S6K1 regulates MMP-2 secretion and activation remain to be defined. The in vitro cell invasion and MMP-2 zymography assays were performed for $24 \mathrm{~h}$ after cell quiescence in serum-free medium, and cell apoptosis can be initiated under this experimental setting. Therefore, the effects of p70S6K1 on Ang1-mediated cell invasion and MMP-2 secretion might be, at least partly, due to the alterations in cell survival. In addition, overexpression of p70S6K-CA failed to further enhance the effect of Ang1 on EC invasion, suggesting that activation of p70S6K1 alone was not sufficient to induce EC invasion.

Based on the wide range of cellular effects of p70S6K1 on ECs, we anticipated that p70S6K1 might have significant effects on angiogenesis. Indeed, overexpression of p70S6K-KD markedly inhibited EC tube formation, whereas p70S6K-CA enhanced Ang1-induced EC tube formation. The effects of p70S6K1 on EC capillary formation may result from the combined effects of p70S6K1 on EC survival, migration and invasion. Notably, modulation of p70S6K1 activity in ECs has significant effects on basal EC behavior in addition to the effects on Ang1induced EC responses. Furthermore, Ang1 induces p70S6K1 activation through PI3K and MAPK signaling pathways. These two signaling cascades, which are critical regulators of the angiogenic phenotypes in ECs, can also be initiated by many other angiogenic factors, such as basic fibroblast growth factor (bFGF) and VEGF. We also found that VEGF treatment potently induces p70S6K1 activation (data not shown). Therefore, p70S6K1 may influence EC responses 
to other angiogenic factors as well. In summary, our data suggest that p70S6K1 functions at a converging point of multiple signaling pathways to modulate the EC responses to Ang1.

\section{Acknowledgements}

This work was supported by National Cancer Institute Grant R01CA109460, and by American Cancer Society Research Scholar Grant 04-076-01-TBE (to B.H. Jiang). We thank Dr. Bert Vogelstein (Howard Hughes Medical Institute and Johns Hopkins University) for providing the AdEasy adenoviral vector system. 


\section{Figures and Figure Legends}

\section{Figure 1.}

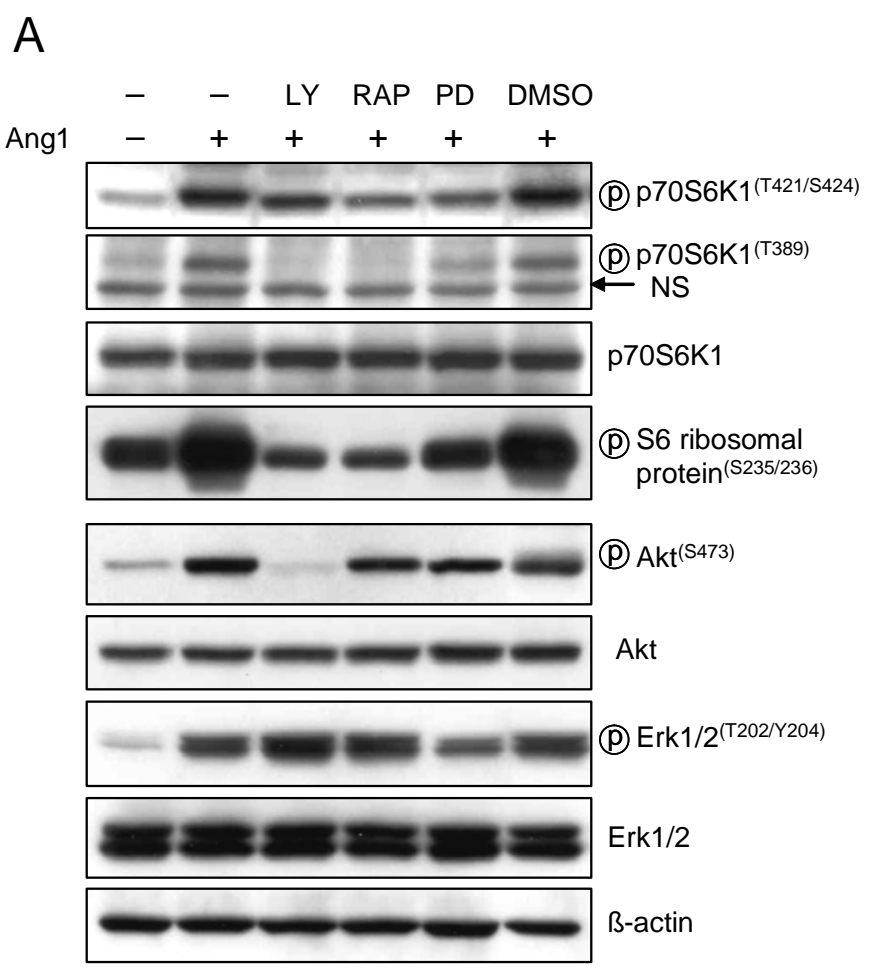

B
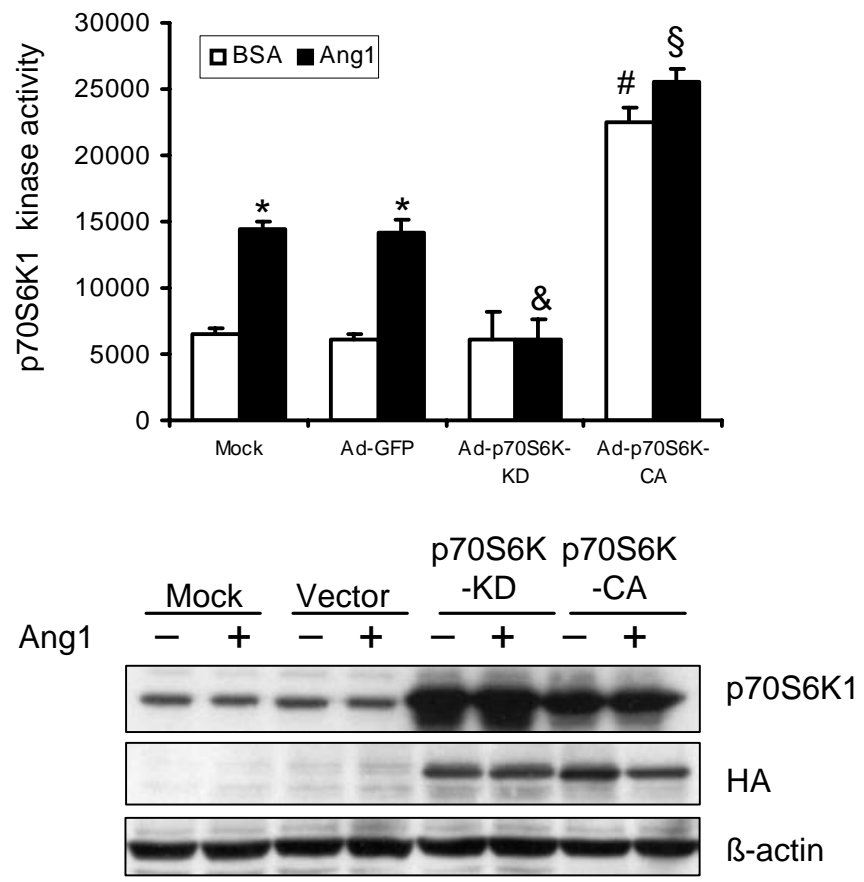

Figure 1. Ang1 induces p70S6K1 activation in HUVECs. A, Serum-starved HUVECs were pretreated with solvent (DMSO), LY294002 (LY), rapamycin (RAP), or PD98059 (PD), followed by treatment with $250 \mathrm{ng} / \mathrm{ml}$ of Ang1 for $30 \mathrm{~min}$. Phosphorylation of S6 ribosomal protein, p70S6K1, Akt, and ERK1/2 was assessed with phosphospecific antibodies as indicated. B, Modulation of p70S6K1 activity in HUVECs by adenovirus-mediated gene transfer. Upper panel: p70S6K1 kinase activity assay. HUVECs were infected with 10 MOI of adenoviruses for $24 \mathrm{~h}$ followed by serum-starvation and subsequent treatment with solvent $(1 \%$ BSA in $1 \times \mathrm{PBS})$ or 250 $\mathrm{ng} / \mathrm{ml}$ of Ang1 for $30 \mathrm{~min}$. The kinase activity of p70S6K1 was assayed as described in Methods. 
p70S6K1 kinase activity was presented as CPM incorporated/min/200 $\mu$ g protein. (* indicates significant different when the value was compared to that of mock or Ad-GFP-infected cells treated with BSA solvent, $\mathrm{p}<0.05 ;{ }^{\&}$ indicates significant different compared to mock or AdGFP-infected cells treated with Ang1, $<<0.05 ;$; indicates significant different when the value was compared to that of mock or Ad-GFP-infected cells treated with BSA solvent, $\mathrm{p}<0.05$; ${ }^{\S}$ indicates significant different compared to mock or Ad-GFP-infected cells treated with Ang1, $\mathrm{p}<0.05)$. Lower panel: cell lysates prepared from the cells treated as described above were subjected to immunoblotting analysis using antibodies against total p70S6K1, HA, or $\beta$-actin. Only p70S6K1 constructs have the HA tag. 
Figure 2.

A

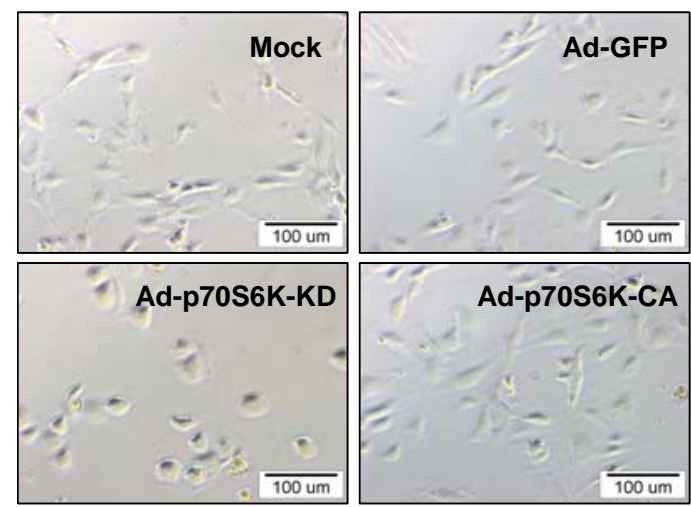

B
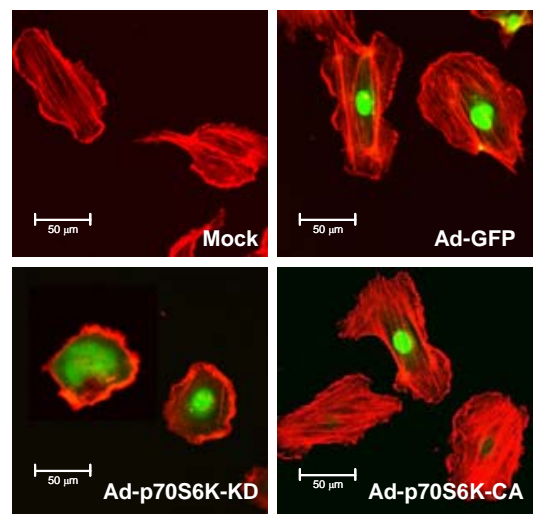

$C$
৫
๒

Ad-GFP
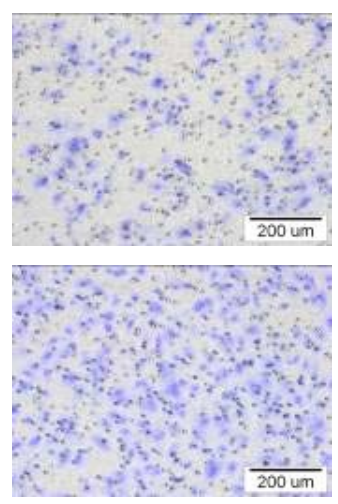

Ad-p70S6K-KD Ad-p70S6K-CA
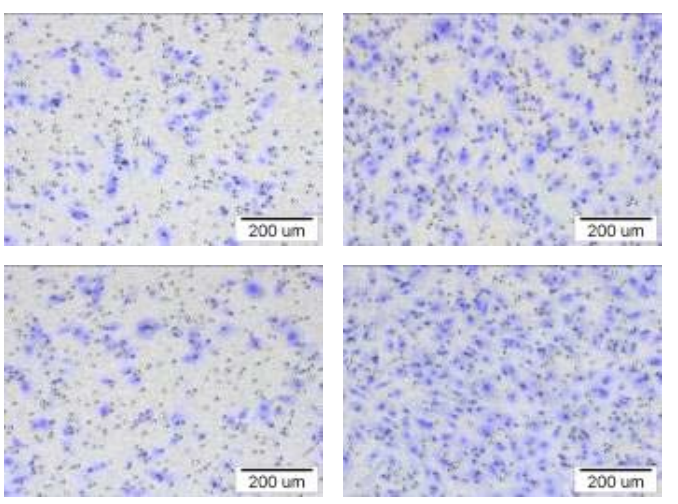

$\frac{1}{8}$
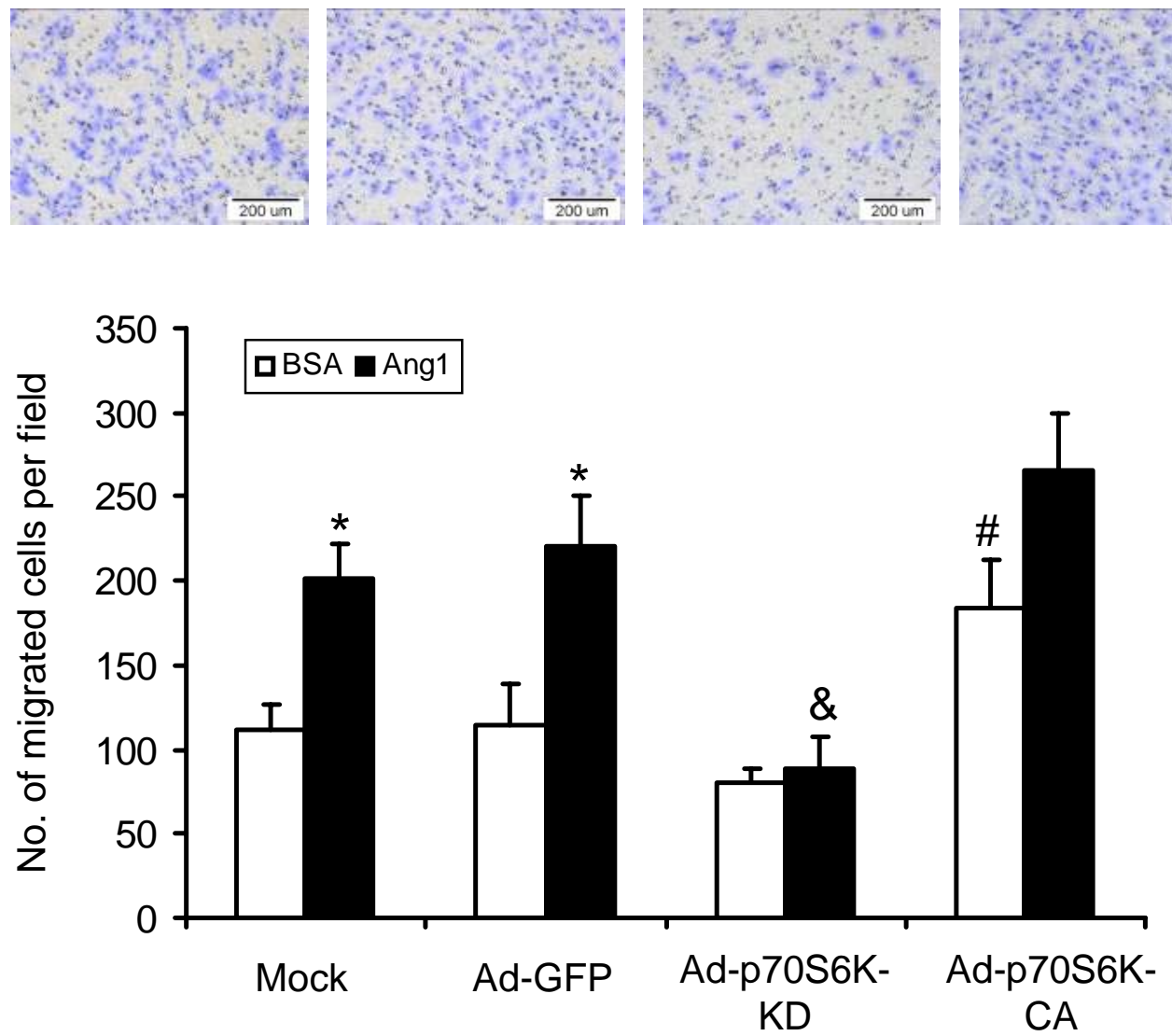
Figure 2. p70S6K1 Regulates actin cytoskeleton remodeling and Ang1-induced cell migration. A, HUVECs were cultured in complete growth medium in plastic petri dish. Cell morphology was photographed by phase-contrast microscope $24 \mathrm{~h}$ after infection with indicated adenoviruses. Original magnification: 200×. B, HUVECs were cultured in complete growth medium on glass coverslips and infected with adenoviruses for $24 \mathrm{~h}$. F-actin was visualized by immunofluorescence staining with rhodamine-conjugated phalloidin. (Red: F-actin; Green: GFP expressed from adenovirus vectors). C, Transwell cell migration assay. HUVECs were infected with adenoviruses for $24 \mathrm{~h}$, then cultured in serum-free medium for $24 \mathrm{~h}$, followed by the chemotaxis assay in the presence or absence of $250 \mathrm{ng} / \mathrm{ml}$ of Ang1 for $6 \mathrm{~h}$. Upper panel, representative photographs of the transwell assays. Lower panel: quantification of cell migration by counting the cell number in high-power fields $(100 \times)$ under a microscope. Data represent mean \pm SD from three random fields. The experiments were repeated three times with similar results. (* indicates significant different when the value was compared to that of mock or AdGFP-infected cells treated with BSA solvent, $\mathrm{p}<0.05 ;{ }^{\&}$ indicates significant different compared to mock or Ad-GFP-infected cells treated with Ang1, p<0.05; " indicates significant different when the value was compared to that of mock or Ad-GFP-infected cells treated with BSA solvent, $\mathrm{p}<0.05)$. 
Figure 3.

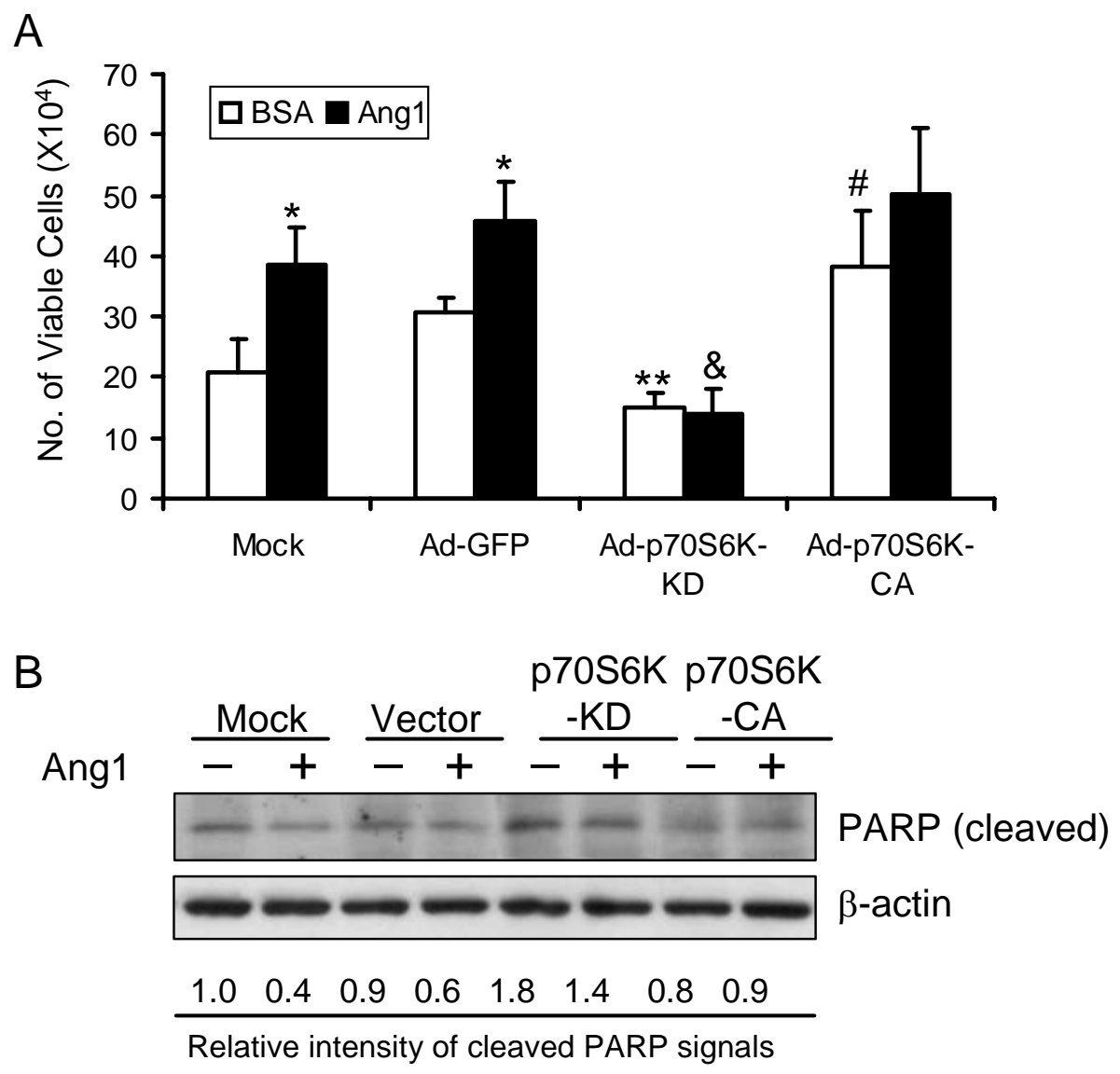

Figure 3. p70S6K1 regulates Ang1-mediated EC survival. A, HUVECs were infected with 10 MOI of adenoviruses for $24 \mathrm{~h}$, the cells were then switched to serum-free medium in the presence or absence of $250 \mathrm{ng} / \mathrm{ml}$ Ang1. Cell viability was determined by trypan blue staining 24 $\mathrm{h}$ after serum-deprivation. (* indicates significant different when the value was compared to that of mock or Ad-GFP-infected cells treated with BSA solvent, $\mathrm{p}<0.05$; ** indicates significant different compared to mock or Ad-GFP-infected cells treated with BSA, $\mathrm{p}<0.05$; ${ }^{\&}$ indicates significant different compared to mock or Ad-GFP-infected cells treated with Ang1, $\mathrm{p}<0.05$; ${ }^{\text {\# }}$ indicates significant different when the value was compared to that of mock or Ad-GFP-infected cells treated with BSA solvent, $\mathrm{p}<0.05)$. B, After the same treatments as described above, HUVECs were collected and cell lysates were subjected to Western blotting using antibodies against PARP and $\beta$-actin, respectively. 


\section{Figure 4.}
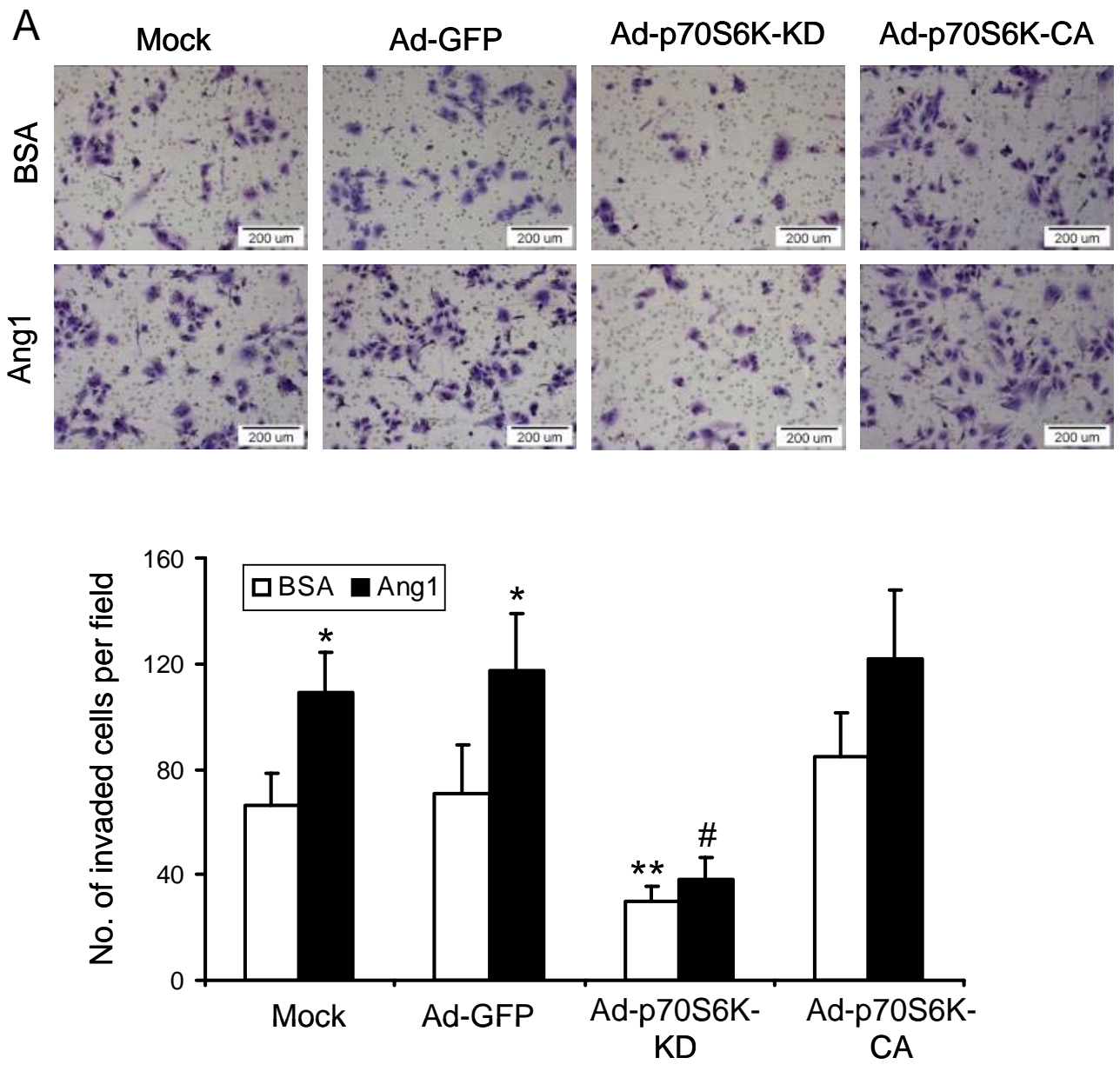

B

$$
\text { p70S6K p70S6K }
$$

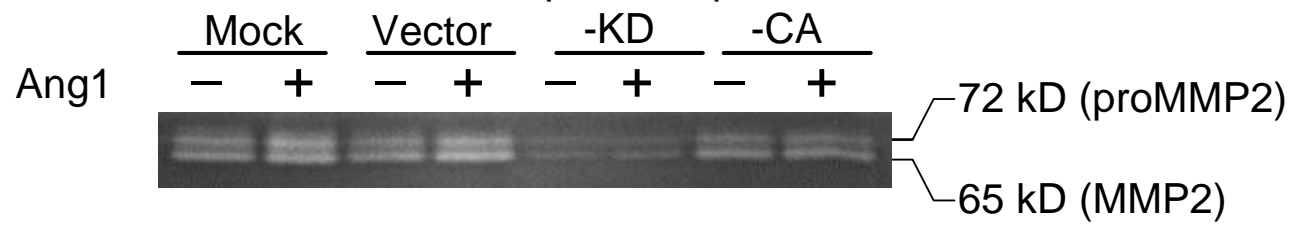

Figure 4. p70S6K1 modulates Ang1-induced EC invasion. A, HUVECs $\left(1 \times 10^{5}\right.$ cells $)$ were loaded to Transwell chamber precoated with Matrigel, and treated with or without $250 \mathrm{ng} / \mathrm{ml}$ Ang1 for 24 h. Invaded cells on the opposite side of the filter were stained with Quik-diff. Upper panel, representative photographs of invasion assays. Lower panel: quantification of cell 
invasion by counting the cell number in high-power fields $(100 \times)$ under a microscope. Data represent mean $\pm \mathrm{SD}$ from three random fields. The experiments were repeated twice with similar results. $(*$ indicates significant different compared to mock or Ad-GFP-infected cells treated with BSA solvent, $\mathrm{p}<0.05 ;{ }^{* *}$ indicates significant different when the value was compared to that of mock or Ad-GFP-infected cells treated with BSA solvent, $\mathrm{p}<0.05 ;{ }^{*}$ indicates significant different compared to mock or Ad-GFP-infected cells treated with Ang1, $\mathrm{p}<0.05)$. B, MMP-2 gelatin zymography assay. HUVECs were either uninfected (mock), or infected with adenovirus expressing GFP, $\mathrm{p} 70 \mathrm{~S} 6 \mathrm{~K}-\mathrm{KD}$, or p70S6K-CA for $24 \mathrm{~h}$, then incubated in serum-free medium for $24 \mathrm{~h}$ in the absence or presence of $250 \mathrm{ng} / \mathrm{ml} \mathrm{Ang1.} \mathrm{The} \mathrm{culture} \mathrm{medium} \mathrm{was} \mathrm{collected} \mathrm{and}$ analyzed by gelatin zymography. 
Figure 5.
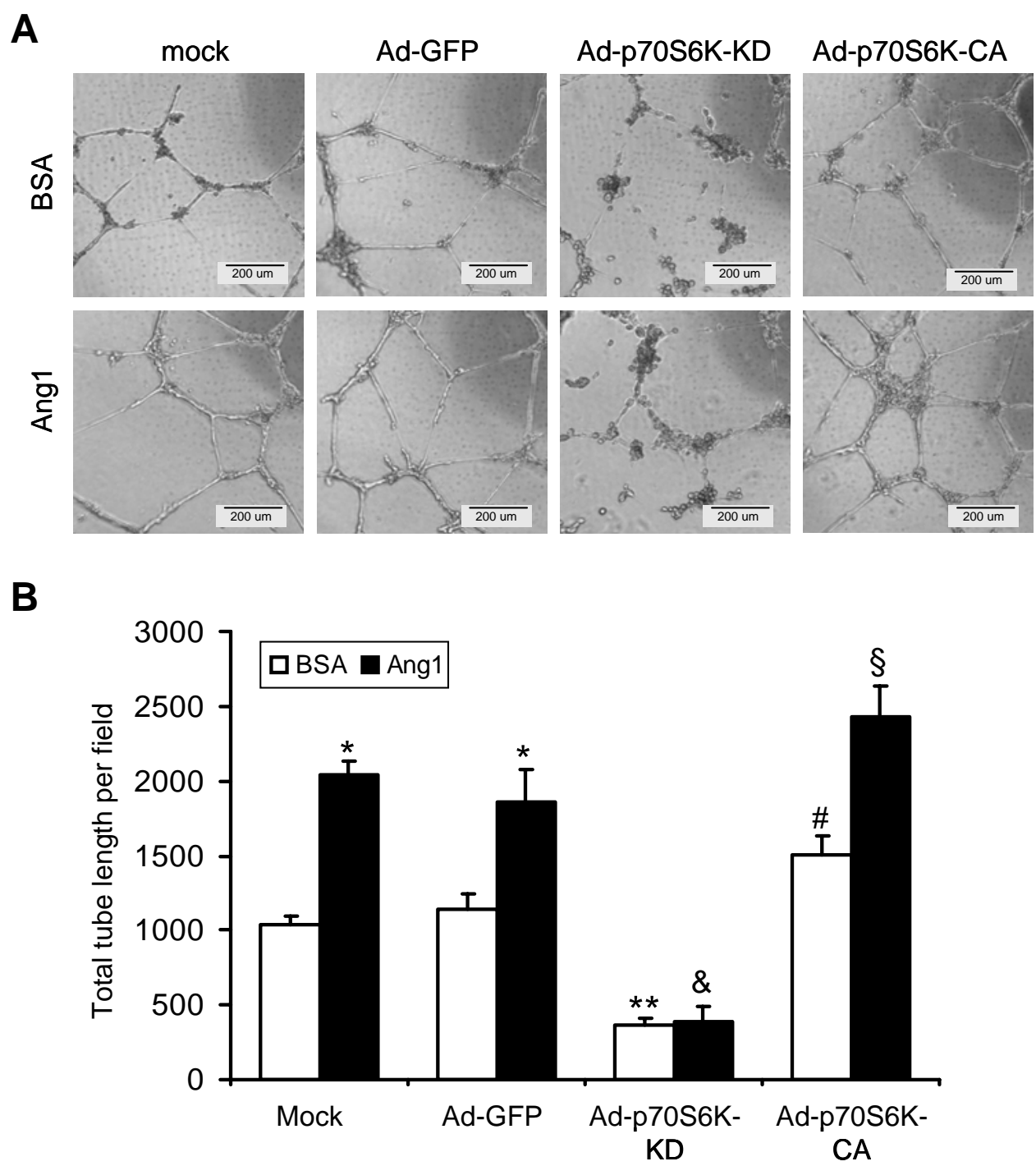

Figure 5. p70S6K1 modulates Ang1-induced EC tube formation. A, HUVECs were either uninfected (mock), or infected with adenovirus expressing GFP, p70S6K-KD, or p70S6K-CA for $24 \mathrm{~h}$, then plated on growth factor-reduced Matrigel in the wells of 96-well plate and treated with BSA or Ang1 for $16 \mathrm{~h}$. EC capillary structures were photographed by phase-contrast microscopy. Original magnification: $100 \times$. B, Quantification of total tube length per high-power field. Data 
are mean $\pm \mathrm{SD}$ of 3 random fields of each experiment that was repeated 3 times. (* indicates significant different when the value was compared to that of mock or Ad-GFP-infected cells treated with BSA solvent, $\mathrm{p}<0.05 ;{ }^{* *}$ indicates significant different when the value was compared to that of mock or Ad-GFP-infected cells treated with BSA solvent, $\mathrm{p}<0.05$; ${ }_{\text {indicates }}$ significant different compared to mock or Ad-GFP-infected cells treated with Ang1, $\mathrm{p}<0.05$; indicates significant different when the value was compared to that of mock or Ad-GFP-infected cells treated with BSA solvent, $\mathrm{p}<0.05 ;{ }^{\S}$ indicates significant different compared to mock or AdGFP-infected cells treated with Ang1, $\mathrm{p}<0.05)$. 


\section{References}

1. Sato TN, Tozawa Y, Deutsch U, Wolburg-Buchholz K, Fujiwara Y, Gendron-Maguire M, et al. Distinct roles of the receptor tyrosine kinases Tie-1 and Tie-2 in blood vessel formation. Nature $1995 \mathrm{Jul}$ 6;376(6535):70-4.

2. Davis S, Aldrich TH, Jones PF, Acheson A, Compton DL, Jain V, et al. Isolation of angiopoietin-1, a ligand for the TIE2 receptor, by secretion-trap expression cloning. Cell 1996 Dec 27;87(7):1161-9.

3. Suri C, Jones PF, Patan S, Bartunkova S, Maisonpierre PC, Davis S, et al. Requisite role of angiopoietin-1, a ligand for the TIE2 receptor, during embryonic angiogenesis. Cell 1996 Dec 27;87(7):1171-80.

4. Kwak HJ, So JN, Lee SJ, Kim I, Koh GY. Angiopoietin-1 is an apoptosis survival factor for endothelial cells. FEBS Lett 1999 Apr 9;448(2-3):249-53.

5. Papapetropoulos A, Garcia-Cardena G, Dengler TJ, Maisonpierre PC, Yancopoulos GD, Sessa WC. Direct actions of angiopoietin-1 on human endothelium: evidence for network stabilization, cell survival, and interaction with other angiogenic growth factors. Lab Invest 1999 Feb;79(2):213-23.

6. Kim I, Kim HG, So JN, Kim JH, Kwak HJ, Koh GY. Angiopoietin-1 regulates endothelial cell survival through the phosphatidylinositol 3'-Kinase/Akt signal transduction pathway. Circ Res 2000 Jan 7;86(1):24-9.

7. Kwak HJ, Lee SJ, Lee YH, Ryu CH, Koh KN, Choi HY, et al. Angiopoietin-1 inhibits irradiation- and mannitol-induced apoptosis in endothelial cells. Circulation 2000 May 16;101(19):2317-24.

8. Witzenbichler B, Maisonpierre PC, Jones P, Yancopoulos GD, Isner JM. Chemotactic properties of angiopoietin-1 and -2 , ligands for the endothelial-specific receptor tyrosine kinase Tie2. J Biol Chem 1998 Jul 17;273(29):18514-21.

9. Koblizek TI, Weiss C, Yancopoulos GD, Deutsch U, Risau W. Angiopoietin-1 induces sprouting angiogenesis in vitro. Curr Biol 1998 Apr 23;8(9):529-32.

10. Kim I, Kim HG, Moon SO, Chae SW, So JN, Koh KN, et al. Angiopoietin-1 induces endothelial cell sprouting through the activation of focal adhesion kinase and plasmin secretion. Circ Res 2000 May 12;86(9):952-9.

11. Hayes AJ, Huang WQ, Mallah J, Yang D, Lippman ME, Li LY. Angiopoietin-1 and its receptor Tie-2 participate in the regulation of capillary-like tubule formation and survival of endothelial cells. Microvasc Res 1999 Nov;58(3):224-37.

12. Babaei S, Teichert-Kuliszewska K, Zhang Q, Jones N, Dumont DJ, Stewart DJ. Angiogenic actions of angiopoietin-1 require endothelium-derived nitric oxide. Am J Pathol 2003 Jun;162(6):1927-36. 
13. Shyu KG, Manor O, Magner M, Yancopoulos GD, Isner JM. Direct intramuscular injection of plasmid DNA encoding angiopoietin-1 but not angiopoietin-2 augments revascularization in the rabbit ischemic hindlimb. Circulation 1998 Nov 10;98(19):2081-7.

14. Suri C, McClain J, Thurston G, McDonald DM, Zhou H, Oldmixon EH, et al. Increased vascularization in mice overexpressing angiopoietin-1. Science 1998 Oct 16;282(5388):468-71.

15. Thurston G, Suri C, Smith K, McClain J, Sato TN, Yancopoulos GD, et al. Leakageresistant blood vessels in mice transgenically overexpressing angiopoietin-1. Science 1999 Dec 24;286(5449):2511-4.

16. Joussen AM, Poulaki V, Tsujikawa A, Qin W, Qaum T, Xu Q, et al. Suppression of diabetic retinopathy with angiopoietin-1. Am J Pathol 2002 May;160(5):1683-93.

17. Chae JK, Kim I, Lim ST, Chung MJ, Kim WH, Kim HG, et al. Coadministration of angiopoietin-1 and vascular endothelial growth factor enhances collateral vascularization. Arterioscler Thromb Vasc Biol 2000 Dec;20(12):2573-8.

18. Thurston G, Rudge JS, Ioffe E, Zhou H, Ross L, Croll SD, et al. Angiopoietin-1 protects the adult vasculature against plasma leakage. Nat Med 2000 Apr;6(4):460-3.

19. Arsic N, Zentilin L, Zacchigna S, Santoro D, Stanta G, Salvi A, et al. Induction of functional neovascularization by combined VEGF and angiopoietin-1 gene transfer using AAV vectors. Mol Ther 2003 Apr;7(4):450-9.

20. Kontos CD, Stauffer TP, Yang WP, York JD, Huang L, Blanar MA, et al. Tyrosine 1101 of Tie2 is the major site of association of p85 and is required for activation of phosphatidylinositol 3-kinase and Akt. Mol Cell Biol 1998 Jul;18(7):4131-40.

21. Jones N, Master Z, Jones J, Bouchard D, Gunji Y, Sasaki H, et al. Identification of Tek/Tie2 binding partners. Binding to a multifunctional docking site mediates cell survival and migration. J Biol Chem 1999 Oct 22;274(43):30896-905.

22. Harfouche R, Hassessian HM, Guo Y, Faivre V, Srikant CB, Yancopoulos GD, et al. Mechanisms which mediate the antiapoptotic effects of angiopoietin-1 on endothelial cells. Microvasc Res 2002 Jul;64(1):135-47.

23. Fujikawa K, de AS, I, Jain SK, Presman E, Christensen RA, Varticovski L. Role of PI 3kinase in angiopoietin-1-mediated migration and attachment-dependent survival of endothelial cells. Exp Cell Res 1999 Dec 15;253(2):663-72.

24. Papapetropoulos A, Fulton D, Mahboubi K, Kalb RG, O'Connor DS, Li F, et al. Angiopoietin-1 inhibits endothelial cell apoptosis via the Akt/survivin pathway. J Biol Chem 2000 Mar 31;275(13):9102-5.

25. Berven LA, Crouch MF. Cellular function of p70S6K1: a role in regulating cell motility. Immunol Cell Biol 2000 Aug;78(4):447-51. 
26. Proud CG. p70 S6 kinase: an enigma with variations. Trends Biochem Sci 1996 May;21(5):181-5.

27. Thomas G. The S6 kinase signaling pathway in the control of development and growth. Biol Res 2002;35(2):305-13.

28. Yu Y, Sato JD. MAP kinases, phosphatidylinositol 3-kinase, and p70 S6 kinase mediate the mitogenic response of human endothelial cells to vascular endothelial growth factor. J Cell Physiol 1999 Feb;178(2):235-46.

29. Tsutsumi N, Yonemitsu Y, Shikada Y, Onimaru M, Tanii M, Okano S, et al. Essential Role of PDGFR \{alpha\}-p70S6K1 Signaling in Mesenchymal Cells During Therapeutic and Tumor Angiogenesis In Vivo: Role of PDGFR \{alpha\} During Angiogenesis. Circ Res 2004 May 14;94(9):1186-94.

30. Cheatham L, Monfar M, Chou MM, Blenis J. Structural and Functional Analysis of pp70S6K1. PNAS 1995 Dec 5;92(25):11696-700.

31. He TC, Zhou S, da Costa LT, Yu J, Kinzler KW, Vogelstein B. A simplified system for generating recombinant adenoviruses. PNAS 1998 Mar 3;95(5):2509-14.

32. Dimmeler S, Zeiher AM. Endothelial cell apoptosis in angiogenesis and vessel regression. Circ Res 2000 Sep 15;87(6):434-9.

33. Harada H, Andersen JS, Mann M, Terada N, Korsmeyer SJ. p70S6 kinase signals cell survival as well as growth, inactivating the pro-apoptotic molecule BAD. Proc Natl Acad Sci U S A 2001 Aug 14;98(17):9666-70.

34. Germain M, Affar EB, D'Amours D, Dixit VM, Salvesen GS, Poirier GG. Cleavage of Automodified Poly(ADP-ribose) Polymerase during Apoptosis. EVIDENCE FOR INVOLVEMENT OF CASPASE-7. Journal of Biological Chemistry 1999 Oct 1;274(40):28379-84.

35. Pepper MS, Montesano R, Mandriota SJ, Orci L, Vassalli JD. Angiogenesis: a paradigm for balanced extracellular proteolysis during cell migration and morphogenesis. Enzyme Protein 1996;49(1-3):138-62.

36. Stetler-Stevenson WG. Matrix metalloproteinases in angiogenesis: a moving target for therapeutic intervention. J Clin Invest 1999 May;103(9):1237-41.

37. Qian Y, Corum L, Meng Q, Blenis J, Zheng JZ, Shi X, et al. PI3K induced actin filament remodeling through Akt and p70S6K11: implication of essential role in cell migration. Am J Physiol Cell Physiol 2004 Jan;286(1):C153-C163.

38. Ridley AJ. Rho GTPases and cell migration. J Cell Sci 2001 Aug 1;114(15):2713-22.

39. Risau W. Mechanisms of angiogenesis. Nature 1997 Apr 17;386(6626):671-4. 


\title{
Chapter 3
}

\section{Insulin-like growth factor-I induces cyclooxygenase-2 expression via PI3K, MAPK and PKC signaling pathways in human ovarian cancer cells}

\author{
Zongxian Cao ${ }^{\S}$, Dan A. Dixon", Jenny Z. Zheng ${ }^{\S}$, Bala Chandran ${ }^{\ddagger}$, and Bing-Hua Jiang
}

${ }^{\S}$ Mary Babb Randolph Cancer Center, Department of Microbiology, Immunology and Cell Biology, West Virginia University, Morgantown, WV 26506-9300, "Department of Biological Sciences and South Carolina Cancer Center, University of South Carolina, 14 Richland Medical Park Drive, Suite 500, Columbia, SC 29203, and ${ }^{\ddagger}$ Department of Microbiology and Immunology, Rosalind Franklin University of Medicine and Science, 3333 Green Bay Road, North Chicago, IL 60064

Running title: IGF-I induces COX-2 expression

Key words: insulin-like growth factor-I, cyclooxygenase-2, prostaglandins, ovarian cancer 


\begin{abstract}
Elevated levels of insulin-like growth factor-I (IGF-I) are associated with ovarian carcinogenesis and progression. However, the molecular mechanisms by which IGF-I contributes to ovarian cancer development remain to be elucidated. Cyclooxygenase-2 (COX-2) is a crucial player in the pathogenesis of human malignancies. Herein we showed that IGF-I efficiently induced COX2 expression and $\mathrm{PGE}_{2}$ biosynthesis at physiologically relevant concentrations in human ovarian cancer cells. IGF-I treatment significantly increased COX-2 transcriptional activation. IGF-I also stabilized COX-2 mRNA through the COX-2 3'-untranslated region (3'-UTR), which appeared independent of the conserved AU-rich elements. We next investigated the signaling pathways involved in IGF-I-induced COX-2 expression. We found that PI3K inhibitor wortmannin or LY294002 blocked COX-2 expression induced by IGF-I. Wortmannin treatment or a dominant negative PI3K mutant significantly inhibited IGF-I-induced COX-2 mRNA stabilization, but only slightly decreased COX-2 transcriptional activation. We showed that ERK1/2 and p38 MAPKs were required for IGF-I-induced COX-2 expression and that activation of both pathways by IGF-I increased $C O X-2$ transcriptional activation and its mRNA stability. IGF-I stimulated PKC activation in the cells and pretreatment with PKC inhibitor bisindolylmaleimide prevented IGF-I-induced COX-2 transcriptional activation and mRNA stabilization, and inhibited COX-2 mRNA and protein expression. Taken together, our data demonstrate that IGF-I induces COX-2 expression in human ovarian cancer cells, which is mediated by three parallel signaling cascades - PI3K, MAPK, and PKC pathways that differentially regulate COX-2 expression at transcriptional and post-transcriptional levels.
\end{abstract}




\section{INTRODUCTION}

The type I insulin-like growth factor receptor (IGF-IR) and its ligand IGF-I have been implicated in the development and progression of human cancer (1-3). An accumulating body of epidemiological evidence suggests that high levels of circulating IGF-I are associated with the risk of a number of human malignancies, such as breast, prostate, colorectal, pancreas, lung, and ovarian cancer (1). Insulin-like growth factors (IGF-I and IGF-2) are small polypeptides structurally related to insulin and exert their mitogenic effects mainly through IGF-IR. IGF-2 is considered as the major IGF isoform in fetal development, whereas IGF-I plays a more important role in adults (1). The bioactivities of IGFs are regulated by a family of IGF binding proteins (i.e., from IGFBP-1 to IGFBP-6) and a group of IGFBP proteases $(1 ; 2 ; 4)$. Activation of IGF-IR by ligand binding initiates the mitogen-activated protein kinase (MAPK) and phosphatidylinositol 3-kinase (PI3K) pathways, which are the major signaling cascades that mediate the mitogenic and antiapoptotic actions of IGFs (1-3). The IGF-IR is frequently overexpressed in several human cancers. The combination of the mitogenic and antiapoptotic effects of IGF-IR activation has a profound impact on tumor growth. In addition, IGF-IR is involved not only in the induction of cell transformation, but also in the maintenance of the transformed phenotype (5). Furthermore, IGF-I has been implicated in tumor neo-vascularization by increasing the expression of hypoxia-inducible factor $1 \alpha$ (HIF-1 $\alpha)$ and vascular endothelial growth factor (VEGF) (6-9). Despite these findings, however, the molecular mechanisms by which IGF-I contributes to cancer progression remain to be elucidated.

The conversion of arachidonic acid to prostaglandins (PGs) is catalyzed by two isoforms of cyclooxygenases, COX-1 and COX-2. COX-1 is constitutively expressed in most human 
tissues, and appears to be responsible for the production of PGs that modulate physiological functions. In contrast, COX-2 is expressed at low or undetectable levels in most normal tissues. COX-2 can be rapidly induced by inflammatory stimuli, and is frequently overexpressed in many human cancers (10-13). Genetic studies showed that transgenic mice overexpressing COX-2 in various types of tissues developed malignant tumors $(10 ; 11)$. Conversely, the development and growth of tumors were markedly retarded in COX-2 knockout mice $(10 ; 11)$. The role of COX-2 in carcinogenesis is further supported by experimental and clinical studies which demonstrate the effectiveness of selective COX-2 inhibitors in the prevention and treatment of human cancers $(10 ; 11)$. The biological effects of COX-2 are mediated by its prostanoid products that affect multiple mechanisms implicated in carcinogenesis. For example, prostaglandin $\mathrm{E}_{2}\left(\mathrm{PGE}_{2}\right)$ can stimulate cell proliferation and motility while inhibiting apoptosis and immune surveillance (10). Importantly, COX-2-derived prostanoids are involved in multiple key points of tumor angiogenesis, including enhancing VEGF production (12).

Expression of COX-2 in human cancer is regulated at both transcriptional and posttranscriptional levels by multiple signaling pathways (14). COX-2 expression can be induced by inflammatory cytokines and by growth factors (13). COX-2 expression can also be induced by activation of oncogenes and inactivation of tumor suppressor genes (13). However, little is known about the precise factors and molecular mechanisms regulating $\mathrm{COX}-2$ gene expression in human ovarian cancer. The novel findings of this study are: (a) COX-2, but not COX-1 expression in human ovarian cancer cells can be potently induced by IGF-I stimulation; (b) IGF-I activates PI3K, MAPK as well as PKC signaling cascades in the cells, and all these pathways are required for IGF-I-induced COX-2 expression; (c) PI3K, MAPK and PKC pathways are differentially involved in transcriptional and post-transcriptional regulation of IGF- 
I-induced COX-2 expression in the cells; (d) PKC is independent of Erk1/2 MAPK in the mediation of IGF-I-induced COX-2 expression. Our data suggest that increased COX-2 expression may be important for IGF-I involvement in ovarian cancer development and progression.

\section{Materials and Methods}

\section{Cell Culture and Reagents}

A2780 and OVCAR-3 human ovarian cancer cells were cultured in RPMI Medium 1640 (Life Technologies, Grand Island, NY), supplemented with 10\% fetal bovine serum, $50 \mathrm{nM}$ insulin (Sigma), 100 units $/ \mathrm{ml}$ penicillin, and $100 \mu \mathrm{g} / \mathrm{ml}$ streptomycin. The cells were maintained at $37^{\circ} \mathrm{C}$ and $5 \% \mathrm{CO}_{2}$ in a humid environment. Actinomycin D, PD98059, bisindolylmaleimide, and recombinant human IGF-I were purchased from Sigma (St Louis, MO). LY294002, wortmannin and SB203580 were purchased from Calbiochem (La Jolla, CA). Monoclonal antibodies against COX-2 and COX-1, and selective COX-2 inhibitor NS398 were obtained from Cayman Chemical Company (Ann Arbor, MI). Antibodies against phosphorylated AKT (Ser473) or total AKT, phosphorylated ERK1/2 (Thr202/Tyr204), and phosphorylated MAPKAPK2 (Thr334)

were purchased from Cell Signaling Technology (Beverly, MA). Antibody against total p44/p42 MAPK was obtained from Santa Cruz Biotechnology (Santa Cruz, CA). Monoclonal antibody against $\beta$-actin was from Sigma. 


\section{Immunoblotting}

After appropriate treatments, cells were washed with ice-cold PBS, and collected by centrifugation. Cell lysates were prepared using RIPA buffer supplemented with protease inhibitors (100 mM Tris, PH 7.4, $150 \mathrm{mM} \mathrm{NaCl,} 5 \mathrm{mM}$ EDTA, 1\% Triton X-100, 1\% deoxycholate acid, $0.1 \%$ SDS, $2 \mathrm{mM}$ phenylmethylsulfonyl fluoride, $1 \mathrm{mM}$ sodium orthovanadate, $2 \mathrm{mM}$ DTT, $20 \mu \mathrm{g} / \mathrm{ml}$ leupeptin, $20 \mu \mathrm{g} / \mathrm{ml}$ pepstatin). Aliquots of protein lysates $(50 \mu \mathrm{g})$ were fractionated by SDS-PAGE, transferred to a nitrocellulose membrane (Schleicher \& Schuell Biosciences, Keene, NH), and subjected to immunoblotting according to the manufacturer's instructions. Immunoreactivity was visualized with chemiluminescence detection reagent (Pierce Biotechnology, Rockford, IL).

\section{RT-PCR}

Total cellular RNAs were prepared using Trizol reagent (Invitrogen) according to the manufacturer's instructions. Aliquots of total RNAs $(1 \mu \mathrm{g})$ were used as templates to synthesize the first strand cDNA using reverse transcriptase (Promega). The following primers were used for PCR amplification: human COX-2: sense 5'-TTCAAATG AGATTGTGGGAAAATTGCT3', antisense 5'-AGATCATCTCTGCCTGAGTATCTT-3'; $\quad$ GAPDH: sense 5'ACCACAGTCCATGCCATCAC -3', antisense 5'-TCCACCACCCTGTTGCTGTA-3'. PCR was performed for 30 cycles, with each cycle at $95^{\circ} \mathrm{C}$ for $1 \mathrm{~min}, 56^{\circ} \mathrm{C}$ for $1 \mathrm{~min}$, and $72^{\circ} \mathrm{C}$ for 1 min. PCR products were separated on a $2 \%$ agarose gel and visualized with ethidium bromide and photographed using an EagleEye II system (Stratagene, La Jolla, CA). 


\section{PGE $_{2}$ ELISA assay}

Cells were seeded at $2 \times 10^{5}$ cells/well in 12 -well plates, and cultured to $80 \%$ confluence in normal growth medium. The cells were cultured in serum-free medium overnight, then changed to fresh basal medium containing various concentrations of IGF-I in the presence or absence of $25 \mu \mathrm{M}$ NS398 for $24 \mathrm{~h}$. Levels of $\mathrm{PGE}_{2}$ released by the cells were measured using an ELISA kit (R\&D systems, Minneapolis, MN) according to the manufacturer's instructions.

\section{Transient transfection and luciferase reporter assay}

A reporter construct containing the 5'-flanking region of the human $C O X-2$ gene (phPES2$1432 /+59)$ was used to study transcriptional activation of the COX-2 promoter (15). The COX-2 3'-UTR reporter luciferase construct Luc-3'UTR contains the full-length human COX-2 3'-UTR region; Luc-3'UTR $\triangle$ ARE contains the 3'-UTR region with the deletion of a conserved 116nucleotide AU-rich sequence element as described previously (16). Cells were seeded at a density of $2 \times 10^{5}$ cells/well in 12 -well plates. The next day, $1 \mu \mathrm{g}$ of plasmid DNA was transfected into the cells using $2 \mu \mathrm{l}$ of Lipofectamine (Invitrogen) as per manufacturer's instructions. After the transfection, the cells were cultured overnight, changed to fresh basal medium with different treatments for $16 \mathrm{~h}$. Luciferase and $\beta$-galactosidase activities were assayed in the cell lysates, and relative luciferase activity was the ratio of luciferase/ $\beta$-galactosidase activity which was normalized to the control. 


\section{PKC Kinase Activity Assay}

The activity of PKC was measured as described previously with modifications (17). Briefly, cells were lysed in a PKC extraction buffer (50 mM HEPES, pH 7.5, $150 \mathrm{mM} \mathrm{NaCl,} 0.1 \%$ Tween 20, $1 \mathrm{mM}$ EDTA, $2.5 \mathrm{mM}$ EGTA, 10\% glycerol) supplemented with protease inhibitors (10 $\mu \mathrm{g} / \mathrm{ml}$ of aprotinin, $10 \mu \mathrm{g} / \mathrm{ml}$ of leupeptin, $0.1 \mathrm{mM}$ phenylmethylsulfonyl fluoride) and phosphatase inhibitors $\left(1 \mathrm{mM} \mathrm{NaF}, 0.1 \mathrm{mM} \mathrm{Na}_{3} \mathrm{VO}_{4}\right)$. PKC proteins were immunoprecipitated from $200 \mu \mathrm{g}$ of the cellular extracts with $2 \mu \mathrm{g}$ of the anti-phospho-PKC (pan) antibody (beta II, Ser660) (Cell Signaling Technology, Beverly, MA). The kinase assay was performed in $40 \mu 1$ of PKC reaction buffer $\left(20 \mathrm{mM}\right.$ HEPES, $\mathrm{pH} 7.5,10 \mathrm{mM} \mathrm{MgCl}_{2}, 1 \mathrm{mM}$ dithiothreitol, $2.5 \mathrm{mM}$ EGTA, $1 \mathrm{mM} \mathrm{NaF}, 0.1 \mathrm{mM} \mathrm{Na}_{3} \mathrm{VO}_{4}, 10 \mu \mathrm{M}$ ATP) containing $1 \mu \mathrm{g}$ of the substrate myelin basic protein and $5 \mu \mathrm{Ci}$ of $\left[\gamma^{32} \mathrm{P}\right] \mathrm{ATP}$. The reactions were performed at $30^{\circ} \mathrm{C}$ for $20 \mathrm{~min}$, and terminated by adding SDS-PAGE sample buffer. Reaction products were analyzed by SDSPAGE and visualized by autoradiography. The radioactive bands were excised and quantified by liquid scintillation counting. The activity of PKC is expressed as counts per min with each $\mu \mathrm{g}$ of protein.

\section{Statistics}

Comparisons between treatments were made by the Student's $t$ test. A difference between the treatments was considered significant at $\mathrm{p}<0.05$. 


\section{RESULTS}

\section{IGF-I stimulates COX-2 mRNA and protein expression, and induces PGE $_{2}$ biosynthesis in human ovarian cancer cells}

To examine whether IGF-I was able to induce COX-2 expression, human ovarian cancer cells A2780 were incubated with various concentrations of IGF-I, and COX-2 mRNA levels were analyzed by RT-PCR. At the range of physiologically relevant concentrations, IGF-I induced COX-2 mRNA expression in a dose-dependent manner (Fig. 1A). Similar results were obtained using another human ovarian cancer cell line, OVCAR-3 (Fig. 1A). We next examined the timedependent effect of IGF-I on COX-2 expression in the cells. A2780 and OVCAR-3 cells were incubated with IGF-I for $0,0.5,1,2,4,6,12$, or $24 \mathrm{~h}$; and COX-2 mRNA expression was examined. IGF-I increased COX-2 expression within $1 \mathrm{~h}$, and the induction reached the maximum at $6 \mathrm{~h}$ (Fig. 1B). COX-2 protein levels were examined to determine whether the elevated COX-2 mRNA levels correlated with increased COX-2 protein expression. As shown in Fig. 2A, IGF-I greatly upregulated COX-2 protein expression in a dose-dependent fashion in both cell lines. COX-2 protein expression was gradually increased and peaked by $6-8 \mathrm{~h}$, and remained elevated for up to $24 \mathrm{~h}$ (Fig. 2B). By contrast, both cell lines expressed constitutive levels of COX-1 that were not increased by IGF-I treatment (Figs. 2A and 2B). We further examined whether IGF-I-induced COX-2 protein expression was associated with induction of $\mathrm{PGE}_{2}$ biosynthesis. As shown in Fig. 2C, treatment of the cells with IGF-I increased PGE 2 biosynthesis, and pretreatment of the cells with the COX-2 selective inhibitor NS398 completely inhibited the induction. These data show that COX-2 expression and activity were upregulated by IGF-I in human ovarian cancer cells. 


\section{IGF-I increases COX-2 transcriptional activation and its mRNA stability}

To study the mechanism underlying the induction of COX-2 by IGF-I, A2780 cells were transfected with a COX-2 promoter luciferase reporter phPHES2(-1432/+59), which carries the full-length promoter region of human COX-2 gene (15). Treatment of the cells with IGF-I significantly increased $C O X-2$ promoter activity (Fig. 3A), suggesting that IGF-I was able to stimulate $C O X-2$ transcriptional activation.

Post-transcriptional stabilization of COX-2 mRNA plays an important role in the regulation of COX-2 expression. To determine whether IGF-I affects the stability of COX-2 mRNA, the rate of COX-2 mRNA decay was examined in A2780 cells. In the absence of IGF-I treatment, the half-life $\left(\mathrm{t}_{1 / 2}\right)$ of COX-2 mRNA in the cells was $60 \mathrm{~min}$. IGF-I treatment increased the stability of COX-2 mRNA and extended the $\mathrm{t}_{1 / 2}$ to $215 \mathrm{~min}$ (Fig. 3B). It is known that the 3'untranslated region (3'-UTR) of COX-2 mRNA is involved in promoting its mRNA decay (16). We therefore asked whether IGF-I treatment affected COX-2 3'-UTR activity. We found that treatment of cells with IGF-I caused up to 2-fold increase of COX-2 3'-UTR reporter activity, suggesting that IGF-I increased COX-2 mRNA stability (Fig. 3C). Within the proximal end of COX-2 3'-UTR, there is a highly conserved AU-rich mRNA decay sequence element (ARE) (16). To determine whether the stabilization of COX-2 mRNA by IGF-I was dependent on the conserved ARE sequence, luciferase reporter assays were performed by using the Luc-3'UTR and Luc-3'UTR $\triangle$ ARE constructs. We found that the luciferase activity was dramatically increased when the ARE region was deleted from the full-length COX-2 3'-UTR (Fig. 3D). This result suggested that in human ovarian cancer cells, the COX-2 ARE facilitated COX-2 mRNA decay. Interestingly, IGF-I treatment similarly increased luciferase reporter activity when the 
ARE was deleted (Fig. 3D), implying that IGF-I promoted COX-2 mRNA stabilization through other regions of the 3'UTR. Taken together, these results showed that IGF-I upregulated COX-2 expression through both transcriptional activation and post-transcriptional mechanisms.

\section{PI3K signaling pathway is involved in IGF-I-induced COX-2 expression}

We next investigated the signaling pathways that are required for IGF-I-induced COX-2 expression. PI3K signaling is a major pathway initiated by growth factor receptors including IGF-IR. To determine whether PI3K regulates IGF-I-induced COX-2 expression, the cells were treated with PI3K selective inhibitors. As shown in Fig. 4A and 4B, PI3K inhibitors wortmannin and LY294002 inhibited IGF-I-induced COX-2 protein and mRNA expression, indicating that PI3K activation plays an important role in IGF-I-mediated COX-2 expression. We next examined whether PI3K is involved in IGF-I-induced COX-2 transcriptional activation or posttranscriptional mRNA stability. As shown in Fig. 4C, wortmannin treatment slightly reduced COX-2 promoter activity (up to $15 \%$ reduction) in IGF-I-treated cells. In contrast, wortmannin completely inhibited IGF-I-induced increase of the COX-2 3'-UTR activity (Fig. 4D). Similar results were observed by using a dominant-negative PI3K construct (Figs. 4E and 4F). These data indicate that PI3K activation regulates IGF-I-induced COX-2 expression in human ovarian cancer cells primarily through increasing stabilization of COX-2 mRNA.

ERK1/2 and p38 MAP kinases are important for COX-2 induction by IGF-I at both transcriptional and post-transcriptional levels

IGF-I treatment induced the activation of Erk1/2 and p38 MAPKs in human ovarian cancer cells, and treatment with MEK1 inhibitor PD98059 or p38 inhibitor SB203580 inhibited IGF-I- 
induced COX-2 expression, which correlated with the inhibition of Erk1/2 and p38 kinase activation (Figs. 5A and 5B). Consistent with their effects on COX-2 protein expression, the MAPK inhibitors completely prevented IGF-I-induced COX-2 mRNA expression (Fig. 5C). To test whether ERK1/2 and p38 regulate COX-2 transcriptional activation, COX-2 promoter reporter activity was analyzed in the cells treated by PD98509 and SB203580. As shown in Figs. 5D and 5E, PD98509 and SB203580 treatment significantly inhibited IGF-I-induced COX-2 promoter reporter activity in a dose-dependent manner, indicating that ERK1/2 and p38 activities are required for COX-2 transcriptional activation. PD98509 and SB203580 similarly inhibited the COX-2 3'-UTR reporter activity, suggesting that ERK1/2 and p38 also regulate IGF-Iinduced COX-2 expression by increasing COX-2 mRNA stabilization.

\section{PKC activation is required for IGF-I-mediated COX-2 expression}

To determine whether IGF-I stimulates PKC activation, PKC kinase activity was analyzed in human ovarian cancer cells. We found that IGF-I treatment significantly increased PKC activity which was inhibited by PKC inhibitor bisindolylmaleimide (Fig. 6A). We next determined whether IGF-I-induced PKC activation contributed to COX-2 induction. Treatment of the cells with bisindolylmaleimide inhibited COX-2 protein and mRNA expression induced by IGF-I (Figs. 6B and 6C). Blockade of PKC activity also significantly inhibited IGF-I-induced COX-2 promoter and 3'-UTR reporter activities (Figs. 6D and 6E), indicating that PKC activation was important for IGF-I-mediated COX-2 transcriptional activation and mRNA stabilization. PKC was shown to regulate IL-1 $\beta$-induced COX-2 expression through ERK1/2 activation in astrocytes (18). However, we found that pretreatment with the PKC inhibitor did not alter IGF-Iinduced ERK1/2 activation in the human ovarian cancer cells (Fig. 6F), suggesting that 
regulation of IGF-I-induced COX-2 expression by $\mathrm{PKC}$ is independent of ERK1/2 activation in the cells.

\section{DISCUSSION}

The exact roles of IGF-I in regulating COX-2 expression are not well understood. The findings in this study demonstrated that IGF-I induced COX-2 expression and prostaglandin synthesis in human ovarian cancer cells. A recent study showed that enhanced autocrine expression of IGF-II up-regulated COX-2 mRNA expression in Caco-2 human colon cancer cells (19). In human keratinocytes, COX-2 mRNA and protein expression was stimulated by exogenous IGF-II (20). It was recently reported that local IGF-I expression in colorectal cancer tissue was associated with COX-2 mRNA levels (21). IL-1 $\beta$-induced COX-2 expression was enhanced by IGF-I treatment in rat renal mesangial cells (22). However, other recent studies showed that IGF-I failed to induce COX-2 expression in HT-29 colon cancer cells, hepatic stellate cells, and human vein vascular endothelial cells (23-25), and IGF-I treatment even decreased COX-2 expression in osteoblasts (26). Thus, the effects of IGF-I on COX-2 expression appear to be cell-type specific, which may reflect its ability to promote organ-specific tumorigenesis $(1 ; 2 ; 4)$.

Recent studies showed that COX-2 was overexpressed in ovarian cancer, and that COX-2 overexpression correlated with a more aggressive phenotype and a worse clinical outcome $(27 ; 28)$. In addition, some studies showed that COX-1 was overexpressed in ovarian cancer $(29 ; 30)$. The discrepancy of COX isoform expression in ovarian cancer may be due to the differences in patient population and detection methodology. In this study, we found that both COX-1 and COX-2 are expressed in A2780 and OVCAR-3 ovarian cancer cells, and that basal 
levels of COX-1 are relatively high in the cells. IGF-1 treatment dramatically increases COX-2 expression, but not COX-1 expression in the cells. These data suggest that, in addition to inhibiting COX-1, COX-2 activity should also be targeted for ovarian cancer patients with elevated levels of IGF-1. Recent studies show that high levels of COX-2 and $\mathrm{PGE}_{2}$ expression are associated with cancer progression and angiogenesis in other human cancers such as colon, gastric, and breast cancers $(12 ; 13 ; 31 ; 32)$. Since IGF-I and its receptor IGF-IR are frequently overexpressed in human ovarian cancer $(1 ; 2 ; 4)$, the induction of COX-2 expression by IGF-I may play an important role in the angiogenesis switch during ovarian cancer development and progression. In addition, $\mathrm{PGE}_{2}$ is a signaling molecule which may be involved in tumor development and angiogenesis through autocrine effect by binding to its cognate E-prostanoid receptors or paracrine effect by acting on the neighboring cells through the induction of growth factors including VEGF and bFGF (33;34). Thus, IGF-I-induced expression of COX-2 and $\mathrm{PGE}_{2}$ may have profound impacts on ovarian cancer development, progression, and angiogenesis.

Overexpression of COX-2 in human cancer is due to deregulated transcriptional and posttranscriptional control $(10 ; 11 ; 14)$. Here we have shown that IGF-I was able to stimulate both COX-2 transcriptional activation and mRNA stability, which correlated with elevated COX-2 mRNA and protein expression. Increasing evidence indicates that post-transcriptional regulation via the stabilization of COX-2 mRNA plays an important role in the COX-2 expression $(10 ; 14)$. We found that the conserved ARE sequence in COX-2 3'-UTR attenuates COX-2 expression in human ovarian cancer cells. The data are consistent with several recent studies showing that the 3'-UTR of COX-2 mRNA and its ARE sequence are important for regulating COX-2 mRNA stability $(16 ; 35 ; 36)$. Interestingly, the stabilization of COX-2 mRNA induced by IGF-I was independent of the ARE region in the COX-2 3'-UTR. Recently other cis-acting regions were 
identified within the COX-2 3'-UTR that are important for the post-transcriptional regulation of COX-2 (37;38). It would be of interest to identify these mRNA regions that are regulated by IGF-I to induce COX-2 expression in human ovarian cancer cells in the future study.

We found that treatment of the cells with PI3K inhibitors blocked both COX-2 protein and mRNA expression induced by IGF-I, indicating that PI3K signaling plays an important role in IGF-I-induced COX-2 expression. Our results are in agreement with several recent reports that PI3K positively regulates COX-2 expression induced by other factors. PI3K/Akt activation was shown to be required for K-Ras-induced COX-2 expression in rat intestinal epithelial cells (39;40). PI3K activity also mediates COX-2 expression in response to LPS, interferon- $\gamma$, UVB treatment, and high glucose stimulation (41-44). Our data indicate that PI3K regulates IGF-Iinduced COX-2 expression predominantly by modulating the stability of COX-2 mRNA. In addition, we recently showed that IGF-I induced PI3K-dependent phosphorylation of several key components of protein translational apparatus, including p70S6K1, S6 ribosomal protein, 4EBP1, and eIF4E in human ovarian cancer cells (9). Thus, it is possible that PI3K/Akt pathway may also regulate COX-2 protein translation in response to IGF-I treatment.

Many factors known to induce COX-2 expression also activate MAPK signaling pathway. Our findings indicate that ERK1/2 and p38 MAPKs are involved in the regulation of IGF-Iinduced COX-2 expression in human ovarian cancer cells. We found that inhibition of MEK1/ERK1/2 by PD98509 completely blocked IGF-I-induced COX-2 protein and mRNA expression, and that ERK1/2 activation was involved in both transcriptional and posttranscriptional regulation of COX-2 expression in response to IGF-I treatment. Similarly, IGF-Iinduced activation of the p38 MAPK pathway was shown to regulate COX-2 expression on these levels. We found that the p38 selective inhibitor SB203580 suppressed IGF-I-induced activation 
of COX-2 promoter activity and mRNA stabilization. This is consistent with previous findings showing that p38 MAPK was involved in COX-2 transcription presumably through increasing AP-1 activity (41;45-47), and that p38 MAPK regulated COX-2 mRNA stabilization by its downstream kinase MK-2 (36;47;48).

PKC activity regulated COX-2 expression induced by inflammatory stimuli and stress signals $(15 ; 18 ; 47 ; 49 ; 50)$. Activation of PKC promotes COX-2 gene transcription through the transcription factors NF-kB and C/EBP $(15 ; 49)$. PKC also regulates the stability of COX-2 mRNA (47). In this study, we showed that IGF-I was able to stimulate PKC activation in human ovarian cancer cells. We further demonstrated that PKC was involved in both transcriptional and post-transcriptional regulation of COX-2 expression. It was observed that MAPK could be a downstream signal of PKC for regulating COX-2 expression $(18 ; 47)$. However, we found that in ovarian cancer cells, blockade of PKC activity did not inhibit IGF-I-induced ERK1/2 activation, suggesting that induction of COX-2 expression by PKC is independent of MAPK in human ovarian cancer cells.

In summary, the present study provides first evidence that IGF-I upregulates COX-2 expression and the associated $\mathrm{PGE}_{2}$ biosynthesis in human ovarian cancer cells, and this effect is mediated by PI3K, MAPK, and PKC signaling cascades which are differentially involved in the transcriptional and posttranscriptional regulation of COX-2 expression (Fig. 7). Emerging evidence indicates that COX-2 is important in multiple steps of malignant transformation and tumor progression $(10 ; 11)$. Our data suggest that increased COX-2 expression may be important for ovarian cancer development, progression, and angiogenesis in patients associated with high levels of IGF-I. 


\section{Acknowledgements}

We are grateful to Dr. Hiroyasu Inoue (Nara Women's University, Japan) for providing phPHES2(-1432/+59) plasmid.

\section{Grants}

* This work was supported by National Cancer Institute Grants CA109460 (B.H. Jiang), CA75911 and CA099925 (B. Chandran), and by American Cancer Society Research Scholar Grant 04-076-01-TBE. 
Figures and figure legends

Fig. 1.
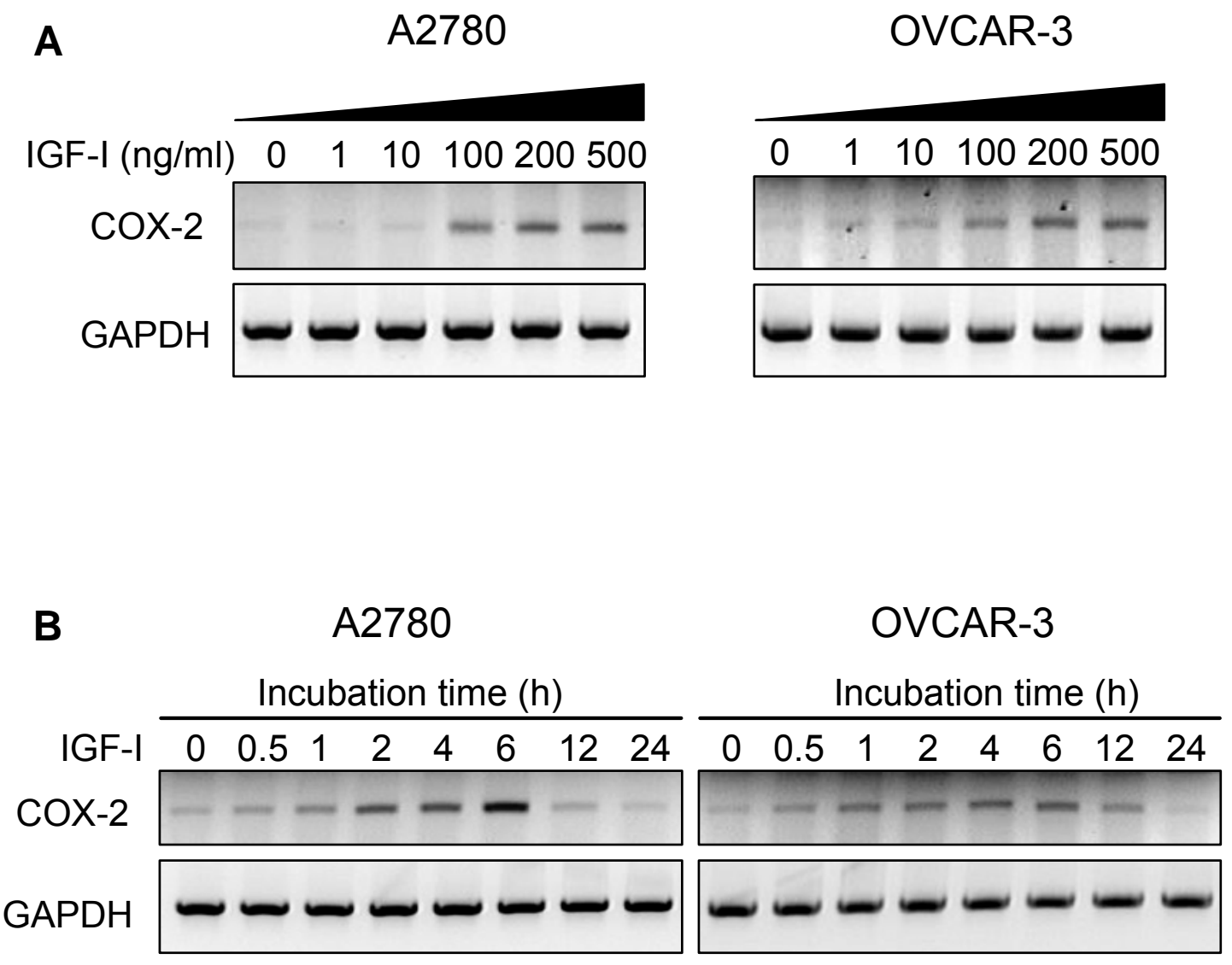

Fig. 1. IGF-I upregulates COX-2 mRNA expression. (A) A2780 and OVCAR-3 cells were cultured in serum-free medium for $16 \mathrm{~h}$, and then treated with the indicated concentrations of IGF-I for 6 h. COX-2 and GAPDH mRNA levels in the cells were detected by RT-PCR. (B) The cells were treated with $200 \mathrm{ng} / \mathrm{ml}$ IGF-I for 0 to $24 \mathrm{~h}$ as indicated. COX-2 and GAPDH mRNA expression was analyzed by RT-PCR. 
Fig. 2.
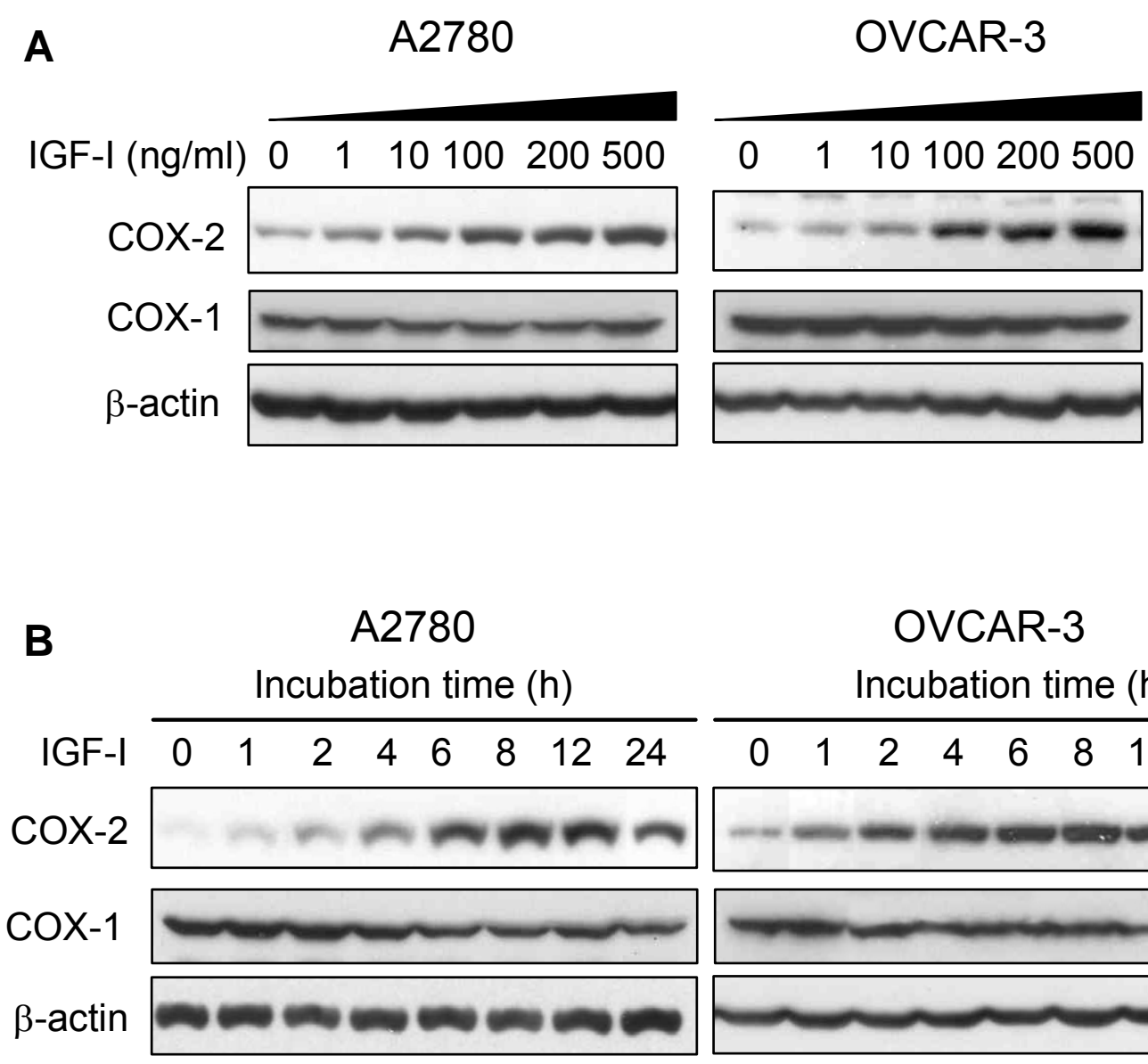

OVCAR-3
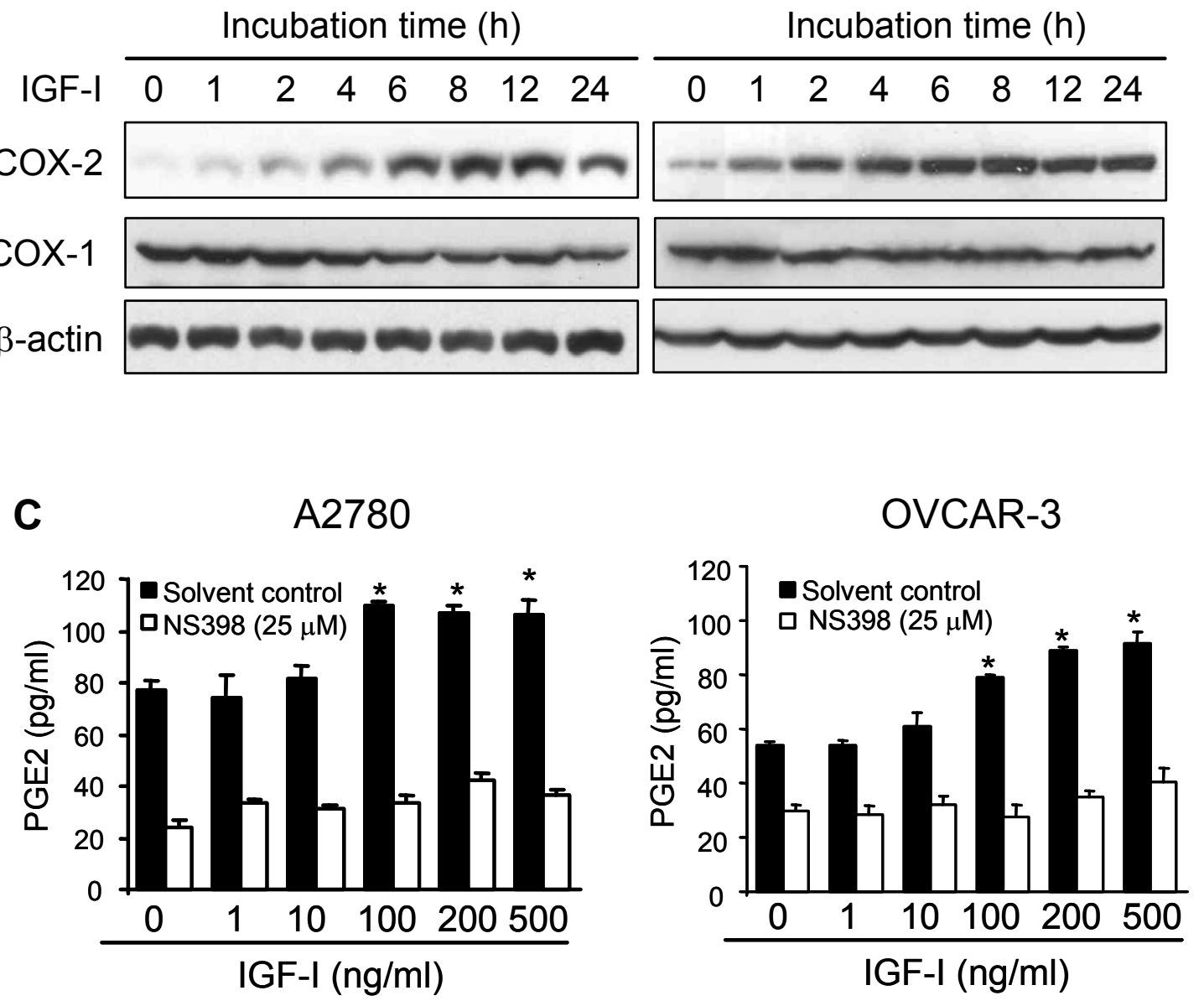
Fig. 2. IGF-I induces COX-2 protein expression and PGE 2 biosynthesis. (A) The serumstarved cells were treated with the indicated concentrations of IGF-I for $8 \mathrm{~h}$. Total cellular lysates were subjected to immunoblotting using antibodies against COX-2, COX-1, or $\beta$-actin. (B) The serum-starved cells were treated with $200 \mathrm{ng} / \mathrm{ml}$ IGF-I for 0 to $24 \mathrm{~h}$ as indicated. COX-2, COX-1, and $\beta$-actin protein levels were analyzed by immunobloting. (C) The cells were incubated in basal medium containing the indicated concentrations of IGF-I in the presence or absence of 25 $\mu \mathrm{M}$ NS398 for $24 \mathrm{~h}$. $\mathrm{PGE}_{2}$ levels in the medium were determined by ELISA assay. * indicates that the value is significantly different when compared to that of the control $(p<0.05)$. 
Fig. 3.
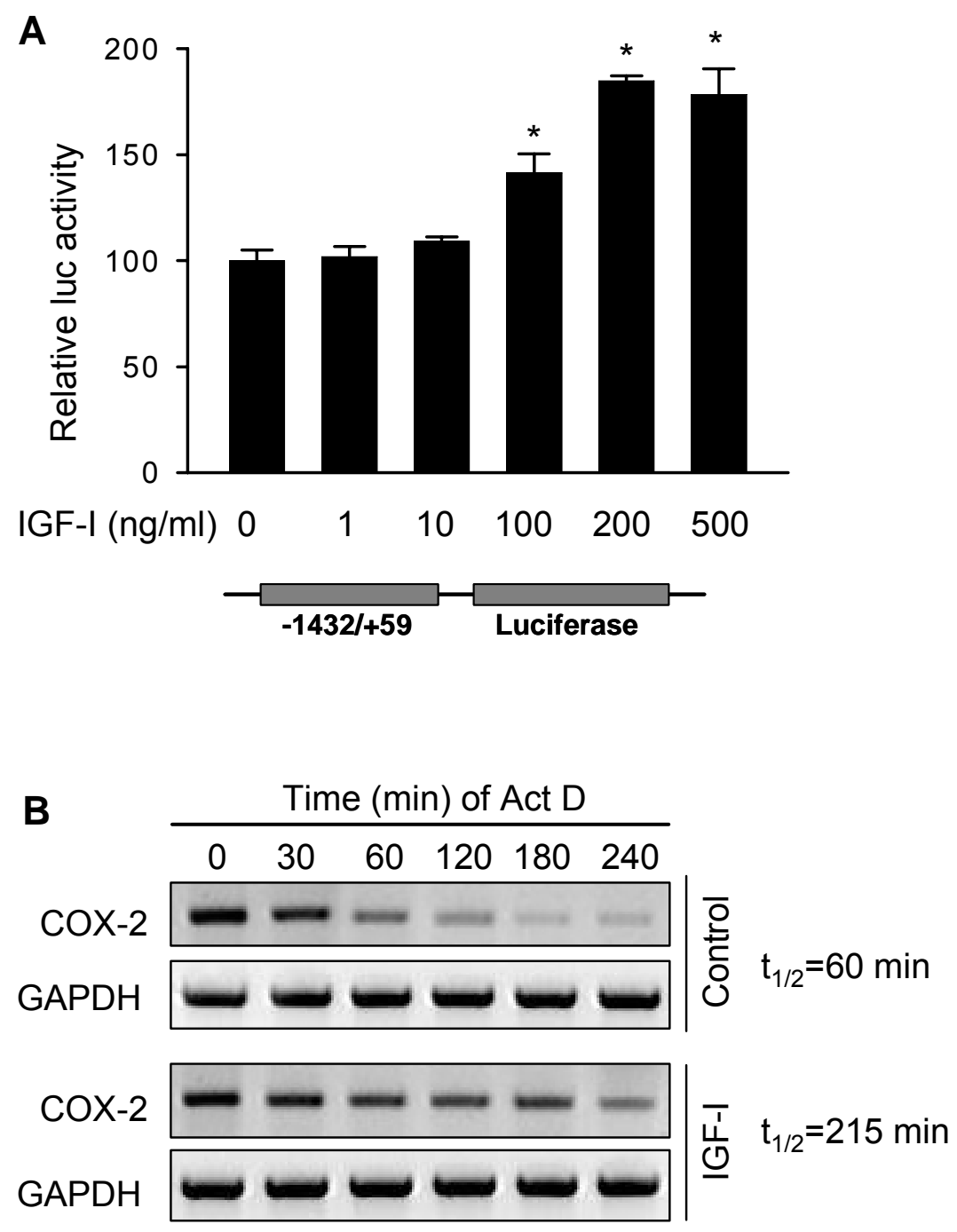
Fig. 3.
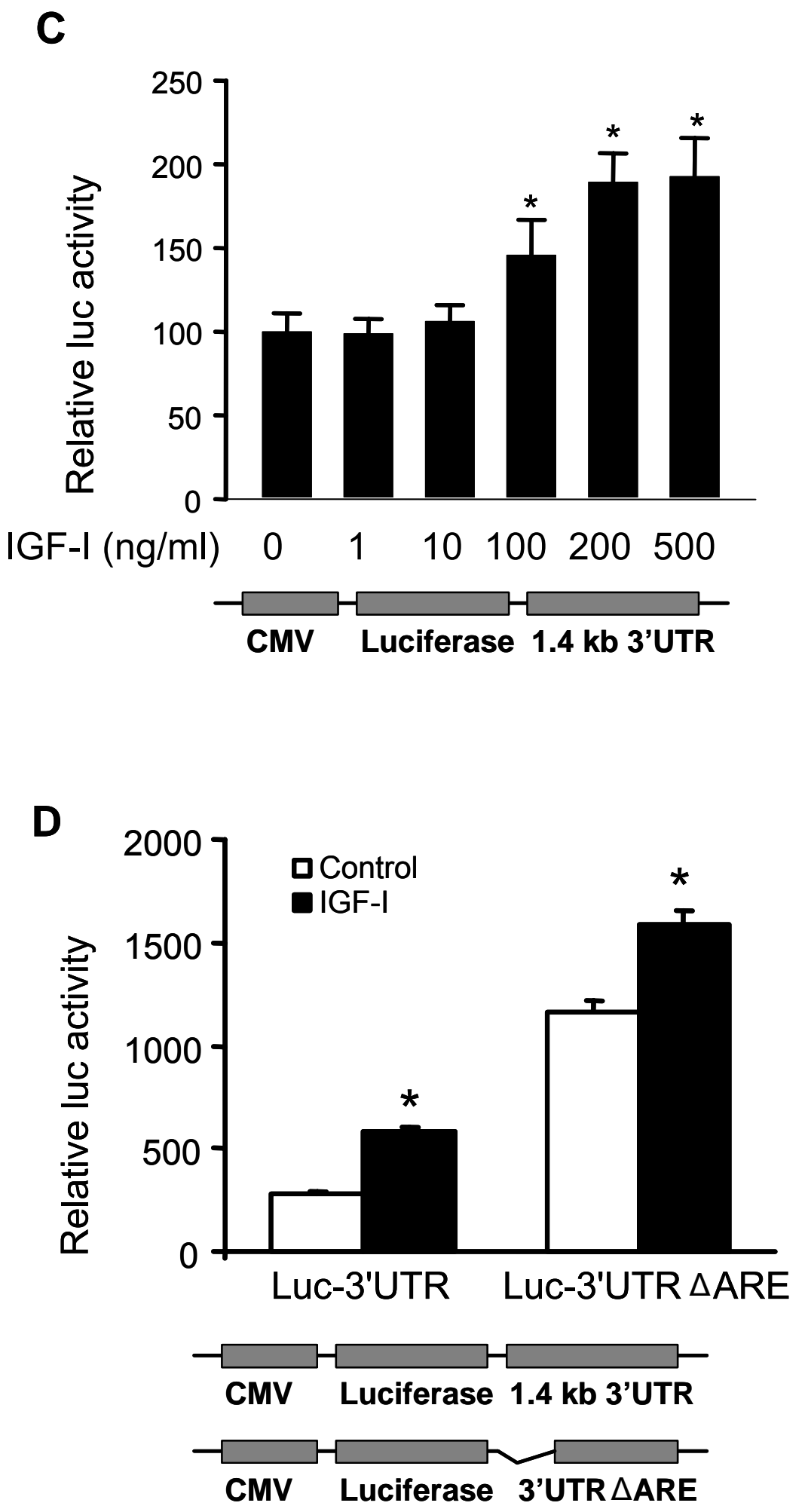
Fig. 3. IGF-I treatment induces COX-2 transcriptional activation and mRNA stability. (A) A2780 cells were co-transfected with a COX-2 promoter reporter construct phPHES2(-1432/+59) and pCMV- $\beta$-gal, and incubated overnight. The cells were treated with the indicated concentrations of IGF-I for $16 \mathrm{~h}$. Relative luciferase activity was presented as the ratio of luciferase to $\beta$-gal activity that was normalized to that of the control. (B) The cells were treated with solvent (control) or $200 \mathrm{ng} / \mathrm{ml} \mathrm{IGF-I} \mathrm{for} 1 \mathrm{~h}$, and then treated with $5 \mu \mathrm{g} / \mathrm{ml}$ actinomycin D $($ Act $D)$ to stop the transcription. The cells were harvested at the indicated time after the addition of Act D, and the levels of COX-2 mRNA were detected by RT-PCR. The densitometry intensity of COX-2 signal was normalized to that of GAPDH levels, and the half-life $\left(\mathrm{t}_{1 / 2}\right)$ of COX-2 mRNA was calculated using the regression program of Microsoft Excel 2000. (C) The cells were transfected with a luciferase reporter construct containing full-length COX-2 3'-UTR region (Luc-3'UTR). Relative luciferase activity was analyzed in the cells as described above after the cells were treated for $16 \mathrm{~h}$ with the indicated concentrations of IGF-I. (D) The cells were transfected with Luc-3'UTR or Luc-3'UTR $\triangle$ ARE (the deletion of AU-rich sequence element from 3'-UTR region). Luciferase activity was assayed after the treatment of the cells with $200 \mathrm{ng} / \mathrm{ml} \mathrm{IGF-I} \mathrm{for} 16 \mathrm{~h}$. The data were presented as mean $\pm \mathrm{SD}$. All transient transfection assays were performed in triplicate and repeated at least three times. *indicates that the value is significantly different when compared to that of the control $(p<0.05)$. 
Fig. 4.
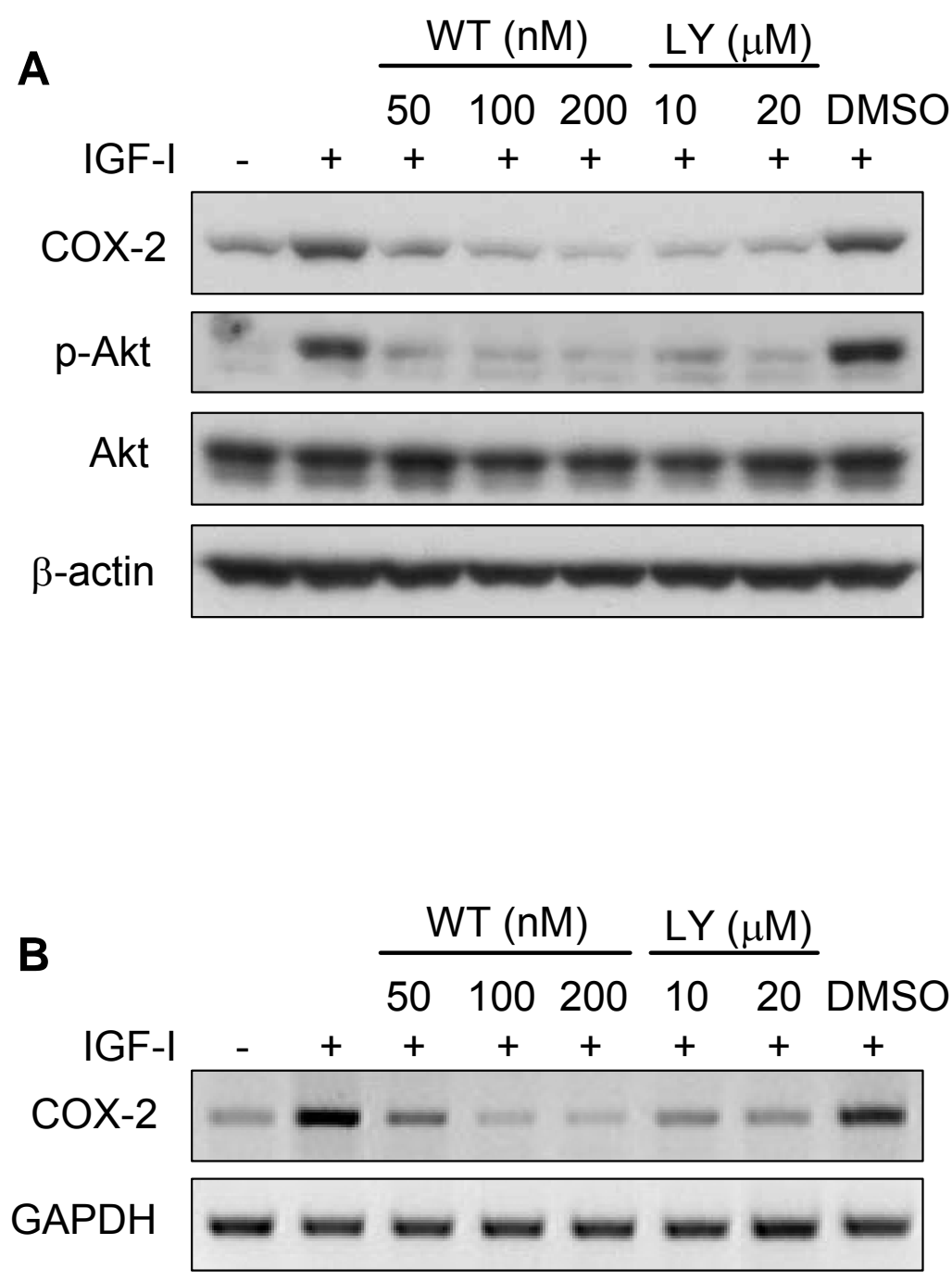
Fig. 4.

C
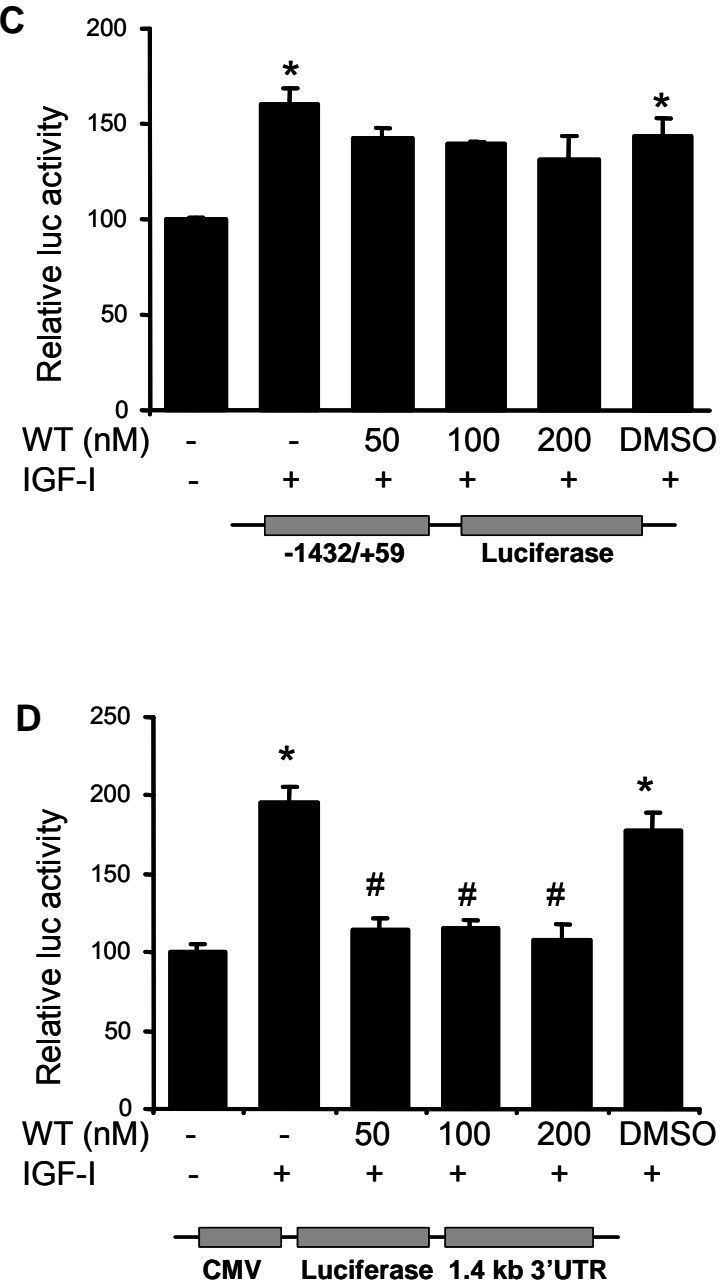
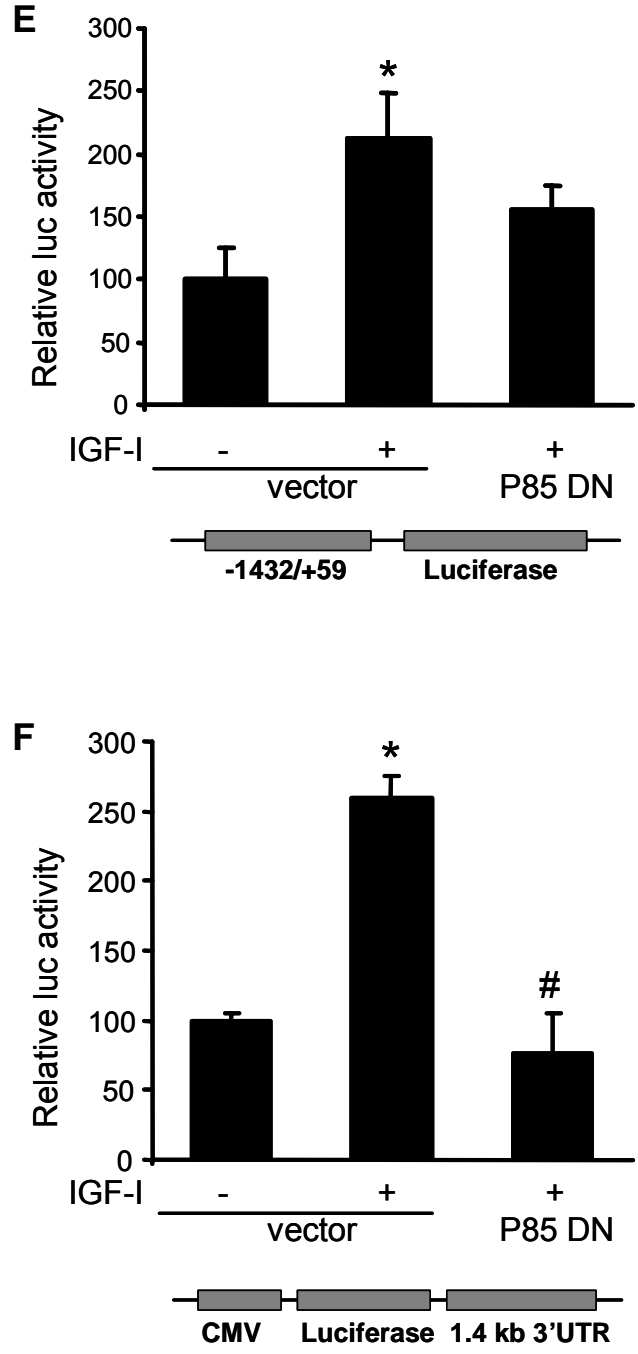

Fig. 4. PI3K signaling is required for IGF-I-induced COX-2 expression. (A) Serum-starved A2780 cells were pretreated with wortmannin (WT), LY294002 (LY) or the solvent DMSO followed by the incubation with $200 \mathrm{ng} / \mathrm{ml} \mathrm{IGF-I} \mathrm{for} 8 \mathrm{~h}$. COX-2, phospho-Akt (p-Akt, Ser473), total Akt, and $\beta$-actin protein levels were analyzed by immunoblotting. (B) The cells were pretreated with wortmannin (WT), LY294002 (LY) or solvent (DMSO) followed by incubation with $200 \mathrm{ng} / \mathrm{ml}$ IGF-I for $6 \mathrm{~h}$. COX-2 and GAPDH mRNA levels were detected by RT-PCR. (C 
and D) The cells were transfected with phPHES2(-1432/+59) and Luc-3'UTR, respectively; and cultured overnight. The cells were switched to serum-free medium in the absence or presence of wortmannin or $200 \mathrm{ng} / \mathrm{ml} \mathrm{IGF-I} \mathrm{for} 16 \mathrm{~h}$. Luciferase activity was assayed and was presented as mean \pm SD from three independent experiments. $*$ indicates that the value is significantly different when compared to that of the control $(\mathrm{p}<0.05)$; \# indicates that the value is significantly different when compared to that of IGF-I treatment alone ( $p<0.05)$. (E) A2780 cells were cotransfected with phPHES2(-1432/+59), pCMV-ßgal, empty vector, or a vector expressing dominant-negative PI3K construct (p85 DN); and cultured overnight. The cells were switched to serum-free medium, and incubated in the absence or presence of $200 \mathrm{ng} / \mathrm{ml} \mathrm{IGF-I} \mathrm{for} 16 \mathrm{~h}$. Relative luciferase activity was analyzed. (F) The cells were co-transfected with Luc-3'UTR, pCMV- $\beta g a l$, empty vector, or a vector expressing p85 DN. The cells were switched to serumfree medium and incubated in the absence or presence of $200 \mathrm{ng} / \mathrm{ml}$ IGF-I for $16 \mathrm{~h}$. Relative luciferase activity was analyzed as described above. *indicates that the value is significantly different when compared to that of the control $(\mathrm{p}<0.05)$; \# indicates that the value is significantly different when compared to that of the vector-transfected cells treated with IGF-I alone $(\mathrm{p}<0.05)$. 
Fig. 5.

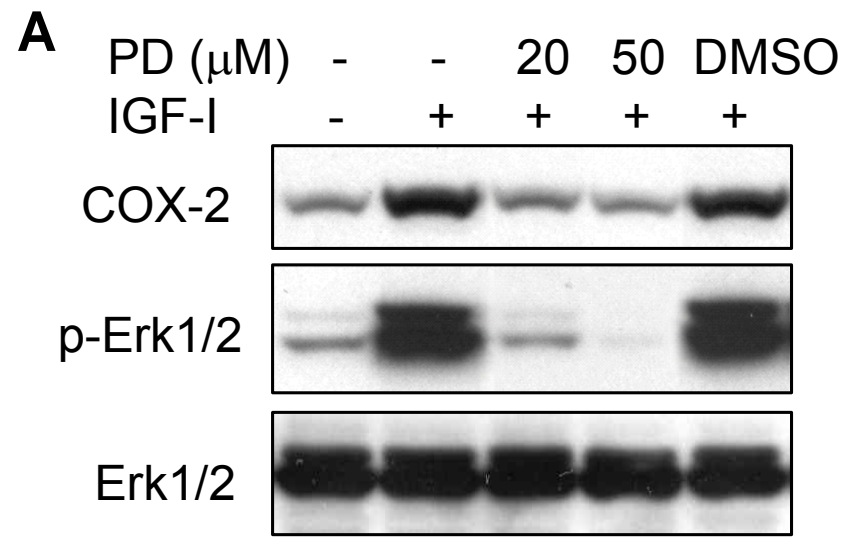

B $\mathrm{SB}(\mu \mathrm{M})$ - -1020 DMSO
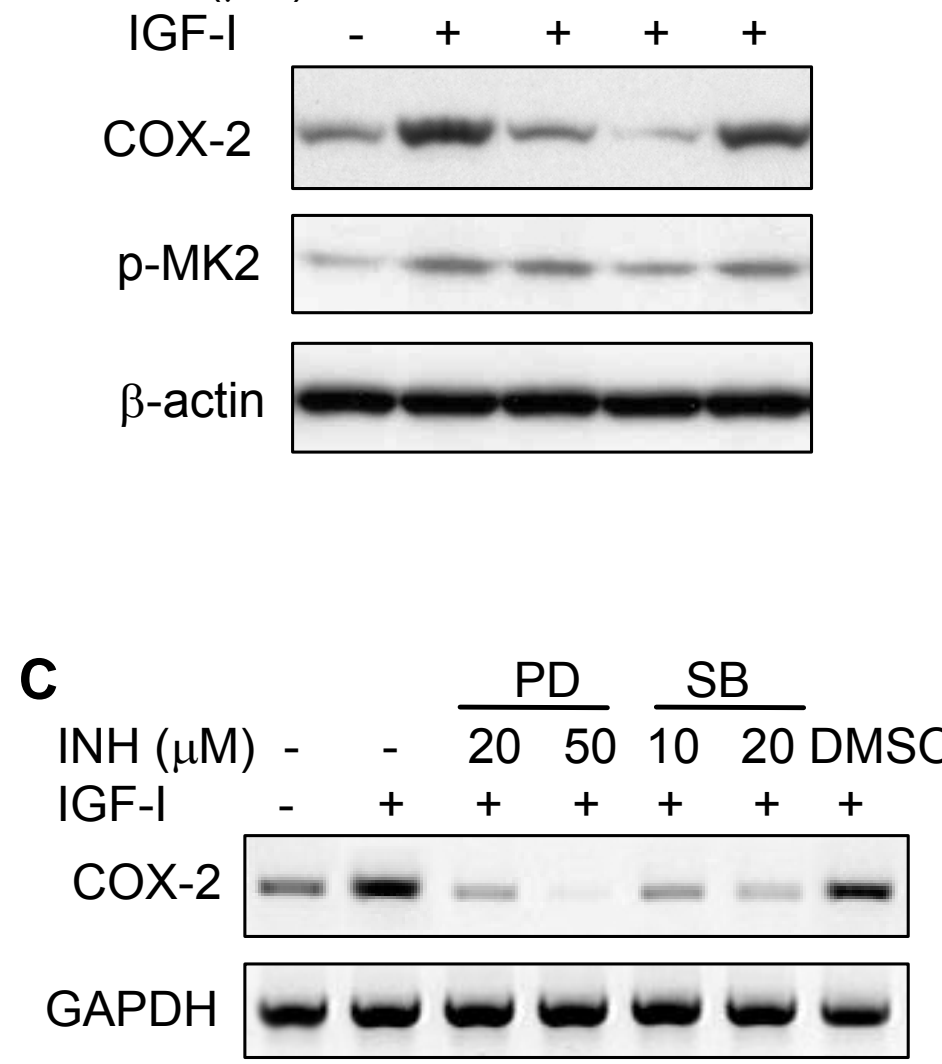
Fig. 5.
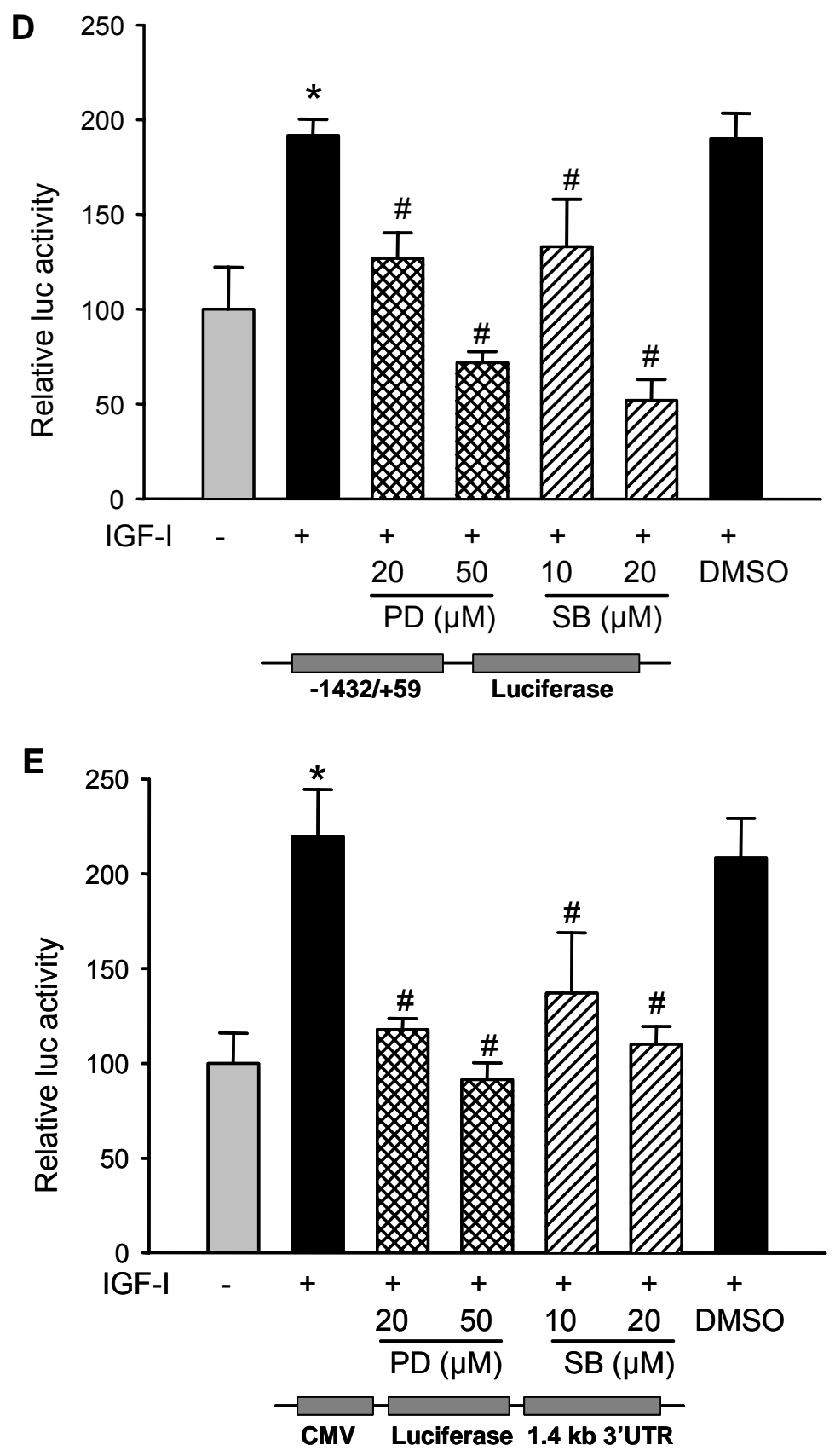

Fig. 5. IGF-I-induced COX-2 expression is dependent on MAPK activation. (A and B) A2780 cells were pretreated with the solvent (-), PD98059 (PD) or SB203580 (SB) for $1 \mathrm{~h}$, then treated with $200 \mathrm{ng} / \mathrm{ml} \mathrm{IGF-I} \mathrm{for} 8 \mathrm{~h}$. Specific protein levels were analyzed by immunoblotting using antibodies against COX-2, phospho-Erk1/2 (p-Erk1/2, Thr202/Tyr204), total Erk1/2, 
phospho-MK2 ( $p-M K 2, T h r 33)$, and $\beta$-actin, respectively. (C) The cells were pretreated with PD, SB, or DMSO for $1 \mathrm{~h}$, followed by incubation with $200 \mathrm{ng} / \mathrm{ml}$ IGF-I for $6 \mathrm{~h}$. COX-2 and GAPDH mRNA levels were analyzed by RT-PCR. (D and E) The cells were transfected with phPHES2(-1432/+59) and Luc-3'UTR plasmids, respectively; and cultured overnight. The cells were switched to serum-free mdium, and incubated in the absence or presence of DMSO, PD, or SB with $200 \mathrm{ng} / \mathrm{ml}$ IGF-I as indicated for $16 \mathrm{~h}$. Relative luciferase activity was analyzed as described in Fig. 3. Data are mean \pm SD from five independent experiments. * indicates that the value is significantly different when compared to that of the control $(\mathrm{p}<0.05)$; \# indicates that the value is significantly different when compared to that of IGF-I treatment alone $(\mathrm{p}<0.05)$. 
Fig. 6.
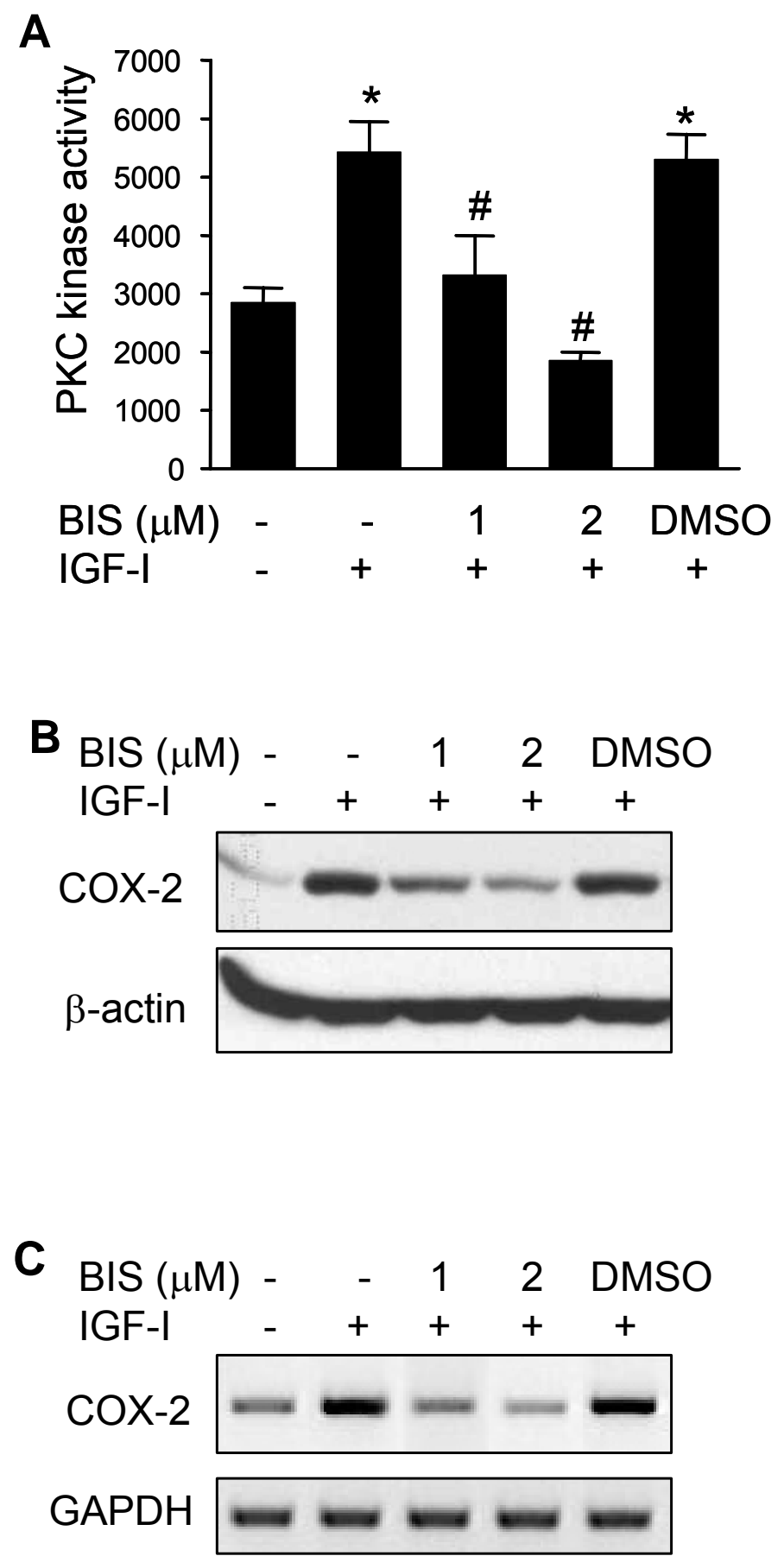
Fig. 6.
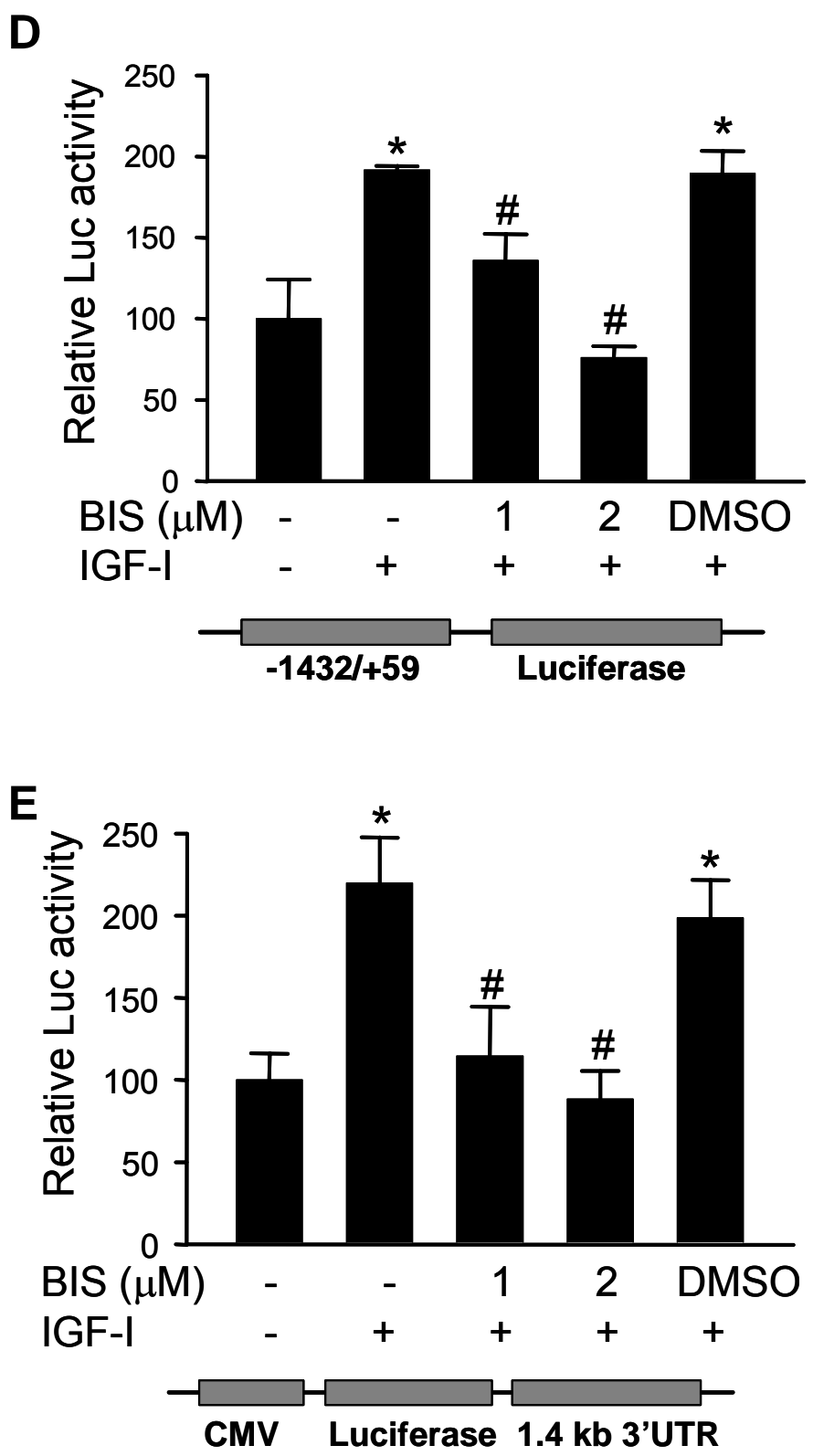

F $\operatorname{BIS}(\mu \mathrm{M})-\quad-\quad 12$ DMSO

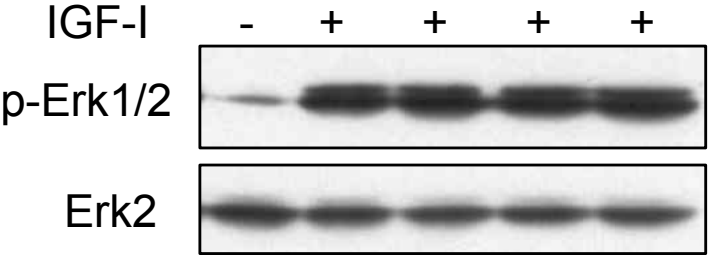


Fig. 6. PKC activity is important for IGF-I-induced COX-2 expression. (A) Serum-starved A2780 cells were pretreated with PKC inhibitor bisindolylmaleimide (BIS) for $30 \mathrm{~min}$, followed by incubation with $200 \mathrm{ng} / \mathrm{ml}$ IGF-I for $6 \mathrm{~h}$. Total PKC activity was measured using myelin basic protein as a substrate as described in Experimental Procedures. (B) The serum-starved cells were pretreated with BIS and treated with $200 \mathrm{ng} / \mathrm{ml}$ IGF-I for $6 \mathrm{~h}$. COX-2 and $\beta$-actin protein levels were analyzed by immunoblotting. (C) The cells were treated as above. COX-2 and GAPDH mRNA levels in the cells were analyzed by RT-PCR. (D and E) The cells were transfected with phPHES2 (-1432/+59) and Luc-3'UTR reporter constructs, respectively. The cells were cultured overnight after the transfection, then switched to serum-free medium in the absence or presence of BIS and $200 \mathrm{ng} / \mathrm{ml}$ IGF-I for $16 \mathrm{~h}$. Relative luciferase activity was analyzed in the cells. Data represent mean \pm SD from five independent experiments. * indicates that the value is significantly different when compared to that of the control $(p<0.05)$; \# indicates that the value is significantly different when compared to that of IGF-I treatment alone $(p<0.05)$. (F) The serum-starved cells were pretreated with BIS, followed by incubation with $200 \mathrm{ng} / \mathrm{ml}$ IGF-I for $4 \mathrm{~h}$. Specific protein levels were analyzed by immunoblotting using antibodies against phospho-Erk1/2 (p-Erk1/2, Thr202/Tyr204), and total Erk1/2, respectively. 
Fig. 7.

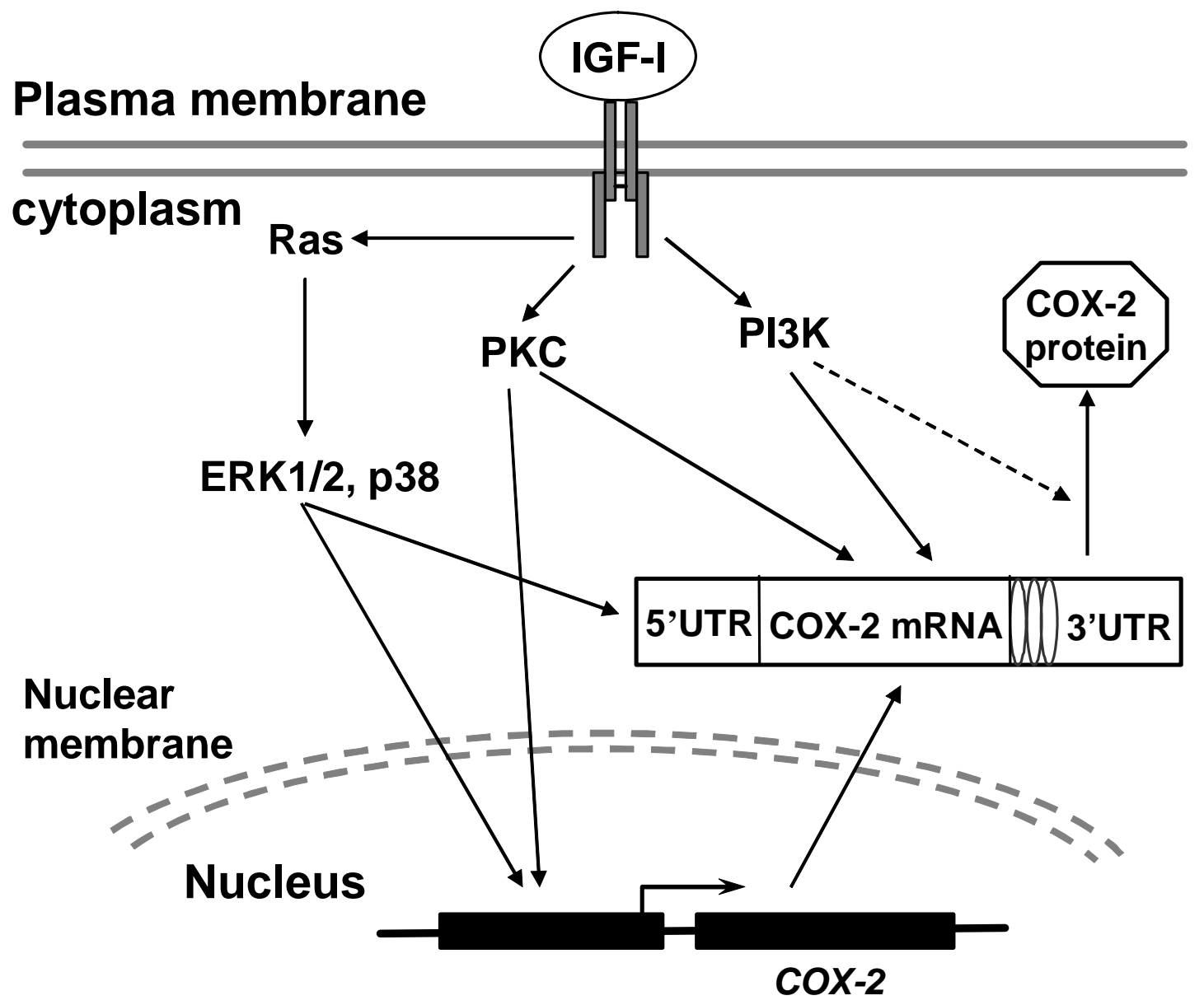

Fig. 7. Schematic representation of the mechanism by which IGF-I induces COX-2 expression in human ovarian cancer cells. 


\section{References}

1. Yu H, Rohan T. Role of the Insulin-Like Growth Factor Family in Cancer Development and Progression. J Natl Cancer Inst 2000 Sep 20;92(18):1472-89.

2. LeRoith D, Roberts CT, Jr. The insulin-like growth factor system and cancer. Cancer Lett 2003 Jun 10;195(2):127-37.

3. Baserga R, Peruzzi F, Reiss K. The IGF-1 receptor in cancer biology. Int J Cancer 2003 Dec 20;107(6):873-7.

4. Kalli KR, Conover CA. The insulin-like growth factor/insulin system in epithelial ovarian cancer. Front Biosci 2003 May 1;8:d714-d722.

5. LeRoith D, Baserga R, Helman L, Roberts CT, Jr. Insulin-like Growth Factors and Cancer. Ann Intern Med 1995 Jan 1;122(1):54-9.

6. Fukuda R, Hirota K, Fan F, Jung YD, Ellis LM, Semenza GL. Insulin-like growth factor 1 induces hypoxia-inducible factor 1-mediated vascular endothelial growth factor expression, which is dependent on MAP kinase and phosphatidylinositol 3-kinase signaling in colon cancer cells. J Biol Chem 2002 Oct 11;277(41):38205-11.

7. Reinmuth N, Liu W, Fan F, Jung YD, Ahmad SA, Stoeltzing O, et al. Blockade of Insulinlike Growth Factor I Receptor Function Inhibits Growth and Angiogenesis of Colon Cancer. Clin Cancer Res 2002 Oct 1;8(10):3259-69.

8. Stoeltzing O, Liu W, Reinmuth N, Fan F, Parikh AA, Bucana CD, et al. Regulation of Hypoxia-Inducible Factor-1\{alpha\}, Vascular Endothelial Growth Factor, and Angiogenesis by an Insulin-Like Growth Factor-I Receptor Autocrine Loop in Human Pancreatic Cancer. Am J Pathol 2003 Sep 1;163(3):1001-11.

9. Cao Z, Fang J, Xia C, Shi X, Jiang BH. trans-3,4,5'-Trihydroxystibene Inhibits HypoxiaInducible Factor 1 alpha\} and Vascular Endothelial Growth Factor Expression in Human Ovarian Cancer Cells. Clin Cancer Res 2004 Aug 1;10(15):5253-63.

10. Dannenberg AJ, Subbaramaiah K. Targeting cyclooxygenase-2 in human neoplasia: rationale and promise. Cancer Cell 2003 Dec;4(6):431-6.

11. Chun KS, Surh YJ. Signal transduction pathways regulating cyclooxygenase-2 expression: potential molecular targets for chemoprevention. Biochem Pharmacol 2004 Sep 15;68(6):1089-100.

12. Gately S, Li WW. Multiple roles of COX-2 in tumor angiogenesis: a target for antiangiogenic therapy. Semin Oncol 2004 Apr;31(2 Suppl 7):2-11.

13. Wendum D, Masliah J, Trugnan G, Flejou JF. Cyclooxygenase-2 and its role in colorectal cancer development. Virchows Arch 2004 Oct;445(4):327-33. 
14. Dixon DA. Regulation of COX-2 expression in human cancers. Prog Exp Tumor Res 2003;37:52-71.

15. Inoue $\mathrm{H}$, Yokoyama $\mathrm{C}$, Hara $\mathrm{S}$, Tone $\mathrm{Y}$, Tanabe $\mathrm{T}$. Transcriptional regulation of human prostaglandin-endoperoxide synthase- 2 gene by lipopolysaccharide and phorbol ester in vascular endothelial cells. Involvement of both nuclear factor for interleukin-6 expression site and cAMP response element. J Biol Chem 1995 Oct 20;270(42):24965-71.

16. Dixon DA, Kaplan CD, McIntyre TM, Zimmerman GA, Prescott SM. Post-transcriptional Control of Cyclooxygenase-2 Gene Expression. THE ROLE OF THE 3'UNTRANSLATED REGION. J Biol Chem 2000 Apr 14;275(16):11750-7.

17. Soh JW, Lee EH, Prywes R, Weinstein IB. Novel Roles of Specific Isoforms of Protein Kinase C in Activation of the c-fos Serum Response Element. Mol Cell Biol 1999 Feb $1 ; 19(2): 1313-24$.

18. Molina-Holgado E, Ortiz S, Molina-Holgado F, Guaza C. Induction of COX-2 and PGE(2) biosynthesis by IL-1beta is mediated by PKC and mitogen-activated protein kinases in murine astrocytes. Br J Pharmacol 2000 Sep;131(1):152-9.

19. Di Popolo A, Memoli A, Apicella A, Tuccillo C, di Palma A, Ricchi P, et al. IGF-II/IGF-I receptor pathway up-regulates COX-2 mRNA expression and PGE2 synthesis in Caco-2 human colon carcinoma cells. Oncogene 2000 Nov 16;19(48):5517-24.

20. Kim HJ, Kim TY. IGF-II-mediated COX-2 gene expression in human keratinocytes through extracellular signal-regulated kinase pathway. J Invest Dermatol 2004 Sep;123(3):547-55.

21. Bustin SA, Dorudi S, Phillips SM, Feakins RM, Jenkins PJ. Local expression of insulinlike growth factor-I affects angiogenesis in colorectal cancer. Tumour Biol 2002 May;23(3):130-8.

22. Guan Z, Buckman SY, Baier LD, Morrison AR. IGF-I and insulin amplify IL-1 betainduced nitric oxide and prostaglandin biosynthesis. Am J Physiol 1998 Apr;274(4 Pt 2):F673-F679.

23. Liu W, Reinmuth N, Stoeltzing O, Parikh AA, Tellez C, Williams $\mathrm{S}$, et al. Cyclooxygenase-2 is up-regulated by interleukin-1 beta in human colorectal cancer cells via multiple signaling pathways. Cancer Res 2003 Jul 1;63(13):3632-6.

24. Mallat A, Gallois C, Tao J, Habib A, Maclouf J, Mavier P, et al. Platelet-derived Growth Factor-BB and Thrombin Generate Positive and Negative Signals for Human Hepatic Stellate Cell Proliferation. ROLE OF A PROSTAGLANDIN/CYCLIC AMP PATHWAY AND CROSS-TALK WITH ENDOTHELIN RECEPTORS. J Biol Chem 1998 Oct 16;273(42):27300-5. 
25. Wu G, Mannam AP, Wu J, Kirbis S, Shie JL, Chen C, et al. Hypoxia induces myocytedependent COX-2 regulation in endothelial cells: role of VEGF. AJP - Heart and Circulatory Physiology 2003 Dec 1;285(6):H2420-H2429.

26. Rechler MM. Insulin-like growth factor binding proteins 1. Vitam Horm 1993;47:1-114.

27. Munkarah A, li-Fehmi R. COX-2: a protein with an active role in gynecological cancers. Curr Opin Obstet Gynecol 2005 Feb;17(1):49-53.

28. Nasi ML, Castiglione M. Cyclooxygenase-2 (COX-2) a new prognostic and predictive factor for ovarian cancer? Are all the criteria fulfilled? Ann Oncol 2002 Aug;13(8):1169-71.

29. Dore M, Cote LC, Mitchell A, Sirois J. Expression of prostaglandin G/H synthase type 1, but not type 2, in human ovarian adenocarcinomas. J Histochem Cytochem 1998 Jan;46(1):77-84.

30. Gupta RA, Tejada LV, Tong BJ, Das SK, Morrow JD, Dey SK, et al. Cyclooxygenase-1 is overexpressed and promotes angiogenic growth factor production in ovarian cancer. Cancer Res 2003 Mar 1;63(5):906-11.

31. Uefuji K, Ichikura T, Mochizuki H. Cyclooxygenase-2 expression is related to prostaglandin biosynthesis and angiogenesis in human gastric cancer. Clin Cancer Res 2000 Jan;6(1):135-8.

32. Chang SH, Liu CH, Conway R, Han DK, Nithipatikom K, Trifan OC, et al. Role of prostaglandin E2-dependent angiogenic switch in cyclooxygenase 2-induced breast cancer progression. Proc Natl Acad Sci U S A 2004 Jan 13;101(2):591-6.

33. Wang D, DuBois RN. Cyclooxygenase 2-derived prostaglandin E2 regulates the angiogenic switch. Proc Natl Acad Sci U S A 2004 Jan 13;101(2):415-6.

34. Zhi YH, Liu RS, Song MM, Tian Y, Long J, Tu W, et al. Cyclooxygenase-2 promotes angiogenesis by increasing vascular endothelial growth factor and predicts prognosis in gallbladder carcinoma. World J Gastroenterol 2005 Jun 28;11(24):3724-8.

35. Dixon DA, Tolley ND, King PH, Nabors LB, McIntyre TM, Zimmerman GA, et al. Altered expression of the mRNA stability factor HuR promotes cyclooxygenase-2 expression in colon cancer cells. J Clin Invest 2001 Dec;108(11):1657-65.

36. Lasa M, Mahtani KR, Finch A, Brewer G, Saklatvala J, Clark AR. Regulation of Cyclooxygenase 2 mRNA Stability by the Mitogen-Activated Protein Kinase p38 Signaling Cascade. Mol Cell Biol 2000 Jun 15;20(12):4265-74.

37. Cok SJ, Morrison AR. The 3'-Untranslated Region of Murine Cyclooxygenase-2 Contains Multiple Regulatory Elements That Alter Message Stability and Translational Efficiency. J Biol Chem 2001 Jun 15;276(25):23179-85. 
38. Faour WH, He Y, He QW, de Ladurantaye M, Quintero M, Mancini A, et al. Prostaglandin E2 Regulates the Level and Stability of Cyclooxygenase-2 mRNA through Activation of p38 Mitogen-activated Protein Kinase in Interleukin-1beta -treated Human Synovial Fibroblasts. J Biol Chem 2001 Aug 17;276(34):31720-31.

39. Sheng H, Shao J, Dixon DA, Williams CS, Prescott SM, DuBois RN, et al. Transforming growth factor-betal enhances Ha-ras-induced expression of cyclooxygenase- 2 in intestinal epithelial cells via stabilization of mRNA. J Biol Chem 2000 Mar 3;275(9):6628-35.

40. Sheng H, Shao J, DuBois RN. K-Ras-mediated Increase in Cyclooxygenase 2 mRNA Stability Involves Activation of the Protein Kinase B. Cancer Research 2001 Mar $1 ; 61(6): 2670-5$.

41. Bachelor MA, Cooper SJ, Sikorski ET, Bowden GT. Inhibition of p38 mitogen-activated protein kinase and phosphatidylinositol 3-kinase decreases UVB-induced activator protein1 and cyclooxygenase-2 in a SKH-1 hairless mouse model. Mol Cancer Res 2005 Feb;3(2):90-9.

42. Chen G, Bower KA, Ma C, Fang S, Thiele CJ, Luo J. Glycogen synthase kinase 3 beta (GSK3beta) mediates 6-hydroxydopamine-induced neuronal death. FASEB J 2004 Jul;18(10):1162-4.

43. Sheu ML, Ho FM, Yang RS, Chao KF, Lin WW, Lin-Shiau SY, et al. High glucose induces human endothelial cell apoptosis through a phosphoinositide 3-kinase-regulated cyclooxygenase-2 pathway. Arterioscler Thromb Vasc Biol 2005 Mar;25(3):539-45.

44. Sheu ML, Chao KF, Sung YJ, Lin WW, Lin-Shiau SY, Liu SH. Activation of phosphoinositide 3-kinase in response to inflammation and nitric oxide leads to the upregulation of cyclooxygenase-2 expression and subsequent cell proliferation in mesangial cells. Cell Signal 2005 Aug;17(8):975-84.

45. Subbaramaiah K, Hart JC, Norton L, Dannenberg AJ. Microtubule-interfering agents stimulate the transcription of cyclooxygenase-2. Evidence for involvement of ERK1/2 AND p38 mitogen-activated protein kinase pathways. J Biol Chem 2000 May $19 ; 275(20): 14838-45$.

46. Subbaramaiah K, Norton L, Gerald W, Dannenberg AJ. Cyclooxygenase-2 is overexpressed in HER-2/neu-positive breast cancer: evidence for involvement of AP-1 and PEA3. J Biol Chem 2002 May 24;277(21):18649-57.

47. Subbaramaiah K, Marmo TP, Dixon DA, Dannenberg AJ. Regulation of Cyclooxgenase-2 mRNA Stability by Taxanes: EVIDENCE FOR INVOLVEMENT OF p38, MAPKAPK-2, and HuR. J Biol Chem 2003 Sep 26;278(39):37637-47.

48. Winzen R, Kracht M, Ritter B, Wilhelm A, Chen CY, Shyu AB, et al. The p38 MAP kinase pathway signals for cytokine-induced mRNA stabilization via MAP kinase-activated protein kinase 2 and an AU-rich region-targeted mechanism. EMBO J 1999 Sep 15;18(18):4969-80. 
49. Huang WC, Chen JJ, Inoue H, Chen CC. Tyrosine phosphorylation of I-kappa B kinase alpha/beta by protein kinase C-dependent c-Src activation is involved in TNF-alphainduced cyclooxygenase-2 expression. J Immunol 2003 May 1;170(9):4767-75.

50. Cosentino F, Eto M, De Paolis P, van der LB, Bachschmid M, Ullrich V, et al. High glucose causes upregulation of cyclooxygenase- 2 and alters prostanoid profile in human endothelial cells: role of protein kinase $C$ and reactive oxygen species. Circulation 2003 Feb 25;107(7):1017-23. 


\section{Chapter 4}

\section{Dual roles of PI3K/Akt signaling pathway in tumor-induced angiogenesis and tumor growth}

Zongxian Cao ${ }^{1}$, Chang Xia ${ }^{1}$, Jing Fang ${ }^{2}$, Lily Yang ${ }^{3}$, Min Ding $^{4}$, and Bing-Hua Jiang ${ }^{1 \#}$

${ }^{1}$ Mary Babb Randolph Cancer Center, Department of Microbiology, Immunology and Cell Biology, West Virginia University, Morgantown, West Virginia 26506-9300, USA. ${ }^{2}$ Institute for Nutritional Sciences, Chinese Academy of Sciences, 294 Tai Yuan Road, Shanghai 200031, China. ${ }^{3}$ Surgical Oncology Research, Department of Surgery, Emory University School of Medicine, Emory University Hospital Room B206, 1364 Clifton Road, NE, Atlanta, GA 30322.

${ }^{4}$ Health Effects Laboratory Division, National Institute for Occupational Safety and Health, Morgantown, WV 26505, USA.

Running title: Dual Roles of PI3K/Akt Signaling in Tumor Angiogenesis

Key Words: Angiogenesis; phosphatidylinositol 3-kinase (PI3K); Akt; HIF-1; VEGF 


\begin{abstract}
We modulated PI3K/Akt signaling specifically in either human microvascular endothelial cells (HMVECs) or cancer cells, and investigated their roles in tumor angiogenesis using a chicken chimeric tumor model system. We found that inhibition of PI3K or Akt activity in HMVECs significantly decreased angiogenesis and tumor growth in vivo, whereas upregulation of endothelial PI3K or Akt activity greatly induced tumor angiogenesis and tumor growth in vivo. In cancer cells, PI3K/Akt signaling regulated HIF-1 $\alpha$-mediated VEGF expression. Inhibition of PI3K or Akt activity in cancer cells markedly suppressed tumor angiogenesis and tumor growth in vivo. Knockdown of HIF-1 $\alpha$ or VEGF expression by Si-RNA had similar effects. We thus demonstrated the important roles of PI3K/Akt signaling pathway in both human endothelial cells and cancer cells for regulating tumor angiogenesis.
\end{abstract}

\title{
Significance
}

Cancer cells and vascular endothelial cells are the key cell types for tumor angiogenesis. Accumulating evidence suggests that PI3K/Akt signaling pathway plays an important role in both cell types. Here we demonstrated that PI3K and Akt activities in endothelial cells are important for tumor angiogenesis and tumor growth in vivo. In human ovarian cancer cells, PI3K/Akt regulates HIF-1 $\alpha$-mediated VEGF expression; PI3K/Akt signaling and its downstream effectors HIF-1 $\alpha$ and VEGF are essential for tumor angiogenesis and tumor growth in vivo. Thus PI3K/Akt signaling pathway plays important roles in both tumor and endothelial cells during tumor angiogenesis, suggesting that targeting PI3K-Akt signaling in both cellular compartments may be more effective to control angiogenesis and tumor growth. 


\section{Introduction}

Angiogenesis, the development of new blood vessels from the pre-existing vasculature, is essential for tumor growth and metastasis $(1 ; 2)$. Anti-angiogenic therapy is an attractive new strategy for cancer treatment, which has some advantages over conventional therapies, such as a potential low rate of drug resistance, direct accessibility from the circulation, and negligible side effects on normal tissues (3-6). Angiogenesis is tightly regulated by the balance of positive and negative angiogenic factors. A variety of angiogenic factors have been identified as potential targets for anti-angiogenesis therapy (7). One of the key inducers of angiogenesis is vascular endothelial growth factor (VEGF), which is a very promising target for anti-angiogenic therapy (6).

VEGF binds to endothelial cell (EC)-specific tyrosine kinase receptors, VEGFR-1 and VEGFR-2. VEGFR-2 is tyrosine-phosphorylated efficiently upon VEGF binding and mediates major positive signals from VEGF in ECs (8). VEGF has multiple effects on ECs: it stimulates cell migration, proliferation, survival, activation of endothelial nitric oxide synthase (eNOS), release of matrix metalloproteinases (MMPs) and plasminogen activators (PAs) $(9 ; 10)$, all of these are critical cellular events during the process of angiogenesis. Considerable evidence suggests that phosphatidylinositol 3-kinase (PI3K)/Akt signaling pathway is the predominant signaling event in VEGF-induced angiogenic responses in ECs. Blockade of PI3K/Akt signaling in ECs inhibits VEGF-induced endothelial cell proliferation, survival, migration, vascular permeability, and angiogenesis (11-15).

VEGF is expressed by many types of cells surrounding the area of angiogenesis, including the activated ECs themselves. A majority of malignant tumors overexpress VEGF, and 
tumor cell-derived VEGF is considered as the primary stimulus for tumor angiogenesis (16). One of the major stimuli for VEGF expression in tumor cells is intratumoral hypoxia, a characteristic property of advanced solid tumors, which is caused by the structural and functional abnormalities of tumor microvasculature, rapid expansion of tumor mass, and tumor-associated anemia $(17 ; 18)$. Hypoxia induces VEGF expression primarily through hypoxia-inducible factor 1 (HIF-1) (19;20). HIF-1 is a heterodimeric transcriptional factor, composed of HIF-1 $\alpha$ and HIF-1ß subunits (21). HIF-1 $\alpha$ is rapidly accumulated under hypoxia conditions due to the inhibition of ubiquitinmediated degradation, and subsequently dimerizes with the constitutively expressed HIF-1 $\beta$, and activates transcription of its target genes, including VEGF (22). HIF-1 $\alpha$ also regulates VEGF expression under normoxic conditions. Previous work done by our laboratory and others has shown that, under normoxic conditions, HIF-1 $\alpha$ expression can be induced by growth factors and oncogenic proteins, which depends on the PI3K/Akt pathway (23-26). In addition, activation of PI3K or Akt is sufficient to induce VEGF expression (14). The PI3K pathway has inherent oncogenic properties $(27 ; 28)$, and constitutive activation of PI3K is present in many human cancers (29). Multiple mechanisms are involved in the activation of PI3K in human cancers, e.g. amplification or activating mutations of $\mathrm{p} 110 \alpha$ gene, mutational inactivation or loss of the tumor suppressor PTEN, which is the antagonist for PI3K (29).

Tumor angiogenesis is a complex process, involving the interaction and coordination between different cell types within the tumor microenvironment. Among these cell types, the tumor cells and vascular endothelial cells are especially important for tumor angiogenesis. As described above, PI3K/Akt signaling pathway appears to play important roles in both cell types. Recently, PI3K/Akt pathway was found to be up-regulated in tumor-derived endothelial cells (30). However, there is no direct evidence about the functional significance of the enhanced 
endothelial PI3K/Akt signaling in tumor angiogenesis in vivo. In this study, we aimed to define the specific role of PI3K/Akt signaling pathway in endothelial cells or cancer cells in tumorinduced angiogenesis and progression in vivo. We developed a chicken chorioallantoic membrane (CAM) tumor model system based on a recently reported nude mouse model, in which human cancer cells were co-implanted subcutaneously with microvascular endothelial cells by using a biodegradable poly(lactic-co-glycolic acid) (PLGA) sponge as a scaffold (31). The implanted human ECs will form microvessels that anastomose with the host vasculature and transport host blood to support tumor growth (31). In this model system, tumor angiogenesis and growth will be predominantly determined by the direct interactions between cancer cells and the implanted human endothelial cells within the defined space of the biodegradable sponge. The CAM model has the advantages of easy manipulation, low cost, and allowing large-scale treatments in a relatively short time. By using this unique model, we were able to specifically modulate the PI3K-Akt signaling in either endothelial cells or cancer cells in culture, and then evaluate their contributions to tumor neovascularization and tumor growth in vivo. We found that modulation of endothelial PI3K or Akt activity significantly affected tumor-induced angiogenesis and tumor growth in vivo. Blockade of PI3K or Akt activation in cancer cells inhibited HIF-1 $\alpha$-mediated VEGF expression, and resulted in dramatic inhibition of tumor growth and angiogenesis in vivo. Downregulation of HIF-1 $\alpha$ and VEGF expression in cancer cells similarly inhibited tumor growth and angiogenesis in vivo. Our results demonstrated the important roles of PI3K/Akt signaling pathway in endothelial cells and cancer cells for tumor angiogenesis, suggesting that targeting PI3K/Akt signaling in both tumor cells and endothelial cells may be more effective to control tumor angiogenesis and tumor progression. 


\section{Materials and methods}

\section{Cell culture}

Human ovarian cancer cells A2780 were cultured in RPMI Medium 1640 (Life Technologies Inc., Grand Island, NY), supplemented with 10\% fetal bovine serum (FBS), $50 \mathrm{nM}$ insulin (Sigma), 100 units/ml penicillin, and $100 \mu \mathrm{g} / \mathrm{ml}$ streptomycin. Human dermal microvascular endothelial cells (HMVEC, Cambrex BioScience, Walkersville, MD) were cultured in endothelial cell growth medium(EGM-2 MV, Cambrex ), and were used at passage 6 or less. All cultures were maintained in a humid environment containing $5 \% \mathrm{CO} 2$ at $37^{\circ} \mathrm{C}$.

\section{Adenovirus preparation and transduction efficiency}

The construction of constitutively active Akt (myrislated Akt), dominant-negative Akt (AktK179M), p110 , wild-type PTEN, and phosphatase mutant PTEN (PTEN C124S) has been described previously (14). Recombinant adenoviruses were made using the AdEasy system (32). Briefly, the constructs were subcloned into the shuttle vector pAdTrack-CMV, then transferred to AdEasy-1 plasmid through homologous recombination as described previously (32). The viral vectors were then transfected into 293 cells to generate viruses. A control virus which carries the green fluorescent protein (Ad-GFP) was derived from the same vector system. Viral titres were determined using the BD Adeno-X ${ }^{\mathrm{TM}}$ Rapid Titer Kit (BD Biosciences Clontech, Mountain View, CA) per the manufacturer's instructions. Adenoviral transduction efficiency for the cell lines was determined using the adenoviral vector Ad-GFP. To achieve more than $90 \%$ of transduction, 50 and 100 multiplicity of infection (MOI) was used for HMVEC and A2780 cells, respectively. 


\section{Collection of cancer cell conditioned medium and VEGF ELISA assays}

Human ovarian cancer cells A2780 were cultured in normal growth medium to $80 \%$ confluence. The cells were washed twice with PBS, and incubated in serum-free medium for $24 \mathrm{~h}$. Conditioned medium (CM) was collected, centrifuged to remove any cellular debris and stored at $-80^{\circ} \mathrm{C}$ until use. VEGF levels in the CM were determined using an ELISA assay kit (R\&D systems, Minneapolis, MN) according to the manufacturer's instruction.

\section{Endothelial cell tube formation assay}

HMVECs were cultured to about $80 \%$ confluence. The cells were either left untreated or infected with $50 \mathrm{MOI}$ of relevant adenoviruses for $24 \mathrm{~h}$ and were then washed and serum-starved in basal EBM2 medium overnight. After trypsinization, cells were resuspended in basal EBM2 at a concentration of $2 \times 10^{5}$ cells $/ \mathrm{ml}$. An aliquot of the cell suspension $(50 \mu \mathrm{l})$ was mixed with an equal volume of cancer cell conditioned medium or basal RPMI1640 medium. The cells were seeded in a 96-well tissue culture plate that had been evenly coated with growth factor-reduced Matrigel (BD Labware, Bedford, MA). Seeded cells were incubated at $37^{\circ} \mathrm{C}$ in a $5 \% \mathrm{CO}_{2}$ incubator for $16 \mathrm{~h}$, and tube formation was examined under a phase-contrast microscope (Olympus IX-71) connected to a digital camera. Tube formation was quantified by calculating the length of the tubular network in five randomly selected fields under $200 \times$ magnification.

\section{Immunoblotting}

After appropriate treatments, the cells were washed with ice-cold phosphate-buffered saline (140

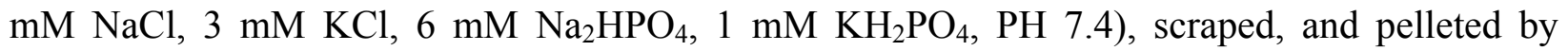
centrifugation. Whole cellular extracts were prepared using modified radioimmune precipitation 
buffer (100 mM Tris, $150 \mathrm{mM} \mathrm{NaCl}, 5 \mathrm{mM}$ EDTA, 1\% Triton X-100, 1\% deoxycholate acid, $0.1 \%$ SDS, $2 \mathrm{mM}$ phenylmethylsulfonyl fluoride, $1 \mathrm{mM}$ sodium orthovanadate, $2 \mathrm{mM}$ DTT, 20 $\mu \mathrm{g} / \mathrm{ml}$ leupeptin, $20 \mu \mathrm{g} / \mathrm{ml}$ pepstatin. $\mathrm{pH}$ 7.4). Protein concentrations of the lysates were assayed using a protein assay reagent (Bio-Rad). Aliquots $(50 \mu \mathrm{g})$ of the protein samples were fractionated by SDS-PAGE and transferred to a nitrocellulose membrane (Schleicher \& Schuell Biosciences, Keene, NH). The blots were blocked in $1 \times \mathrm{TBS}-\mathrm{T}$ solution containing $5 \%$ nonfat dry milk for $2 \mathrm{~h}$ at room temperature, followed by incubation with primary antibodies overnight at $4^{\circ} \mathrm{C}$. Immunoreactivity was visualized with appropriate horseradish peroxidase-conjugated secondary antibodies and enhanced chemiluminescence (PerkinElmer Life Sciences, Boston, MA).

\section{Biodegradable Sponge Fabrication}

The bioabsorbable polymer scaffolds were prepared as previously described $(31 ; 33)$. Briefly, PLGA ( $85 \%$ d,l-lactide/15\%glycolide, Medisorb, Cincinnati, Ohio) was dissolved in chloroform to yield a solution of $5 \%$ polymer. The solution was loaded into Teflon dishes packed with sodium chloride particles which was sieved to a size between 250 and $500 \mu \mathrm{m}$. The solvent was allowed to evaporate and the salt was leached by immersing films in distilled water with several changes. Sponges were subsequently coated with polyvinyl alcohol (PVA, Aldrich Chem. Co., Milwaukee, WI) by immersing them for $16 \mathrm{~h}$ in an aqueous solution containing $10 \mathrm{mg} / \mathrm{mL}$ of PVA in PBS. The sponges were removed from the solution, dried, and cut to $6 \times 6 \times 1 \mathrm{~mm}$ in size. The day before implantation, sponges were soaked in $100 \%$ ethanol for 2 hours, washed twice in PBS, and then left overnight in fresh PBS. 


\section{Implantation of HMVEC and human tumor cells into nude mice}

Just before implantation, $0.9 \times 10^{6}$ HMVECs infected with relevant adenoviruses or parental HMVECs (untransduced) were mixed with $0.1 \times 10^{6}$ A2780 cells, and resuspended in a 1:1 mixture of EBM-MV and growth factor-reduced Matrigel (BD Labware, Bedford, MA) and seeded into the PLGA sponges. The sponges were incubated for $30 \mathrm{~min}$ at $37^{\circ} \mathrm{C}$ to allow for gelation of the Matrigel. Female nude mice (3 to 4 weeks old, CB.17. nude, Taconic, Germantown, NY) were anesthetized with pentobarbital, and two sponges were surgically implanted subcutaneously on the right and left flank regions of each mouse. Mice were euthanized 21 days after transplantation, and the implants were retrieved, immediately measured with calipers, and weighed in an electronic balance. The tumor tissues were fixed overnight in Bouin's solution, and processed for histological examination. The care and treatment of experimental animals was in accordance with West Virginia University Animal Care and Use Committee Policy for Survival Surgery on Rodents.

\section{Implantation of HMVEC and Human Tumor Cells into Chicken Chorioallantoic Membrane (CAM)}

Fertilized chicken eggs (standard pathogen free grade; SPAFAS, Preston, CT) were incubated for $7 \mathrm{~d}$ at $37^{\circ} \mathrm{C}$ in a humidified atmosphere. An artificial air sac was created over the well-formed chicken chorioallantoic membrane $(\mathrm{CAM})$ as described (14). A $1.0 \times 1.0$-cm square window was cut in the shell over the artificial air sac and sealed with $\operatorname{Scotch}^{\circledR}$ tape. On the next day, a piece of PLGA sponge loaded with the cell mixture as described was put onto the exposed CAM. The eggshell window was resealed and the embryo was maintained at $37^{\circ} \mathrm{C}$ in a humidified atmosphere. the chick embryos were opened11 days after implantation, and the implants were 
removed, immediately measured with calipers, and weighed in an electronic balance. The tumor tissues were fixed in Bouin's solution overnight, and processed for histological examination.

\section{Immuonohistochemical Staining of CD31 and Quantification of Microvessel Density}

Neovascularization were evaluated in human tumors grown in nude mice and on the CAM by immuonohistochemical staining of the vascular endothelial marker CD31. Tissue sections were deparaffinized and rehydrated and antigen retrieval was performed by heating in a microwave oven to $89^{\circ} \mathrm{C}$ for $10 \mathrm{~min}$ in $\mathrm{BD}$ Pharmingen ${ }^{\mathrm{TM}}$ Retrievagen A solution ( $\mathrm{pH}$ 6.0). Human microvessels were visualized by incubating sections at $4^{\circ} \mathrm{C}$ overnight with 1:40 dilution of monoclonal mouse antihuman CD31 antibody (Clone JC/70A, DakoCytomation California, Carpinteria, CA). Sections were incubated with appropriate secondary antibodies, and visualization of the complex was accomplished using an $\mathrm{ABC}$ staining kit (Santa Cruz Biotechnology, Santa Cruz, CA). The sections were counterstained with haematoxylin, dehydrated and mounted. The same procedure without primary antibody was included as a negative control.

Microvessel density was determined as described (34). Since microvessels are distributed heterogeneously throughout the tumor, two to four sections from each tumor were scanned under low-power magnification $(40 \times)$ to identify areas of highest CD31-positive vessel density (hotspots). Then 5 high-power fields $(400 \times)$ were randomly chosen from each section to count for the number of CD31-positive microvessels. All of the areas in which cells were stained with the endothelial cell marker CD31 were considered as a microvessel, in spite of their size or morphology. Data were collected by two independent observers without knowledge of which 
tumors were viewed. Microvessel Density (MVD) was defined as the total number of microvessels per 200x field (mean \pm SE).

\section{Generation of A2780 cells stably expressing Si-RNA against HIF-1 $\alpha$ or VEGF}

The hairpin siRNA-encoding DNA oligonucleotides were prepared by Ambion (Austin, TX). The targeting sequences used to silence HIF-1 $\alpha$ and VEGF were: 5'GTGGATTACCACAGCTGA-3' and 5'-GGAGTACCCTGATGAGATC-3', respectively. This sequence was checked against the database to confirm specificity. As a negative control, a scrambled siRNA sequence was used. The hairpin oligonucleotides were ligated into pSilencer 2.1-U6 vector (Ambion, Austin, TX). The constructs were transfected into A2780 cells by Lipofectamine (Invitrogen, Carlsbad, CA) per the manufacturer's instructions. G418 was added to the culture to a final concentration of $500 \mu \mathrm{g} / \mathrm{ml} 24 \mathrm{~h}$ after transfection. After two weeks of selection, the resultant colonies were pooled and maintained in the medium containing 250 $\mu \mathrm{g} / \mathrm{ml}$ of G418.

\section{Transient Transfection and Luciferase Reporter Assay}

The VEGF promoter reporter was constructed by inserting 47 bp of human VEGF promoter 5'flanking sequence (between -985 to -939) into the pGL2-basic luciferase vector (Promega) as described previously (19). The dominant-negative HIF-1 $\alpha$ expressing plasmid was described previously (19). The cells were co-transfected with the reporter, pCMV- $\beta$-gal plasmid, and a dominant-negative or wild-type HIF-1 $\alpha$ expressing plasmid using lipofectomine reagent (Invitrogen). An empty vector plasmid was used to adjust the equal amounts of plasmids used in each experiment. Luciferase activity was measured $24 \mathrm{~h}$ after transfection using a luciferase 
assay reagent (Promega) and normalized to $\beta$-galactosidase activity. The data were mean $\pm \mathrm{SD}$ from three replicate experiments.

\section{Statistical Analysis}

Statistical significance was determined using one-way ANOVA or the Student's t-test. SPSS statistical software (SPSS, Chicago, IL) was employed.

\section{Results}

\section{PI3K/Akt signaling in endothelial cells is important for cancer cell conditioned medium- induced endothelial cell tube formation}

Numerous studies have shown that activation of PI3K/AKT signaling pathway in ECs is crucial for endothelial proliferation, migration, survival, and differentiation induced by the prototypical angiogenic factors, including basic fibroblast growth factor (bFGF), VEGF, and angiopoietin-1 (11-15). Akt activity was found to be up-regulated in tumor-derived ECs (35). Here we wanted to determine the specific roles of PI3K and Akt activities in endothelial cells in tumor-induced angiogenesis. As shown in Fig 1A, conditioned medium (CM) generated from human ovarian cancer cell A2780 was able to dramatically induce Akt activation in human microvascular endothelial cells (HMVECs), which was completely blocked by PI3K inhibitor LY294002. To more specifically inhibit PI3K activity in ECs, we constructed adenovirus vector expressing the tumor suppressor PTEN (Ad-PTEN), which is the natural antagonist of PI3K. We also generated adenovirus expressing a dominant-negative Akt (Ad-Akt DN) to inhibit Akt activity, which is a downstream target of PI3K. To determine the roles of PI3K and Akt in tumor-induced 
angiogenesis, we first performed endothelial cell tube formation assay. As shown in Fig. 1B, pretreatment of HMVECs with LY294002 or transduction of the cells with Ad-PTEN or Ad-Akt DN significantly inhibited ovarian cancer cell CM-induced endothelial cell capillary formation, indicating that activation of PI3K and Akt in ECs is required for tumor-induced angiogenesis in vitro. Then we asked whether overexpession of active forms of PI3K or Akt enhanced tumorinduced angiogenesis. We upregulated PI3K or Akt activity in HMVECs by infecting the cells with adenovirus expressing active form of PI3K (Ad-p110) or Akt (Ad-mAkt). As expected, overexpression of p110 and Akt induced the phosphorylation of the corresponding downstream

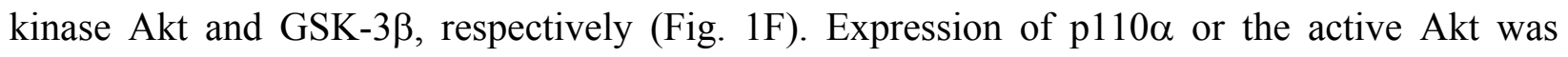
sufficient to induce endothelial cell tube formation, and enhanced the effects of cancer cell CM on tube formation as compared with the mock-infected and vector-infected cells (Fig. 1D, E). Taken together, these data demonstrate that PI3K and Akt activities in human endothelial cells are important for EC function in response to the stimulation of cancer cell secreted-angiogenic factors, suggesting an important role of endothelial PI3K/Akt signaling in tumor-induced angiogenesis.

Modulation of PI3K activity in endothelial cells affects tumor growth and angiogenesis in vivo

We next wanted to determine the role of PI3K in endothelial cells in tumor-induced angiogenesis in vivo. We utilized a recently established animal model to study tumor-induced angiogenesis. In this model, human cancer cells are co-transplanted with human microvascular ECs into nude mice by using a biodegradable PLGA sponge as a scaffold (31). The implanted human ECs will form microvessels that anastomose with the host vasculature and transport mouse blood to 
support tumor growth (31). By using this unique model, we were able to specifically modulate the PI3K and Akt activities in ECs, and evaluate the contribution of endothelial PI3K/Akt signaling to tumor neovascularization. We implanted adenovirus-transduced HMVECs along with human ovarian cancer cell A2780 into nude mice. As shown in Fig 2A-C, co-transplantation of HMVECs facilitated tumor growth compared with implantation of tumor cell alone. Overexpression of $\mathrm{p} 110 \alpha$ in HMVECs (EC/Ad-p110) significantly increased the weight and volume of tumors when compared with tumors formed from co-transplantation of A2780 with parental HMVECs and adenoviral vector-infected HMVECs (Fig 2A-C). In contrast, tumors developed by the implantation of A2780 and HMVECs expressing with PTEN (EC/Ad-PTEN) were much smaller (Fig 2A-C). Implantation of HMVECs expressing p110 $\alpha$ did not form tumors, suggesting that the primary HMVECs overexpressing PI3K were not transformed to develop tumors by themselves. We modified the above-mentioned nude mice model to establish a new animal system in our laboratory for studying tumor angiogenesis - the chicken chorioallantoic membrane (CAM) tumor model. Compared with the nude mouse model, the CAM model has the advantages of easy manipulation, low cost, and allowing large-scale treatments in a relatively short time. We modified PI3K activity in HMVECs and performed similar tumor assays in the CAM model. We observed similar results by using the CAM tumor model when compared to the nude mice model (Fig 2D-E). These results demonstrated that PI3K activity in endothelial cells is important for tumor growth in vivo.

The development and growth of solid tumors is dependent on tumor-induced angiogenesis. To determine whether the modulation of endothelial PI3K activity affected tumor angiogenesis, we visualized tumor microvessels by immunohistochemical staining using a monoclonal anti-human CD31 antibody, and determined the microvessel density in the tumor 
sections. The implanted human ECs contributed to the formation of functional blood vessels in the tumors (Fig. 2F, 2I). As shown in Fig. 2F-K, tumors formed from co-transplantation of EC/Ad-p110 and A2780 were significantly more vascularized than those induced by implantation of EC/Ad-GFP and A2780. Tumors developed from implantation of EC/Ad-PTEN and A2780 were less vascularized (Fig. 2F-K). These data indicate that endothelial PI3K activity plays an important role in tumor-induced angiogenesis, which in turn affects tumor growth in vivo.

The activity of Akt, the key downstream target of PI3K, in ECs is important for tumor growth and angiogenesis in vivo

The serine/threonine kinase Akt is a key transducer of PI3K signal. We showed that endothelial Akt activity was important for cancer cell CM-induced endothelial cell tube formation (Fig. 1). Here, we wanted to further determine the role of Akt activity endothelial cells in tumor growth and angiogenesis in vivo. To modify the Akt activity in HMVECs, the cultured cells were either infected with Ad-mAkt (EC/Ad-mAkt) to express constitutively active Akt, or infected with AdAkt DN (EC/Ad-Akt DN) to inhibit endogenous Akt activity. The transduced HMVECs were then mixed with A2780 ovarian cancer cells, and transplanted into nude mice or the CAM. As shown in Fig 3A-E, tumors that developed by the implantation of A2780 and EC/Ad-mAkt were significantly larger when compared to tumors formed from co-transplantation of A2780 with parental HMVECs and HMVECs infected with Ad-GFP (EC/Ad-GFP), whereas tumors developed by implantation of A2780 and EC/Ad-Akt DN were significantly smaller than those in the A2780 plus EC/Ad-mAkt, and A2780 plus EC/Ad-GFP groups. Implantation of endothelial cells infected by Ad-mAKt alone did not form tumors. These results demonstrate that Akt 
activity in ECs is important for tumor growth in vivo, which is similar to PI3K in the cells.

We next examined whether the effect of Akt in ECs on tumor growth correlated with changes in tumor-induced angiogenesis in vivo. As shown in Figs. 3F-I, significantly more robust angiogenesis was observed in tumors generated from the co-transplantation of EC/Ad-mAkt and A2780 when compared with the control group (EC/Ad-GFP and A2780). Conversely, much less neovascularization was observed in tumors developed from implantation of EC/Ad-Akt DN and A2780 (Fig. 3F-I). These experiments demonstrate that endothelial Akt activity is important for tumor-induced angiogenesis in vivo.

\section{PI3K/Akt signaling pathway regulates HIF-1 $\alpha$-mediated VEGF expression in human ovarian cancer cells; Inhibition of PI3K and Akt activity in the cells compromises tumor- induced in vitro angiogenesis}

Tumor angiogenesis is a complex process that is regulated by many angiogenic factors. One of these key factors is VEGF, which is a potent and EC-specific mitogen that plays a crucial role during the process of tumor angiogenesis. VEGF expression by tumor cells directly correlates with angiogenesis within the tumors (16). Previous studies showed that PI3K/Akt signaling pathway is crucial for VEGF expression in response to hypoxia, growth factors, and oncogenic proteins $(19 ; 20 ; 23-25 ; 36)$. Consistent with these findings, we showed here that PI3K selective inhibitor LY294002 significantly reduced VEGF production by human ovarian cancer cell line A2780 (Fig. 4A). Similar effects were observed in experiments where we utilized Ad-PTEN or Ad-Akt DN to more specifically inhibit PI3K or Akt activity in the cells (Fig. 4A). Inhibition of PI3K and Akt activity by LY294002 or adenoviral constructs markedly suppressed the expression of HIF-1 $\alpha$, which is one of the major transcriptional regulators of the VEGF gene 
(Fig. 4B). Transfection of the cells with a plasmid expressing a dominant-negative HIF-1 $\alpha$ inhibited the expression of the luciferase reporter driven by the full-length promoter of human VGEF gene in a dose-dependent manner (Fig. 4C). LY294002, Ad-PTEN, or Ad-Akt DN also inhibited VEGF luciferase reporter activity, and these inhibitory effects could be completely reversed by overexpression of wild-type HIF-1 $\alpha$ (Fig. 4C). Collectively, these data indicate that HIF-1 $\alpha$-mediated VEGF expression is regulated by PI3K/Akt signaling pathway in human ovarian cancer cells. Because HIF-1 $\alpha$-mediated VEGF expression is important for tumor angiogenesis, these results suggest that inhibition of PI3K/Akt signaling in cancer cells may have an inhibitory effect on tumor angiogenesis. To directly test this hypothesis, we first performed endothelial cell tube formation assay. As shown in Fig. 4D, conditioned medium collected from A2780 cells infected with Ad-PTEN or Ad-Akt-DN had much weaker effects on endothelial cell capillary formation when compared to the effects of CM collected from parental A2780 and AdGFP-infected A2780 cell. These results indicate that PI3K and Akt activities in cancer cells, which regulate VEGF expression, are important for tumor-induced angiogenesis in vitro.

\section{Inhibition of PI3K or Akt activity in cancer cells suppresses tumor growth and tumor in vivo}

We wanted to further determine whether inhibition of PI3K or Akt activity in cancer cells had any inhibitory effects on tumor growth and angiogenesis in vivo. PI3K and Akt activity in A2780

cells was inhibited by adenoviral vector-mediated expression of PTEN and a dominant-negative Akt, respectively. The transduced cells were then mixed with normal HMVECs, and implanted onto the chicken CAM to allow tumor formation. We found that tumors developed from the implantation of HMVECs and A2780 overexpressing PTEN or dominant-negative Akt were 
significantly smaller when compared to tumors formed from the co-implantation of HMVECs and parental A2780, or adenoviral vector-infected A2780 (Fig 5A). We next examined the microvessel density in tumor tissue sections to determine whether the inhibitory effects on tumor growth correlated with the decrease in tumor-induced angiogenesis in vivo. As shown in Fig. 5B, tumors developed from co-implantation of HMVECs and A2780/Ad-PTEN and A2780/Ad-Akt DN were significantly less vascularized than those from the implantation of HMVECs and A2780/Ad-GFP. We also showed that expression of HIF-1 $\alpha$ and VEGF was much lower in tumors developed from co-implantation of HMVECs and A2780/Ad-PTEN and A2780/Ad-Akt DN when compared to the control groups (Fig 5C). These data demonstrate that PI3K and Akt activities in cancer cells are important for tumor growth in vivo, which is due in part to the regulation of HIF-1 $\alpha$ and VEGF expression in the process of tumor-induced angiogenesis.

\section{Knockdown of HIF-1 $\alpha$ and VEGF expression by Si-RNA in human ovarian cancer cells inhibit tumor growth and angiogenesis in vivo}

To determine whether inhibition of HIF-1 $\alpha$ and VEGF expression in cancer cells has similar inhibitory effects on tumor growth and angiogenesis, we specifically inhibited HIF-1 $\alpha$ and VEGF expression using the siRNAs against HIF-1 $\alpha$ and VEGF, respectively. The cells were transfected with constructs expressing HIF-1 $\alpha$ or VEGF si-RNA, and selected with G418 to obtain stable cell clones. A2780 cells stably expressing si-RNA against HIF-1 $\alpha$ decreased HIF$1 \alpha$ protein expression, which correlated with suppression of VEGF transcriptional activation and VEGF protein secretion (Fig 6A). A2780 cells stably expressing si-RNA against VEGF effectively inhibited VEGF mRNA and protein expression (Fig 6B). The conditioned medium generated from A2780 cells stably expressing si-RNA against HIF-1 $\alpha$ or VEGF induced 
significantly less endothelial cell capillary formation when compared to those in the control group (Fig 6C). To test whether inhibition of HIF-1 $\alpha$ or VEGF expression in cancer cells decreases tumor angiogenesis and tumor growth in vivo, A2780 cells stably expressing si-RNA against HIF-1 $\alpha$ or VEGF were mixed with normal HMVECs, and implanted onto the chicken CAM to allow the tumor formation. We found that tumors developed by the implantation of HMVECs and A2780 cells stably expressing si-RNA against HIF-1 $\alpha$ or VEGF were significantly smaller when compared to tumors formed from co-implantation of HMVECs and parental A2780 cells or A2780 cells expressing the scramble siRNA sequence (Fig 7A). When compared to the control group, tumors developed from the implantation of HMVECs and A2780 cells stably expressing si-RNA against HIF-1 $\alpha$ or VEGF had significantly less levels of angiogenesis response (Fig 7B). Expression of VEGF was much lower in tumors developed from the co-implantation of HMVEC and A2780 cells stably expressing si-RNA against HIF-1 $\alpha$ or VEGF when compared to the control group (Fig 7C). These data demonstrate that HIF-1 $\alpha$ or VEGF expression in cancer cells is important for tumor growth and angiogenesis in vivo.

\section{Discussion}

Angiogenesis is a vital process during tumor progression because it supports rapid growth of tumor cells and facilitates metastases $(1 ; 2)$. The study of the molecular mechanisms involved in tumor angiogenesis will identify potential therapeutic targets for treatment of cancer by the new antiangiogenic strategy. Multiple cell types and a variety of proteins are involved in the regulation of tumor angiogenesis. Cancer and vascular endothelial cells are the key cell types for tumor angiogenesis. The angiogenic cytokines secreted by tumor cells are the primary stimuli to 
initiate tumor angiogenesis. VEGF is one of the key cytokines that plays an important role for tumor angiogenesis, which has been considered as one of the primary targets for anti-angiogenic therapy because inhibition of VEGF function has potent anti-tumor activities in experimental and clinical studies (3). HIF-1 is the principal transcription factor that regulates VEGF expression under both hypoxic and normoxic conditions (19;20;23-25;37). Vascular endothelial cells in the tumor microenvironment respond to the proangiogenic stimuli, become activated, and differentiate into new capillaries. Multiple signaling pathways are involved in the induction of angiogenic factors in tumor cells and the functional responses of ECs to these stimuli. Accumulating evidence suggests that PI3K/Akt signaling pathway plays a key role in both cancer cells and endothelial cells (29). In this study, we aimed to specifically modulate PI3K and Akt activities in either EC or cancer cells, and to define their roles in the regulation of angiogenesis and tumor growth in vivo.

To specifically modify PI3K/Akt signaling in either endothelial cells or cancer cells, and examine their effects on tumor angiogenesis, we developed a chicken CAM model system. In this model, human microvascular endothelial cells (HMVECs) were mixed with human ovarian cancer cell A2780, absorbed into a biodegradable PLGA sponge in vitro, and implanted onto the chicken CAM. The porous biodegradable sponges function as temporary scaffolds that maintain implanted cells in a defined space and guide the organization and differentiation of the transplanted human ECs into functional microvessels that anastomose with the host vasculature and transport blood to support tumor growth $(31 ; 33 ; 38)$. In this model system, co-implantation of human ECs and cancer cells resulted in the development of human tumors supported by microvessels developed from the implanted human endothelial cells in the chicken CAM. The development of tumors in the implants was primarily determined by the direct interaction of the 
implanted human ECs and cancer cells. This unique model system allowed us to genetically modify PI3K and Akt activities in either ECs or cancer cells in vitro, and evaluate their contributions to tumor neovascularization and tumor growth in vivo. Our chicken CAM model system was modified from a recently reported nude mouse model (31). Eleven days after transplantation, just before the hatching of the chicks, we observed the formation of large tumors in the sponge implants in the chicken CAM. The overall sizes of tumors generated in the CAM were smaller compared to those generated in the nude mouse model, which usually took 3 weeks. However, we observed similar changes in tumor sizes and tumor angiogenesis in both model systems in response to PI3K/Akt signaling. Therefore, we have successfully established a novel chicken CAM model system to study tumor angiogenesis that can substitute for the nude mouse model. The CAM model has the advantages of easy manipulation, low cost, and allowing large-scale treatments in a relatively short time.

Considerable evidence suggests that PI3K/Akt signaling pathway in ECs is crucial for the functional responses of ECs to a variety of prototypical angiogenic factors including bFGF, VEGF and angiopoietin-1 (11-15). Akt activity was found to be constitutively activated in tumor-derived ECs which showed enhanced survival, proadhesive, and angiogenic properties (35). Therefore, we hypothesized that endothelial PI3K/Akt signaling is important for angiogenesis and tumor growth in vivo. We first demonstrated that PI3K/Akt signaling pathway was significantly activated in normal human microvascular endothelial cells upon the stimulation by conditioned medium (CM) generated from human ovarian cancer cells A2780. The activation of PI3K/Akt signaling correlated with enhanced capillary formation of HMVEC in vitro induced by cancer cell $\mathrm{CM}$, suggesting that PI3K/Akt pathway may be important for the angiogenic responses of ECs to cancer cell-secreted soluble factors. This was confirmed by subsequent 
experiments, in which we showed that blockade of PI3K-Akt signaling in HMVECs completely inhibited cancer cell CM-induced endothelial cell tube formation, and overexpression of wildtype PI3K or active Akt in HMVECs enhanced cancer cell CM-induced angiogenesis in vitro. These observations strongly suggest that endothelial PI3K/Akt signaling may play a critical role in tumor-induced angiogenesis in vivo. To test this, we genetically modified PI3K or Akt activity in HMEVCs by adenoviral vector-mediated transduction, followed by co-implantation with normal A2780 cancer cells into nude mice or onto the chicken CAM. We found that inhibition of PI3K/Akt signaling in HMVECs had dramatic inhibitory effects, whereas upregulation of PI3K or Akt activity in HMVECs had significant stimulatory effects on angiogenesis and tumor growth in vivo. In these experiments, we selectively modulated PI3K/Akt signaling in ECs so that only the endothelial functioning would be changed during tumor angiogenesis and development in vivo. Therefore, our data clearly demonstrate that endothelial PI3K/Akt signaling is crucial for tumor-induced angiogenesis, which further controls tumor growth in vivo. Malignant tumor cells can secrete a variety of angiogenic factors such as bFGF, VEGF, TGF- $\beta$, PDGF, and endothelin-1 (39), and many of these factors can induce activation of PI3K/Akt signaling in ECs. Thus, these results suggest that it might be quite effective to suppress tumor angiogenesis by inhibiting endothelial PI3K/Akt signaling, which appears to be a converging signaling cascade harnessed by many angiogenic factors secreted by tumor cells.

In this study, we showed that in human ovarian cancer cells, PI3K/Akt signaling pathway was required for HIF-1 $\alpha$ expression and VEGF production. Previous studies showed that PI3K/Akt signaling pathway regulates VEGF expression in cancer cells in response to hypoxia, growth factors, and oncogenic proteins $(19 ; 20 ; 23-25 ; 40)$. Consistent with these reports, we showed that inhibition of PI3K or Akt activity significantly suppressed VEGF production in 
human ovarian cancer cell A2780. We further showed that blockade of PI3K or Akt activity inhibited HIF-1 $\alpha$ expression, which is one of the major transcriptional regulators of the VEGF gene expression under both hypoxic and normoxic conditions, and overexpression of wild-type HIF-1 $\alpha$ reversed the inhibitory effects on VEGF transcriptional activation by blockade of PI3K and Akt activation. These results indicate that PI3K/Akt signaling controls HIF-1 $\alpha$-mediated VEGF expression in human ovarian cancer cells. VEGF gene transcription can also be regulated by other transcriptional factors such as AP-1, Sp1, and NF-kB (41;42), and Akt-mediated induction of VEGF expression may be independent of HIF-1 $\alpha$ expression under certain circumstances (42). In this study we did not rule out the involvement of other transcriptional factors in PI3K/Akt-regulated VEGF expression, but the data demonstrate a significant role of HIF-1 $\alpha$ in the PI3K and Akt-regulated VEGF expression. VEGF is one of the key angiogenic factors secreted by tumor cells. The role of PI3K/Akt signaling in regulating VEGF expression suggests that PI3K and Akt activities in cancer cells may be important for tumor angiogenesis. Indeed, we found that inhibition of PI3K or Akt activity in cancer cells substantially suppressed tumor-induced angiogenesis in vitro and in vivo, which correlated with retarded tumor growth in vivo. Blockade of PI3K or Akt activity in cancer cells may affect tumor growth independent of angiogenesis since $\mathrm{PI} 3 \mathrm{~K} / \mathrm{Akt}$ signaling also plays important roles in regulating tumor cell proliferation and survival. Our data indicate that PI3K and Akt activities in cancer cells are important for tumor growth in vivo, which is due at least in part to its regulation of tumorinduced angiogenesis via HIF-1 $\alpha$ and VEGF expression in cancer cells.

We showed that PI3K and Akt activity in cancer cells regulated HIF-1 $\alpha$ and VEGF expression in vitro and in vivo, and inhibition of PI3K or Akt activation suppressed tumor growth and angiogenesis in vivo. These results suggest that HIF-1 $\alpha$ and VEGF are important 
downstream effectors of PI3K/Akt signaling in cancer cells during the process of tumor angiogenesis. Previous work showed that loss of either HIF-1 $\alpha$ or HIF-1 $\beta$ retarded tumor growth, accompanied by decreased vascularization $(43 ; 44)$. It has been well documented that VEGF expression correlated with microvessel density of tumor tissues, and was associated with poor prognosis in several tumor types (3). Experimental and clinical studies have shown that inhibition of VEGF functioning inhibits tumor growth, and improves the responsiveness of cancer patients to conventional chemotherapy $(3 ; 45 ; 46)$. In this study, we wanted to determine whether inhibition of HIF-1 $\alpha$ or VEGF expression in cancer cells was able to inhibit tumor growth and angiogenesis in vivo. We used Si-RNA constructs to specifically knock-down HIF$1 \alpha$ or VEGF expression in A2780 cells. The A2780 cells stably expressing Si-RNA against HIF$1 \alpha$ or VEGF were then mixed with HMVECs, and transplanted onto the chicken CAM. We found that inhibition of HIF-1 $\alpha$ or VEGF expression in cancer cells markedly inhibited tumorinduced angiogenesis, and suppressed tumor growth in vivo, which was similar to the effects of inhibition of PI3K/Akt signaling in cancer cells. These data demonstrate that HIF-1 $\alpha$ or VEGF expression in cancer cells is important for tumor growth and angiogenesis in vivo. Interestingly, a previous study showed that although loss of HIF-1 $\alpha$ inhibited VEGF expression, the growth of tumors was not retarded (20). Another study showed that loss of HIF-1 $\alpha$ inhibited tumor growth, however, vascular density was similar in wild-type and HIF-1 $\alpha$-null tumors (47). In both of the studies, tumors were generated by subcutaneous injection of tumor cells into nude mice. In these endothelial and cancer cells co-implantation model systems, tumor angiogenesis and growth were primarily determined by the direct interactions between cancer cells and endothelial cells. The discrepancies between these previous reports and ours may result from the different model systems used to generate tumors. 
In summary, we demonstrate that modulation of endothelial PI3K or Akt activity significantly affected tumor-induced angiogenesis and tumor growth. Blockade of PI3K or Akt activation in tumor cells inhibited HIF-1-mediated VEGF expression, and resulted in dramatic inhibition of tumor growth and angiogenesis in vivo. Similarly, downregulation of HIF-1 $\alpha$ or VEGF expression in cancer cells inhibited tumor growth and angiogenesis in vivo. Our results thus demonstrate the important role of PI3K/Akt signaling pathway in both endothelial cells and cancer cells for tumor angiogenesis, suggesting that the targeting of PI3K/Akt signaling in both endothelial cells and cacer cells may be more effective to control tumor growth and angiogenesis. 
Figures and figure legends:

Fig. 1

A

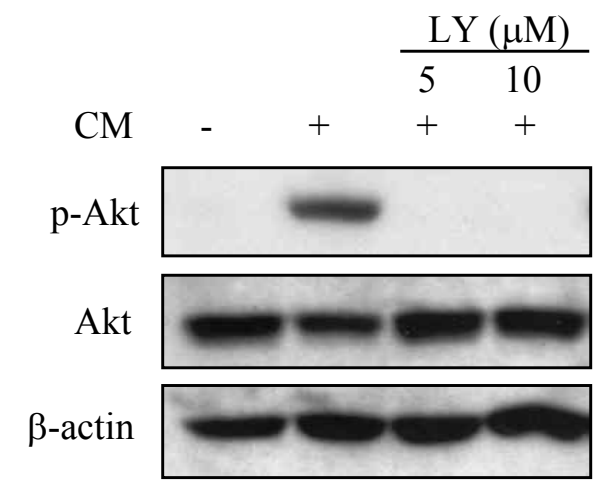

B
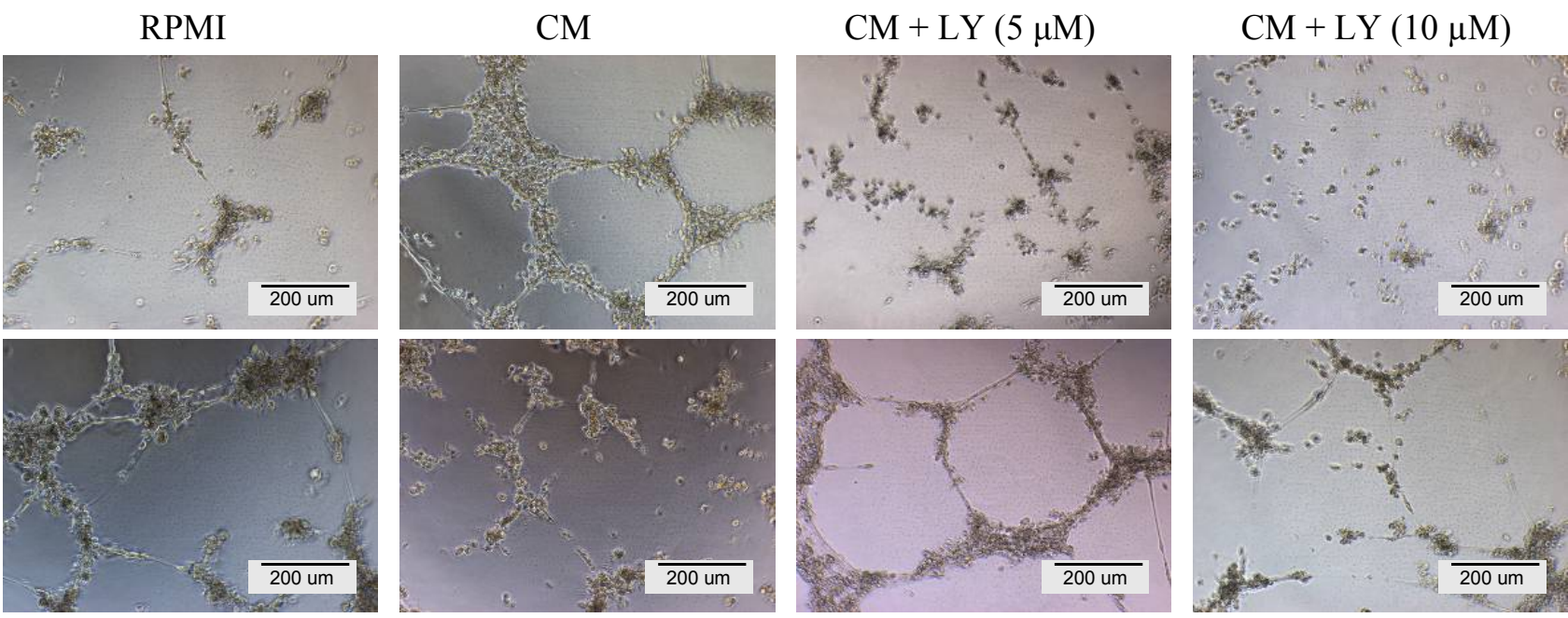

$\mathrm{CM}+\mathrm{Ad}-\mathrm{GFP}$

$\mathrm{CM}+\mathrm{Ad}-\mathrm{PTEN}$

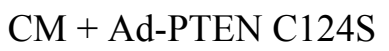

$\mathrm{CM}+\mathrm{Ad}-\mathrm{Akt} \mathrm{DN}$

C

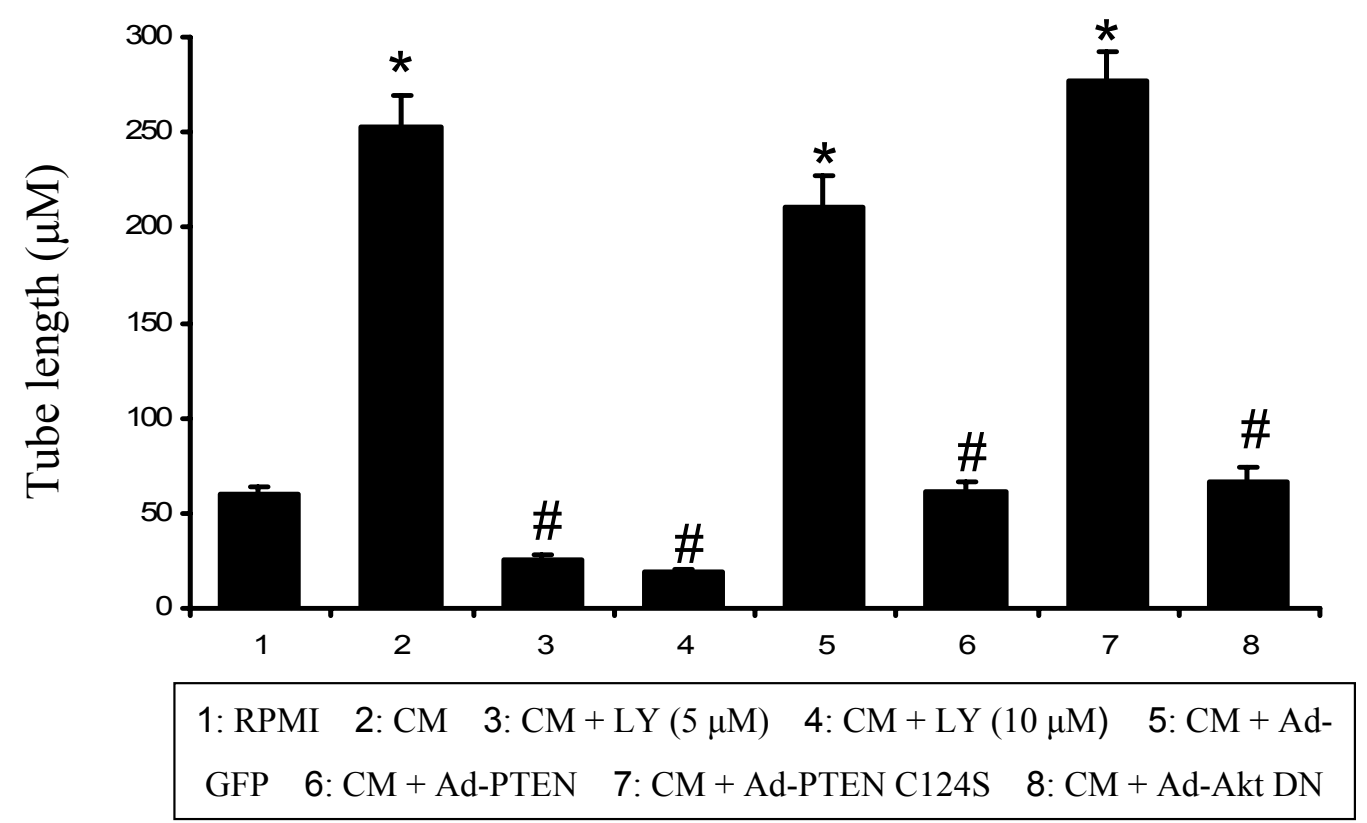


Fig. 1.

D
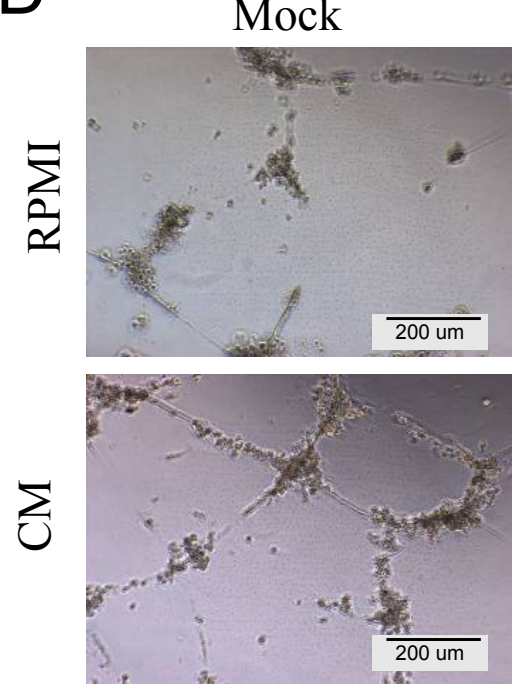

Ad-GFP
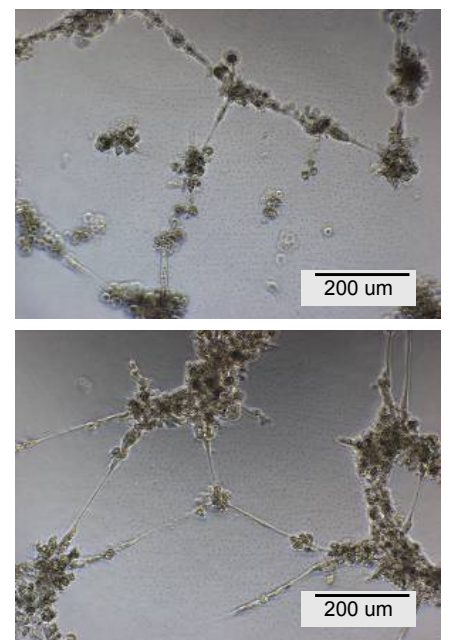

Ad-P110
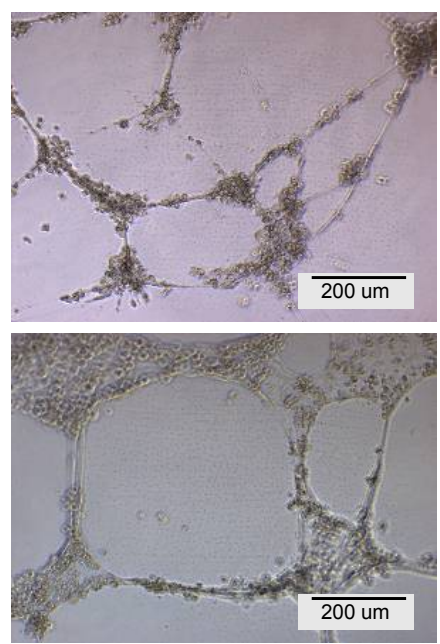

Ad-mAkt
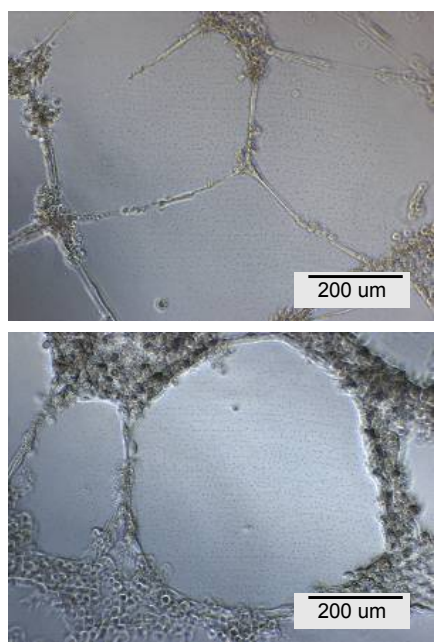

E

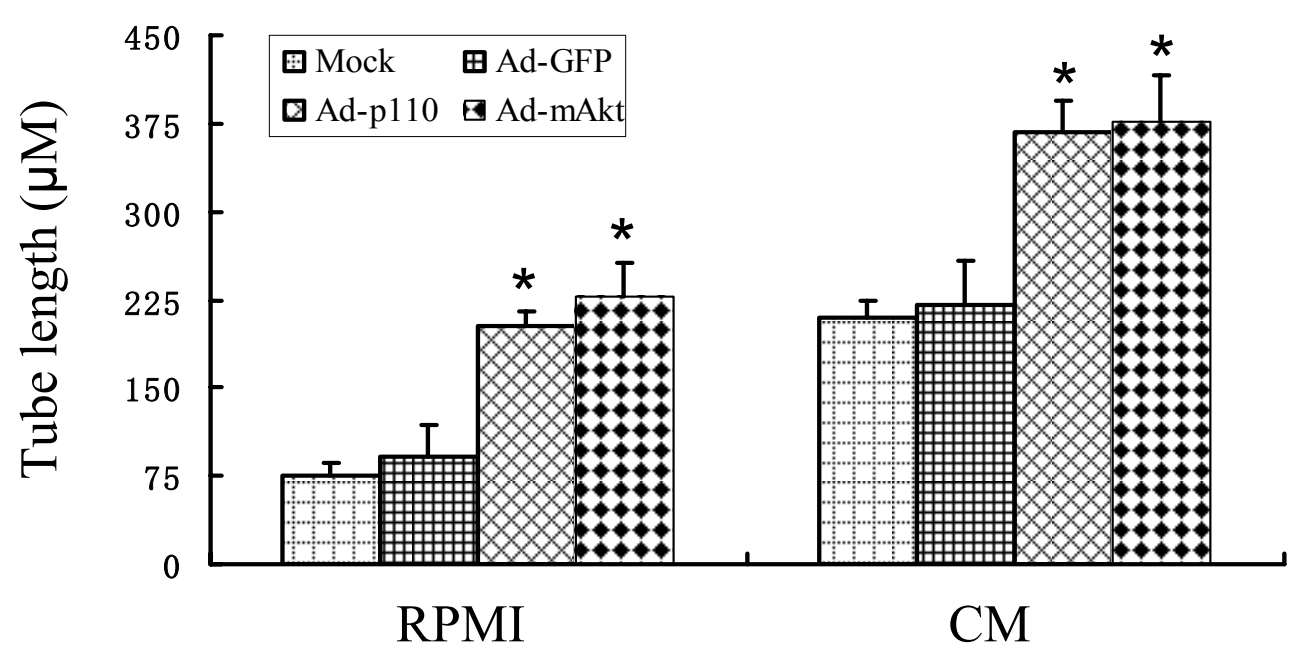

F
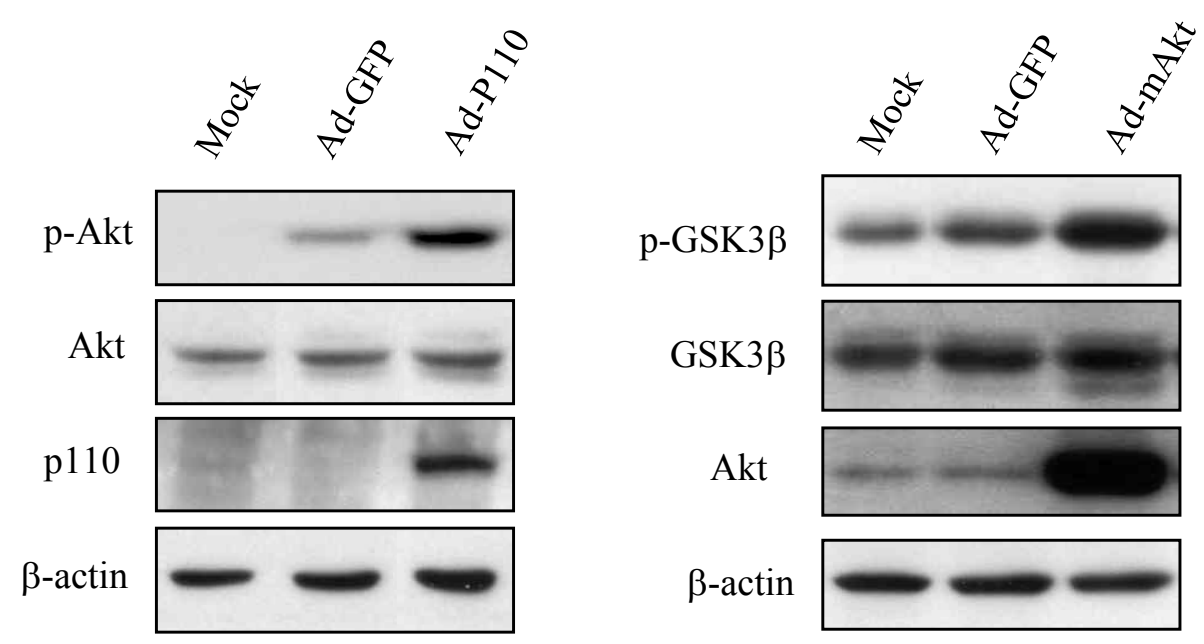
Fig. 1. PI3K/Akt signaling in human microvascular endothelial cells (HMVEC) is critical for tumor conditioned medium-induced endothelial cell tube formation. A: conditioned medium (CM) from A2780 cell culture activates PI3K/Akt signaling in HMVEC. A2780 CM was added into serum-starved endothelial cells for $30 \mathrm{~min}$, which were pretreated or not with PI3K specific inhibitor LY94002 for $1 \mathrm{~h}$. Cell lysates were subjected to immunoblotting analysis using antibodies against phospho-Akt, total Akt, or $\beta$-actin, respectively. B: PI3K and Akt are required for A2780 CM-induced endothelial tube formation. HMVEC cells were either uninfected (mock) or infected with Ad-GFP, Ad-PTEN, Ad-PTEN C/S, or Ad-Akt DN for $24 \mathrm{~h}$. The cells were then serum-starved, and then incubated in the absence or presence of LY94002 for 30 min. Tube formation assay was performed on growth factor-reduced Matrigel in the presence or absence of A2780 conditioned medium. Shown are representative tube-like structures photographed $24 \mathrm{~h}$ after the assay under a phase contrast microscope. C: quantification of tube length from the experiments described in Fig 1B. (*indicates significant difference when compared to RPMI-treated control, $\mathrm{p}<0.01$; \#indicates significant difference when compared to CM-treated control, $\mathrm{p}<0.01)$. D: expression of active forms of PI3K or Akt enhances tumorinduced angiogenesis in vitro. HMVEC cells were either uninfected (mock) or infected with AdGFP, Ad-p110, or Ad-mAkt (active Akt) for $24 \mathrm{~h}$. The cells were then serum-starved, and tube formation assay was performed and the tube structures were photographed as described above. E: summary of tube length from the experiments described in Fig 1D. (*indicates significant difference when compared to Mock and Ad-GFP groups, $\mathrm{p}<0.05)$. F: Left panel, HMVEC were either uninfected (Mock) or infected with Ad-GFP or Ad-p110 for $24 \mathrm{~h}$. The cells were serum starved overnight, cell lysates were subjected to immunobloting analysis using antibodies against phospho-Akt, total Akt, p110, and $\beta$-actin, respectively. Right panel, cell lysates from mock- 
infected endothelial cells or cells infected with Ad-GFP or Ad-mAkt were analysed by immunobloting using antibodies against phospho-GSK3 $\beta$, total GSK3 $\beta$, total Akt, or $\beta$-actin, respectively. 
Fig. 2

A

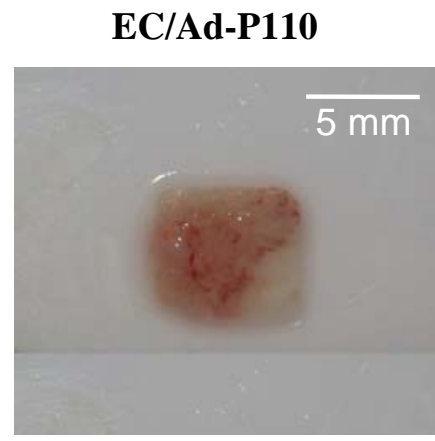

$5 \mathrm{~mm}$

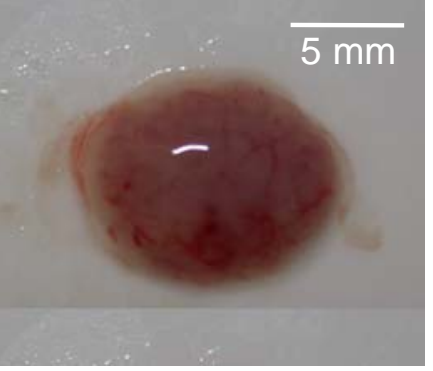

A2780+EC/Ad-GFP
A2780
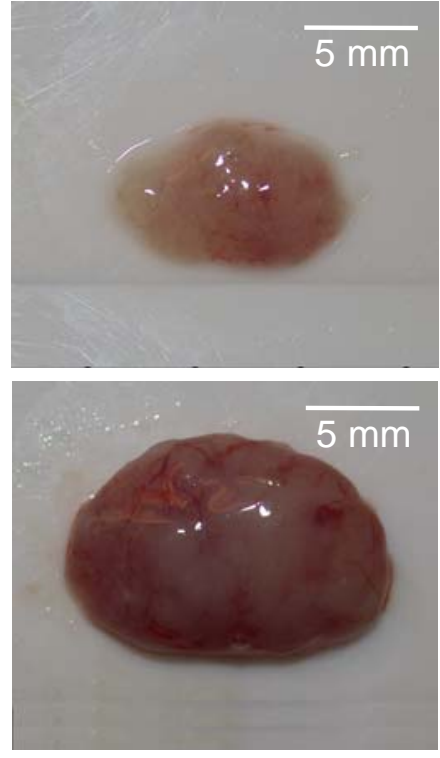

A2780+EC/Ad-P110
A2780+EC

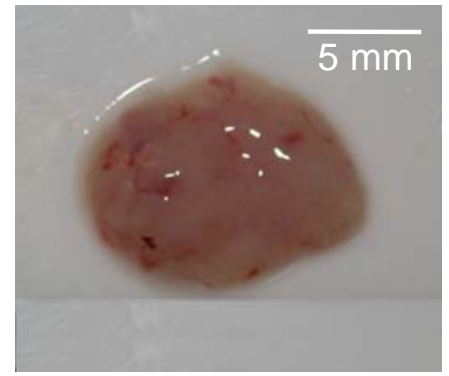

$5 \mathrm{~mm}$

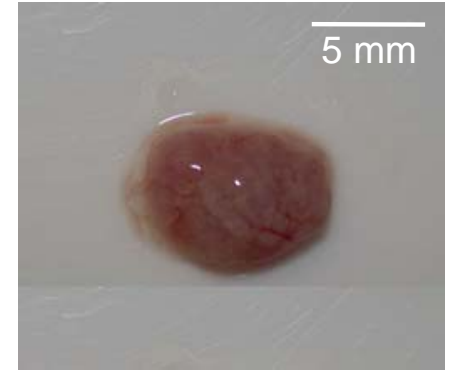

A2780+EC/Ad-PTEN

B

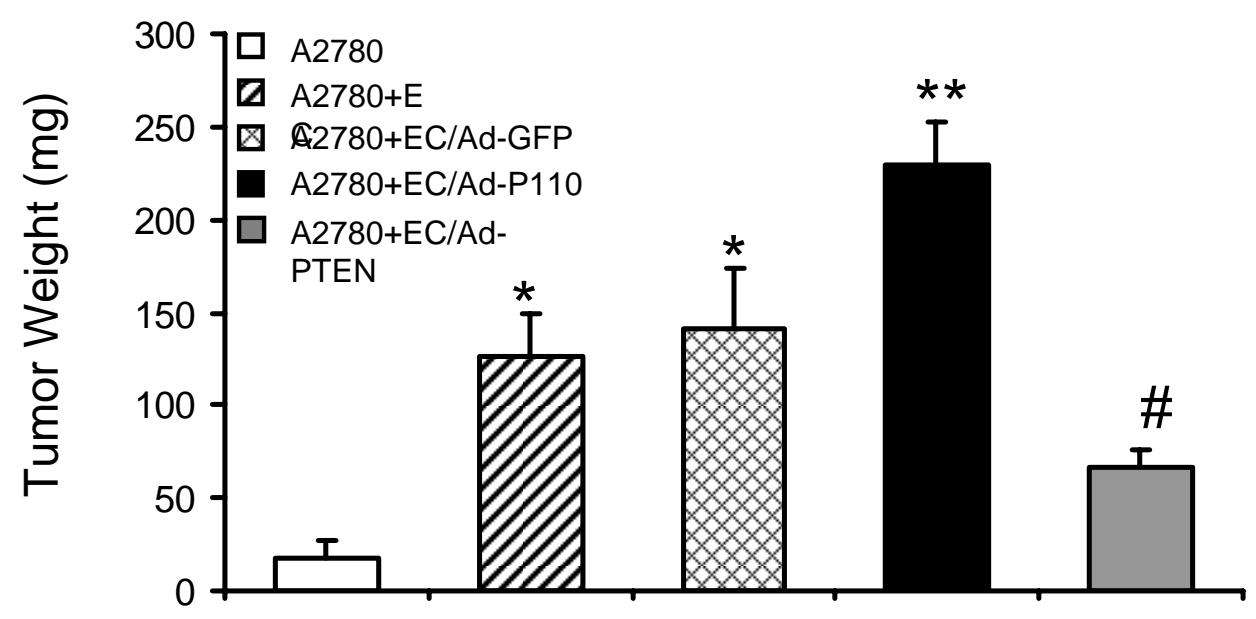

C

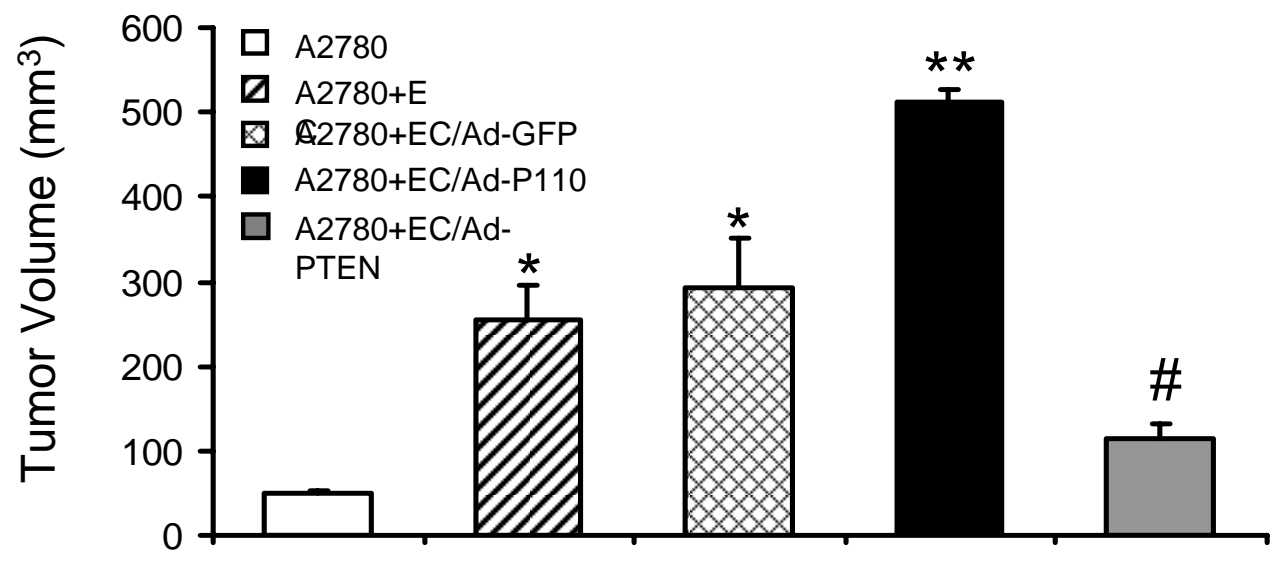


Fig. 2
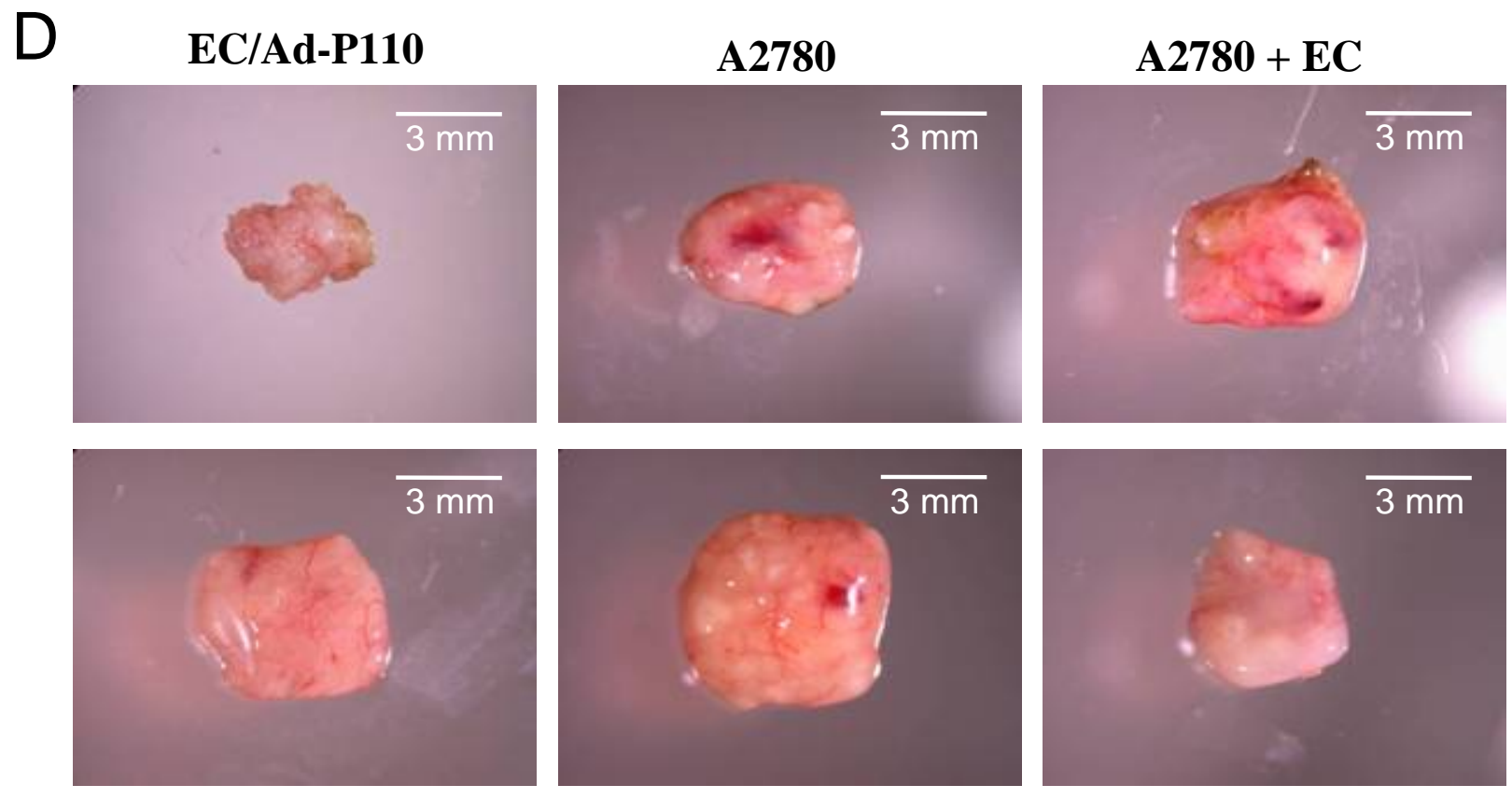

A2780 + EC/Ad-GFP A2780 + EC/Ad-P110 A2780 + EC/Ad-PTEN

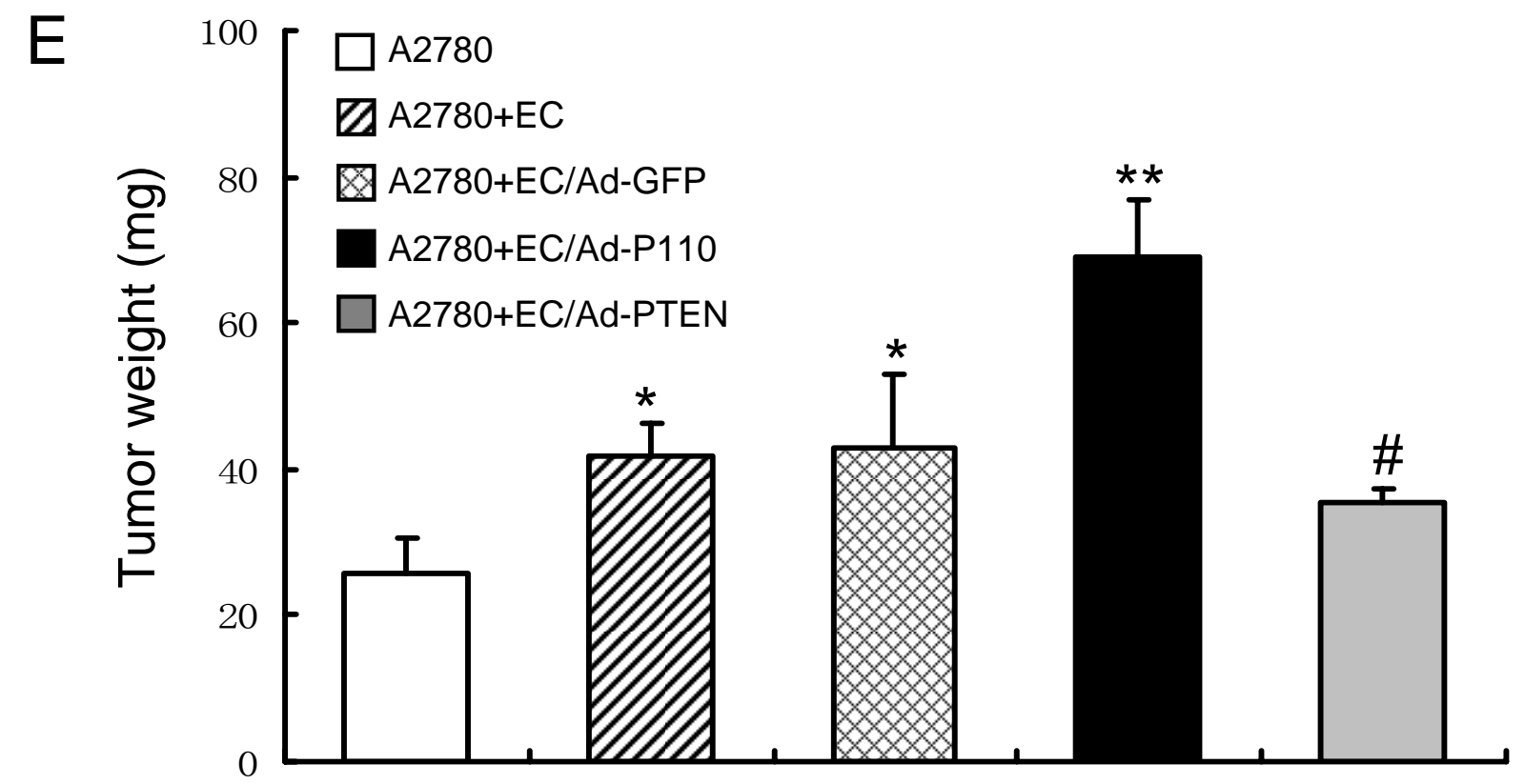


Fig. 2.

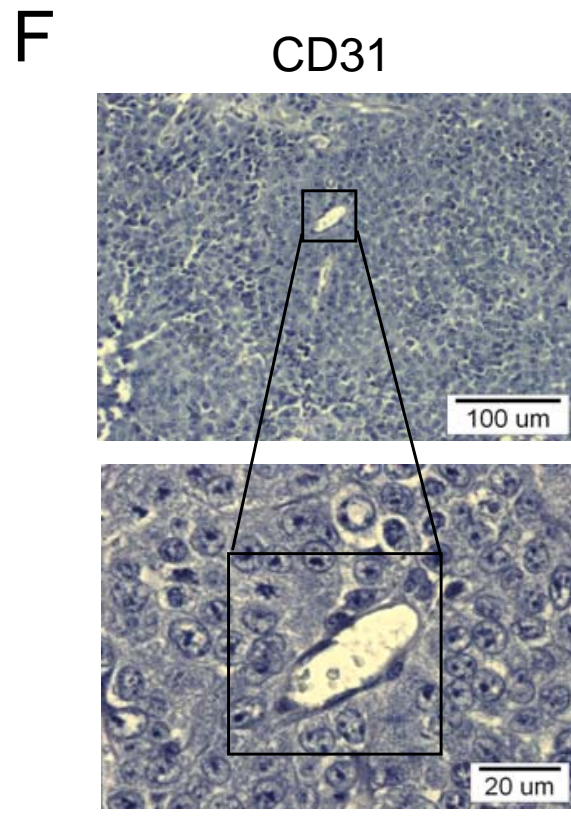

A2780

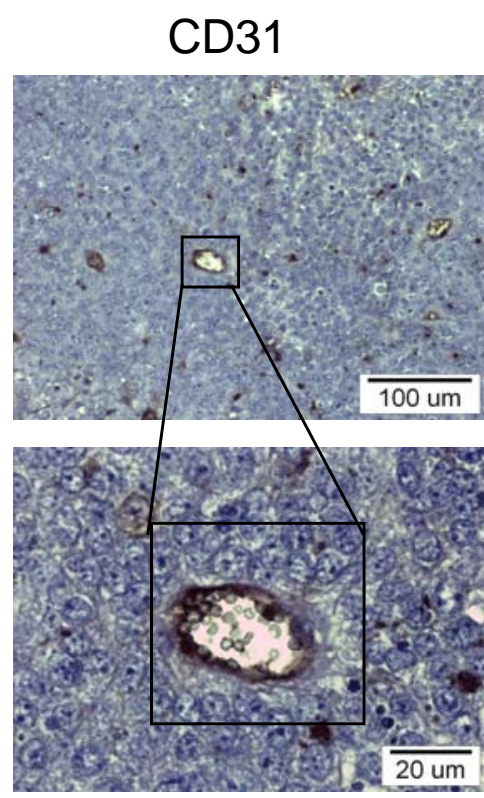

A2780+EC

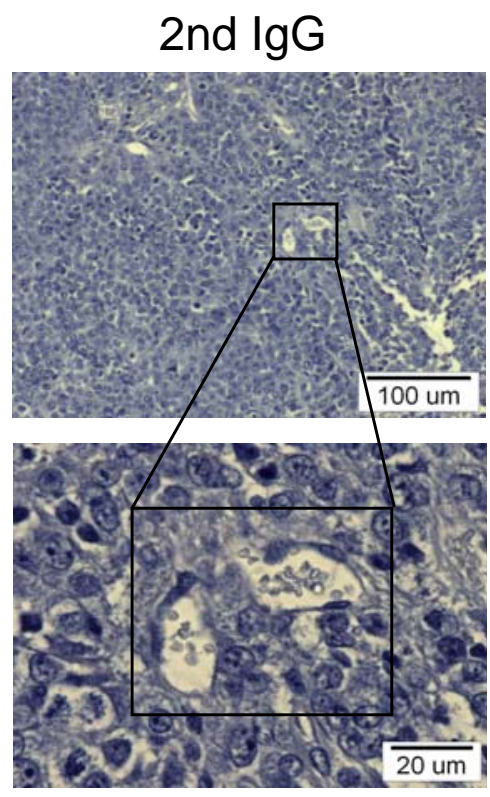

A2780+EC
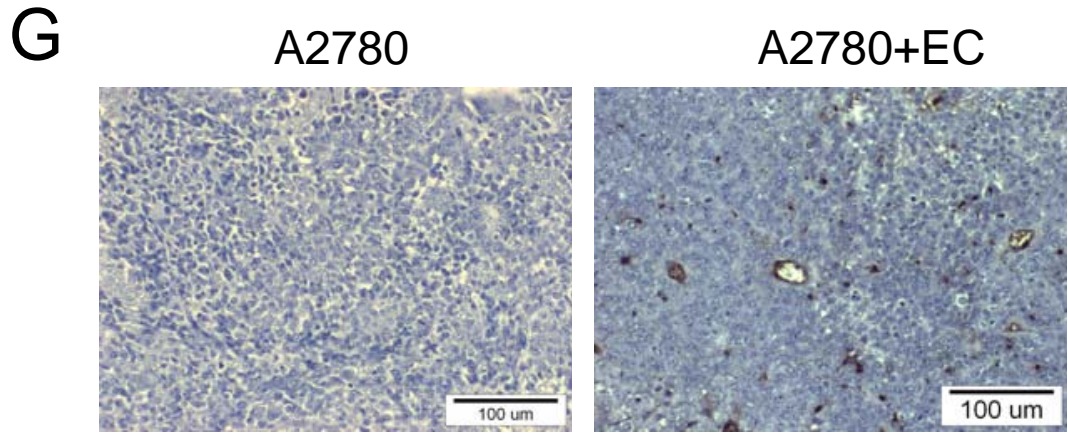

A2780+EC/GFP

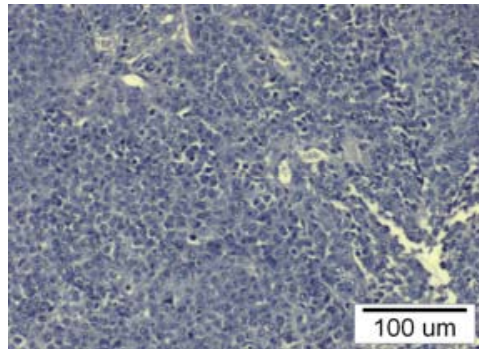

Negative control

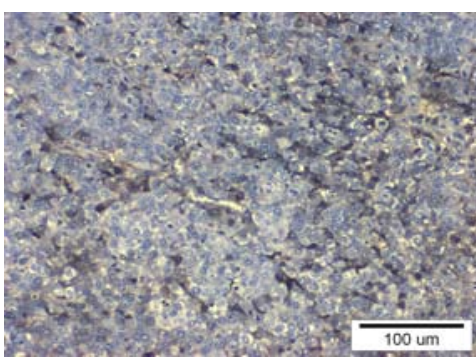

A2780+EC/p110
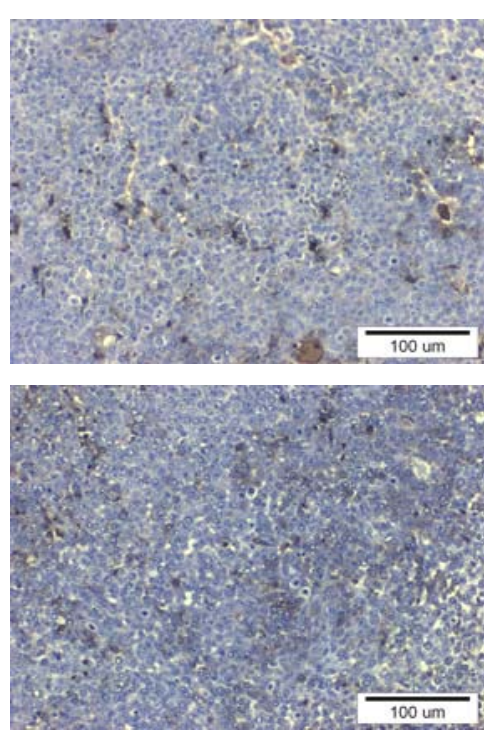

A2780+EC/PTEN 
Fig. 2.

$\mathrm{H}$

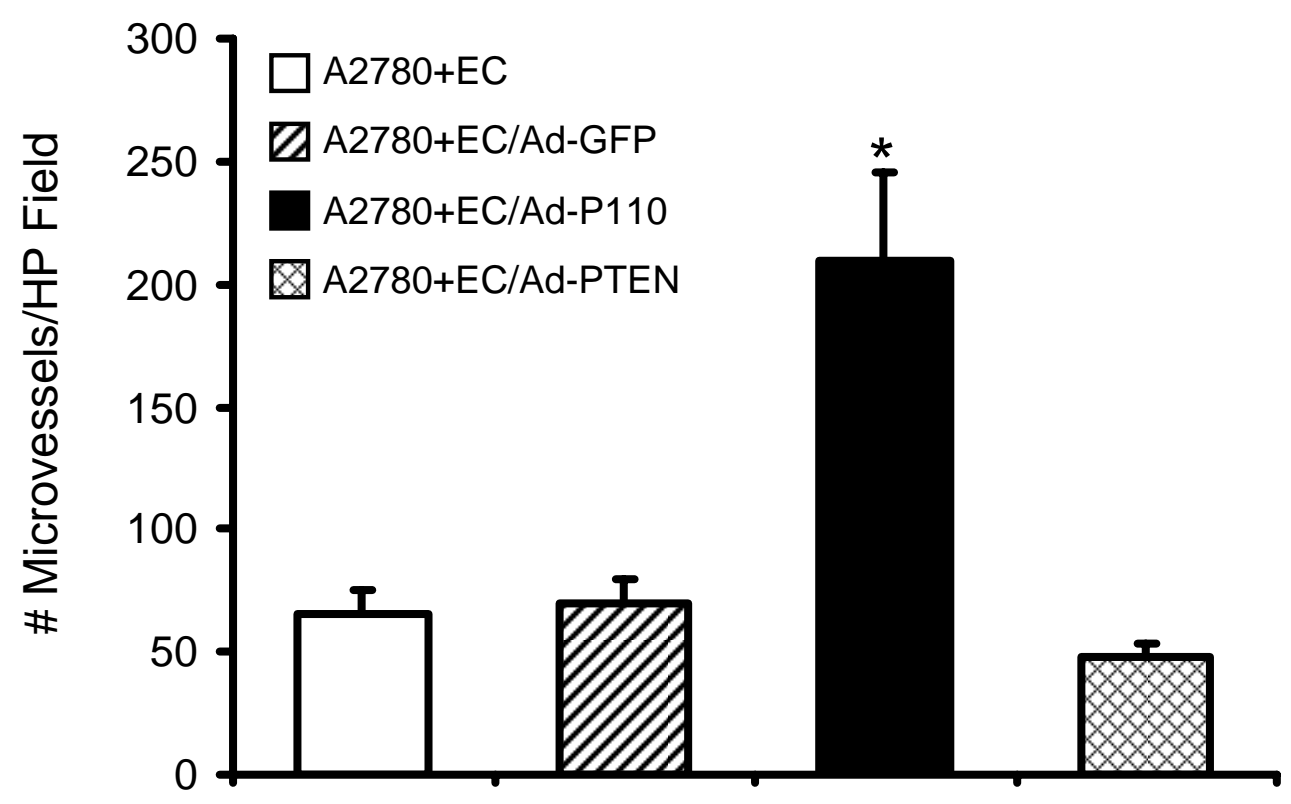

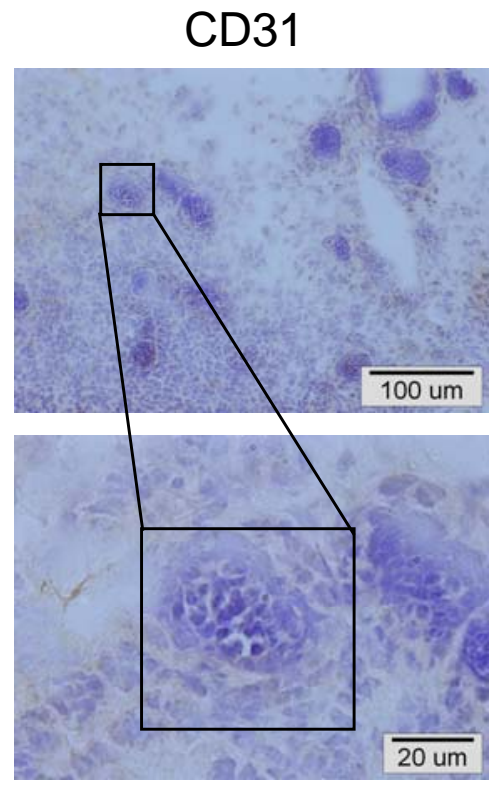

A2780
CD31

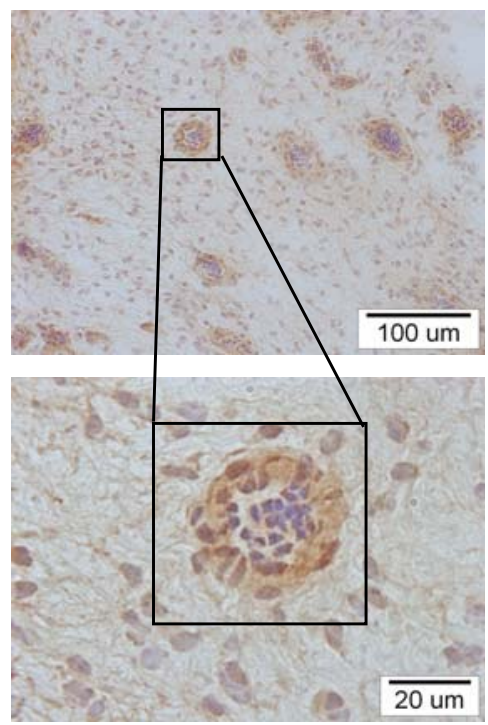

A2780+EC 2nd IgG

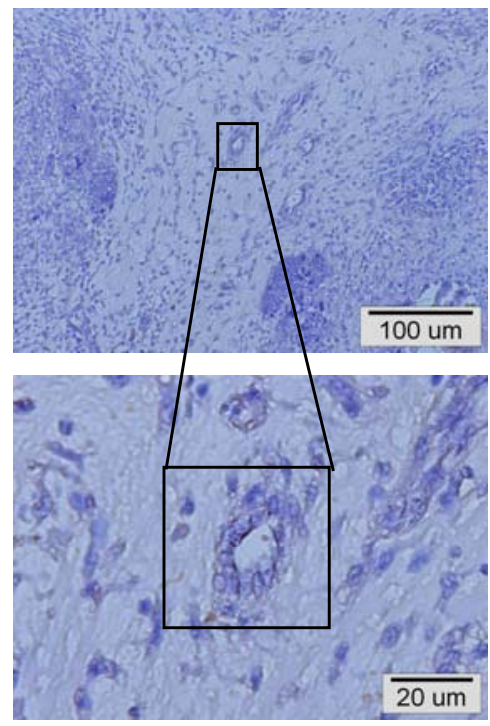

A2780+EC 
Fig. 2.

J

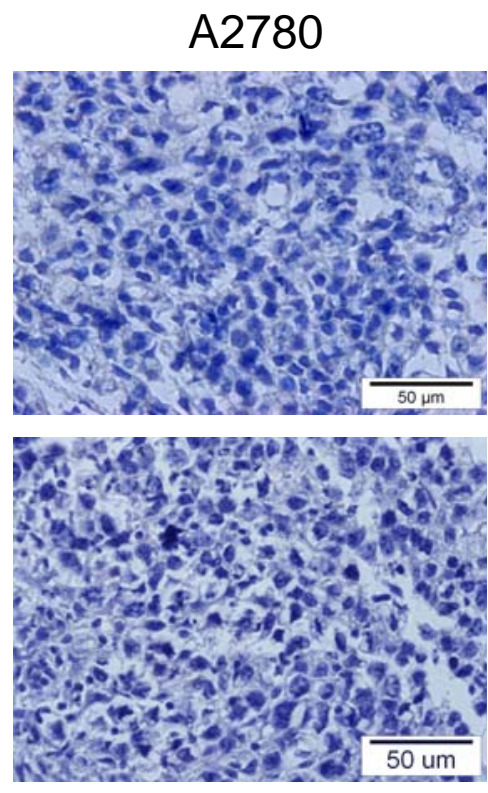

Negative control
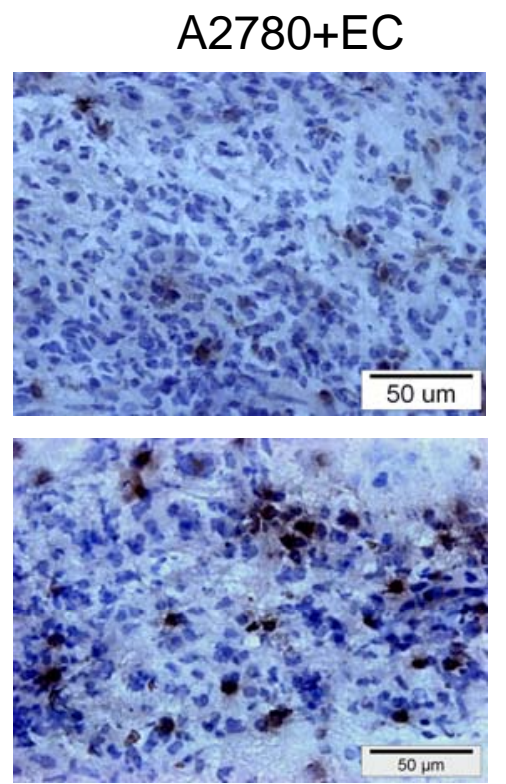

A2780+EC/p110
A2780+EC/GFP
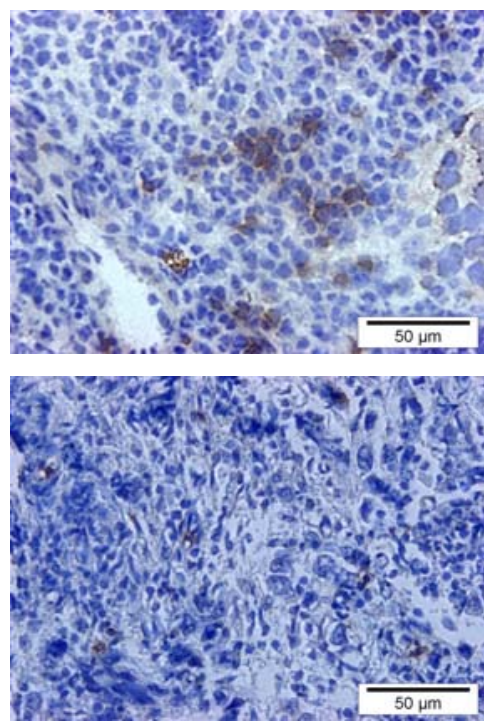

A2780+EC/PTEN

K

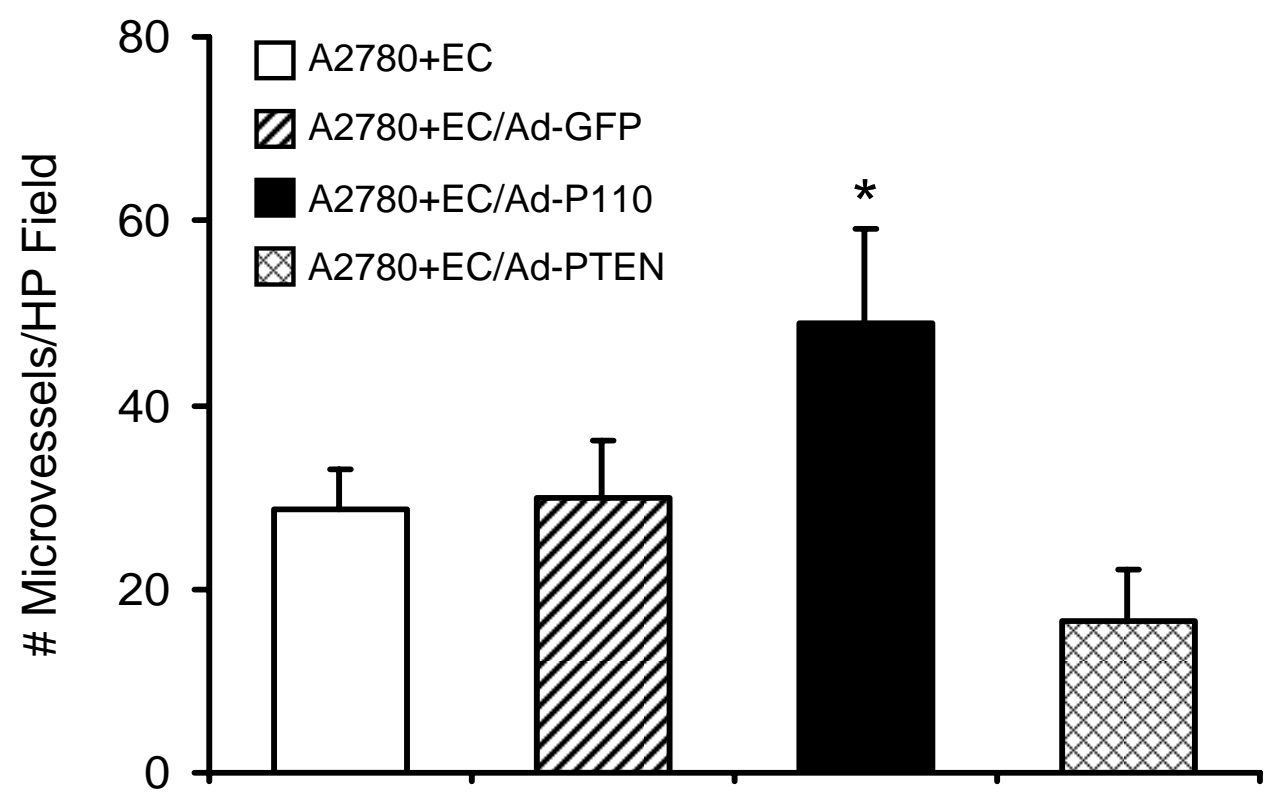




\section{Fig. 2.}

Fig. 2. PI3K activity in human endothelial cells is important for tumor growth and tumor angiogenesis in vivo. A: Results generated from nude mice tumor model. Shown are macroscopic views of representative tumors. A2780 ovarian cancer cells $\left(0.1 \times 10^{6}\right)$ were mixed with $0.9 \times 10^{6}$ HMVECs uninfected or infected with Ad-GFP, Ad-p110 or Ad-PTEN. The cell mixture was absorbed into PLGA sponges and implanted subcutaneously into nude mice. Mice were euthanized 21 days after transplantation, and the implants were retrieved and photographed. B: Summary of tumor weight from the experiments described in Fig 2A. Tumor weight was measured by an electronic balance. Data represent mean values \pm SE from 4 replicates. C: Summary of tumor volume from the experiments described in Fig 2A. The three dimensions of tumors were measured with a caliper and tumor volume was calculated by the formula: length $\times$ width $\times$ depth. Data represent mean values \pm SE from 4 replicates. (*indicates significant difference when compared to A2780 group, $\mathrm{p}<0.05$; ** indicates significant difference when compared to A2780 + EC group, $\mathrm{p}<0.05$; \#indicates significant difference when compared to A2780 + EC and A2780 + EC/Ad-GFP groups, p<0.05 compared with). D: Results generated from the chicken chorioallantoic membrane (CAM) model. Shown are macroscopic views of representative tumors from the CAM model. A2780 and HMVEC cell mixtures as described above were absorbed into PLGA sponges, and implanted onto the CAM of day 8 chicken embryos. Tumors were removed from the CAM 12 days after implantation, and photographed under an anatomical microscope. E: Summary of tumor weight from the experiments described in Fig 2D. Tumor weight was measured by an electronic balance. Data represent mean values \pm SE from 5 replicates. (*indicates significant difference when compared to A2780 group, p < 0.05;

\footnotetext{
**indicates significant difference when compared to A2780 + EC group, p < 0.05; \#indicates
} 
significant difference when compared to A2780 + EC and A2780 + EC/Ad-GFP groups, p<0.05). F-K: Modulation of PI3K activity in human endothelial cells affects tumor induced-angiogenesis. F: Implanted human endothelial cells form functional blood vessels inside the tumors generated in the nude mouse model. Tumor sections at $5 \mu \mathrm{M}$ were stained using a monoclonal anti-human CD31 antibody to visualize the microvessels inside the tumors. $2^{\text {nd }}$ IgG: negative control. G: Representative CD31 staining (brown color) of tissue sections of tumors generated in the nude mouse model. Original magnification of the microphotographs: 200×. H: Quantitation of CD31positive microvessels within tumor tissues generated in the nude mouse model. Data represent the mean number of microvessels obtained from five 200× field (mean \pm SE). (*indicates significant difference when compared to A2780+EC and A2780+EC/Ad-GFP groups, $\mathrm{p}<0.05$ ). I: Implanted human endothelial cells form functional blood vessels inside the tumors generated in the CAM model. Microvessels inside the tumors were visualized by immunohistochemical staining using a monoclonal anti-human CD31 antibody. $2^{\text {nd }}$ IgG: negative control. J: CD31 staining (brown color) of tissue sections of tumors generated from the CAM model. Original magnification of the microphotographs: 400×. K: Quantitation of CD31-positive microvessels within tumor tissues generated from the CAM model. Data represent the mean number of microvessels obtained from five $400 \times$ field (mean \pm SE). (*indicates significant difference when compared to A2780+EC and A2780+EC/Ad-GFP groups, $\mathrm{p}<0.05)$. 
Fig. 3

A
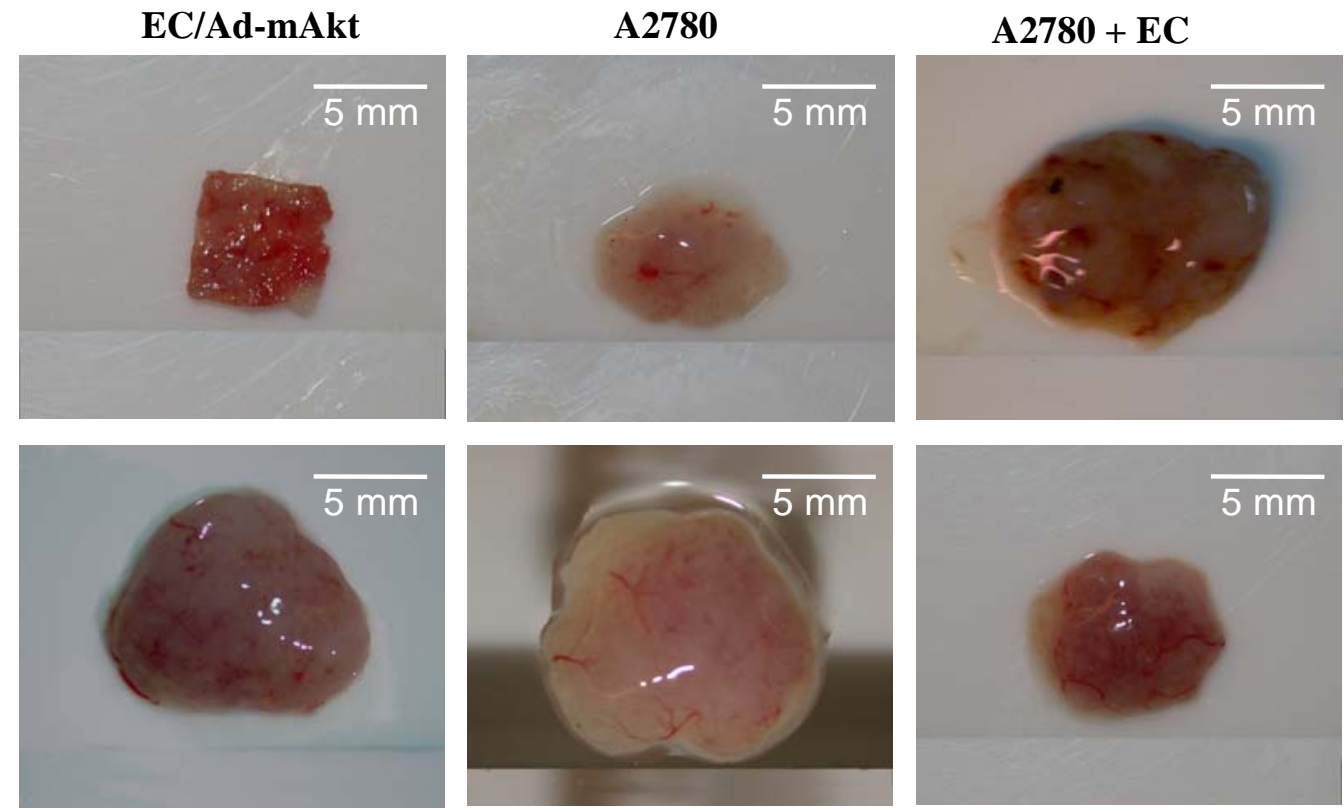

A2780 + EC/Ad-GFP

A2780 + EC/Ad-mAkt

A2780 + EC/Ad-Akt-DN

B

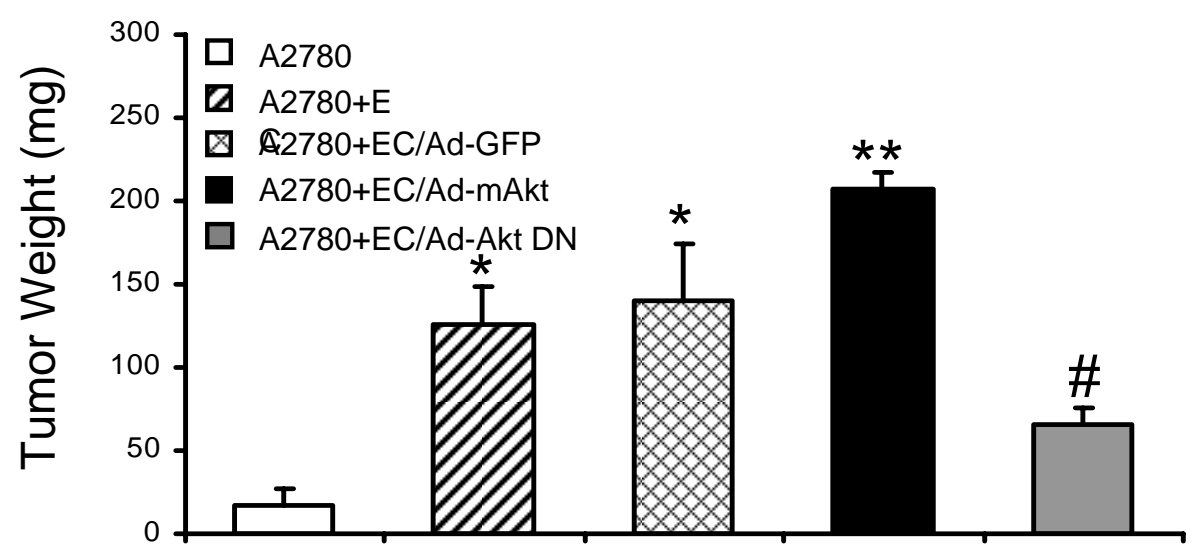

C

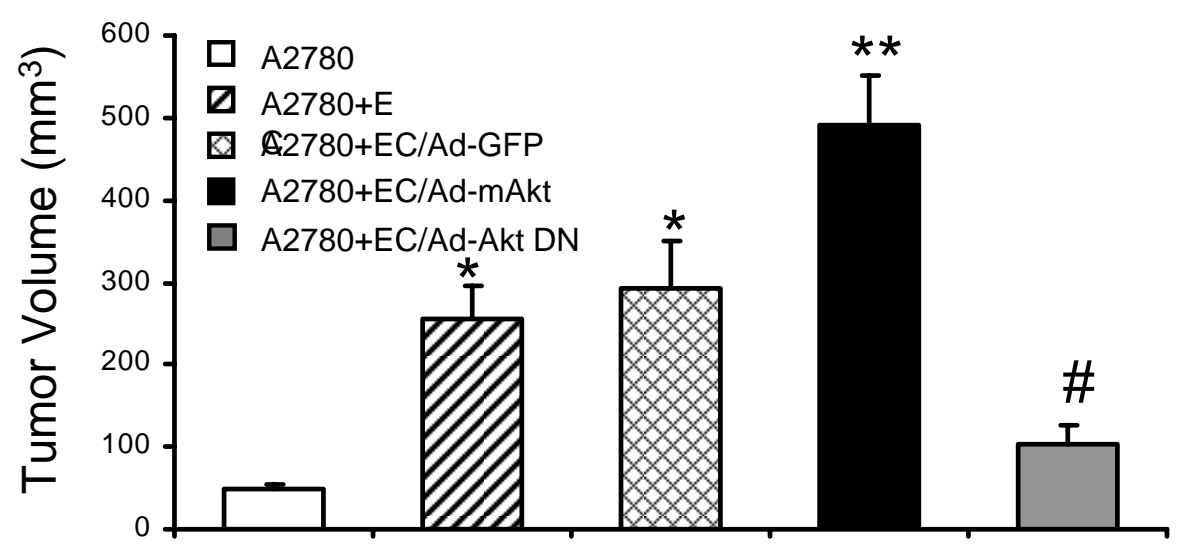


Fig. 3

D
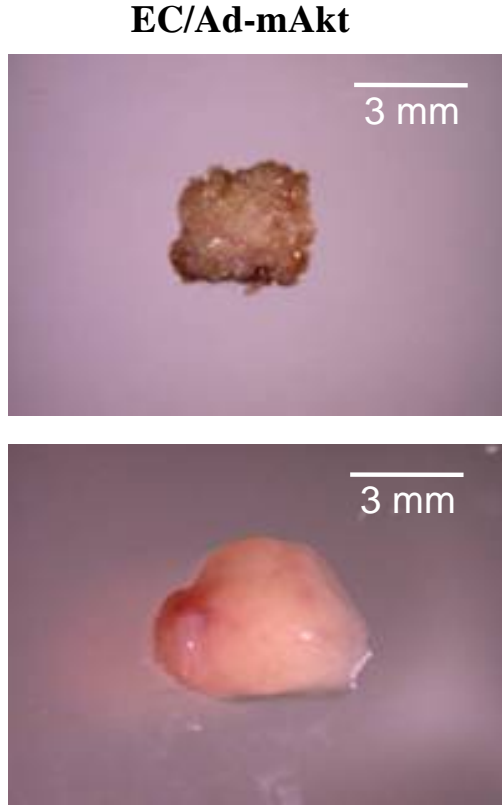

A2780 + EC/Ad-GFP
A2780
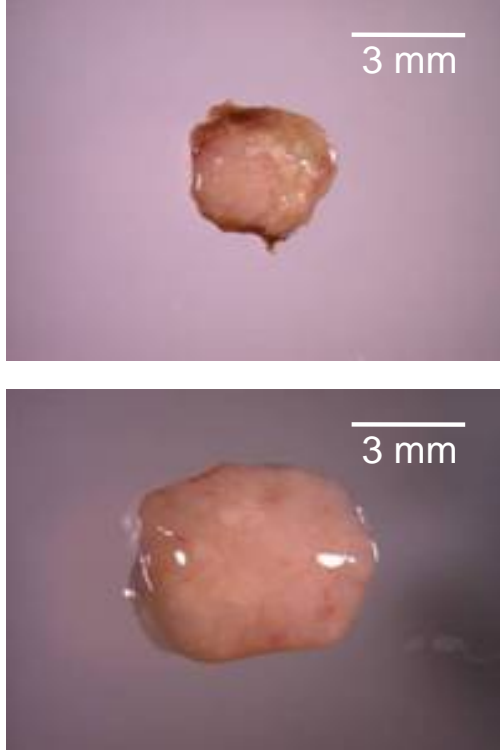

A2780 + EC/Ad-mAkt
A2780 + EC

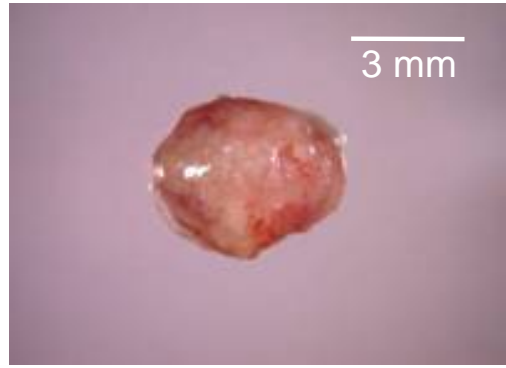

$\overline{3 \mathrm{~mm}}$

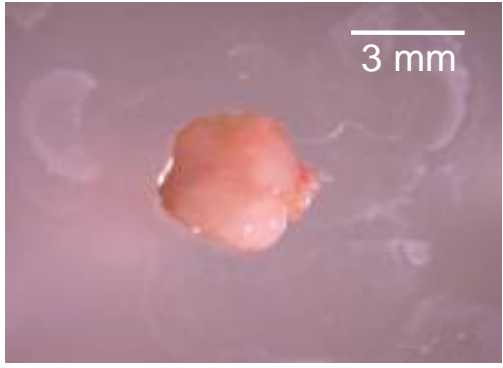

A2780 + EC/Ad-Akt-DN

E

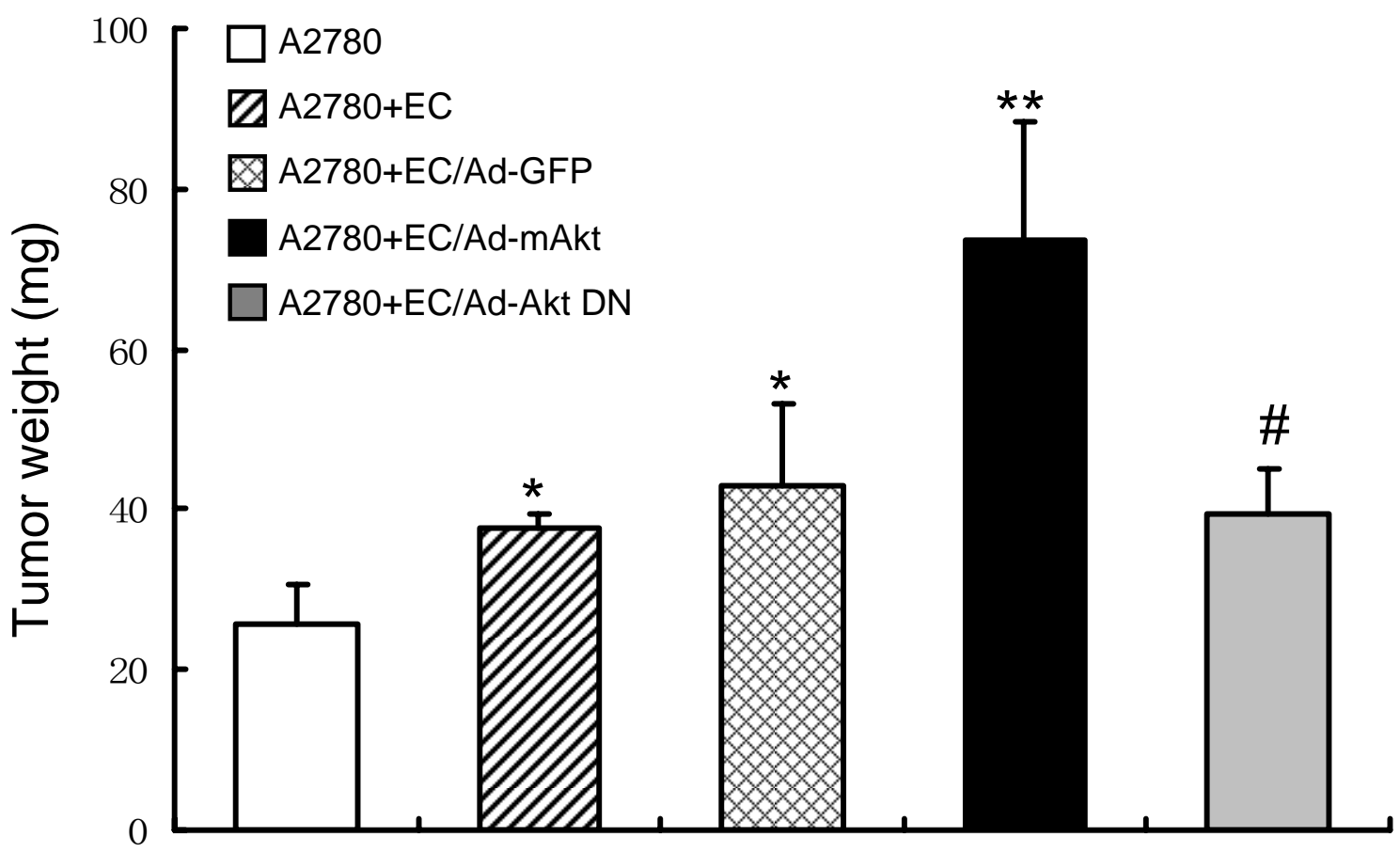


Fig. 3

F
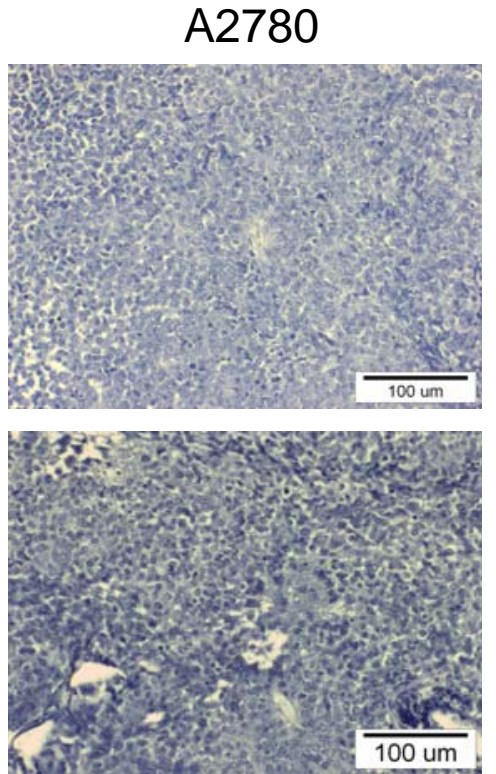

Negative control
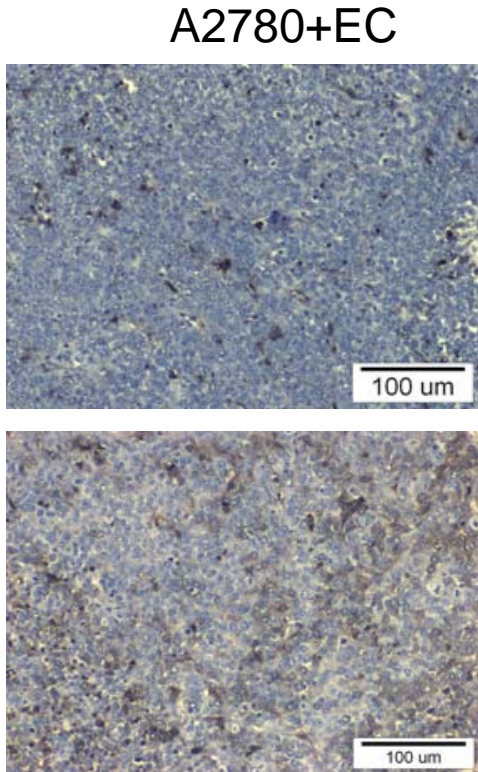

A2780+EC/mAkt
A2780+EC/GFP
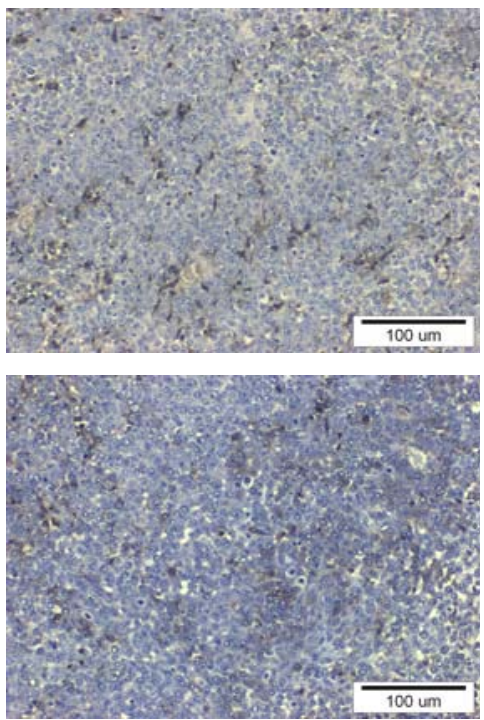

A2780+EC/Akt DN

G

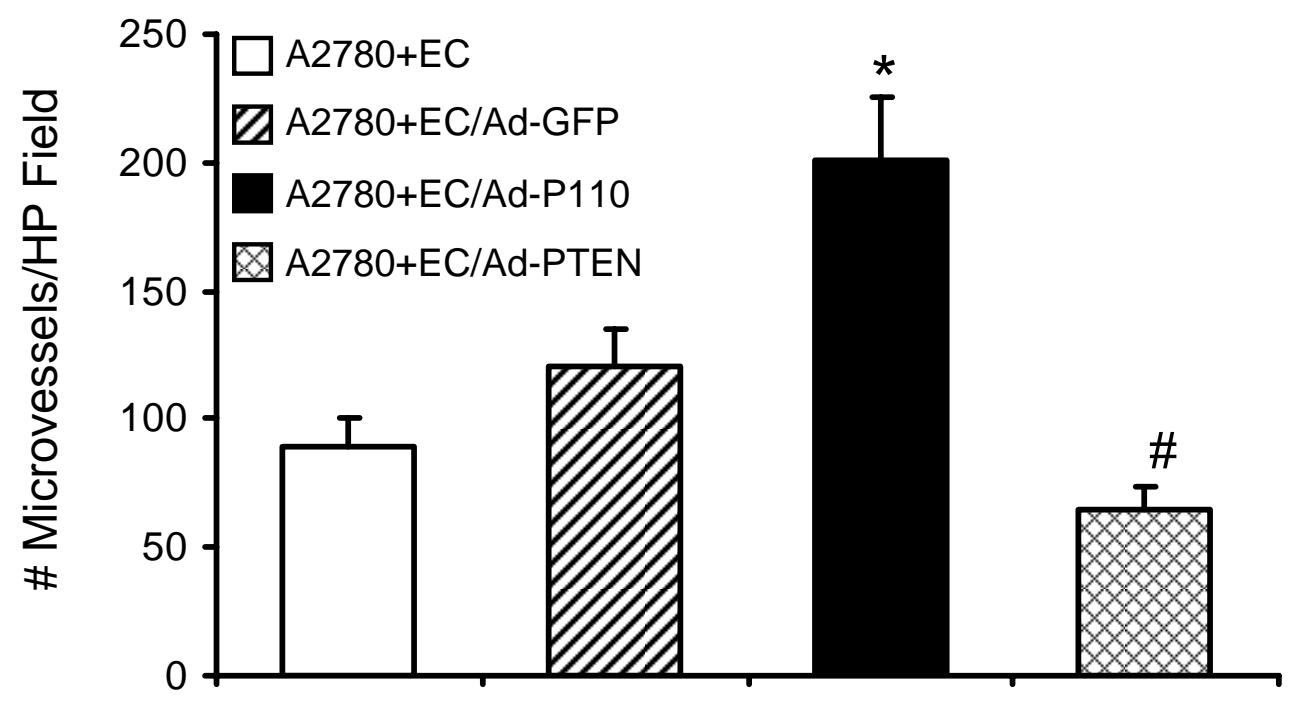


Fig. 3
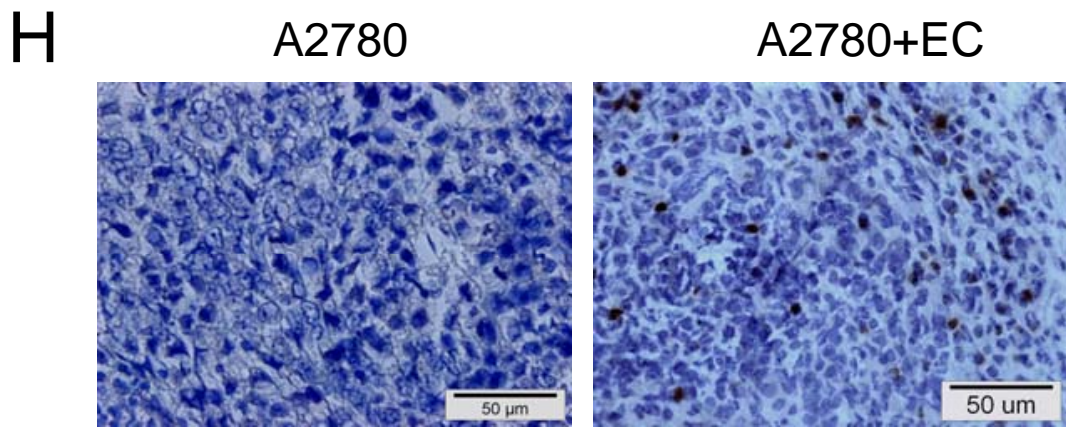

A2780+EC/GFP

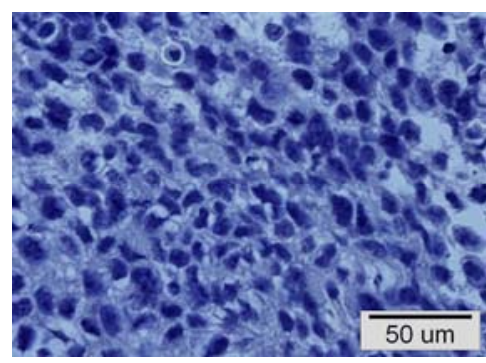

Negative control

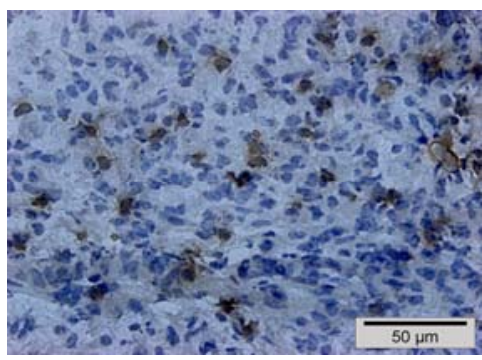

A2780+EC/mAkt
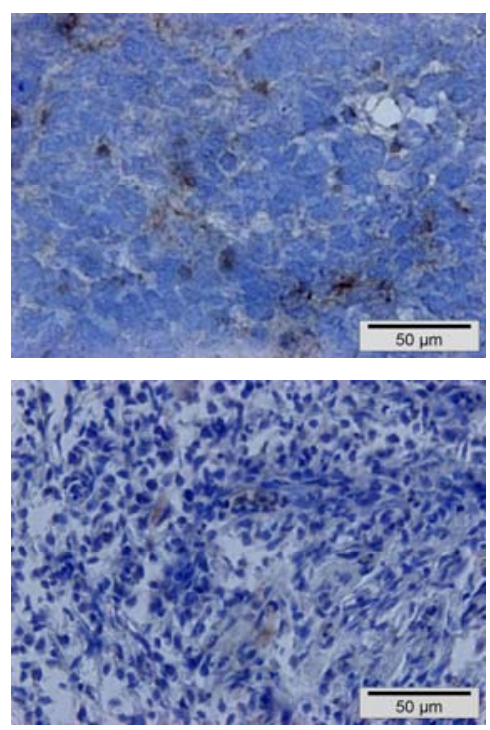

A2780+EC/Akt DN

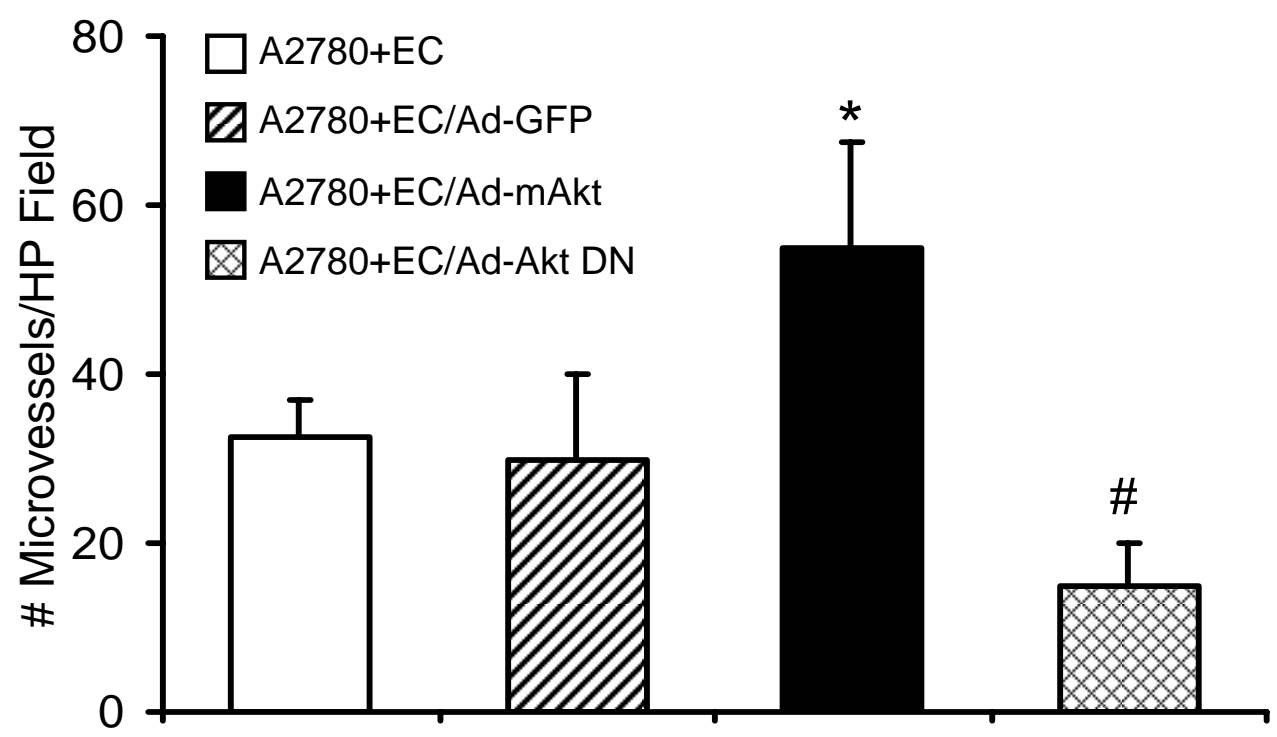


Fig. 3. Modulation of Akt activity in human endothelial cells affects tumor growth and tumor induced-angiogenesis in vivo. A: Macroscopic views of representative tumors generated from nude mouse tumor model. A2780 ovarian cancer cells $\left(0.1 \times 10^{6}\right)$ were mixed with $0.9 \times 10^{6}$ HMVEC uninfected or infected with Ad-GFP, Ad-mAkt or Ad-Akt DN. The cell mixture was absorbed into PLGA sponges, and implanted subcutaneously into nude mice. Mice were euthanized21 days after transplantation, and the implants were retrieved and photographed. B: Summary of tumor weight from the experiments described in Fig 3A. Data represent mean values \pm SE from 4 replicates. C: Summary of tumor volume from the experiments described in Fig 3A. Data represent mean values \pm SE from 4 replicates. (*indicates significant difference when compared to A2780 group, $\mathrm{p}<0.05$; **indicates significant difference when compared to A2780 + EC group, $\mathrm{p}<0.05$; \# indicates significant difference when compared to A2780 + EC and A2780 + EC/Ad-GFP groups, $\mathrm{p}<0.05)$. D: Macroscopic view of representative tumors generated from the CAM tumor model. The A2780 and HMVEC cell mixtures as describes above were absorbed into PLGA sponges, and implanted onto the CAM of day 8 chicken embryos. Tumors were removed from the CAM12 days after implantation, and photographed under an anatomical microscope. E: Summary of tumor weight from the experiments described in Fig 3D. Data represent mean values \pm SE from 6 replicates. (*indicates significant difference when compared to A2780 group, $\mathrm{p}<0.05 ; * *$ indicates significant difference when compared to A2780+EC and A2780+EC/Ad-GFP groups, $\mathrm{p}<0.05$; \#indicates significant difference when compared to A2780+EC/Ad-p110 group, p<0.05). F: Modulation of Akt activity in human endothelial cells affects tumor induced-angiogenesis in the nude mice model. Shown are representative CD31 staining (brown color) of tissue sections of tumors from nude mice. Original magnification of the microphotographs: 200×. G: Quantification of CD31-positive 
microvessels within tumor tissues from the nude mice model. Data represent the mean number of microvessels obtained from five $200 \times$ field (mean \pm SE). (*indicates significant difference when compared to A2780+EC and A2780+EC/Ad-GFP groups, $\mathrm{p}<0.05$; \#indicates significant difference when compared to A2780 + EC/Ad-p110 group, p<0.05). H: Modulation of Akt activity in human endothelial cells affects tumor induced-angiogenesis in the CAM model. Shown are representative CD31 staining (brown color) of tissue sections of the tumors. Original magnification of the microphotographs: 400×. I: Quantification of CD31-positive microvessels within tumor tissues generated in the CAM model. Data represent the mean number of microvessels obtained from five $400 \times$ field (mean \pm SE). $(*$ indicates significant difference when compared to A2780+EC and A2780+EC/Ad-GFP groups, $\mathrm{p}<0.05$; \#indicates significant difference when compared to A2780 + EC/Ad-mAkt group, $\mathrm{p}<0.05)$. 
Fig. 4.

A
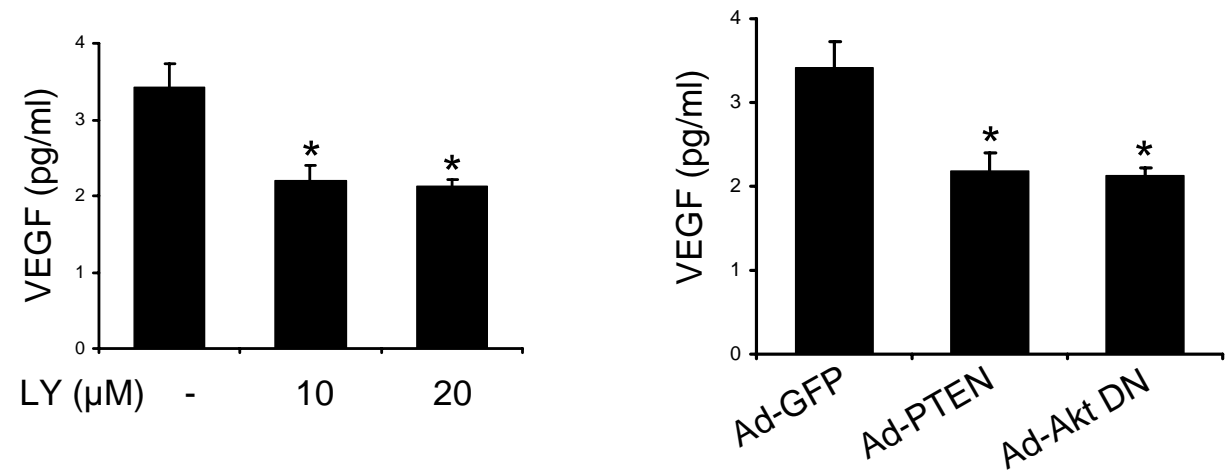

B
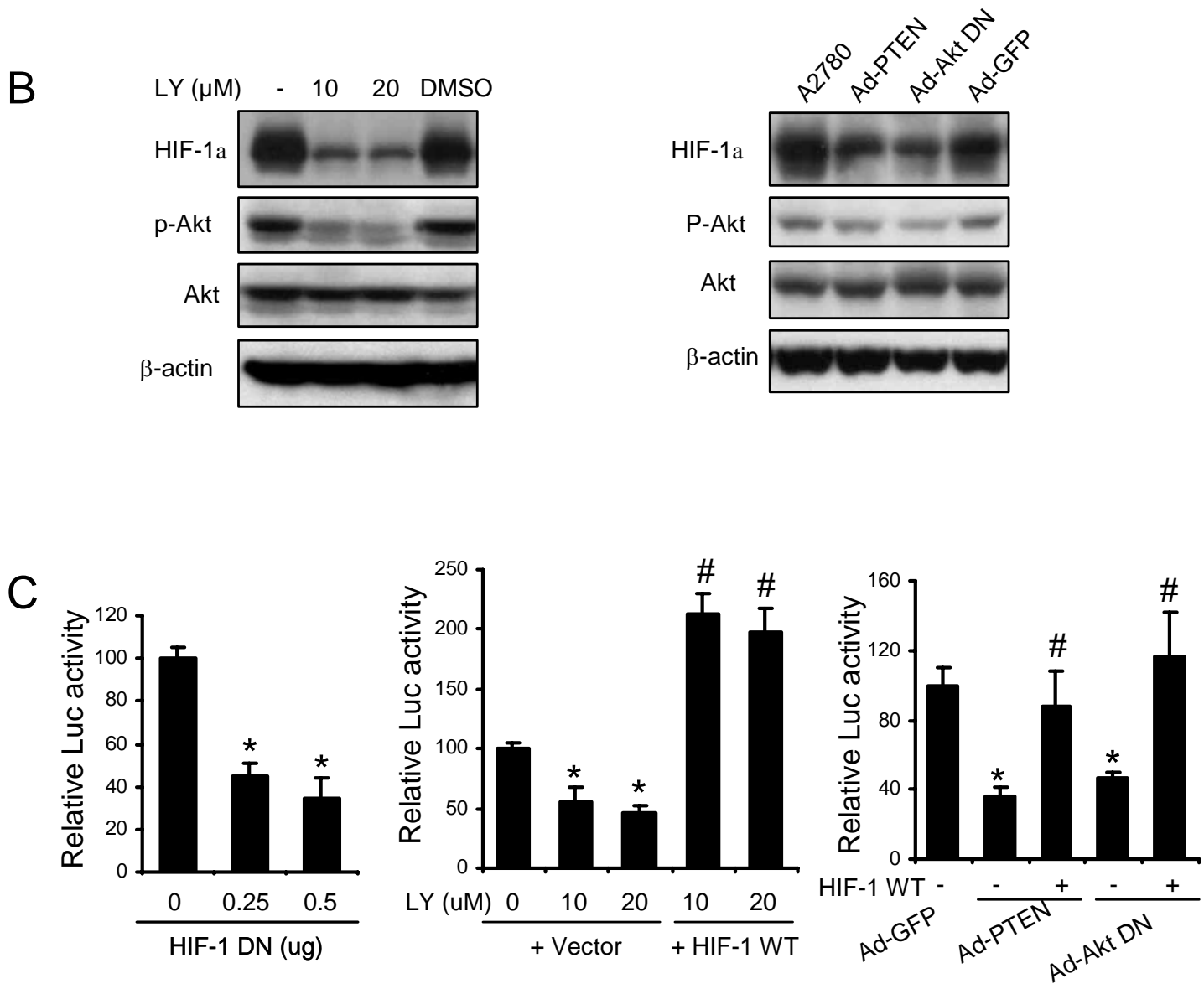
Fig. 4.
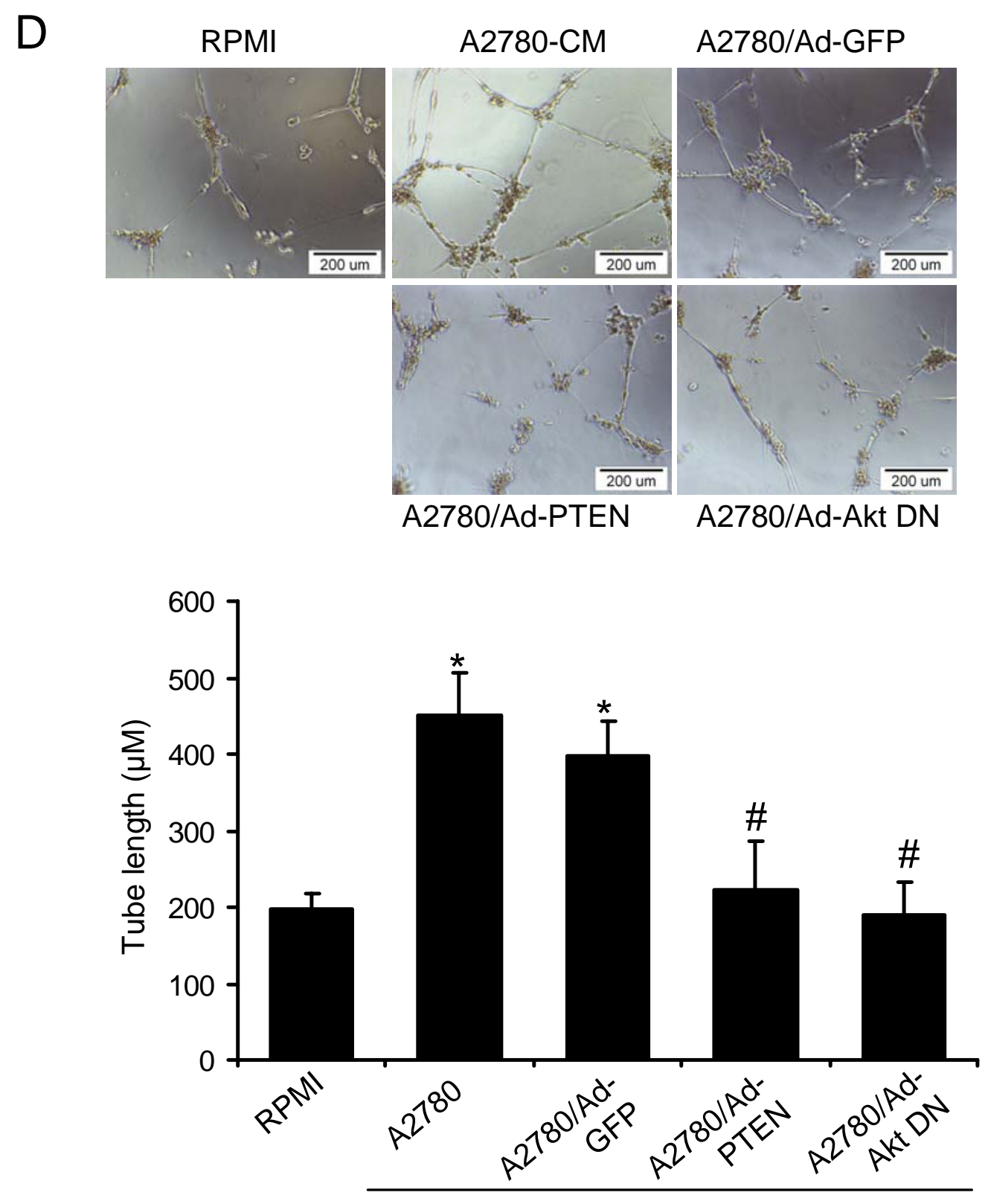

Conditioned medium

Fig. 4. PI3K-Akt signaling regulates VEGF expression through HIF-1 $\alpha$ in human ovarian cancer cells; inhibition of PI3K or Akt activity in the cells inhibits tumor CM-induced EC tube formation. A: Inhibition of PI3K and Akt activity reduces VEGF production by A2780 cells. Left panel, 2780 cells were treated with the indicated doses of LY294002 for 12 h, and 
VEGF levels in the conditioned medium were measured by ELISA. Right panel, A2780 cells infected by Ad-GFP, Ad-PTEN, or Ad-Akt DN have reduced VEGF expression. B: Inhibition of PI3K and Akt activity inhibits HIF-1 $\alpha$ expression. Left panel, A2780 cells were treated with the indicated doses of LY294002 or solvent DMSO for $6 \mathrm{~h}$. Western blotting was performed to detect the levels of HIF-1 $\alpha$, phosphor-Akt, total Akt, and $\beta$-actin, respectively. Right panel, cell lysates were prepared from parental A2780 cells, A2780 cells infected by Ad-GFP, Ad-PTEN, or Ad-Akt DN. Immunoblotting was performed as described above. C: PI3K and Akt activities regulate HIF-1 $\alpha$-mediated transcriptional activation of VEGF. Left panel, A2780 cells were cotransfected with a luciferase reporter construct driven by the full-length promoter of VEGF gene and a plasmid expressing a dominant-negative HIF-1 $\alpha$. Luciferase activity was measured $24 \mathrm{~h}$ after transfection. Middle panel, A2780 cells were co-transfected with the VEGF luciferase reporter construct and a plasmid expressing wild-type HIF-1 $\alpha$. The cells were then treated with LY294002. Luciferase activity was measured $12 \mathrm{~h}$ after the treatment. Right panel, A2780 cells infected by Ad-GFP, Ad-PTEN, or Ad-Akt DN were co-transfected with the VEGF luciferase reporter construct and a plasmid expressing wild-type HIF-1 $\alpha$. Luciferase activity was measured $24 \mathrm{~h}$ after transfection. D: Expression of PTEN and dominant-negative Akt in A2780 cells inhibited tumor CM-induced endothelial cell tube formation. Upper panel, EC tube formation assay was performed on growth factor-reduced Matrigel in the presence or absence of conditioned medium collected from A2780 cells, A2780 cells infected by Ad-GFP, Ad-PTEN, or Ad-Akt DN. Tube-like structures were photographed $24 \mathrm{~h}$ later under a phase contrast microscope. Lower panel, quantification of tube length by calculating the length of the tubular network in five randomly selected fields under $200 \times$ magnification. $(*, p<0.05$ compared with RPMI-treated group; \#, $\mathrm{p}<0.05$ compared with CM-treated A2780 and A2780/Ad-GFP groups). 
Fig. 5
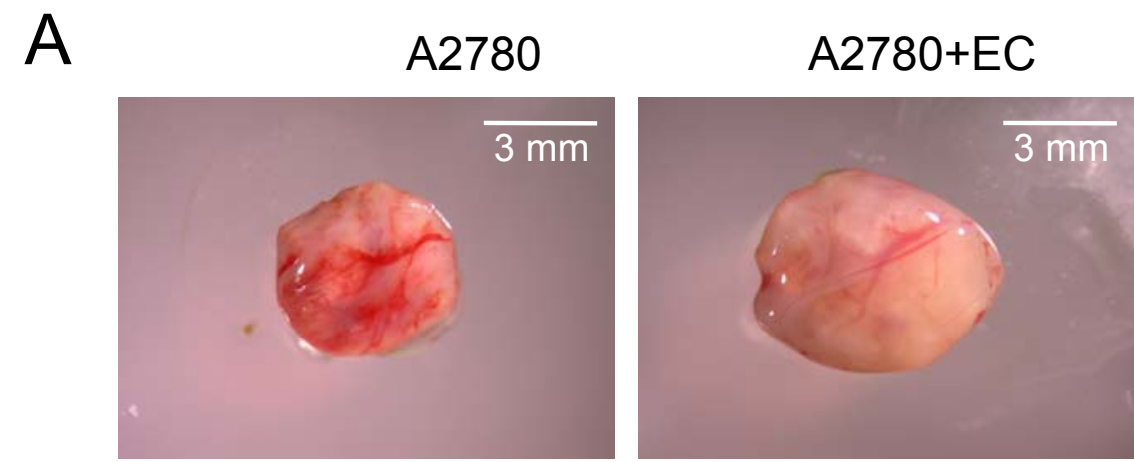

A2780/Ad-GFP

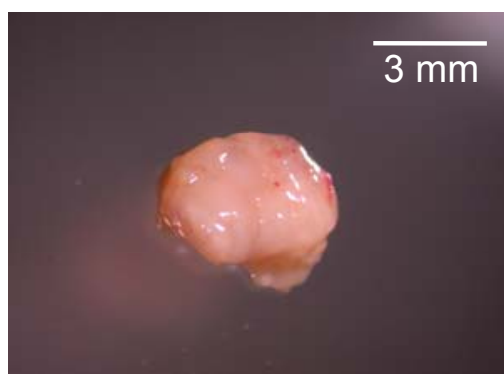

A2780/Ad-PTEN A2780/Ad-Akt DN
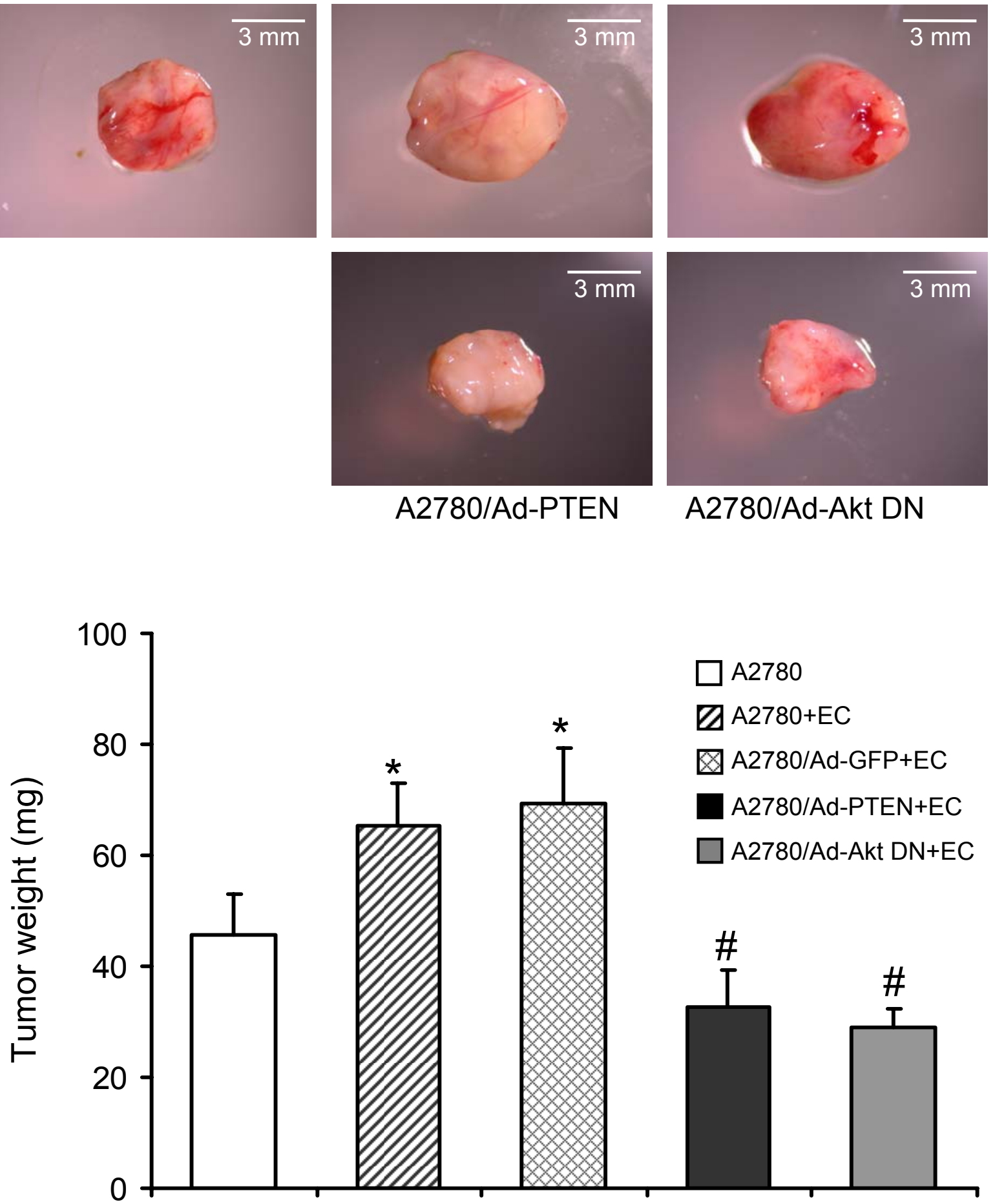
Fig. 5

B
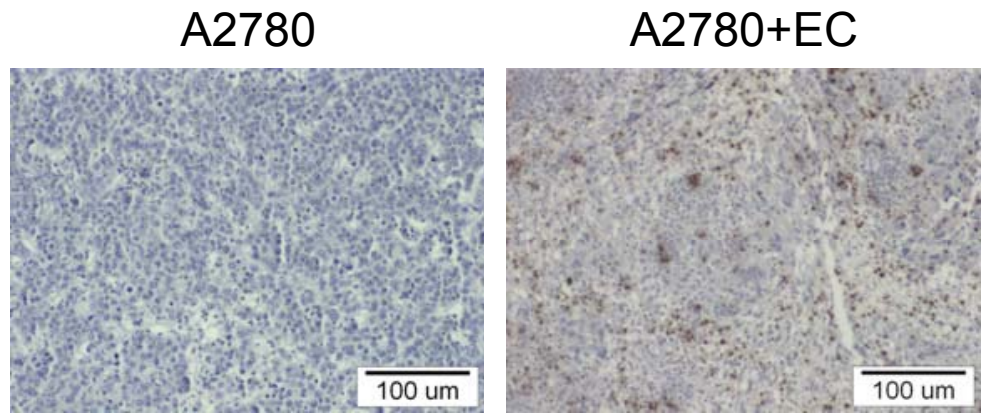

A2780/Ad-GFP+EC
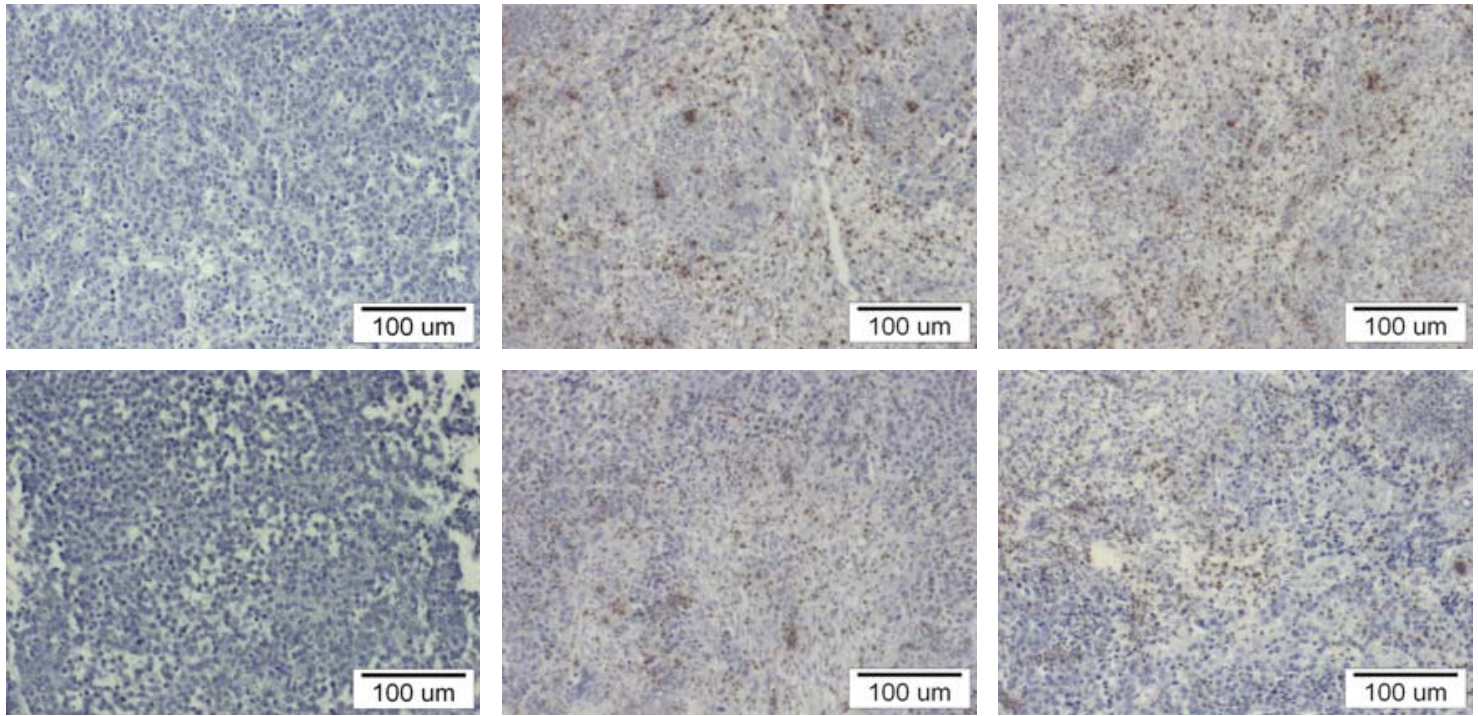

Negative control

A2780/Ad-PTEN+EC

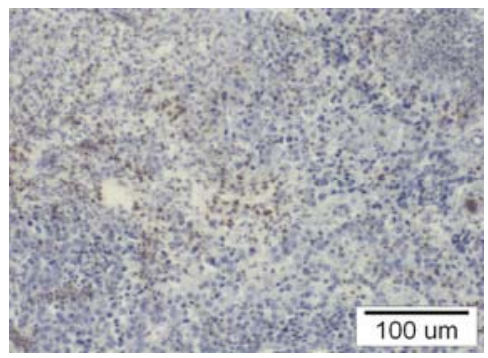

A2780/Ad-Akt DN+EC

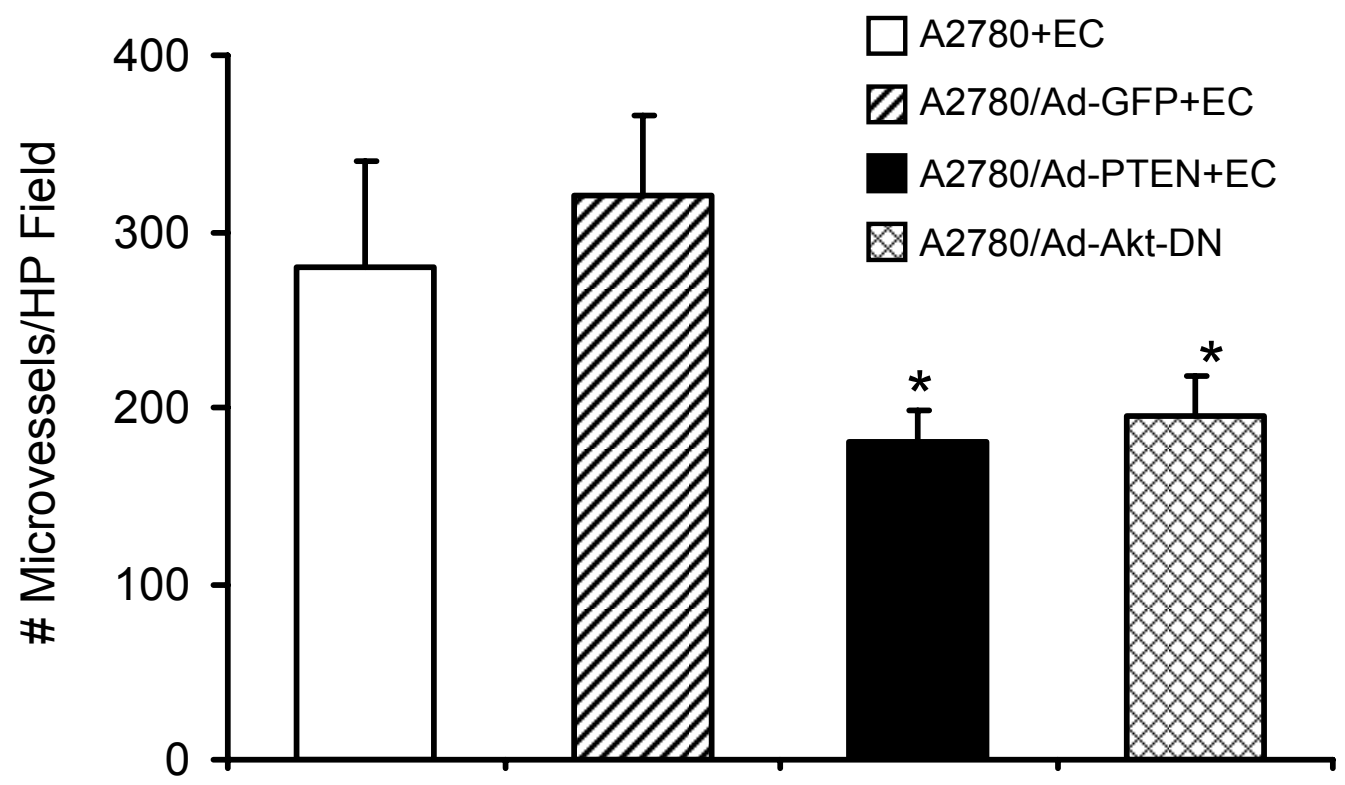


Fig. 5

C

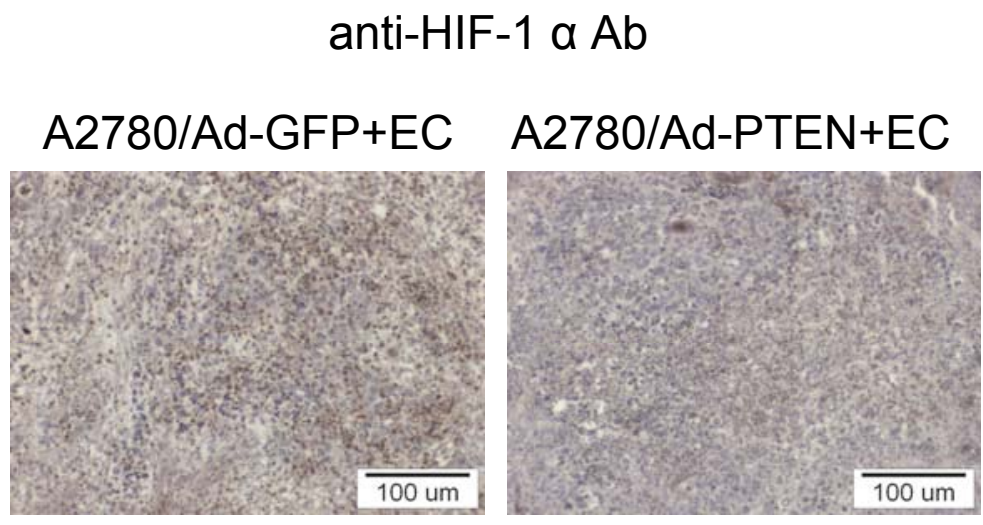

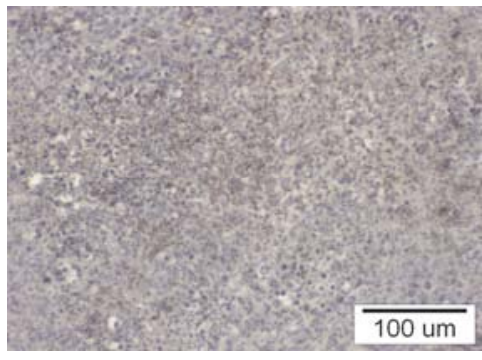

A2780/Ad-Akt DN+EC

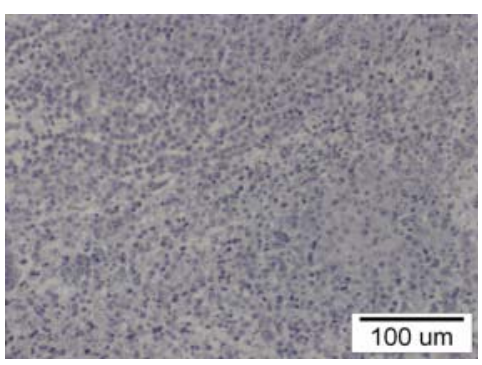

Negative control

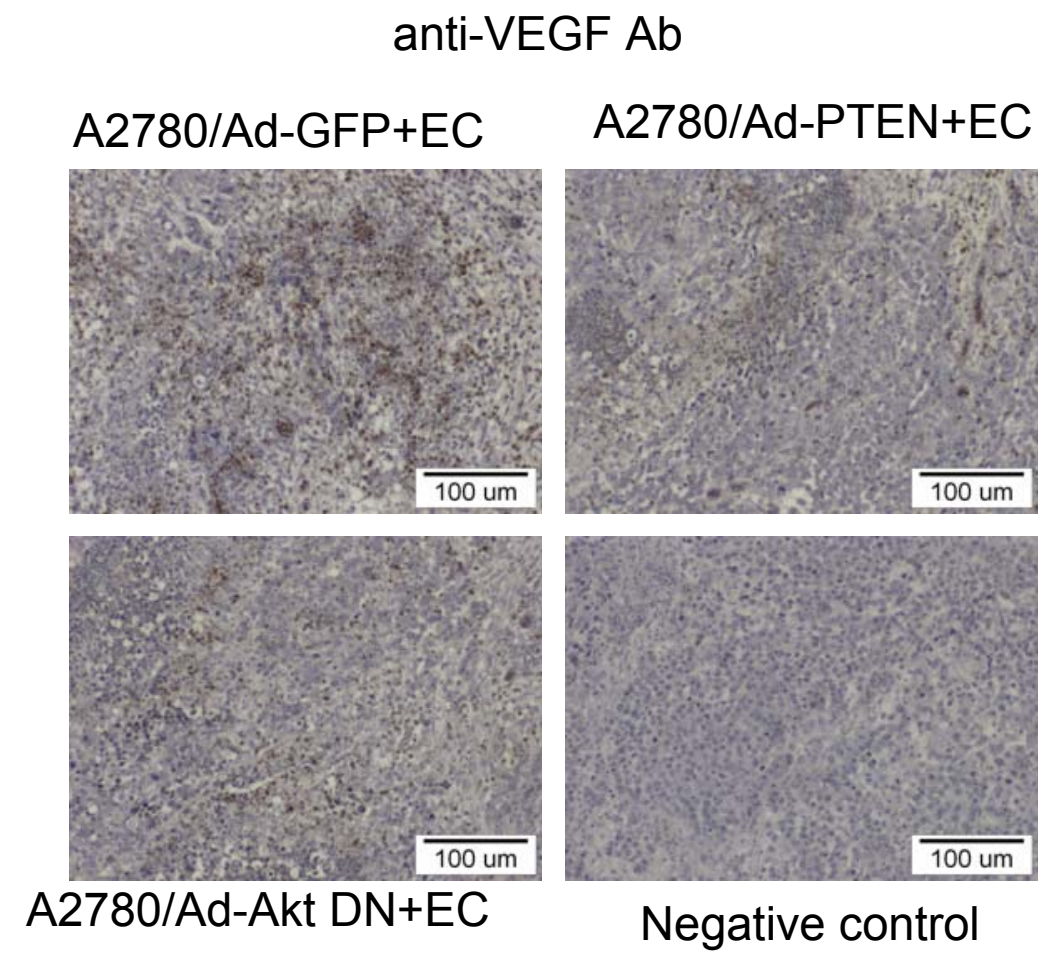


Fig. 5. Overexpression of PTEN or dominant-negative Akt in human ovarian cancer cells inhibits tumor growth and tumor-induced angiogenesis in vivo. A: Inhibition of PI3K or Akt activity in cancer cells inhibits tumor growth. Upper panel, Shown are macroscopic views of representative tumors from the CAM. HMVECs $\left(0.9 \times 10^{6}\right)$ were mixed with $0.1 \times 10^{6}$ A2780 ovarian cancer cells uninfected or infected by Ad-GFP, Ad-PTEN or Ad-Akt DN. The cell mixture was absorbed into PLGA sponges and implanted onto the CAM of day- 8 chicken embryos. Tumors were removed from the CAM 12 days after implantation, and photographed under an anatomical microscope. Lower panel, Tumor weight. Data represent mean values $\pm \mathrm{SE}$ from 6 replicates. (*indicates significant difference when compared to A2780+EC and A2780/Ad-GFP+EC groups, $\mathrm{p}<0.05$; \#indicates significant difference when compared to A2780/Ad-GFP+EC group, $\mathrm{p}<0.05)$. B: Inhibition of PI3K or Akt activity in cancer cells inhibits tumor-induced angiogenesis in vivo. Upper panel, Representative CD31 staining (brown color) of tissue sections of tumors from the CAM. Original magnification of the microphotographs: 200×. Lower panel, Quantification of CD31-positive microvessels within tumor tissues. Data represent the mean number of microvessels in a $200 \times$ field (mean $\pm \mathrm{SE}$ ). (*indicates significant difference when compared to A2780+EC and A2780/Ad-GFP+EC groups, $\mathrm{p}<0.05$ ). C: Overexpression of PTEN or dominant-negative Akt in human ovarian cancer cells inhibits HIF$1 \alpha$ and VEGF expression in vivo. Upper panel, HIF-1 $\alpha$ expression in tumors tissues was analyzed by immunohistochemcal staining using an anti-HIF-1 $\alpha$ antibody. Original magnification of the microphotographs: 200×. Lower panel, VEGF expression in tumors tissues was analyzed by immunohistochemcal staining using an anti-VEGF antibody. Original magnification of the microphotographs: $200 \times$. 
Fig. 6.
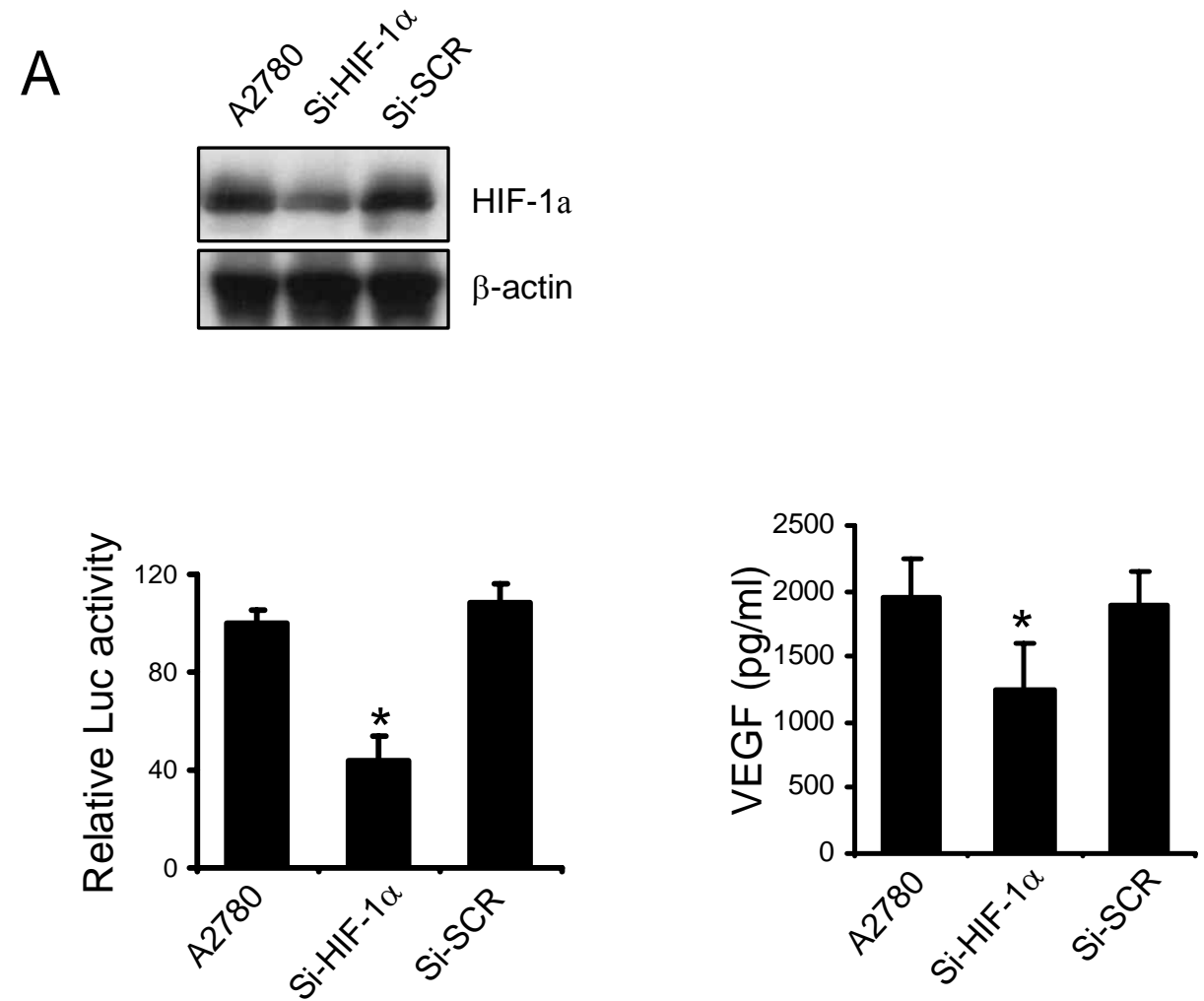

B
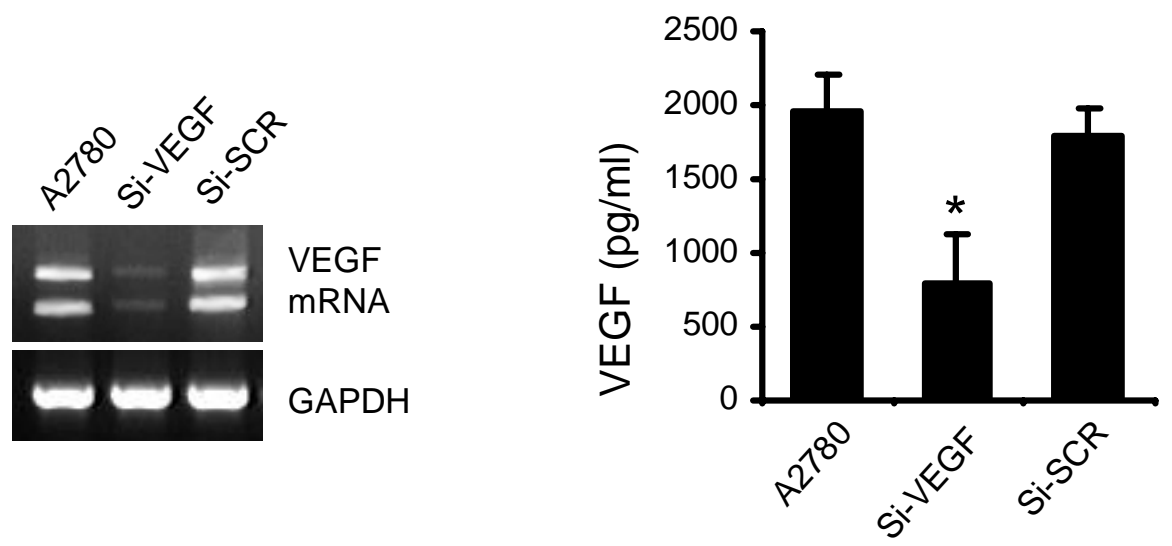
Fig. 6.
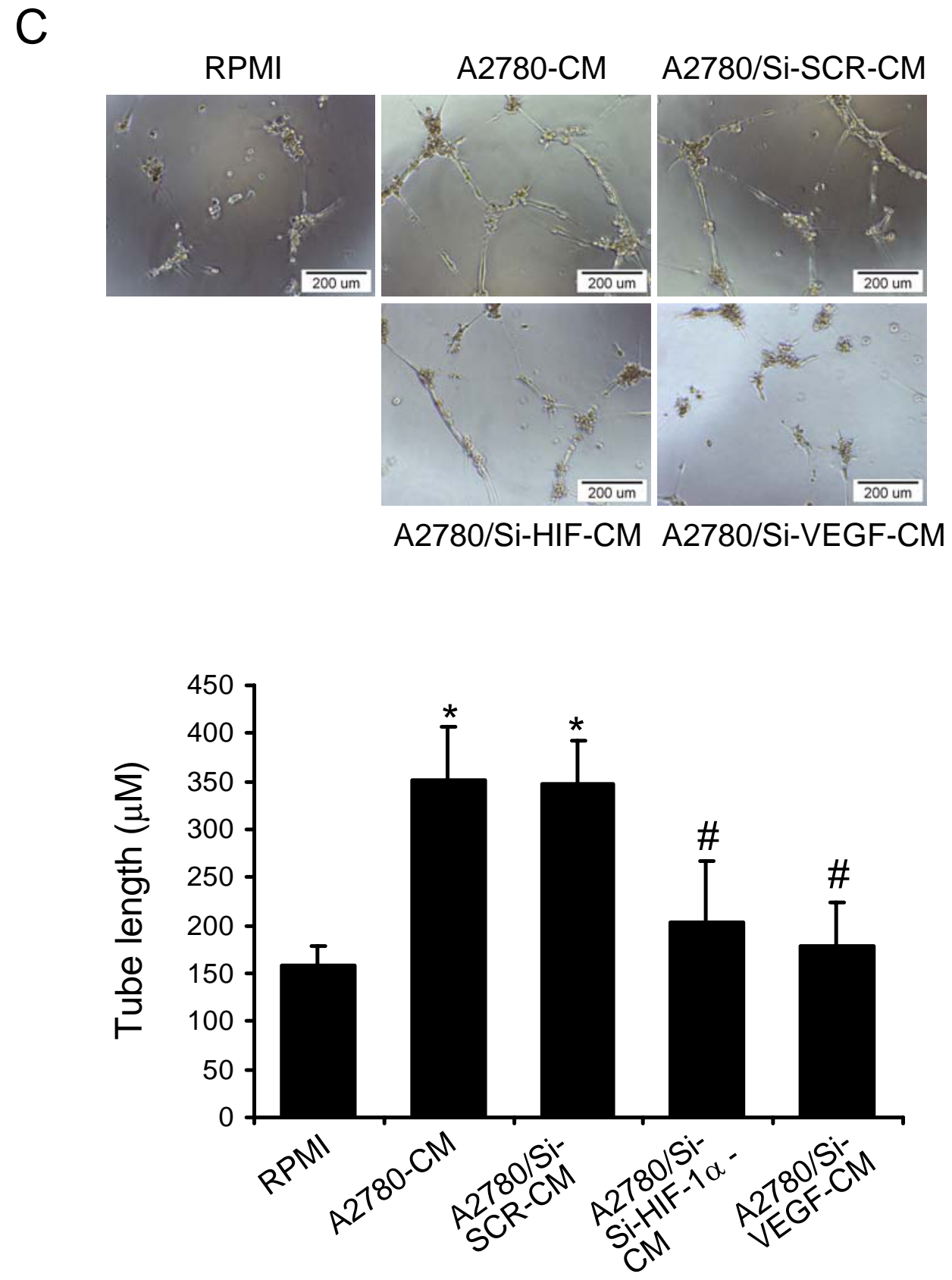
Fig. 6. Conditioned medium collected from ovarian cancer cells stably expressing HIF-1 $\alpha$ or VEGF siRNAs have reduced ability to induce EC tube formation. A: Knockdown of HIF$1 \alpha$ expression suppresses HIF-1 $\alpha$ and VEGF expression in human ovarian cancer cells. Upper panel, Total protein samples prepared from A2780 cells stably expressing SiRNA against HIF$1 \alpha$ were analyzed by immunobloting using antibodies against HIF- $1 \alpha$ and $\beta$-actin, respectively. Lower left panel, HIF-1 $\alpha$ regulates transcriptional activation of VEGF. Parental A2780 cells, A2780 cells stably expressing SiRNA against HIF-1 $\alpha$ or a scramble (SCR) sequence were transfected with the VEGF luciferase reporter construct. Luciferase activity was measured $24 \mathrm{~h}$ after transfection. (*indicates significant difference when compared to the controls, $\mathrm{p}<0.05$ ). Lower right panel, expression of HIF-1 $\alpha$ siRNA reduces VEGF secretion in A2780 cells. ELISA assays were performed to detect VEGF levels in the conditioned medium collected from parental A2780 cells, A2780 cells stably expressing HIF-1 $\alpha$ siRNA or a scramble siRNA sequence. (*indicates significant difference when compared to the controls, $p<0.05$ ). B: Inhibition of VEGF expression by VEGF siRNA. Left panel RT-PCR was carried out to detect VEGF mRNA levels in parental A2780 cells, A2780 cells stably expressing siRNA against VEGF or a scramble siRNA sequence. Right panel, levels of VEGF protein secretion were determined by ELISA in the conditioned medium collected from parental A2780 cells, A2780 cells stably expressing siRNA against VEGF or a scramble siRNA sequence. (*indicates significant difference when compared to the controls, $\mathrm{p}<0.05)$. C: Conditioned medium collected from ovarian cancer cells stably expressing HIF-1 $\alpha$ or VEGF siRNAs have reduced ability to induce EC tube formation. Upper panel, tube formation assay was performed on growth factor-reduced Matrigel in the presence or absence of conditioned medium collected from A2780 cells, A2780 cells stably expressing siRNA against HIF-1 $\alpha$, VEGF or a scramble siRNA sequence. Tube structures were 
photographed $24 \mathrm{~h}$ later under a phase contrast microscope. Lower panel, quantification of tube length by calculating the length of the tubular network in five randomly selected fields under 200× magnification. (*indicates significant difference when compared to RPMI-treated group, $\mathrm{p}<0.05$; \# indicates significant difference when compared to A2780-CM and A2780/Si-SCRCM-treated groups, $\mathrm{p}<0.05)$. 
Fig. 7

A

A2780
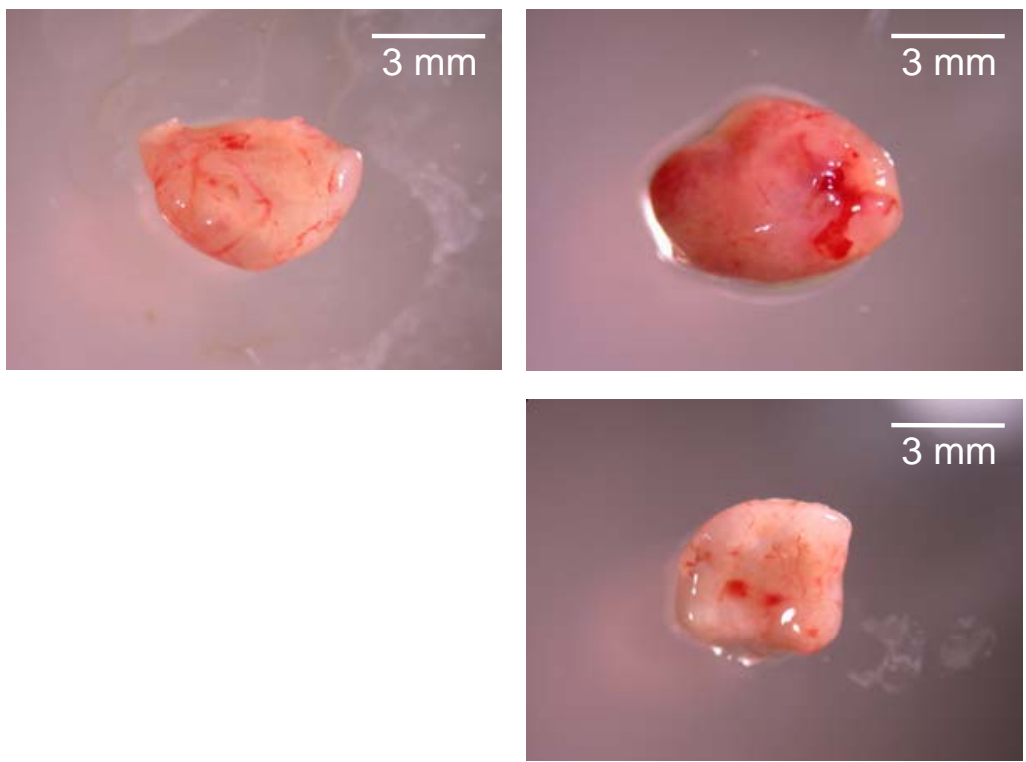

A2780/Si-HIF+EC
A2780/Si-SCR+EC
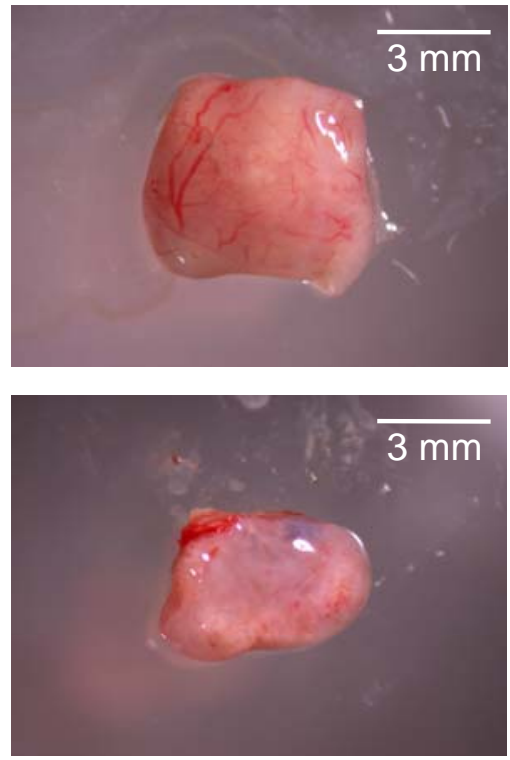

A2780/Si-VEGF+EC

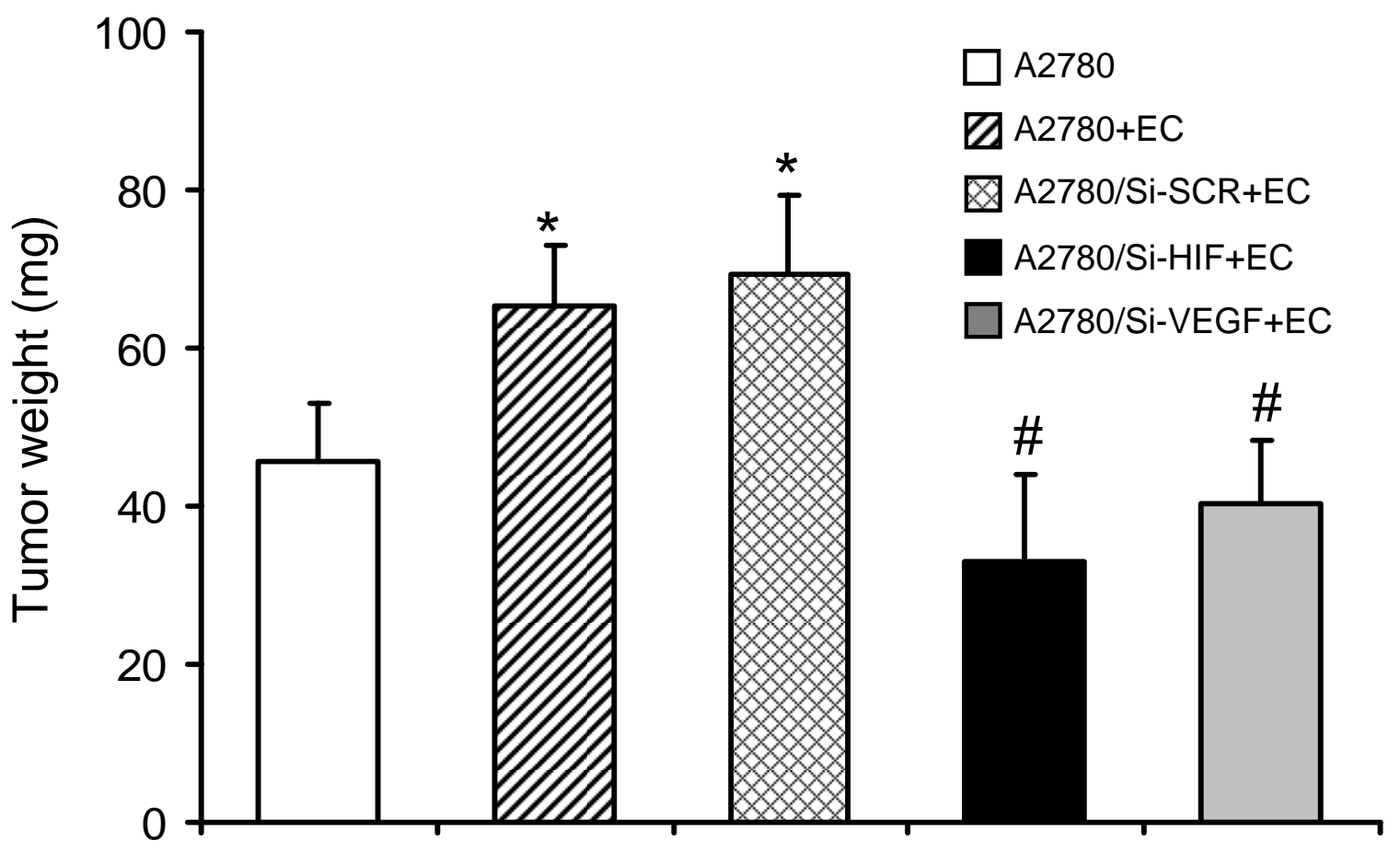


Fig. 7

B
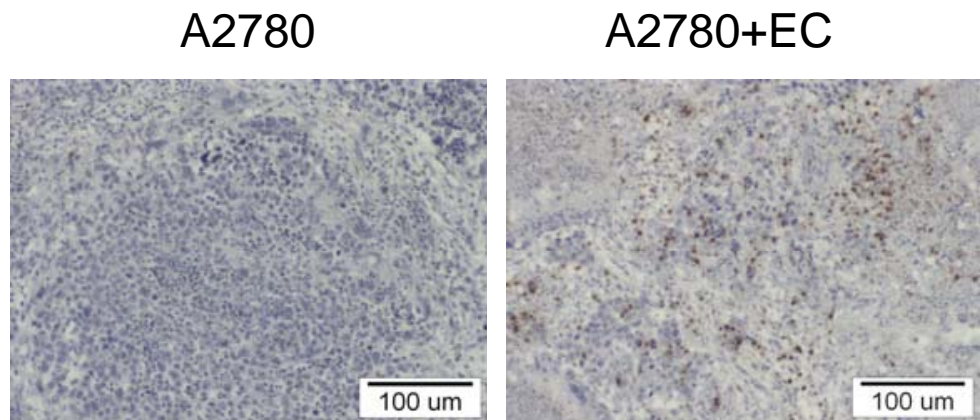

A2780/Si-SCR+EC

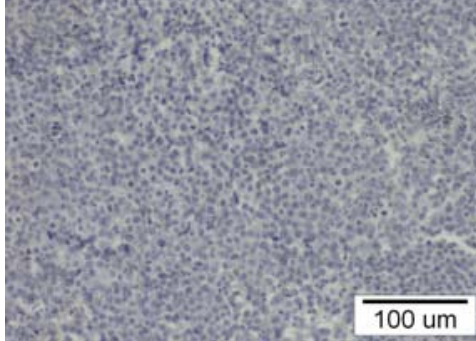

Negative control

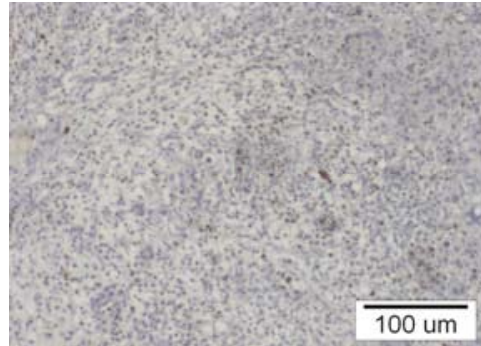

A2780/Si-HIF+EC
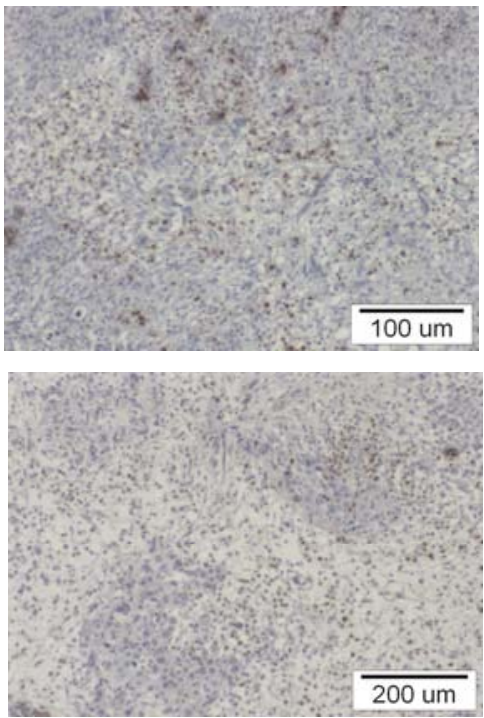

A2780/Si-VEGF+EC

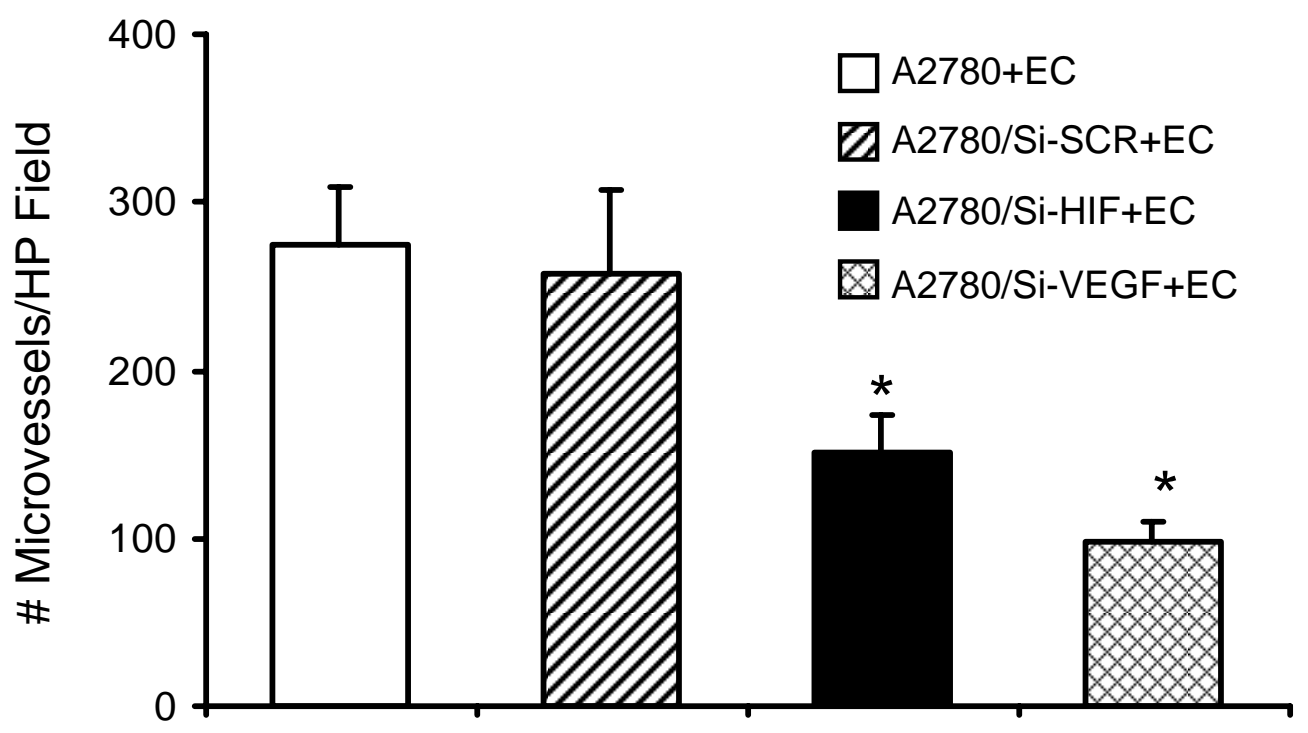


Fig. 7.

C

Anti-HIF-1a Ab

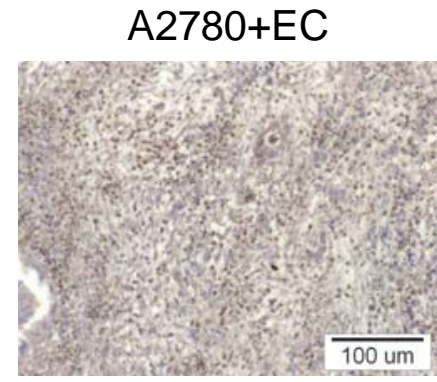

A2780/Si-SCR+EC

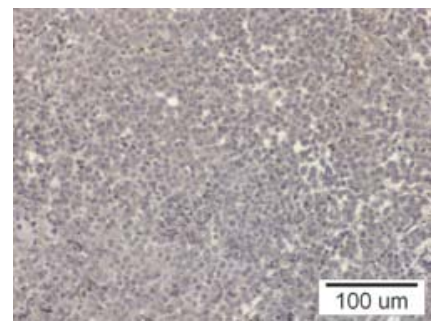

A2780/Si-HIF+EC
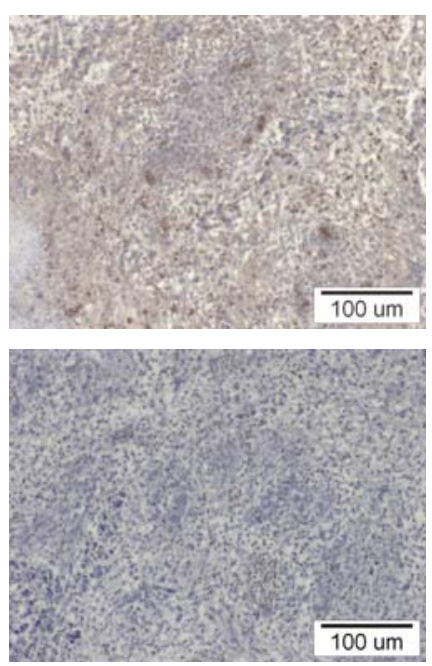

Negative control

\section{Anti-VEGF Ab}

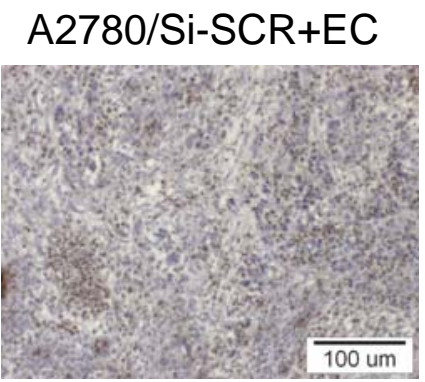

A2780/Si-VEGF+EC

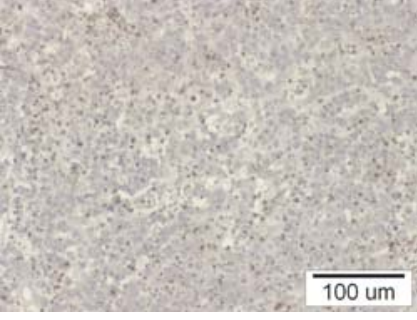

A2780/Si-HIF+EC
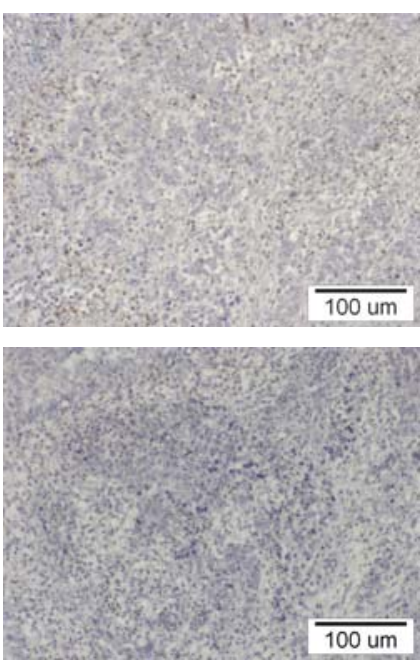

Negative control 
Fig. 7. Knockdown of HIF-1 $\alpha$ and VEGF expression in ovarian cancer cells inhibits tumor growth and angiogenesis in vivo. A: Knockdown of HIF-1 $\alpha$ and VEGF expression in ovarian cancer cells inhibits tumor growth in vivo. Upper panel, macroscopic view of representative tumors from the CAM. HMVEC $(0.9 \times 106)$ were mixed with $0.1 \times 10^{6}$ A2780 ovarian cancer cells, or A2780 cells stably expressing siRNA against HIF-1 $\alpha$, VEGF or a scramble sequence. The cell mixture was absorbed into PLGA sponges, and implanted onto the CAM of day- 8 chicken embryos. Tumors were removed from the CAM 12 days after implantation, and photographed under an anatomical microscope. Lower panel, Tumor weight. Data represent mean values \pm SE from 6 replicates. (*indicates significant difference when compared to A2780 group, $\mathrm{p}<0.05$; \#indicates significant difference when compared to A2780+EC and A2780+EC/Si-SCR groups, $\mathrm{p}<0.05)$. B: Inhibition of HIF-1 $\alpha$ or VEGF expression in cancer cells inhibits tumor-induced angiogenesis in vivo. Upper panel, Representative CD31 staining (brown color) of tissue sections of tumors from the CAM. Original magnification of the microphotographs: 200×. Lower panel, quantification of CD31-positive microvessels within tumor tissues. Data represent the mean number of microvessels obtained in a 200x field. (*indicates significant difference when compared to A2780+EC and A2780+EC/Si-SCR groups, p $<0.05)$. C: Knockdown of HIF-1 $\alpha$ and VEGF expression in ovarian cancer cells inhibits HIF$1 \alpha$ and VEGF expression in vivo. Upper panel, HIF-1 $\alpha$ expression in tumors tissues was analyzed by immunohistochemcal staining using an anti-HIF-1 $\alpha$ antibody. Original magnification of the microphotographs: 200×. Lower panel, VEGF expression in tumors tissues was analyzed by immunohistochemcal staining using an anti-VEGF antibody. Original magnification of the microphotographs: $200 \times$. 
Fig. 8.

\section{Ovarian cancer cell}

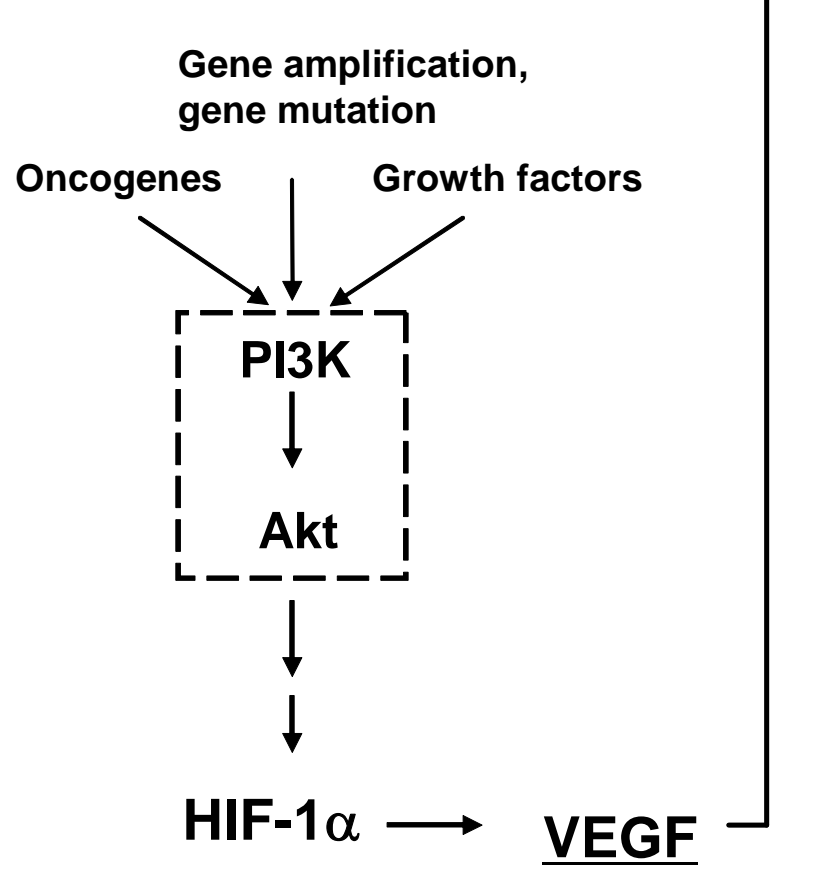

\section{Endothelial cell}

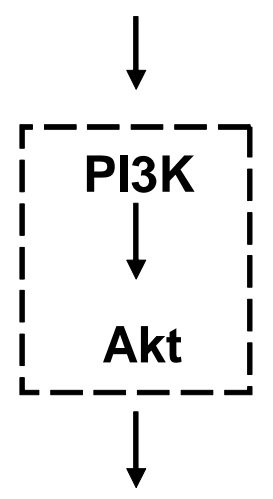

Migration, invasion, survival, differentiation

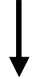

Angiogenesis

Fig. 8. Schematic representation of the dual roles of PI3K/Akt signaling in tumor-induced angiogenesis. 


\section{References}

1. Folkman J. What is the evidence that tumors are angiogenesis dependent? J Natl Cancer Inst 1990 Jan 3;82(1):4-6.

2. McMahon G. VEGF receptor signaling in tumor angiogenesis. Oncologist 2000;5 Suppl $1: 3-10$.

3. Longo R, Sarmiento R, Fanelli M, Capaccetti B, Gattuso D, Gasparini G. Anti-angiogenic therapy: rationale, challenges and clinical studies. Angiogenesis 2002;5(4):237-56.

4. Kerbel RS. Inhibition of tumor angiogenesis as a strategy to circumvent acquired resistance to anti-cancer therapeutic agents. Bioessays 1991 Jan;13(1):31-6.

5. Boehm T, Folkman J, Browder T, O'Reilly MS. Antiangiogenic therapy of experimental cancer does not induce acquired drug resistance. Nature 1997 Nov 27;390(6658):404-7.

6. Gordon MS. Vascular endothelial growth factor as a target for antiangiogenic therapy. J Clin Oncol 2000 Nov 1;18(21 Suppl):45S-6S.

7. Kerbel R, Folkman J. Clinical translation of angiogenesis inhibitors. Nat Rev Cancer 2002 Oct;2(10):727-39.

8. Robinson CJ, Stringer SE. The splice variants of vascular endothelial growth factor (VEGF) and their receptors. J Cell Sci 2001 Mar;114(Pt 5):853-65.

9. Ferrara N. VEGF and the quest for tumour angiogenesis factors. Nat Rev Cancer 2002 Oct;2(10):795-803.

10. Carmeliet P, Collen D. Role of vascular endothelial growth factor and vascular endothelial growth factor receptors in vascular development. Curr Top Microbiol Immunol 1999;237:133-58.

11. Gerber HP, McMurtrey A, Kowalski J, Yan M, Keyt BA, Dixit V, et al. Vascular endothelial growth factor regulates endothelial cell survival through the phosphatidylinositol 3'-kinase/Akt signal transduction pathway. Requirement for Flk1/KDR activation. J Biol Chem 1998 Nov 13;273(46):30336-43.

12. Gratton JP, Morales-Ruiz M, Kureishi Y, Fulton D, Walsh K, Sessa WC. Akt downregulation of p38 signaling provides a novel mechanism of vascular endothelial growth factor-mediated cytoprotection in endothelial cells. J Biol Chem 2001 Aug 10;276(32):30359-65.

13. Huang J, Kontos CD. PTEN modulates vascular endothelial growth factor-mediated signaling and angiogenic effects. J Biol Chem 2002 Mar 29;277(13):10760-6. 
14. Jiang BH, Zheng JZ, Aoki M, Vogt PK. Phosphatidylinositol 3-kinase signaling mediates angiogenesis and expression of vascular endothelial growth factor in endothelial cells. PNAS 2000 Feb 15;97(4):1749-53.

15. Thakker GD, Hajjar DP, Muller WA, Rosengart TK. The role of phosphatidylinositol 3kinase in vascular endothelial growth factor signaling. J Biol Chem 1999 Apr 9;274(15):10002-7.

16. Ferrara N, Davis-Smyth T. The biology of vascular endothelial growth factor. Endocr Rev 1997 Feb;18(1):4-25.

17. Vaupel P, Thews O, Hoeckel M. Treatment resistance of solid tumors: role of hypoxia and anemia. Med Oncol 2001;18(4):243-59.

18. Harris AL. Hypoxia--a key regulatory factor in tumour growth. Nat Rev Cancer 2002 Jan;2(1):38-47.

19. Forsythe JA, Jiang BH, Iyer NV, Agani F, Leung SW, Koos RD, et al. Activation of vascular endothelial growth factor gene transcription by hypoxia-inducible factor 1 . Molecular and Cellular Biology 1996;16(9):4604-13.

20. Carmeliet P, Dor Y, Herbert JM, Fukumura D, Brusselmans K, Dewerchin M, et al. Role of HIF-1[alpha] in hypoxiamediated apoptosis, cell proliferation and tumour angiogenesis. Nature 1998 Jul 30;394(6692):485-90.

21. Jiang BH, Rue E, Wang GL, Roe R, Semenza GL. Dimerization, DNA binding, and transactivation properties of hypoxia-inducible factor 1. The Journal Of Biological Chemistry 1996 Jul 26;271(30):17771-8.

22. Harris AL. Hypoxia--a key regulatory factor in tumour growth. Nat Rev Cancer 2002 Jan;2(1):38-47.

23. Laughner E, Taghavi P, Chiles K, Mahon PC, Semenza GL. HER2 (neu) signaling increases the rate of hypoxia-inducible factor 1alpha (HIF-1alpha) synthesis: novel mechanism for HIF-1-mediated vascular endothelial growth factor expression. Mol Cell Biol 2001 Jun;21(12):3995-4004.

24. Zelzer E, Levy Y, Kahana C, Shilo BZ, Rubinstein M, Cohen B. Insulin induces transcription of target genes through the hypoxia-inducible factor HIF-1alpha/ARNT. EMBO J 1998 Sep 1;17(17):5085-94.

25. Zhong H, Chiles K, Feldser D, Laughner E, Hanrahan C, Georgescu MM, et al. Modulation of hypoxia-inducible factor 1alpha expression by the epidermal growth factor/phosphatidylinositol 3-kinase/PTEN/AKT/FRAP pathway in human prostate cancer cells: implications for tumor angiogenesis and therapeutics. Cancer Res 2000 Mar 15;60(6):1541-5. 
26. Jiang BH, Jiang G, Zheng JZ, Lu Z, Hunter T, Vogt PK. Phosphatidylinositol 3-kinase signaling controls levels of hypoxia-inducible factor 1. Cell Growth Differ 2001 Jul;12(7):363-9.

27. Chang HW, Aoki M, Fruman D, Auger KR, Bellacosa A, Tsichlis PN, et al. Transformation of chicken cells by the gene encoding the catalytic subunit of PI 3-kinase. Science 1997 Jun 20;276(5320):1848-50.

28. Staal SP, Hartley JW. Thymic lymphoma induction by the AKT8 murine retrovirus. J Exp Med 1988 Mar 1;167(3):1259-64.

29. Brader S, Eccles SA. Phosphoinositide 3-kinase signalling pathways in tumor progression, invasion and angiogenesis. Tumori 2004 Jan;90(1):2-8.

30. BUSSOLATI BENE, DEAMBROSIS ILAR, RUSSO SIMO, DEREGIBUS MC, CAMUSSI GIOV. Altered angiogenesis and survival in human tumor-derived endothelial cells. FASEB J 2003 Jun 1;17(9):1159-61.

31. Nor JE, Peters MC, Christensen JB, Sutorik MM, Linn S, Khan MK, et al. Engineering and characterization of functional human microvessels in immunodeficient mice. Lab Invest 2001 Apr;81(4):453-63.

32. He TC, Zhou S, da Costa LT, Yu J, Kinzler KW, Vogelstein B. A simplified system for generating recombinant adenoviruses. PNAS 1998 Mar 3;95(5):2509-14.

33. Mooney DJ, Sano K, Kaufmann PM, Majahod K, Schloo B, Vacanti JP, et al. Long-term engraftment of hepatocytes transplanted on biodegradable polymer sponges. J Biomed Mater Res 1997 Dec 5;37(3):413-20.

34. Weidner N, Semple JP, Welch WR, Folkman J. Tumor angiogenesis and metastasis-correlation in invasive breast carcinoma. The New England Journal of Medicine 1991 Jan 3;324(1):1-8.

35. Bussolati B, Deambrosis I, Russo S, Deregibus MC, Camussi G. Altered angiogenesis and survival in human tumor-derived endothelial cells. FASEB J 2003 Jun;17(9):1159-61.

36. Jiang BH, Jiang G, Zheng JZ, Lu Z, Hunter T, Vogt PK. Phosphatidylinositol 3-kinase signaling controls levels of hypoxia-inducible factor 1. Cell Growth Differ 2001 Jul;12(7):363-9.

37. Jiang BH, Jiang G, Zheng JZ, Lu Z, Hunter T, Vogt PK. Phosphatidylinositol 3-kinase signaling controls levels of hypoxia-inducible factor 1. Cell Growth Differ 2001 Jul;12(7):363-9.

38. Peters MC, Polverini PJ, Mooney DJ. Engineering vascular networks in porous polymer matrices. J Biomed Mater Res 2002 Jun 15;60(4):668-78. 
39. Tsujii M, Kawano S, Tsuji S, Sawaoka H, Hori M, DuBois RN. Cyclooxygenase Regulates Angiogenesis Induced by Colon Cancer Cells. Cell 1998 May 29;93(5):705-16.

40. Jiang BH, Jiang G, Zheng JZ, Lu Z, Hunter T, Vogt PK. Phosphatidylinositol 3-kinase signaling controls levels of hypoxia-inducible factor 1. Cell Growth Differ 2001 Jul;12(7):363-9.

41. Harris AL. Hypoxia--a key regulatory factor in tumour growth. Nat Rev Cancer 2002 Jan;2(1):38-47.

42. Pore N, Liu S, Shu HK, Li B, Haas-Kogan D, Stokoe D, et al. Sp1 Is Involved in Aktmediated Induction of VEGF Expression through an HIF-1-independent Mechanism. Mol Biol Cell 2004 Nov 1;15(11):4841-53.

43. Maxwell PH, Dachs GU, Gleadle JM, Nicholls LG, Harris AL, Stratford IJ, et al. Hypoxiainducible factor-1 modulates gene expression in solid tumors and influences both angiogenesis and tumor growth. PNAS 1997 Jul 22;94(15):8104-9.

44. Ryan HE, Lo J, Johnson RS. HIF-1alpha is required for solid tumor formation and embryonic vascularization. The EMBO Journal 1998 Jun 1;17(11):3005-15.

45. Holash J, Davis S, Papadopoulos N, Croll SD, Ho L, Russell M, et al. VEGF-Trap: a VEGF blocker with potent antitumor effects. Proc Natl Acad Sci U S A 2002 Aug 20;99(17):11393-8.

46. Kim KJ, Li B, Winer J, Armanini M, Gillett N, Phillips HS, et al. Inhibition of vascular endothelial growth factor-induced angiogenesis suppresses tumour growth in vivo. Nature 1993 Apr 29;362(6423):841-4.

47. Ryan HE, Poloni M, McNulty W, Elson D, Gassmann M, Arbeit JM, et al. Hypoxiainducible factor-1alpha is a positive factor in solid tumor growth. Cancer Res 2000 Aug 1;60(15):4010-5. 


\title{
Chapter 5
}

\section{trans-3,4,5'-Trihydroxystibene (resveratrol) Inhibits Hypoxia-Inducible Factor $1 \alpha$ and Vascular Endothelial Growth Factor Expression in Human Ovarian Cancer Cells}

\author{
Zongxian Cao ${ }^{1}$, Jing Fang ${ }^{1}$, Chang Xia ${ }^{1}$, Xianglin Shi ${ }^{2}$ and Bing-Hua Jiang ${ }^{1,2}$ \\ ${ }^{1}$ Department of Microbiology, Immunology and Cell Biology, Mary Babb Randolph Cancer \\ Center, West Virginia University, Morgantown, West Virginia, and ${ }^{2}$ Institute for Nutritional \\ Sciences, Chinese Academy of Sciences, Shanghai, China.
}

Running title: Resveratrol Inhibits HIF-1 $\alpha$ and VEGF Expression

Key Words: trans-resveratrol; hypoxia-inducible factor 1 (HIF-1); vascular endothelial growth factor (VEGF); ovarian carcinoma; tumor angiogenesis

This manuscript was published in Clinical Cancer Research in 2004. (Vol. 10, 5253-5263) 


\begin{abstract}
trans-3,4,5'-Trihydroxystibene (resveratrol) is a natural product commonly found in the human diet and has been shown recently to have anticancer effects on various human cancer cells. However, the molecular basis for its anticancer action remains to be elucidated. In this study, we investigated the effect of resveratrol on hypoxia-inducible factor $1 \alpha$ (HIF-1 $\alpha)$ and vascular endothelial growth factor (VEGF) expression in human ovarian cancer cells A2780/CP70 and OVCAR-3. We found that although resveratrol did not affect HIF-1 $\alpha$ mRNA levels, it did dramatically inhibit both basal-level and growth factor-induced HIF-1 $\alpha$ protein expression in the cells. Resveratrol also greatly inhibited VEGF expression. Mechanistically, we demonstrated that resveratrol inhibited HIF-1 $\alpha$ and VEGF expression through multiple mechanisms. First, resveratrol inhibited AKT and mitogen-activated protein kinase activation, which played a partial role in the down-regulation of HIF-1 $\alpha$ expression. Second, resveratrol inhibited insulin-like growth factor 1-induced HIF-1 $\alpha$ expression through the inhibition of protein translational regulators, including $M_{\mathrm{r}}$ 70,000 ribosomal protein S6 kinase 1, S6 ribosomal protein, eukaryotic initiation factor 4E-binding protein 1, and eukaryotic initiation factor 4E. Finally, we showed that resveratrol substantially induced HIF-1 $\alpha$ protein degradation through the proteasome pathway. Our data suggested that resveratrol may inhibit human ovarian cancer progression and angiogenesis by inhibiting HIF-1 $\alpha$ and VEGF expression and thus provide a novel potential mechanism for the anticancer action of resveratrol.
\end{abstract}




\section{Introduction}

trans-3,4,5'-Trihydroxystibene (resveratrol), a polyphenolic, was identified originally as a phytoalexin produced by plants in response to injury, UV irradiation, and insect or fungal attack (1). Resveratrol is present in more than 70 plant species and is especially abundant in food products such as grapes, peanuts, and mulberries (2). During the past few years, resveratrol has attracted considerable attention as one of the most promising cancer chemopreventive agents. Resveratrol was shown to affect diverse cellular events associated with each step of carcinogenesis, i.e., tumor initiation, promotion, and progression (2) . At the molecular level, these effects corresponded with the inhibition of free radical formation, cyclooxygenase, and cytochrome P450 activity, as well as the inhibition of protein kinase $\mathrm{C}$ activity $(3,4)$. Additionally, resveratrol inhibited cell proliferation by decreasing DNA synthesis through its inhibitory effects on ribonucleotide reductase, DNA polymerase, and ornithine decarboxylase activities $(3,4)$. Resveratrol induces apoptosis in various malignant cells through multiple mechanisms, such as up-regulation of CD95L expression, enhancement of p53 expression and activity, induction of B-cell CLL/lymphoma 2-associated X protein expression, suppression of Bcell CLL/lymphoma 2 expression, and inhibition of nuclear factor $\kappa \mathrm{B}$ activity $(3,4)$. Therefore, resveratrol possesses therapeutic potential based on its suppression of tumor cell growth by inducing cell cycle arrest and apoptosis. For example, in a rat ascetic hepatoma model, i.p. administration of resveratrol caused apoptosis in the tumor cell population and significantly decreased tumor cell numbers (5) . Despite these findings, however, the molecular mechanisms by which resveratrol exerts its anticancer effects remain largely unknown. 
Ovarian cancer represents the fourth leading cause of cancer-related death for women and is the most common cause of death from gynecologic cancer in the Western world (6) . The overall 5 -year survival rate of ovarian cancer is $50 \%$ and about $30 \%$ for advanced stage disease (7) . The symptoms of the disease are observed only after it has spread to the surfaces of the peritoneal cavity. At this stage, it is impossible to remove all apparent lesions by surgical operations, and this accounts for the high rate of cancer recurrence after surgery. Consequently, the majority of ovarian cancer patients require chemotherapy. However, the major challenge in ovarian cancer treatment is the broad resistance to available chemotherapeutic drugs (6). The combination of cisplatin and paclitaxel as a chemotherapy regimen has improved the survival rate of ovarian cancer patients (8), but in the majority of cases, the cancer ultimately progresses, and the ovarian cancer patient dies from chemotherapy-refractory cancer (6) .

It has been well established that solid tumor growth is angiogenesis dependent (9) . Advanced solid tumors have a characteristic property of intratumoral hypoxia, which is caused by the structural and functional abnormalities of the tumor microvasculature, rapid expansion of tumor mass, and tumor-associated anemia (10). Hypoxia condition is a strong stimulus for angiogenesis, and this is predominantly accomplished by hypoxia-inducible factor 1 (HIF-1)mediated up-regulation of vascular endothelial growth factor (VEGF) expression $(11,12,13)$. VEGF, also known as the vascular permeability factor, is a potent and endothelial cell-specific mitogen that plays a crucial role during the process of tumor angiogenesis. VEGF expression is elevated in many human cancers, including ovarian carcinoma $(14,15)$. HIF-1 is a heterodimeric transcriptional factor composed of HIF-1 $\alpha$ and HIF-1ß subunits (16) . HIF-1 binds to the hypoxia-responsive element in the promoter region of the VEGF gene and up-regulates VEGF expression (16) . HIF-1a-deficient cells have reduced VEGF production under hypoxia $(17,18)$. 
VEGF expression levels in vivo are also much lower in HIF-1 $\alpha$ null tumors (17) . HIF-1 $\alpha$ expression increases dramatically under hypoxia. However, under normoxic conditions, HIF-1 $\alpha$ protein is expressed at a very low level due to rapid degradation via the ubiqitin-proteasomal pathway. Certain oncogenic proteins and growth factors have been shown to up-regulate HIF-1 $\alpha$ expression in normoxic cells $(19,20,21,22,23)$. HIF-1ar was also shown to be elevated in various human tumors, including ovarian cancer (24). The effect of VEGF on vascular permeability has been implicated in the pathogenesis of ovarian cysts and malignant ascites (25, 26) . In addition, increased levels of VEGF expression and the microvessel density in ovarian cancer directly correlate with poor prognosis $(27,28)$. Therefore, an anti-angiogenic therapy that targets the HIF-1 $\alpha$ /VEGF system would be a rational strategy for the treatment of ovarian cancer.

In this study, we have demonstrated for the first time that resveratrol has a strong inhibitory effect on HIF-1 $\alpha$ and VEGF expression in human ovarian cancer cells. Our data showed that resveratrol did not affect HIF-1 $\alpha$ mRNA levels; rather, it interfered with the protein translational machinery and promoted HIF-1 $\alpha$ protein degradation. These unique actions of resveratrol provide important clues to the molecular basis for its anticancer effects.

\section{MATERIALS AND METHODS}

\section{Cell Culture and Reagents}

A2780/CP70 and OVCAR-3 human ovarian cancer cells were cultured in RPMI 1640 (Life Technologies, Inc., Grand Island, NY), supplemented with 10\% fetal bovine serum, 50 nм insulin (Sigma), 100 units $/ \mathrm{ml}$ penicillin, and $100 \mu \mathrm{g} / \mathrm{ml}$ streptomycin. The cells were maintained at $37^{\circ} \mathrm{C}$ 
and $5 \% \mathrm{CO}_{2}$ in a humid environment. Resveratrol was purchased from ICN Biomedicals, Inc. (Aurora, OH). Cycloheximide was obtained from EMD Biosciences, Inc. (San Diego, CA). Recombinant human insulin and insulin-like growth factor 1 (IGF-1) were obtained from Sigma. LY294002, rapamycin, and PD98059 were purchased from Calbiochem (La Jolla, CA). Monoclonal HIF-1 a antibody was obtained from BD Transduction Laboratories (Lexington, KY). Antibodies specific for phosphorylated (Thr-202/Tyr-204) or total p44/p42 mitogenactivated protein kinase (MAPK) were from Santa Cruz Biotechnology (Santa Cruz, CA). Antibodies against phosphorylated (Ser-473) or total AKT, phosphorylated (Thr-421/Ser-424) or total $M_{\mathrm{r}}$ 70,000 ribosomal protein S6 kinase 1 (p70S6K1), phosphorylated (Ser-235/236) S6 ribosomal protein, phosphorylated (Ser-65) eukaryotic initiation factor 4E (eIF4E)-binding protein 1 (4E-BP1), and phosphorylated (Ser-209) eIF4E were obtained from Cell Signaling Technology (Beverly, MA). Anti-glyceraldehyde-3-phosphate dehydrogenase (GAPDH) monoclonal antibody was from R\&D Systems (Minneapolis, MN).

\section{Treatment of the Cells with Resveratrol}

Exponentially growing cells (about 80\% confluence) were treated with resveratrol at $12.5,25$, $37.5,50,75,100$, and $150 \mu_{\mathrm{M}}$ for $6 \mathrm{~h}$ in complete medium. For time-dependent studies, cells were treated with $50 \mu \mathrm{m}$ resveratrol from 0 to $24 \mathrm{~h}$. The control cells were incubated with the highest amount of solvent (DMSO) used for dissolving corresponding doses of resveratrol in the dosedependent studies. For experiments in which cells received growth factor stimulation, cells were starved in serum-free and insulin-free medium overnight and then pretreated with resveratrol for $30 \mathrm{~min}$, followed by incubation with growth factors for $6 \mathrm{~h}$. 


\section{Western Blotting}

Cells were washed with ice-cold PBS [140 mм NaCl, $3 \mathrm{~mm} \mathrm{KCl,} 6$ mм $\mathrm{Na}_{2} \mathrm{HPO}_{4}$, and 1 mм $\mathrm{KH}_{2} \mathrm{PO}_{4}(\mathrm{pH}$ 7.4)], scraped, and pelleted by centrifugation. Whole-cell extracts were prepared using modified radioimmune precipitation buffer [100 mм Tris, 5 mм EDTA, 1\% Triton X-100, $1 \%$ deoxycholate acid, $0.1 \%$ SDS, $2 \mathrm{~mm}$ phenylmethylsulfonyl fluoride, $1 \mathrm{~mm}$ sodium orthovanadate, 2 mм DTT, $20 \mu \mathrm{g} / \mathrm{ml}$ leupeptin, and $20 \mu \mathrm{g} / \mathrm{ml}$ pepstatin (pH 7.4)]. Protein concentrations of the lysates were assayed using a protein assay reagent (Bio-Rad). Aliquots (50 $\mu \mathrm{g})$ of protein samples were fractionated by $8 \%$ SDS-PAGE, transferred to a nitrocellulose membrane (Schleicher \& Schuell Biosciences, Keene, NH), and subjected to immunoblotting analysis. Monoclonal HIF-1 $\alpha$ antibody was used at a dilution of 1:3,000 in blocking buffer [1x Tris-buffered saline plus Tween 20: $20 \mathrm{~mm}$ Tris ( $\mathrm{pH}$ 7.4), $137 \mathrm{~mm} \mathrm{NaCl}$, and 0.1\% Tween 20] containing 5\% nonfat dry milk. Anti-GAPDH antibody was used at a dilution of 1:10,000. All other polyclonal antibodies were diluted at 1:2,000 in 1x Tris-buffered saline plus Tween 20 containing 5\% BSA. The blots were blocked in 1x Tris-buffered saline plus Tween 20 containing $5 \%$ nonfat dry milk for $2 \mathrm{~h}$ at room temperature, followed by incubation with the appropriately diluted primary antibodies overnight at $4^{\circ} \mathrm{C}$. Immunoreactivity was visualized with appropriate horseradish peroxidase-conjugated secondary antibodies and enhanced chemiluminescence (Perkin-Elmer Life Sciences, Boston, MA).

\section{Northern Blotting}

Total cellular RNA was extracted from the cells using Trizol reagent (Invitrogen) according to the manufacturer's instructions. Aliquots $(15 \mu \mathrm{g})$ of total RNA were fractionated by electrophoresis in $1 \%$ agarose gel with $2.2 \mathrm{~m}$ formaldehyde, transferred to a Nytron supercharge 
membrane (Schleicher \& Schuell) by capillary transfer with a downward transfer system (Schleicher \& Schuell), and cross-linked to the membrane by UV irradiation. The blot was prehybridized for $1 \mathrm{~h}$ at $42^{\circ} \mathrm{C}$ in $10 \mathrm{ml}$ of Ultrahyb buffer (Ambion). Human VEGF, HIF-1a, and ß-actin cDNA probes were labeled with $\left[\alpha-{ }^{32} \mathrm{P}\right] \mathrm{dATP}$ by random priming using the RadPrime DNA labeling system (Invitrogen) and purified with the ProbeQuant G-50 Micro Columns (Amersham Biosciences, Piscataway, NJ). Heat-denatured probes were added to the hybridization buffer to a final concentration of $1 \times 10^{6} \mathrm{cpm} / \mathrm{ml}$, and hybridization was continued overnight at $42^{\circ} \mathrm{C}$. The membrane was washed twice for $15 \mathrm{~min}$ in $2 \times \mathrm{SSC} / 0.1 \% \mathrm{SDS}$ at $42^{\circ} \mathrm{C}$, and $2 \times 15 \mathrm{~min}$ in $0.1 \times \mathrm{SSC} / 0.1 \% \mathrm{SDS}$ at $60^{\circ} \mathrm{C}$. The membrane was wrapped and overlaid with a Kodak Biomax MS film, and an intensifying screen. Autoradiography was performed overnight at $-80^{\circ} \mathrm{C}$.

\section{Enzyme-Linked Immunosorbent Assay}

The levels of VEGF protein secreted by the cells in the medium were determined by a VEGF ELISA kit (R\&D Systems). In brief, subconfluent cells were changed into fresh medium in the presence of solvent or various concentrations of resveratrol for $12 \mathrm{~h}$, or the cells were cultured in serum-free and insulin-free medium overnight, followed by incubation with IGF-1 in the absence or presence of various concentrations of resveratrol for $12 \mathrm{~h}$. The medium was collected, and VEGF protein concentrations were measured by ELISA according to the manufacturer's instructions. The results were normalized to the number of cells per plate. The data were presented as mean $\pm \mathrm{SD}$ from three replicate experiments. 


\section{Transient Transfection and Luciferase Reporter Assays}

The VEGF promoter reporter was constructed by inserting 47 bp of human VEGF promoter 5'flanking sequence between -985 and -939 , which contains the HIF-1 binding site, into the pGL2basic luciferase vector (Promega) as described previously (11). The dominant-negative HIF-1 $\alpha$ expressing plasmid was described previously (11). The cells were cotransfected with the reporter, pCMV-ß-gal plasmid, and a dominant-negative or wild-type HIF-1a-expressing plasmid using LipofectAMINE reagent (Invitrogen). An empty vector plasmid was used to adjust the equal amounts of plasmids used in each experiment. The cells were cultured overnight after transfection. The cells were then treated with resveratrol for $12 \mathrm{~h}$. Luciferase activity was measured using a luciferase assay reagent (Promega) and normalized to ß-galactosidase activity. The data were mean $\pm \mathrm{SD}$ from three replicate experiments.

\section{Cell Viability Assays}

Cell viability was assayed by the trypan blue dye exclusion method. A2780/CP70 and OVCAR-3 cells were seeded into 6 -well plate at a density of $1 \times 10^{5} /$ well. The cells were treated with 50 or $100 \mu_{\mathrm{M}}$ resveratrol for $12 \mathrm{~h}$ and then trypsinized and resuspended. A 1:1 dilution of the cell suspension using $0.4 \%$ trypan blue was loaded into the counting chambers of a hemocytometer, and the number of stained cells and the total number of cells were counted. Cell viability was the percentage of unstained cells. The data were mean \pm SD from three replicate experiments.

\section{Statistical Analysis}

When applicable, the data were analyzed by Student's $t$ test using SPSS statistical software (SPSS, Inc., Chicago, IL). 


\section{RESULTS}

\section{Resveratrol Inhibited HIF-1a Expression in Human Ovarian Cancer Cells}

In our preliminary studies, human ovarian cancer cell lines A2780/CP70 and OVCAR-3 were shown to express high steady-state levels of HIF-1 $\alpha$. Initial experiments were performed to determine the effect of resveratrol on HIF-1 $\alpha$ expression in these cells. Both cell lines expressed high levels of HIF-1 $\alpha$ protein under normal culture conditions (Fig. 1). Treatment of the cells with resveratrol for $6 \mathrm{~h}$ resulted in a dose-dependent reduction of HIF-1 $\alpha$ protein levels (Fig. 1, A and $B$ ). The concentrations of resveratrol required for $50 \%$ inhibition of HIF- $1 \alpha$ in A2780/CP70 and OVCAR-3 cells were 20 and $30 \mu \mathrm{m}$, respectively. In the presence of $50 \mu \mathrm{m}$ resveratrol, HIF1 $\alpha$ protein levels decreased significantly at $1 \mathrm{~h}$ and were almost undetectable at $6 \mathrm{~h}$ and thereafter

(Fig. 1, C and D). It was known that prolonged treatment of resveratrol inhibited tumor cell growth and induced apoptosis $(3,4)$. To determine whether the effect of resveratrol on HIF-1 $\alpha$ expression might be due to the cellular cytotoxic effect, we performed cell viability assays following treatment with 50 and $100 \mu \mathrm{m}$ resveratrol for $6 \mathrm{~h}$. The resveratrol treatment did not affect cell viability (Fig. 1E), suggesting that the decrease of HIF-1 $\alpha$ expression by resveratrol was not due to cell death.

\section{Resveratrol Prevented HIF-1 $\alpha$ Expression Induced by Growth Factors}

Growth factors and hormones play important roles in malignant transformation and tumor cell growth (29) . Furthermore, previous work by our laboratory and others showed that stimulation by serum or specific growth factors induces HIF-1 $\alpha$ expression in several cultured cells $(19,23$, 30) . Here, we investigated whether certain growth factors can up-regulate HIF-1 $\alpha$ expression in 
human ovarian cancer cells, and whether resveratrol can inhibit the induction. A2780/CP70 and OVCAR-3 cells were cultured in serum-free and insulin-free medium for $18 \mathrm{~h}$ and then exposed to serum in the absence or presence of various doses of resveratrol for $6 \mathrm{~h}$. Serum markedly induced HIF-1 $\alpha$ protein expression in both A2780/CP70 and OVCAR-3 cells (Fig. 2A). Seruminduced HIF-1 $\alpha$ expression was inhibited by resveratrol in a dose-dependent manner (Fig. $2 A$ ). To examine the effects of specific growth factors that are reportedly relevant to ovarian cancer progression (26), the cells were exposed to $200 \mathrm{~nm}$ insulin or $200 \mathrm{ng} / \mathrm{ml} \mathrm{IGF-1.} \mathrm{Both} \mathrm{insulin} \mathrm{and}$ IGF-1 significantly increased HIF-1 $\alpha$ expression in ovarian cancer cells, whereas pretreatment with resveratrol effectively inhibited the HIF-1a induction (Fig. 2, B and C). At concentrations of $50 \mu_{\mathrm{M}}$ and higher, resveratrol inhibited both basal-level and growth factor-induced HIF-1 $\alpha$ expression to almost undetectable levels (Fig. 2). Overall, these results demonstrated that while specific growth factors such as insulin and IGF-1 up-regulated HIF-1 $\alpha$ expression in human ovarian cancer cells, resveratrol strongly inhibited the growth factor-induced HIF-1 $\alpha$ expression in the cells.

\section{Resveratrol Did Not Affect HIF-1a mRNA Levels}

To examine whether inhibition of HIF-1 $\alpha$ protein levels by resveratrol was caused by a decrease in its mRNA level, HIF-1 $\alpha$ mRNA levels were measured by Northern blotting. As shown in Fig. 3, $A$ and $B$, IGF-1 did not induce HIF-1 $\alpha$ mRNA expression in A2780/CP70 and OVCAR-3 cells, which corresponds with previous observations that IGF-1 did not increase HIF-1 $\alpha$ mRNA levels in other cell lines (31). Resveratrol treatment did not have any effect on HIF-1 $\alpha$ mRNA levels in A2780/CP70 and OVCAR-3 cells (Fig. 3). These results indicated that inhibition of HIF-1 $\alpha$ 
expression by resveratrol was not through the inhibition of its mRNA level, suggesting posttranscriptional mechanisms of resveratrol action on HIF-1 $\alpha$ expression.

\section{Resveratrol Inhibited Vascular Endothelial Growth Factor Expression in A2780/CP70 and OVCAR-3 Cells}

VEGF is one of the target genes of HIF-1, which plays a crucial role in tumor angiogenesis (11, $12,13,16)$. HIF-1 regulates the expression of VEGF at the transcriptional level $(11,12,13,16)$. To determine whether resveratrol inhibits VEGF expression in human ovarian cancer cells, VEGF mRNA levels were measured by Northern blot analysis. A2780/CP70 and OVCAR-3 cells expressed high levels of VEGF mRNA under normal culture conditions (Fig. 4A), which correlated with high levels of HIF-1 $\alpha$ expression in the cells (Fig. 1). Treatment of the cells with resveratrol resulted in a dose-dependent inhibition of VEGF mRNA expression(Fig. 4A). IGF-1 treatment significantly increased VEGF mRNA expression, and resveratrol inhibited IGF-1induced VEGF mRNA expression in a dose-dependent manner (Fig. 4B). To determine whether down-regulation of VEGF mRNA levels by resveratrol subsequently leads to a decrease in VEGF protein expression, we assayed VEGF protein levels by ELISA. Treatment of the cells with resveratrol inhibited VEGF protein levels in a dose-dependent manner (Fig. 5A). Resveratrol also inhibited IGF-1-induced VEGF protein expression in the cells (Fig. 5B). No apparent cytotoxic effects were observed in the experiments when cells were treated with 50 and $100 \mu \mathrm{M}$ resveratrol for $12 \mathrm{~h}$ (Fig. 5C). 


\section{Resveratrol Inhibited Vascular Endothelial Growth Factor Transcriptional Activation through HIF-1a}

To determine whether resveratrol inhibited VEGF transcriptional activation, we tested the effect of resveratrol on the expression of a VEGF promoter reporter plasmid containing HIF-1 binding site, which was an indicator of VEGF transcriptional activation. Resveratrol treatment inhibited the VEGF reporter activity, and cotransfection of HIF-1 $\alpha$ wild-type plasmid reversed resveratrolinhibited reporter activity to an even higher level (Fig. 6A). This result suggested that reveratrol inhibited VEGF transcriptional activation through HIF-1 $\alpha$ expression in the ovarian cancer cells. The expression of a dominant-negative HIF-1 plasmid inhibited the reporter activity in a dosedependent manner (Fig. 6B). This result indicated that HIF-1 $\alpha$ expression was required for VEGF transcriptional activation in the cells. Thus, these data further confirmed that HIF-1 $\alpha$ expression was important for resveratrol-inhibited VEGF expression.

\section{Resveratrol Inhibited AKT and Mitogen-Activated Protein Kinase Activation}

Next, we investigated the signaling pathways involved in resveratrol-induced inhibition of HIF$1 \alpha$ protein expression in the cells. As shown in Fig. 3, resveratrol did not affect HIF- $1 \alpha$ mRNA levels, suggesting that resveratrol may either decrease HIF-1 $\alpha$ protein synthesis, and/or increase HIF-1 $\alpha$ protein degradation. Previously, we and others have shown that specific growth factors, such as insulin and IGF-1, induce HIF-1 $\alpha$ protein expression via the phosphatidylinositol 3'kinase (PI3K)/AKT and MAPK signaling pathways in several cell types $(23,31,32)$. Previous studies further showed that growth factor-induced activation of PI3K/AKT and MAPK signaling mediates HIF-1 $\alpha$ expression by increasing HIF-1 $\alpha$ protein synthesis but not decreasing HIF-1 $\alpha$ protein degradation $(19,31,33)$. In this study, we found that serum and specific growth factors 
such as insulin and IGF-1 induced high levels of HIF-1 $\alpha$ protein expression in human ovarian cancer cells (Fig. 2). Thus, we examined whether resveratrol treatment affected IGF-1-induced activation of the PI3K/AKT and MAPK signaling pathways. Phosphorylation levels of AKT and MAPK, which correspond with their activation, were analyzed by immunoblotting. IGF-1 greatly increased AKT and MAPK phosphorylation in both cell lines (Fig. 7). Treatment of the cells with PI3K-specific inhibitor LY294002 completely blocked IGF-1-induced AKT phosphorylation and inhibited IGF-1-induced HIF-1 $\alpha$ expression (data not shown), which was consistent with the effect of LY294002 on HIF-1 $\alpha$ expression in other cell lines $(23,31,32)$. MAPK/extracellular signal-regulated kinase1 inhibitor PD98059 inhibited MAPK activation and prevented HIF-1 $\alpha$ expression induced by IGF-1 (Fig. 7, $C$ and $D$ ). Although resveratrol could inhibit HIF-1 $\alpha$ expression completely, it only partly reduced both AKT and MAPK phosphorylation induced by IGF-1 in the cells (Fig. 7). These results indicated that inhibition of AKT and MAPK activation by resveratrol played a partial role in its down-regulation of HIF-1 $\alpha$ expression.

\section{Resveratrol Interfered with Protein Translational Machinery}

Growth factor-induced activation of PI3K/AKT and MAPK pathways has been shown to regulate HIF-1 $\alpha$ protein synthesis via phosphorylation of protein translational regulators, including p70S6K1 and 4E-BP1 $(31,32,33,34,35)$. We next examined whether resveratrol affected the protein translational machinery. We investigated the effect of resveratrol on the phosphorylation of the components of protein translational apparatus, including p70S6K1, S6 ribosomal protein, 4E-BP1, and eIF4E. In A2780/CP70 and OVCAR-3 cells, the phosphorylation of p70S6K1 induced by IGF-1 was blocked by LY294002, rapamycin, and PD98059 (Fig. 8A). Similarly, resveratrol inhibited IGF-1-induced p70S6K1 phosphorylation at 50 and $100 \mu \mathrm{M}$ (Fig. 8A). 
Strikingly, treatment of the cells with resveratrol at as low as $10 \mu \mathrm{M}$ dramatically inhibited IGF-1induced phosphorylation of S6 ribosomal protein, comparable with the effect of LY294002, rapamycin, and PD98059 (Fig. 8B). Phosphorylation of the S6 ribosomal protein by p70S6K1 and other kinases is involved in the initiation of protein synthesis (36). Resveratrol also reduced phosphorylation of 4E-BP1 and, to a much greater extent, the mRNA cap-binding protein eIF4E (Fig. 8C), which is the key enzyme for cap-dependent initiation of protein translation. Expression of eIF4E was shown recently to be sufficient to elevate HIF-1 $\alpha$ protein levels (21). In this study, we found that treatment of the cells with rapamycin also inhibited IGF-1-induced HIF-1 $\alpha$ expression in the cells (Fig. 8D). Rapamycin is a specific inhibitor of the mammalian target of rapamycin (mTOR), which is the upstream kinase for 4E-BP1 and p70S6K1. These results indicated that resveratrol interfered with protein translational regulation, which contributed to its inhibitory effect on HIF-1 $\alpha$ protein expression.

\section{Resveratrol Promoted HIF-1 $\alpha$ Protein Degradation via the Proteasomal Pathway}

HIF-1 $\alpha$ protein levels are regulated by a balance between HIF-1 $\alpha$ protein synthesis and degradation in the cells. Hypoxia or hypoxia-mimetic agent $\mathrm{CoCl}_{2}$ can rapidly induce HIF-1 $\alpha$ protein accumulation due to a marked decrease in HIF-1 $\alpha$ protein degradation (37). Based on the results presented above, we found that resveratrol could inhibit completely both growth factorinduced and basal-level HIF-1 $\alpha$ expression (Fig. 1; Fig. 2). These observations suggested that, in addition to inhibiting the HIF-1 $\alpha$ protein synthesis, resveratrol may also promote HIF-1 $\alpha$ protein degradation. Thus, we examined the effect of resveratrol on the stability of HIF-1 $\alpha$ protein in the cells. A2780/CP70 cells were cultured in complete medium to subconfluence and then pretreated with solvent alone or resveratrol for $1 \mathrm{~h}$, followed by incubation with cycloheximide to block 
ongoing protein synthesis. The cells were collected at various time intervals, and HIF-1 $\alpha$ protein levels were examined. In the presence of cycloheximide, the half-life of HIF-1 $\alpha$ protein in the cells pretreated with $50 \mu \mathrm{m}$ resveratrol was $2.55 \mathrm{~min}$, which was significantly shorter than that for cells treated with solvent alone $(7.5 \mathrm{~min} ; \mathrm{p}<0.05$. Fig. 9). This result demonstrated that resveratrol increased HIF-1 $\alpha$ protein degradation. To examine whether resveratrol-induced HIF$1 \alpha$ degradation is mediated by the proteasome degradation pathway, we treated the cells with proteasome inhibitor MG132 in the presence or absence of resveratrol, and analyzed HIF-1 $\alpha$ protein levels. As shown in Fig. 10, treatment of the cells with MG132 increased HIF-1 $\alpha$ protein ubiquitination and total HIF-1 $\alpha$ protein levels. Resveratrol-induced HIF-1 $\alpha$ inhibition was prevented completely by MG132 (Fig. 10). These data indicated that resveratrol induced HIF-1 $\alpha$ protein degradation through the proteasome degradation pathway.

\section{DISCUSSION}

Angiogenesis, the development of new blood vessels from the pre-existing vasculature, is essential for tumor growth and metastasis $(9,38)$. HIF-1-mediated VEGF expression plays a pivotal role during the process of tumor angiogenesis (38). In this study, we demonstrated for the first time that resveratrol, a natural product with cancer chemopreventive effects, markedly inhibited HIF-1 $\alpha$ and VEGF expression in human ovarian cancer cells. Resveratrol was shown to affect PI3K/AKT and MAPK-signaling pathways, to interfere with protein translational machinery, and to enhance HIF-1 $\alpha$ protein degradation. The data presented here suggested that resveratrol may inhibit human ovarian cancer progression by interfering with tumor angiogenesis 
mediated by HIF-1 $\alpha$ and VEGF, thereby providing a novel mechanism for the anticancer action of resveratrol.

Numerous studies have implicated the role of IGFs in the development and progression of human malignancies such as ovarian carcinoma (29). In addition, IGF-1 has been shown to induce HIF-1 $\alpha$ expression in several cultured cells $(30,31)$. IGF-1 is a growth factor commonly used to up-regulate the PI3K/AKT and MAPK signaling pathways in various cell types. In this study, we used IGF-1 as a stimulus to investigate the mechanism of resveratrol on HIF-1 $\alpha$ expression in human ovarian cancer cells. IGF-1 treatment significantly increased HIF-1 $\alpha$ protein levels in human ovarian cancer cells, which is consistent with previous findings that IGF-1 stimulates HIF-1 $\alpha$ expression in other cell lines $(30,31)$. Moreover, IGF-1 also markedly upregulated HIF-1 $\alpha$ target gene VEGF expression in human ovarian cancer cells. These results correspond with previous reports that IGF-1 is involved in tumor-induced angiogenesis associated with the up-regulation of VEGF expression in human colon cancer and pancreatic cancer $(39,40)$. Several studies have shown that growth factors including IGF-1 do not induce HIF-1 $\alpha$ mRNA expression but increase HIF-1 $\alpha$ protein synthesis $(31,32)$. Similarly, we did not observe the induction of HIF-1 $\alpha$ mRNA expression by IGF-1 in the ovarian cancer cells. Resveratrol treatment did not have any effect on HIF-1 $\alpha$ mRNA levels in the cells, suggesting that resveratrol inhibited HIF-1 $\alpha$ protein expression through post-transcriptional mechanisms, for example, by influencing HIF-1 $\alpha$ protein synthesis and/or degradation.

To further define the molecular mechanisms by which resveratrol inhibited HIF-1 $\alpha$ expression, we next examined whether resveratrol affected HIF-1 $\alpha$ protein synthesis. Recently, it was reported that IGF-1-induced expression of HIF-1 $\alpha$ and VEGF in HCT116 colon cancer cells 
can be blocked by the PI3K inhibitor wortmannin, MAPK/extracellular signal-regulated kinase kinase inhibitor PD98095, or mTOR inhibitor rapamycin and that these inhibitors also blocked the phosphorylation of the translational regulatory protein 4E-BP1, p70S6K1, and eIF4E (31) . Epidermal growth factor and $\mathrm{HER}^{\text {neu }}$ were also shown to induce HIF-1 $\alpha$ expression through similar signaling pathways in breast cancer and prostate cancer cells, respectively $(19,33)$. Induction of HIF-1 $\alpha$ expression by these growth factors and oncogenes was due to an increase in HIF-1 $\alpha$ protein synthesis but was not due to a decrease in HIF-1 $\alpha$ protein degradation $(19,31$, 33). In this study, we found that IGF-1 treatment induced HIF-1 $\alpha$ and VEGF expression and activation of AKT and MAPK in human ovarian cancer cells. Resveratrol treatment partly reduced AKT and MAPK activation; however, resveratrol could dramatically inhibit HIF-1 $\alpha$ protein expression to undetectable levels. Thus, inhibition of AKT and MAPK activation by resveratrol only played a partial role in its down-regulation of HIF-1 $\alpha$ expression.

We next examined the effect of resveratrol on protein translational machinery, which has been shown to regulate HIF-1 $\alpha$ protein synthesis induced by growth factors. Regulation of protein synthesis allows for a more rapid response to diverse stimuli in the absence of transcription. Eukaryotic initiation factors (eIFs) and p70S6K1 play critical roles in protein translational regulation. p70S6K1 phosphorylates the S6 ribosomal protein of the 40S subunit of the ribosome, and stimulates the translation of mRNAs with a 5 ' oligopyrimidine tract that encodes major components of the protein synthesis apparatus (41). p70S6K1 is a downstream effector of PI3K; full activation of p70S6K1 also requires mTOR activity $(36,41,42)$. The activity of p70S6K1 is controlled by multiple phosphorylation events. Phosphorylation of Thr421 and Ser-424 on the COOH-terminal autoinhibitory domain is mediated by MAPK (41) . In this study, we found that IGF-1-induced phosphorylation of p70S6K1 was inhibited by 
resveratrol at 50-100 $\mu \mathrm{M}$. This effect was consistent with its inhibitory effects on AKT and MAPK activation as shown in Fig. 9. Remarkably, phosphorylation of S6 ribosomal protein, a downstream effector of p70S6K1, was dramatically inhibited by resveratrol treatment at as low as $10 \mu \mathrm{M}$. Because other kinases including cAMP-dependent protein kinase and protein kinase C are also known to phosphorylate S6 ribosomal protein (43), it is possible that resveratrol may also inhibit some of these kinases in addition to p70S6K1. 4E-BP1 functions in the PI3K/AKT pathway and is phosphorylated by mTOR and other unidentified kinases (36). 4E-BP1 binds to eIF4E and inhibits eIF4E function. Hyperphosphorylation of 4E-BP1 disrupts this binding, releasing eIF4E to be phosphorylated at Ser-209 by Mnk1 and to associate with eIF4G to initiate cap-dependent translation (36). eIF4E is the key enzyme for cap-dependent initiation of protein translation. Expression of eIF4E was shown recently to be sufficient to elevate HIF-1a protein levels (21). In the present study, we found that resveratrol inhibited phosphorylation of 4E-BP1 at Ser-65 and greatly inhibited phosphorylation of eIF4E at Ser-209. We showed that treatment of the cells with mTOR inhibitor rapamycin completely inhibited IGF-1-induced HIF-1 $\alpha$ expression. Thus, these data indicated that resveratrol interfered with protein translational regulation, which contributed to its inhibitory effect on HIF-1 $\alpha$ protein expression.

HIF-1 $\alpha$ protein levels are also subject to posttranslational regulation. Under normoxic conditions, HIF-1 $\alpha$ protein is expressed at very low levels due to rapid degradation via the ubiqitin-proteasomal pathway. Conversely, under hypoxic conditions, HIF-1 $\alpha$ protein levels are increased dramatically due to a marked decrease in HIF-1 a protein degradation (37). In this study, we found that resveratrol could eliminate both growth factor-induced and basal-level HIF-1 $\alpha$ expression. These observations suggested that, in addition to inhibiting HIF-1 $\alpha$ protein synthesis, resveratrol may also promote HIF-1 $\alpha$ protein degradation. Indeed, the half-life of HIF-1 $\alpha$ protein 
was shortened significantly in the presence of resveratrol, demonstrating that resveratrol induced HIF-1 $\alpha$ protein degradation (Fig. 9). We further showed that resveratrol-induced HIF-1 $\alpha$ protein degradation was through the proteasome pathway. HIF-1 $\alpha$ protein degradation is mediated by the oxygen-dependent HIF-prolyl hydroxylases. Prolyl hydroxylation of HIF-1 $\alpha$ by HIF-prolyl hydroxylase is required for the binding of HIF-1 $\alpha$ to the von Hippel Lindau tumor suppressor protein, which serves as the $\mathrm{E}_{3}$ ubiquitin-protein ligase that targets HIF-1 $\alpha$ for proteasomal degradation (37). HIF-prolyl hydroxylases are hydroxygenases requiring oxygen and 2oxoglutarate as cosubstrates. The binding of oxygen to the iron-containing central moiety of HIFprolyl hydroxylase requires the vitamin C-dependent maintenance of iron in its ferrous state (37). Recently, vitamin C was shown to abrogate efficiently HIF-1 $\alpha$ protein levels in several human cancer cell lines by increasing HIF-prolyl hydroxylase activity (44). Both vitamin C and resveratrol have multiple hydroxyl groups, which are essential for their antioxidant activities. In addition, resveratrol was shown to be a much more potent antioxidant than vitamin $\mathrm{C}$ and can enhance the activity of vitamin $\mathrm{C}$ when used together (45). We speculate that the effect of resveratrol on HIF-1 $\alpha$ degradation could possibly result from its interference with HIF-prolyl hydroxylase activity, which requires additional investigation.

The distinct ability of resveratrol to inhibit HIF-1 $\alpha$ and VEGF expression observed in this study raises the possibility of its usefulness in the therapy of human ovarian cancer. Tumor angiogenesis triggered by HIF- $1 \alpha$ and VEGF is a vital process for tumor progression because it nourishes tumor cell growth and facilitates metastases (38). In addition, tumor cell-derived VEGF was also shown to have an autocrine stimulatory effect on tumor cell growth because various human tumor cells, including ovarian cancer cells, express VEGF receptors $(14,38,46)$. Therefore, resveratrol may potentially inhibit ovarian cancer progression based on its remarkable 
inhibitory effect on HIF-1 $\alpha$ and VEGF expression. Furthermore, the A2780/CP70 human ovarian cancer cell line used in this study is cisplatin resistant. A2780/CP70 was developed by chronic exposure of the parent cisplatin-sensitive A2780 cell line to increasing concentrations of cisplatin in culture (47). OVCAR-3 was derived from the malignant ascites of a patient with progressive ovarian cancer resistant to clinically relevant concentrations of cisplatin (48). Therefore, our data suggest that resveratrol may exert anticancer effects even in cisplatin-resistant ovarian cancer patients. Indeed, resveratrol recently has been shown to have synergistic cytotoxic activity when used in combination with chemotherapeutic drugs or cytotoxic factors in the treatment of drug refractory tumor cells (49). Finally, based on its effects on protein translational regulation and HIF-1 $\alpha_{\alpha}$ protein degradation, two processes that are not cell-type specific, resveratrol may inhibit expression of HIF-1 $\alpha$ and VEGF in other human malignancies with high levels of HIF-1 $\alpha$ expression. This may also explain, at least in part, the broad spectrum of anticancer effects of resveratrol observed previously in various human cancer cell lines. 
Figures and Figure Legends

Fig. 1.

A

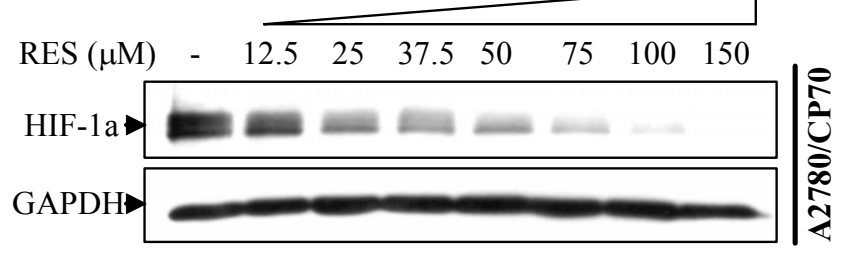

B

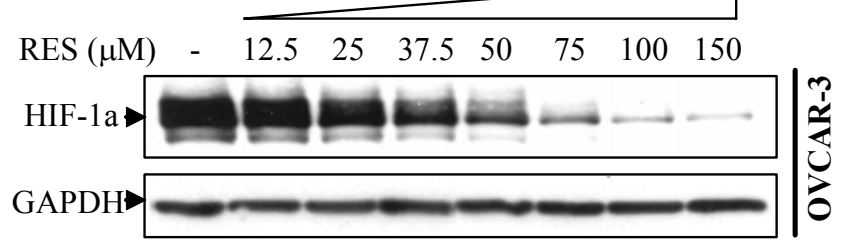

C

Incubation time $(\mathrm{h})$

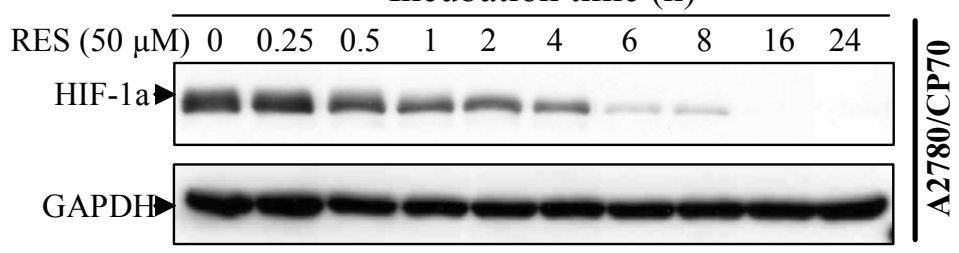

D

Incubation time $(\mathrm{h})$

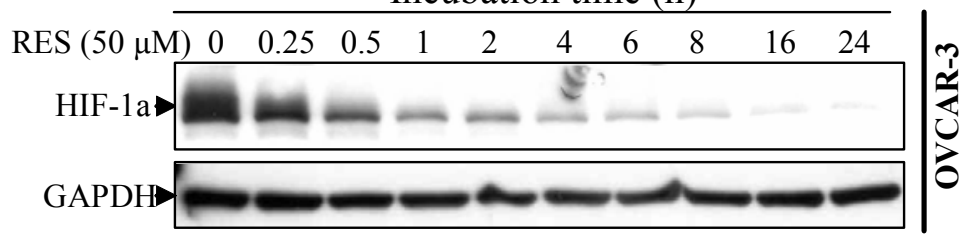

$\mathbf{E}$

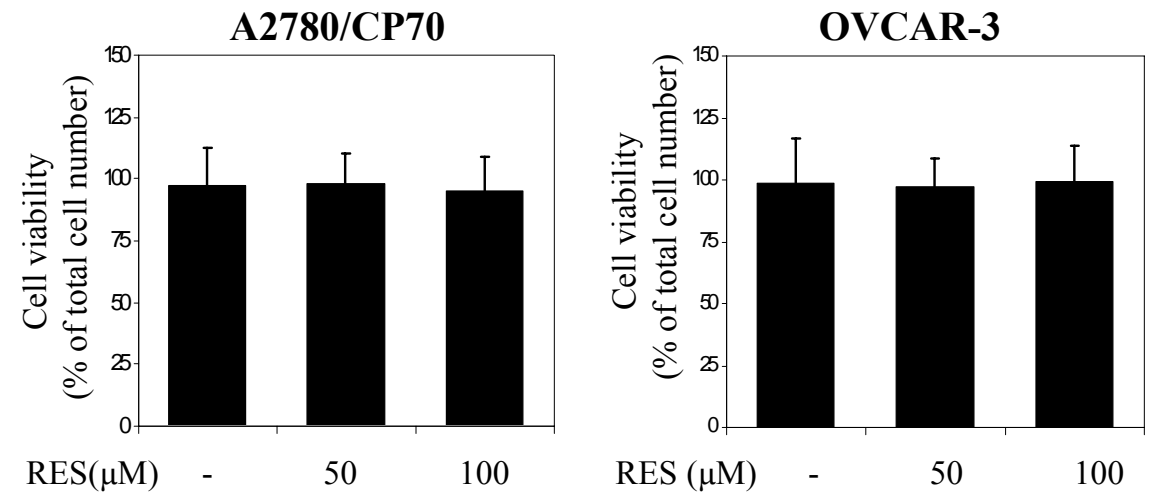


Fig. 1. Resveratrol (RES) decreased HIF-1 $\alpha$ protein levels in A2780/CP70 and OVCAR-3 cells. $A$ and $B, A 2780 / C P 70$ and OVCAR-3 cells were cultured to $80 \%$ confluence and then treated with solvent alone or various concentrations of resveratrol for $6 \mathrm{~h}$. Cell lysates were subjected to immunoblotting analysis using an anti-HIF-1 $\alpha$ monoclonal antibody. The blot was stripped off and rehybridized with an anti-GAPDH antibody as a control for protein loading and transfer efficiency. $C$ and $D, \mathrm{~A} 2780 / \mathrm{CP} 70$ and OVCAR-3 cells were cultured to $80 \%$ confluence and then treated with $50 \mu \mathrm{m}$ resveratrol for $0-24 \mathrm{~h}$ as indicated. The HIF-1 $\alpha$ and GAPDH proteins were analyzed by immunoblotting as described above. E, A2780/CP70 and OVCAR-3 cells were treated with 50 and $100 \mu \mathrm{m}$ resveratrol for $6 \mathrm{~h}$. Cell viability was assayed by the trypan blue dye exclusion method. The percentage of viable cells represented the mean \pm SD from three replicate experiments. 
Fig. 2 .

A

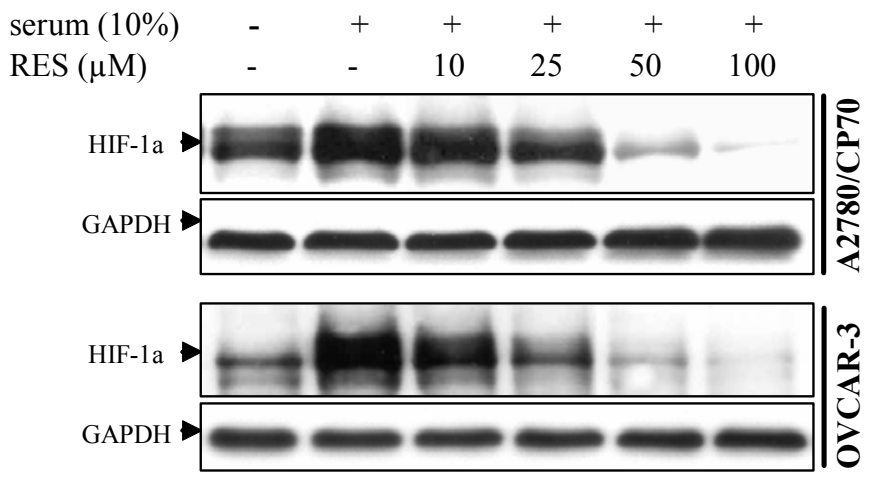

B
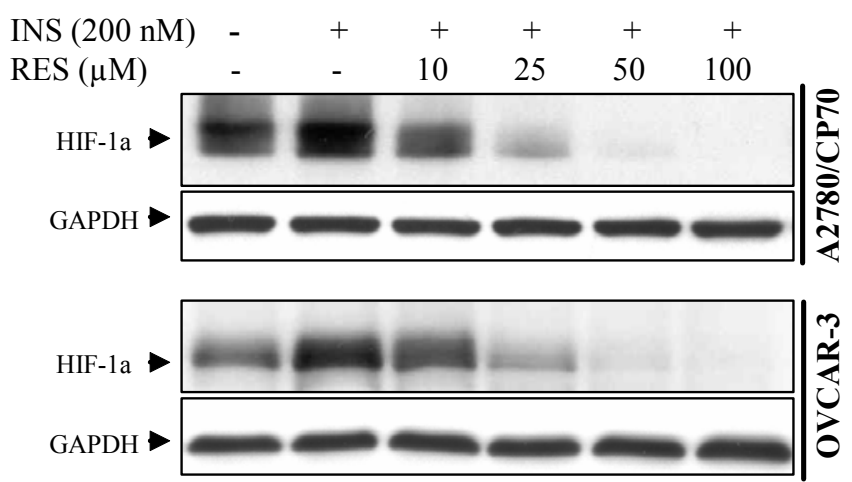

C

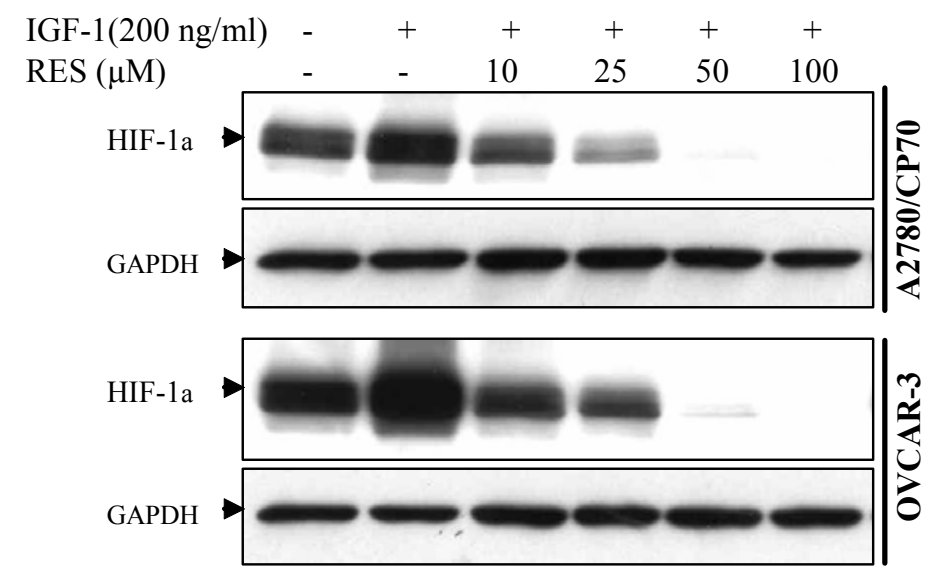


Fig. 2. Resveratrol (RES) inhibited serum-induced, insulin-induced, and IGF-1-induced HIF-1a expression. Serum-starved A2780/CP70 and OVCAR-3 cells were pretreated with solvent alone (lane 1, 2) or various doses of resveratrol for $30 \mathrm{~min}$, followed by stimulation with $10 \%$ fetal bovine serum (A), $200 \mu \mathrm{M}$ of insulin (INS; B), or $200 \mathrm{ng} / \mathrm{ml} \mathrm{IGF-1} \mathrm{(C)} \mathrm{for} 6 \mathrm{~h}$. Whole cell extracts were subjected to immunoblotting analysis using antibodies specific for HIF-1 $\alpha$ or GAPDH. 
Fig. 3.

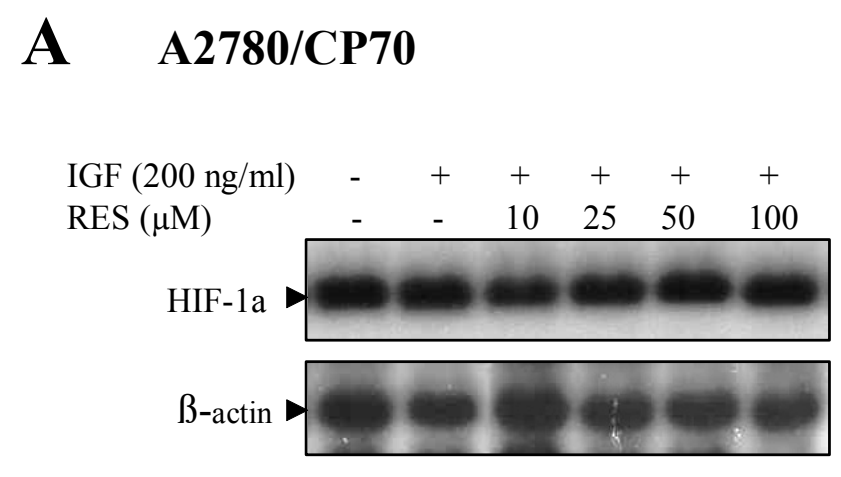

\section{B OVCAR-3}

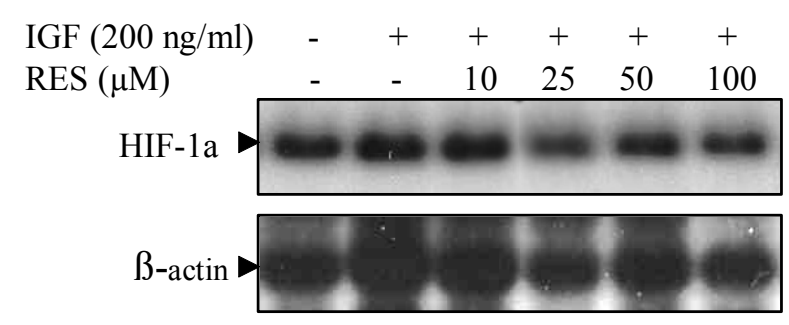

Fig. 3. Effect of resveratrol (RES) on HIF-1 $\alpha$ mRNA levels. Serum-starved A2780/CP70 and OVCAR-3 cells were pretreated with solvent alone (Lanes 1 and 2) or various doses of resveratrol for $30 \mathrm{~min}$, followed by incubation with $200 \mathrm{ng} / \mathrm{ml} \mathrm{IGF-1} \mathrm{for} 6 \mathrm{~h}$. Total RNA was extracted and subjected to Northern blot analysis using a human HIF-1 $\alpha$ cDNA probe. The blot was stripped off and reprobed with $B$-actin cDNA probe as an internal control. 
Fig. 4.

A
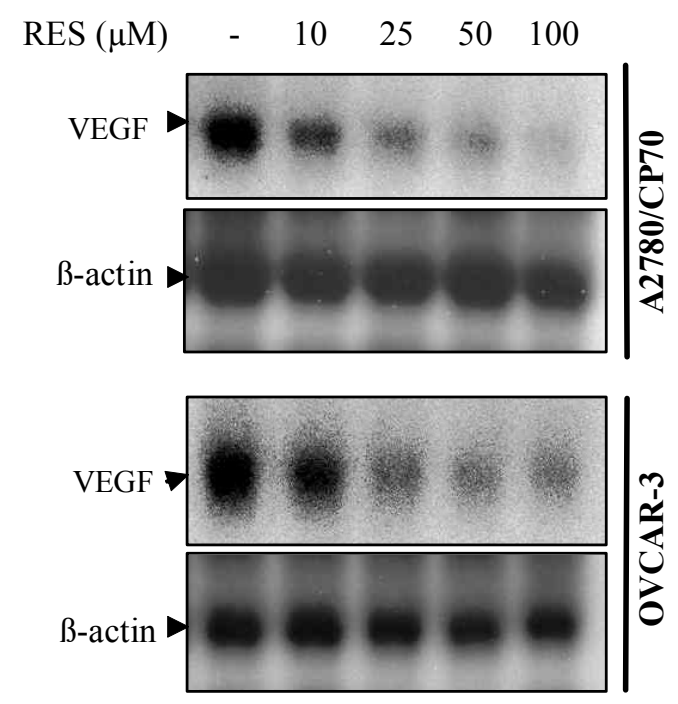

\section{B}
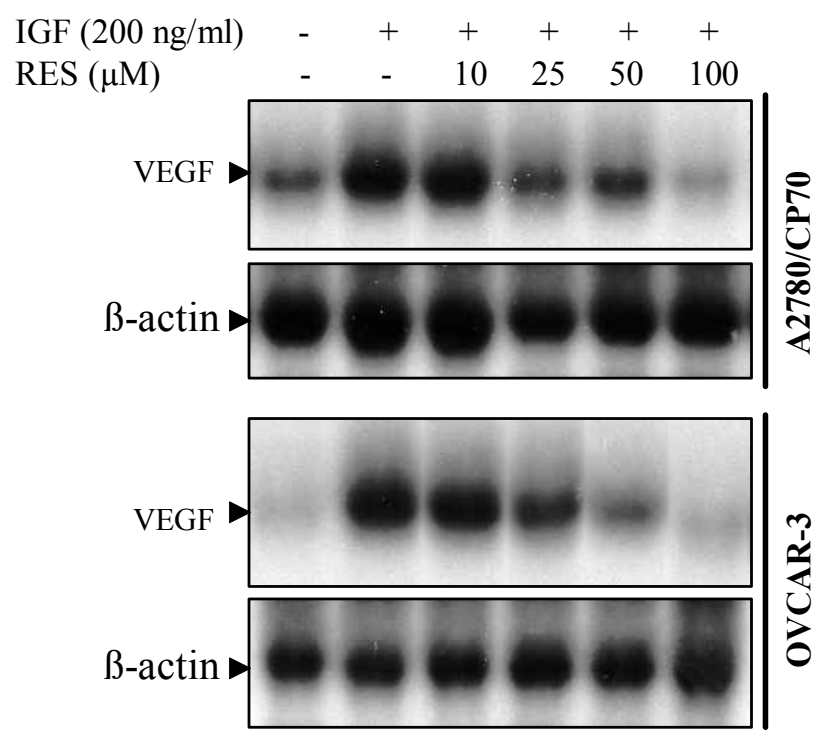
Fig. 4. Effect of resveratrol (RES) on VEGF mRNA expression in the cells. $A$, A2780/CP70 and OVCAR-3 cells cultured in complete medium were treated with solvent alone (Lane 1) or various doses of resveratrol for $6 \mathrm{~h}$. Total RNA was extracted and analyzed by Northern blotting using a VEGF cDNA probe. The blot was stripped off and reprobed with $\beta$-actin cDNA probe as an internal control. B, serum-starved A2780/CP70 and OVCAR-3 cells were pretreated with solvent alone (Lanes 1 and 2) or various doses of resveratrol for $30 \mathrm{~min}$, followed by incubation with $200 \mathrm{ng} / \mathrm{ml}$ IGF-1 for $6 \mathrm{~h}$. Total RNA was extracted and analyzed by Northern blotting using VEGF or $\beta$-actin cDNA probe. 
Fig. 5.

A
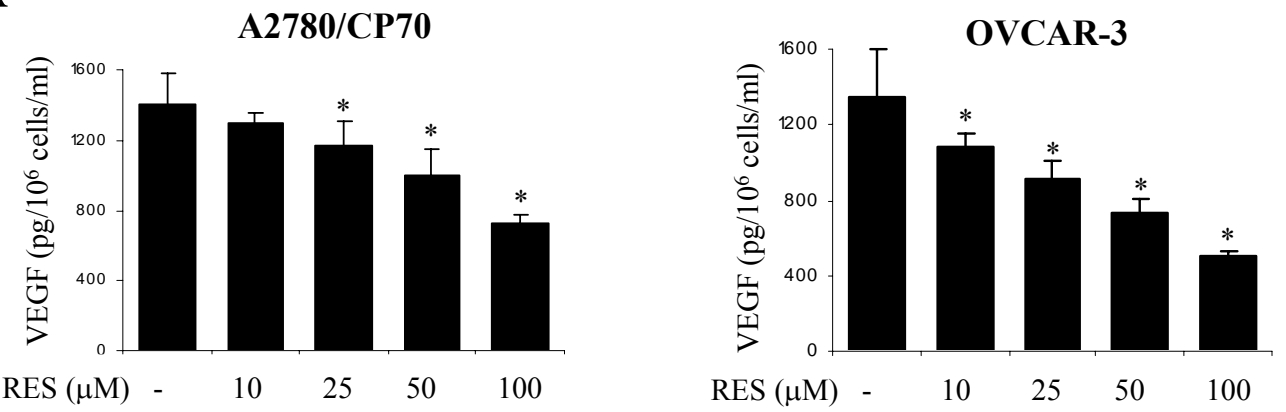

B
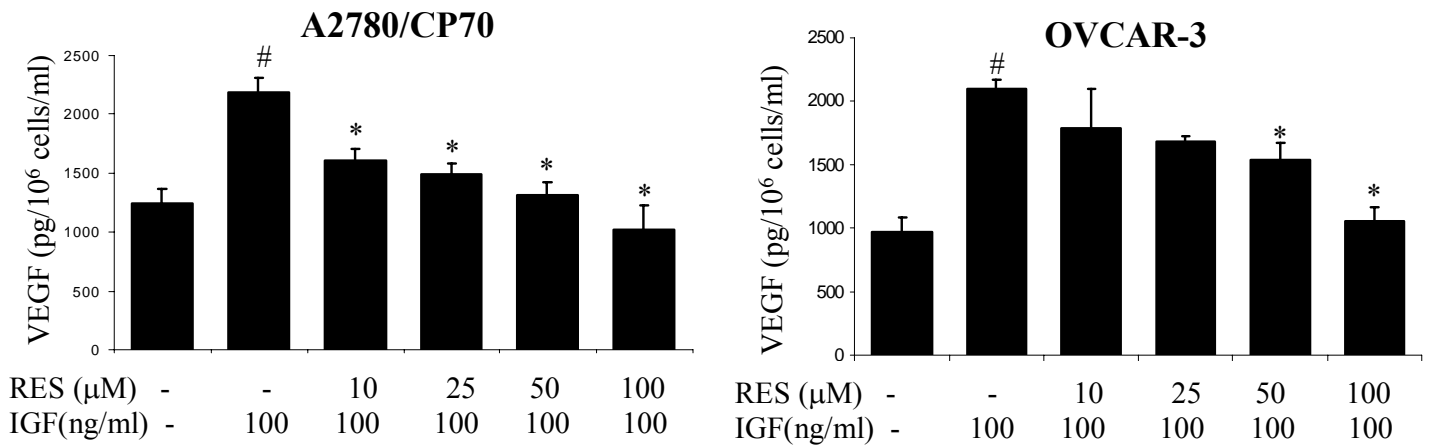

C
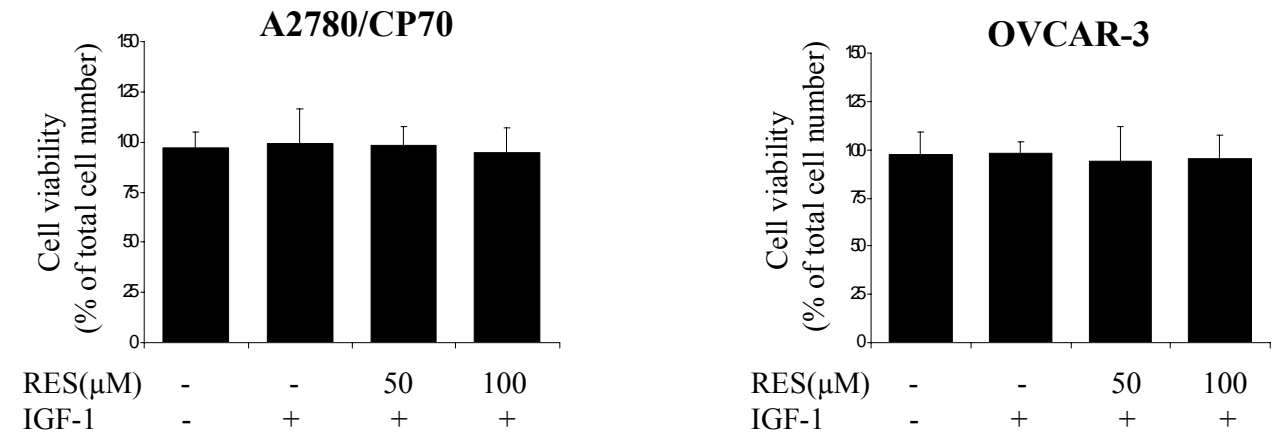
Fig. 5. Effect of resveratrol (RES) on VEGF protein levels. A, A2780/CP70 and OVCAR-3 cells cultured in complete medium were treated with solvent alone or various doses of resveratrol for $12 \mathrm{~h}$. VEGF protein concentrations in the medium were measured by ELISA assays. The results were normalized to the number of cells per plate, and data were presented as mean $\pm \mathrm{SD}$ from three replicate experiments. *, significant difference when compared with the solvent treatment $(P<0.01)$. B, cells were cultured in serum-free and insulin-free medium overnight, followed by the addition of IGF-1 in the absence or presence of various concentrations of resveratrol for $12 \mathrm{~h}$. VEGF protein concentrations in the medium were measured by ELISA assay. \#, significant difference when compared with the unstimulated control $(P<0.01) ; *$, significant difference when compared with IGF-1-treated cells $(P<0.01)$. $C$, cells were cultured in serum-free and insulin-free medium overnight, followed by exposure to IGF-1 in the absence or presence of 50 or $100 \mu \mathrm{m}$ resveratrol for $12 \mathrm{~h}$. Cell viability was assayed by the trypan blue dye exclusion method. The percentage of cell viability represented mean \pm SD from three triplicate experiments. 
Fig. 6.

A

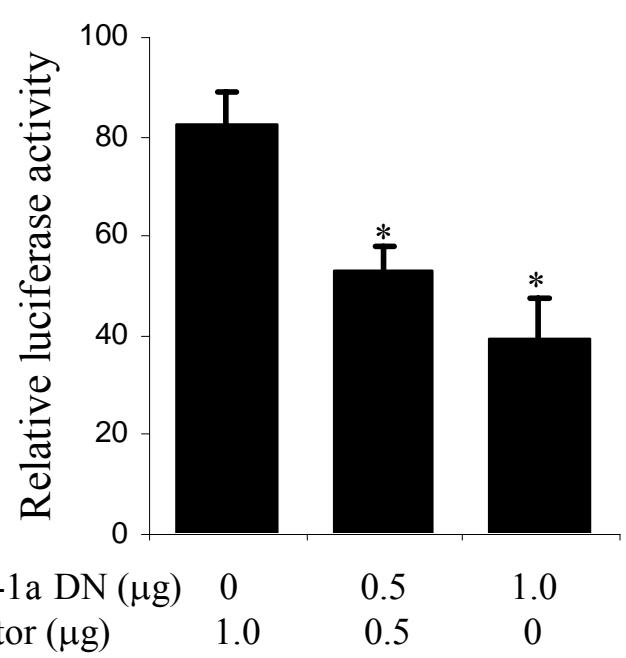

B

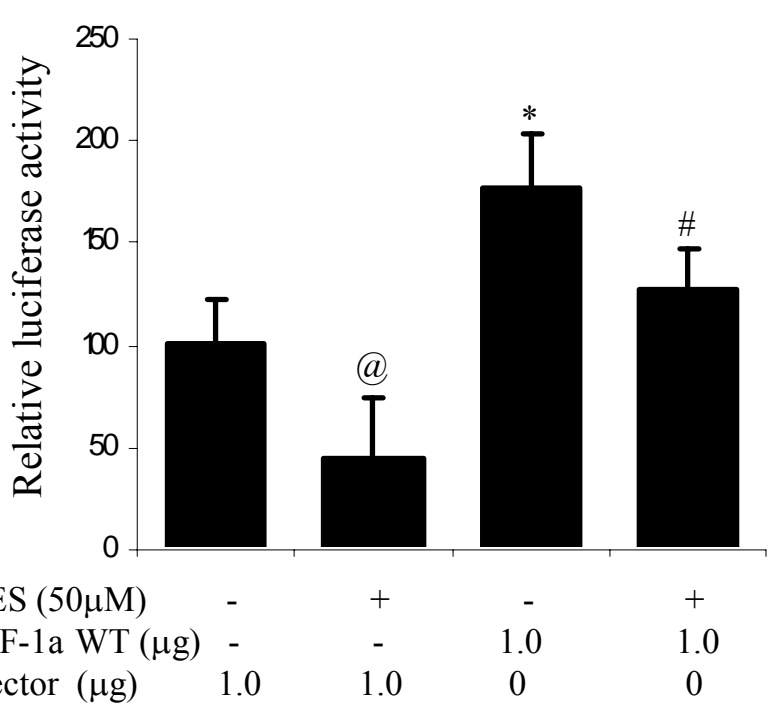

Fig. 6. HIF-1 $\alpha$-mediated VEGF transcriptional activation in human ovarian cancer cells. $A$, A2780/CP70 cells were cultured in normal growth medium. HIF-1 $\alpha$-expressing plasmid was cotransfected into the cells with the reporter plasmid and the pCMV-ß-gal plasmid. An empty vector plasmid was used to adjust to the same amounts of plasmids used in each transfection. After overnight recovery, the cells were treated with solvent or $50 \mu \mathrm{M}$ resveratrol (RES) for $12 \mathrm{~h}$. Luciferase activity was measured and normalized to $\beta$-galactosidase activity. Assays were performed in triplicate, and data were presented as mean \pm SD. *, significant difference compared with the solvent control; \#, significant difference compared with the vector control $(P$ $<0.01)$. $B$, cells were cotransfected with the indicated amount of a dominant-negative HIF-1 $\alpha$ plasmid, pCMV-ß-gal plasmid, and a VEGF promoter reporter plasmid. Luciferase activity was measured $24 \mathrm{~h}$ after transfection and normalized to ß-galactosidase activity. Assays were performed in triplicate, and data were presented as mean \pm SD. *, significant difference when compared with the control $(P<0.01)$. 
Fig. 7.

\section{A $\quad \mathrm{A2780/CP70}$}

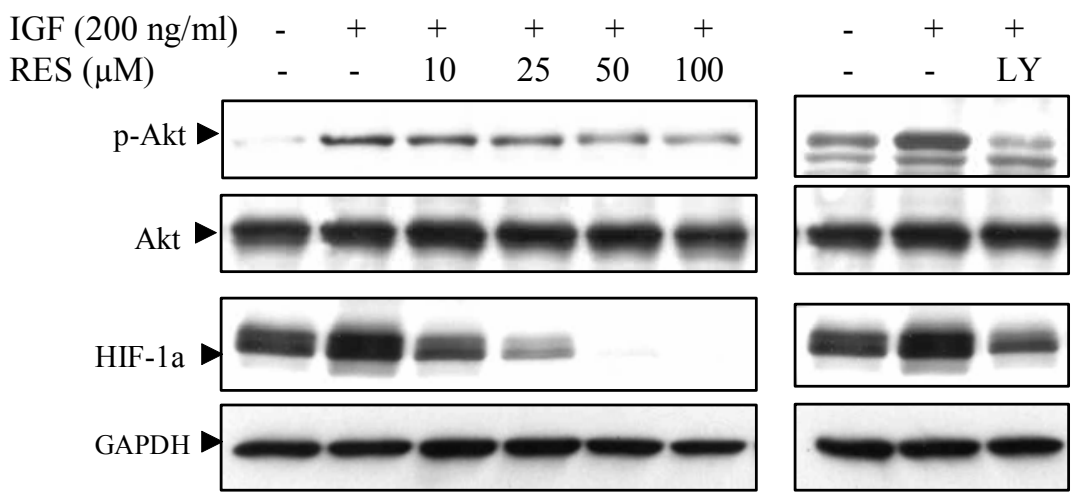

\section{B OVCAR-3}

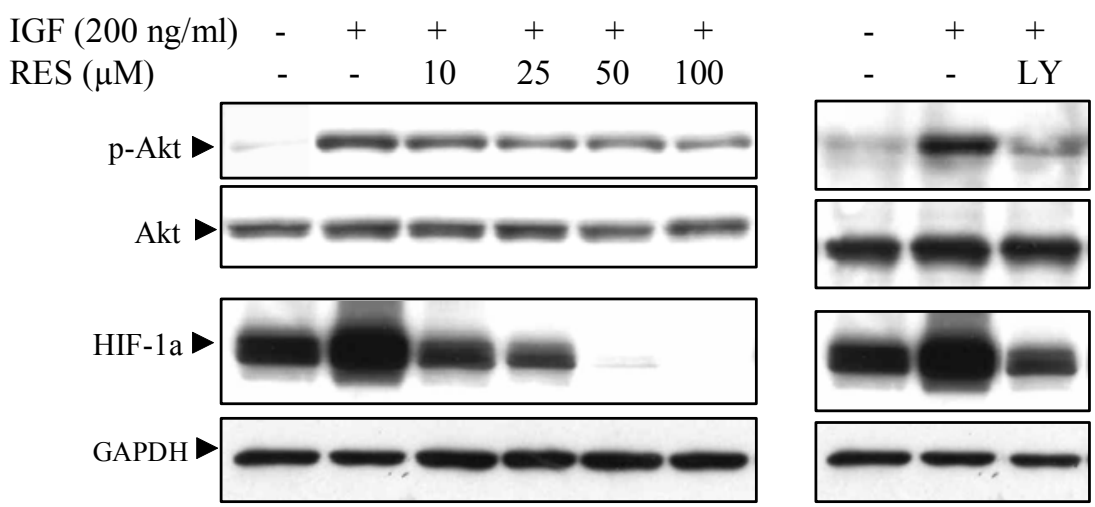


Fig. 7.

\section{C $\quad \mathbf{A 2 7 8 0 / C P 7 0}$}

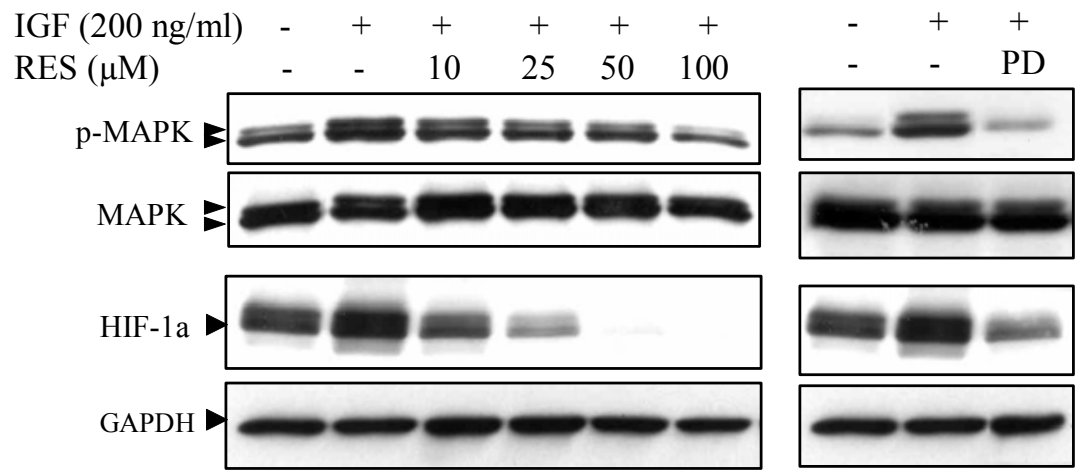

D OVCAR-3

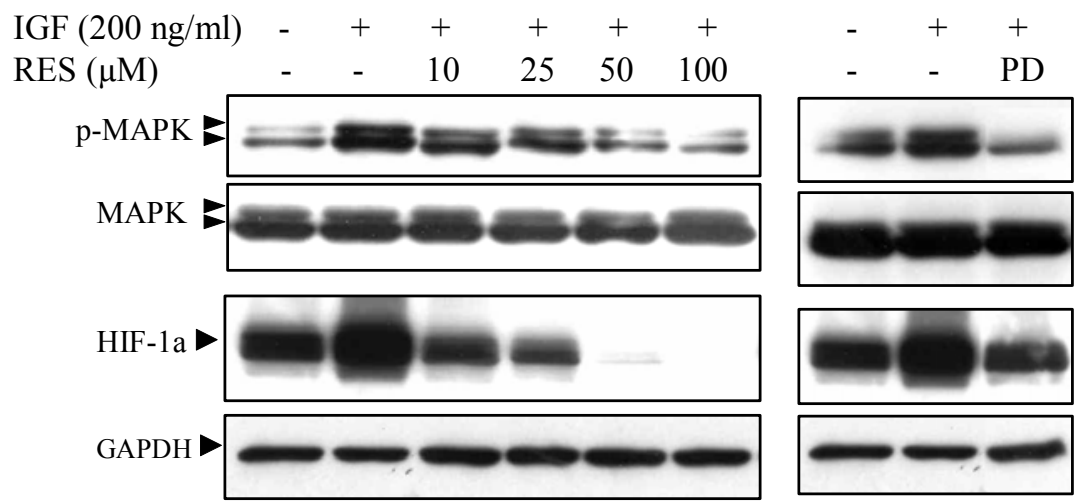


Fig. 7. Effect of resveratrol (RES) on AKT and MAPK activation. $A$ and $B$, effects of resveratrol on AKT activation and HIF-1 $\alpha$ expression in ovarian cancer cells. Serum-starved A2780/CP70 and OVCAR-3 cells were pretreated with solvent alone or various doses of resveratrol for $30 \mathrm{~min}$, followed by incubation with $200 \mathrm{ng} / \mathrm{ml} \mathrm{IGF-1} \mathrm{for} 6 \mathrm{~h}$ as indicated. Cell lysates were subjected to immunoblotting analysis using antibodies against phospho-AKT ( $p$ AKT; Ser-473), total AKT (AKT), HIF-1 $\propto$, and GAPDH, respectively. $C$ and $D$, effects of resveratrol and PD98059 on MAPK activation and HIF-1 $\alpha$ expression. Serum-starved A2780/CP70 and OVCAR-3 cells were pretreated with solvent alone, various doses of resveratrol, or $50 \mu \mathrm{M}$ PD98059 for $30 \mathrm{~min}$, followed by incubation with $200 \mathrm{ng} / \mathrm{ml} \mathrm{IGF-1} \mathrm{for} 6 \mathrm{~h}$ as indicated. Cell lysates were subjected to immunoblotting analysis using antibodies against phospho-p42/p44 MAPK ( $p$-MAPK; extracellular signal-regulated kinase 1/2), total MAPK (MAPK), HIF-1 $\propto$, and GAPDH, respectively. 
Fig. 8.

A

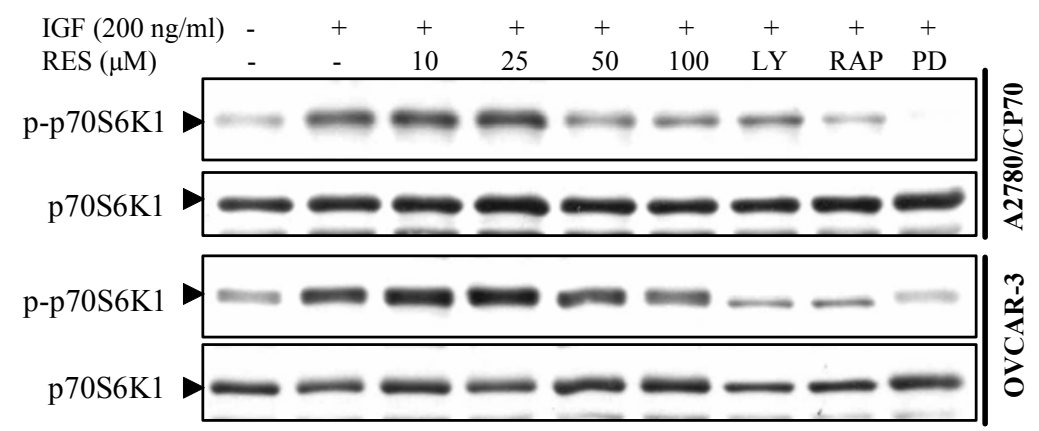

B

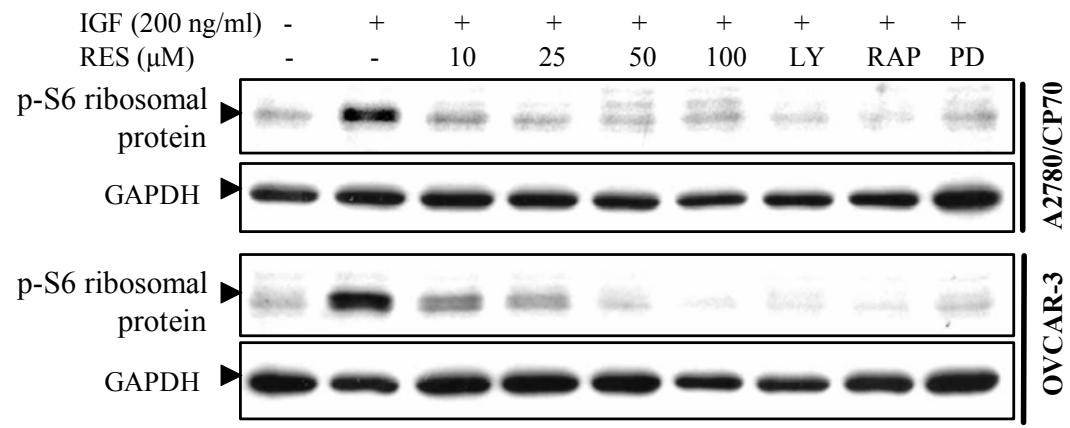

C

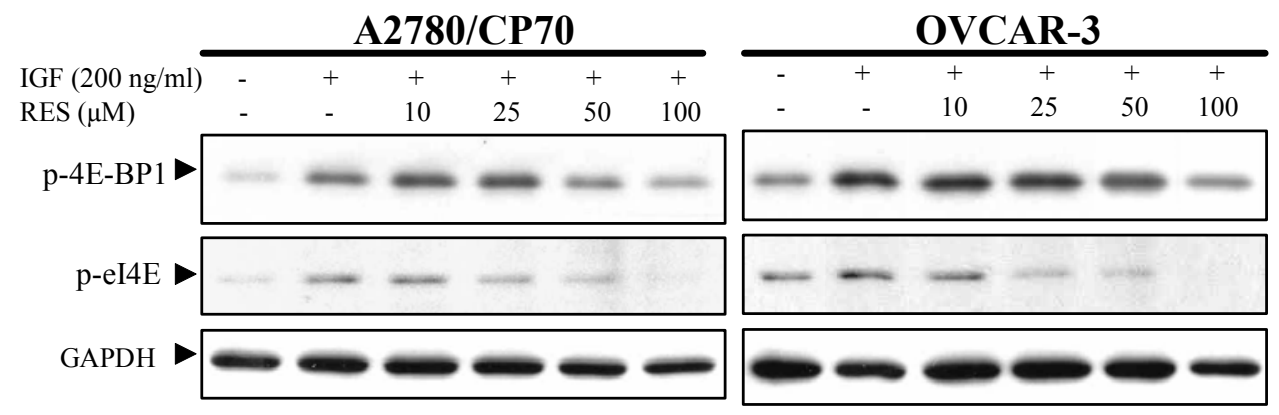

D

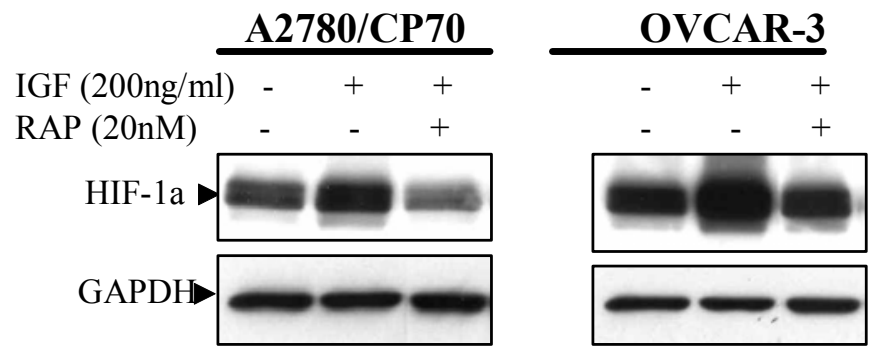


Fig. 8. Effect of resveratrol on phosphorylation of p70S6K1, S6 ribosomal protein, 4E-BP1, and eIF4E. $A$, serum-starved A2780/CP70 and OVCAR-3 cells were pretreated with solvent alone (Lanes 1 and 2) or various doses of resveratrol (RES), $20 \mu \mathrm{M}$ LY294002 (LY), $25 \mathrm{nM}_{\mathrm{M}}$ rapamycin $(R A P)$, or $50 \mu \mathrm{M}$ PD98059 $(P D)$ for $30 \mathrm{~min}$, followed by incubation with $200 \mathrm{ng} / \mathrm{ml}$ IGF-1 for $6 \mathrm{~h}$. Cell lysates were analyzed by immunoblotting using antibodies specific for phospho-p70S6K1 (p-p70S6K1; Thr-421/Ser-424) and total p70S6K1. B, protein samples from cells treated as described above were analyzed by immunoblotting using specific antibodies against phospho-S6 ribosomal protein (Ser-235/236) and GAPDH. C, serum-starved A2780/CP70 and OVCAR-3 cells were pretreated with solvent alone or various doses of resveratrol for $30 \mathrm{~min}$, followed by incubation with $200 \mathrm{ng} / \mathrm{ml} \mathrm{IGF-1} \mathrm{for} 6 \mathrm{~h}$. Cell lysates were analyzed by immunoblotting using antibodies specific for phospho-4E-BP1 ( $p-4 E-B P 1$; Ser-65), phospho-eIF4E (p-eIF4E; Ser-209), and GAPDH. D, A2780/CP70 and OVCAR-3 cells were serum-starved overnight and then pretreated with $20 \mathrm{~nm}$ rapamycin for $30 \mathrm{~min}$, followed by exposure to $200 \mathrm{ng} / \mathrm{ml} \mathrm{IGF-1} \mathrm{for} 6 \mathrm{~h}$. Immunoblotting analysis was performed using anti-HIF-1 $\alpha$ and GAPDH, respectively. 
Fig. 9.
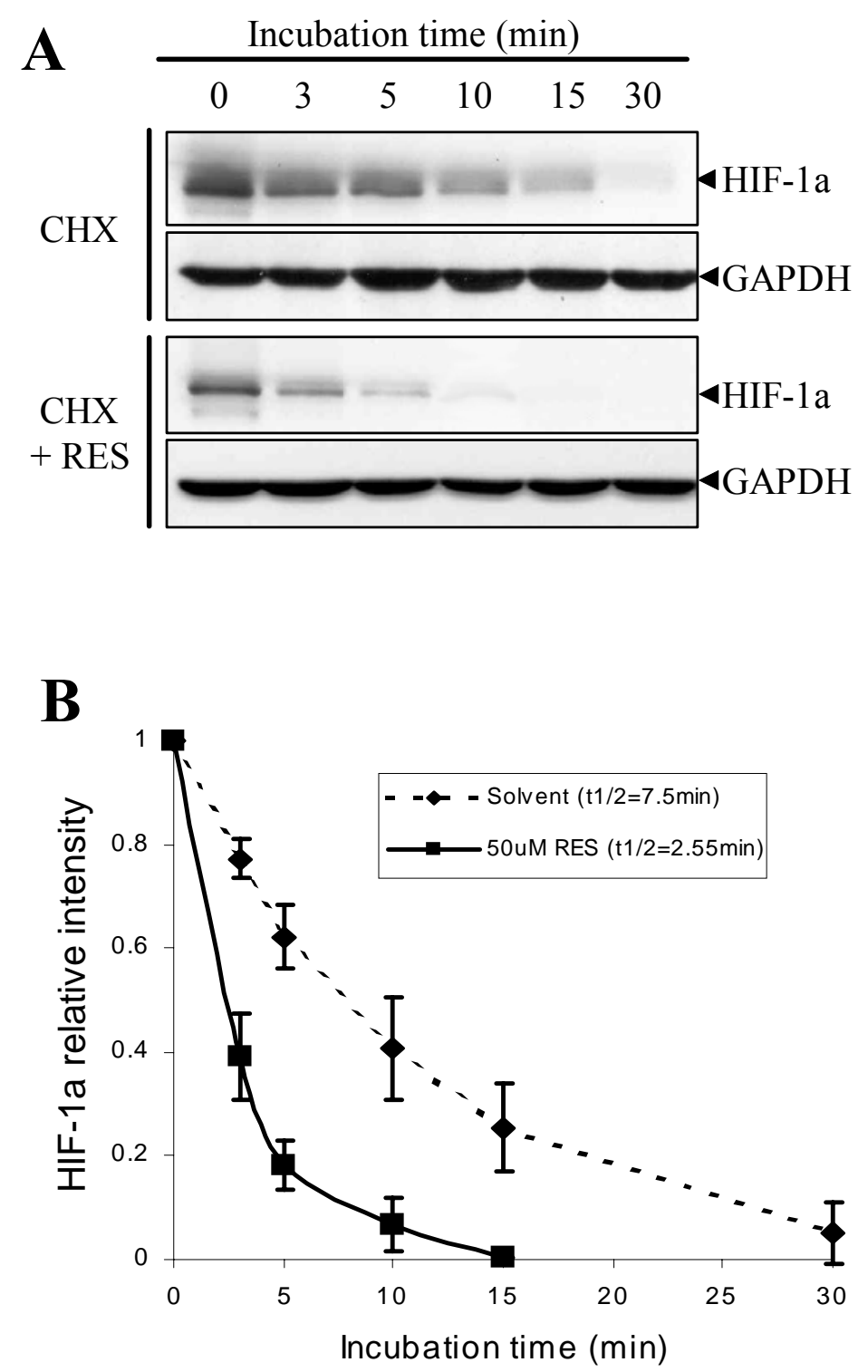

Fig. 9. Effect of resveratrol on HIF-1 $\alpha$ protein stability. A, A2780/CP70 cells were cultured in normal growth medium to $80 \%$ confluence. The cells were treated with solvent alone (CHX; top panel) or $50 \mu \mathrm{M}$ resveratrol $(C H X+R E S$; bottom panel) for $1 \mathrm{~h}$, followed by incubation with 100 $\mu \mathrm{M}$ cycloheximide from 0 to $30 \mathrm{~min}$. Cell lysates were subjected to immunoblotting using 
antibodies against HIF- $1 \alpha$ or GAPDH. $B$, intensity of HIF- $1 \alpha$ protein signals obtained in $A$ was quantified using EagleSight densitometry software (Version 3.21; Stratagene). The HIF-1 $\alpha$ densitometry data were normalized to that of the control (Lane 1) and GAPDH levels. The plots represented mean $\pm \mathrm{SD}$ from three independent experiments. Calculation of HIF-1 $\alpha$ half-life was performed by the Regression program of Microsoft Excel 2000. 
Fig. 10.

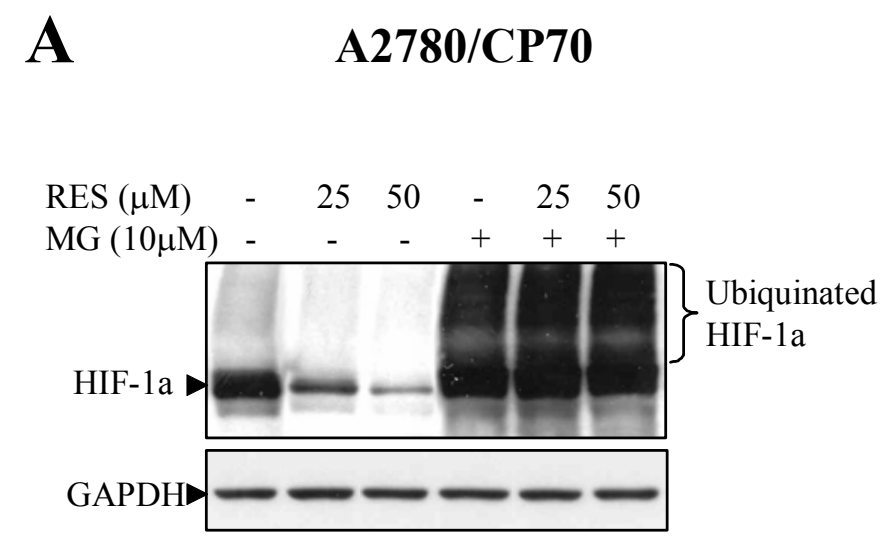

\section{B OVCAR-3}

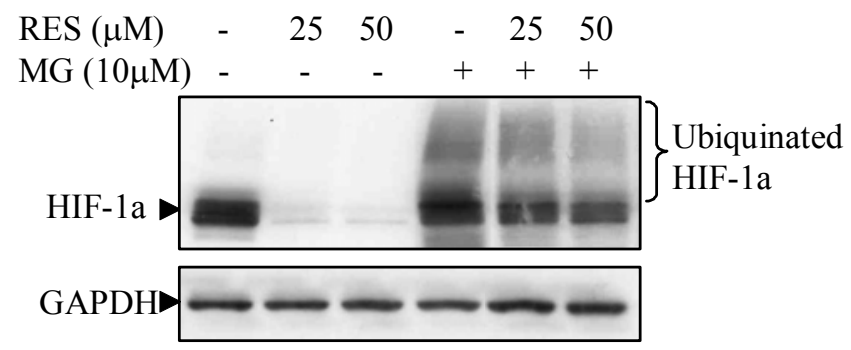

Fig. 10. Resveratrol-induced HIF-1 $\alpha$ protein degradation is mediated by the proteasome pathway. A2780/CP70 and OVCAR-3 cells were pretreated with vehicle or $10 \mu \mathrm{M}$ MG132 (MG) for $30 \mathrm{~min}$, followed by treatment with 25 or $50 \mu \mathrm{M}$ resveratrol (RES) for $6 \mathrm{~h}$. Whole-cell lysates were subjected to immunoblotting analysis using antibodies against HIF-1 $\alpha$ and GAPDH. 


\section{References}

1. Langcake, P., Pryce, R. J. The production of resveratrol by Vitis vinifera and other members of the Vitaceae as a response to infection or injury. Physiol Plant Pathol 1976; 9:77-86..

2. Jang, M., Cai, L., Udeani, G. O., Slowing, K. V., Thomas, C. F., Beecher, C. W., Fong, H. H., Farnsworth, N. R., Kinghorn, A. D., Mehta, R. G., Moon, R. C., and Pezzuto, J. M. Cancer chemopreventive activity of resveratrol, a natural product derived from grapes. Science 1997;275:218-220.

3. Gusman, J., Malonne, H., and Atassi, G. A reappraisal of the potential chemopreventive and chemotherapeutic properties of resveratrol. Carcinogenesis 2001;22:1111-1117.

4. Bhat, K. P. and Pezzuto, J. M. Cancer chemopreventive activity of resveratrol. Ann N Y Acad Sci 2002;957:210-229.

5. Carbo, N., Costelli, P., Baccino, F. M., Lopez-Soriano, F. J., and Argiles, J. M. Resveratrol, a natural product present in wine, decreases tumour growth in a rat tumour model. Biochem Biophys Res Commun 1999;254:739-743.

6. Perez, R. P., Godwin, A. K., Hamilton, T. C., and Ozols, R. F. Ovarian cancer biology. Semin Oncol 1991;18:186-204.

7. Greenlee, R. T., Hill-Harmon, M. B., Murray, T., and Thun, M. Cancer statistics, 2001. CA Cancer J Clin 2001;51:15-36.

8. McGuire, W. P., Hoskins, W. J., Brady, M. F., Kucera, P. R., Partridge, E. E., Look, K. Y., Clarke-Pearson, D. L., and Davidson, M. Cyclophosphamide and cisplatin compared with paclitaxel and cisplatin in patients with stage III and stage IV ovarian cancer. N Engl J Med, 334: 1-6, 1996.

9. Folkman, J. What is the evidence that tumors are angiogenesis dependent? J Natl Cancer Inst, 82: 4-6, 1990.

10. Vaupel, P., Thews, O., and Hoeckel, M. Treatment resistance of solid tumors: role of hypoxia and anemia. Med Oncol, 18: 243-259, 2001.

11. Forsythe, J. A., Jiang, B. H., Iyer, N. V., Agani, F., Leung, S. W., Koos, R. D., and Semenza, G. L. Activation of vascular endothelial growth factor gene transcription by hypoxia-inducible factor 1. Mol Cell Biol, 16: 4604-4613, 1996.

12. Chiarugi, V., Magnelli, L., Chiarugi, A., and Gallo, O. Hypoxia induces pivotal tumor angiogenesis control factors including p53, vascular endothelial growth factor and the NFkappaB-dependent inducible nitric oxide synthase and cyclooxygenase-2. J Cancer Res Clin Oncol, 125: 525-528, 1999. 
13. Wenger, R. H. Cellular adaptation to hypoxia: O2-sensing protein hydroxylases, hypoxiainducible transcription factors, and O2-regulated gene expression. FASEB J, 16: 1151$1162,2002$.

14. Boocock, C. A., Charnock-Jones, D. S., Sharkey, A. M., McLaren, J., Barker, P. J., Wright, K. A., Twentyman, P. R., and Smith, S. K. Expression of vascular endothelial growth factor and its receptors flt and KDR in ovarian carcinoma. J Natl Cancer Inst, 87: 506-516, 1995.

15. Abu-Jawdeh, G. M., Faix, J. D., Niloff, J., Tognazzi, K., Manseau, E., Dvorak, H. F., and Brown, L. F. Strong expression of vascular permeability factor (vascular endothelial growth factor) and its receptors in ovarian borderline and malignant neoplasms. Lab Invest, 74: 1105-1115, 1996.

16. Semenza, G. L. Hypoxia, clonal selection, and the role of HIF-1 in tumor progression. Crit Rev Biochem Mol Biol, 35: 71-103, 2000.

17. Ryan, H. E., Poloni, M., McNulty, W., Elson, D., Gassmann, M., Arbeit, J. M., and Johnson, R. S. Hypoxia-inducible factor-1alpha is a positive factor in solid tumor growth. Cancer Res, 60: 4010-4015, 2000.

18. Carmeliet, P., Dor, Y., Herbert, J. M., Fukumura, D., Brusselmans, K., Dewerchin, M., Neeman, M., Bono, F., Abramovitch, R., Maxwell, P., Koch, C. J., Ratcliffe, P., Moons, L., Jain, R. K., Collen, D., Keshert, E., and Keshet, E. Role of HIF-1alpha in hypoxiamediated apoptosis, cell proliferation and tumour angiogenesis. Nature, 394: 485-490, 1998.

19. Zhong, H., Chiles, K., Feldser, D., Laughner, E., Hanrahan, C., Georgescu, M. M., Simons, J. W., and Semenza, G. L. Modulation of hypoxia-inducible factor 1alpha expression by the epidermal growth factor/phosphatidylinositol 3kinase/PTEN/AKT/FRAP pathway in human prostate cancer cells: implications for tumor angiogenesis and therapeutics. Cancer Res, 60: 1541-1545, 2000.

20. Blancher, C., Moore, J. W., Robertson, N., and Harris, A. L. Effects of ras and von Hippel-Lindau (VHL) gene mutations on hypoxia-inducible factor (HIF)-1alpha, HIF2alpha, and vascular endothelial growth factor expression and their regulation by the phosphatidylinositol 3'-kinase/Akt signaling pathway. Cancer Res, 61: 7349-7355, 2001.

21. Karni, R., Dor, Y., Keshet, E., Meyuhas, O., and Levitzki, A. Activated pp60c-Src leads to elevated hypoxia-inducible factor (HIF)-1alpha expression under normoxia. J Biol Chem, 277: 42919-42925, 2002.

22. Fukuda, R., Hirota, K., Fan, F., Jung, Y. D., Ellis, L. M., and Semenza, G. L. Insulin-like growth factor 1 induces hypoxia-inducible factor 1-mediated vascular endothelial growth factor expression, which is dependent on MAP kinase and phosphatidylinositol 3-kinase signaling in colon cancer cells. J Biol Chem, 277: 38205-38211, 2002. 
23. Jiang, B. H., Jiang, G., Zheng, J. Z., Lu, Z., Hunter, T., and Vogt, P. K. Phosphatidylinositol 3-kinase signaling controls levels of hypoxia-inducible factor 1. Cell Growth Differ, 12: 363-369, 2001.

24. Zhong, H., De Marzo, A. M., Laughner, E., Lim, M., Hilton, D. A., Zagzag, D., Buechler, P., Isaacs, W. B., Semenza, G. L., and Simons, J. W. Overexpression of hypoxiainducible factor 1alpha in common human cancers and their metastases. Cancer Res, 59: 5830-5835, 1999.

25. Boss, E. A., Massuger, L. F., Thomas, C. M., Geurts-Moespot, A., Boonstra, H., and Sweep, C. G. Vascular endothelial growth factor in ovarian cyst fluid. Cancer, 91: 371$377,2001$.

26. Mesiano, S., Ferrara, N., and Jaffe, R. B. Role of vascular endothelial growth factor in ovarian cancer: inhibition of ascites formation by immunoneutralization. Am J Pathol, 153: 1249-1256, 1998.

27. Gasparini, G., Bonoldi, E., Viale, G., Verderio, P., Boracchi, P., Panizzoni, G. A., Radaelli, U., Di Bacco, A., Guglielmi, R. B., and Bevilacqua, P. Prognostic and predictive value of tumour angiogenesis in ovarian carcinomas. Int J Cancer, 69: 205-211, 1996.

28. Shen, G. H., Ghazizadeh, M., Kawanami, O., Shimizu, H., Jin, E., Araki, T., and Sugisaki, Y. Prognostic significance of vascular endothelial growth factor expression in human ovarian carcinoma. Br J Cancer, 83: 196-203, 2000.

29. Yee, D. Are the insulin-like growth factors relevant to cancer? Growth Horm IGF Res, 11: 339-345, 2001.

30. Zelzer, E., Levy, Y., Kahana, C., Shilo, B. Z., Rubinstein, M., and Cohen, B. Insulin induces transcription of target genes through the hypoxia-inducible factor HIF1alpha/ARNT. EMBO J, 17: 5085-5094, 1998.

31. Fukuda, R., Hirota, K., Fan, F., Jung, Y. D., Ellis, L. M., and Semenza, G. L. Insulin-like growth factor 1 induces hypoxia-inducible factor 1-mediated vascular endothelial growth factor expression, which is dependent on MAP kinase and phosphatidylinositol 3-kinase signaling in colon cancer cells. J Biol Chem, 277: 38205-38211, 2002.

32. Treins, C., Giorgetti-Peraldi, S., Murdaca, J., Semenza, G. L., and Van Obberghen, E. Insulin stimulates hypoxia-inducible factor 1 through a phosphatidylinositol 3kinase/target of rapamycin-dependent signaling pathway. J Biol Chem, 277: 2797527981, 2002.

33. Laughner, E., Taghavi, P., Chiles, K., Mahon, P. C., and Semenza, G. L. HER2 (neu) signaling increases the rate of hypoxia-inducible factor 1alpha (HIF-1alpha) synthesis: novel mechanism for HIF-1-mediated vascular endothelial growth factor expression. Mol Cell Biol, 21: 3995-4004, 2001. 
34. Bilton, R. L. and Booker, G. W. The subtle side to hypoxia inducible factor (HIFalpha) regulation. Eur J Biochem, 270: 791-798, 2003.

35. Semenza, G. Signal transduction to hypoxia-inducible factor 1. Biochem Pharmacol, 64: 993-998, 2002.

36. Gingras, A. C., Raught, B., and Sonenberg, N. Regulation of translation initiation by FRAP/mTOR. Genes Dev, 15: 807-826, 2001.

37. Wenger, R. H. Cellular adaptation to hypoxia: O2-sensing protein hydroxylases, hypoxiainducible transcription factors, and O2-regulated gene expression. FASEB J, 16: 1151$1162,2002$.

38. McMahon, G. VEGF receptor signaling in tumor angiogenesis. Oncologist, 5 Suppl 1: 3$10,2000$.

39. Reinmuth, N., Liu, W., Fan, F., Jung, Y. D., Ahmad, S. A., Stoeltzing, O., Bucana, C. D., Radinsky, R., and Ellis, L. M. Blockade of insulin-like growth factor I receptor function inhibits growth and angiogenesis of colon cancer. Clin Cancer Res, 8: 3259-3269, 2002.

40. Stoeltzing, O., Liu, W., Reinmuth, N., Fan, F., Parikh, A. A., Bucana, C. D., Evans, D. B., Semenza, G. L., and Ellis, L. M. Regulation of hypoxia-inducible factor-1alpha, vascular endothelial growth factor, and angiogenesis by an insulin-like growth factor-I receptor autocrine loop in human pancreatic cancer. Am J Pathol, 163: 1001-1011, 2003.

41. Berven, L. A. and Crouch, M. F. Cellular function of p70S6K: a role in regulating cell motility. Immunol Cell Biol, 78: 447-451, 2000.

42. Hudson, C. C., Liu, M., Chiang, G. G., Otterness, D. M., Loomis, D. C., Kaper, F., Giaccia, A. J., and Abraham, R. T. Regulation of hypoxia-inducible factor 1alpha expression and function by the mammalian target of rapamycin. Mol Cell Biol, 22: 70047014, 2002.

43. Flotow, H. and Thomas, G. Substrate recognition determinants of the mitogen-activated 70K S6 kinase from rat liver. J Biol Chem, 267: 3074-3078, 1992.

44. Knowles, H. J., Raval, R. R., Harris, A. L., and Ratcliffe, P. J. Effect of ascorbate on the activity of hypoxia-inducible factor in cancer cells. Cancer Res, 63: 1764-1768, 2003.

45. Stojanovic, S., Sprinz, H., and Brede, O. Efficiency and mechanism of the antioxidant action of trans-resveratrol and its analogues in the radical liposome oxidation. Arch Biochem Biophys, 391: 79-89, 2001.

46. Masood, R., Cai, J., Zheng, T., Smith, D. L., Hinton, D. R., and Gill, P. S. Vascular endothelial growth factor (VEGF) is an autocrine growth factor for VEGF receptorpositive human tumors. Blood, 98: 1904-1913, 2001. 
47. Godwin, A. K., Meister, A., O'Dwyer, P. J., Huang, C. S., Hamilton, T. C., and Anderson, M. E. High resistance to cisplatin in human ovarian cancer cell lines is associated with marked increase of glutathione synthesis. Proc Natl Acad Sci U S A, 89: 3070-3074, 1992.

48. Hamilton, T. C., Young, R. C., McKoy, W. M., Grotzinger, K. R., Green, J. A., Chu, E. W., Whang-Peng, J., Rogan, A. M., Green, W. R., and Ozols, R. F. Characterization of a human ovarian carcinoma cell line (NIH:OVCAR-3) with androgen and estrogen receptors. Cancer Res, 43: 5379-5389, 1983.

49. Cal, C., Garban, H., Jazirehi, A., Yeh, C., Mizutani, Y., and Bonavida, B. Resveratrol and cancer: chemoprevention, apoptosis, and chemo-immunosensitizing activities. Curr Med Chem Anti -Canc Agents, 3: 77-93, 2003. 
Chapter 6

Summary and Conclusions 
This dissertation research focuses on the role of PI3K/Akt pathway in the regulation of both physiological angiogenesis and tumor-induced angiogenesis. Ang1 is the second known factor specific for endothelial cells that plays a distinct role in angiogenesis as compared to VEGF. PI3K/Akt signaling has been recognized as the key signaling event modulating Ang1-induced various angiogenic responses in endothelial cells, such as cell survival, migration, sprouting, and tube formation (1-6). However, it remains unclear about the downstream targets of PI3K/Akt pathway involved in regulating the function of Ang1. We found that the serine/thrionine kinase p70S6K1 was potently activated by Ang1 treatment of human endothelial cells in a PI3Kdependent manner. To determine whether p70S6K1 modulates the angiogenic effects of Ang1, p70S6K1 activity in HUVECs was modified by adenovirus-mediated expression of either a dominant negative or a constitutively active mutant of p70S6K1. By performing multiple classical in vitro angiogenesis assays, we clearly demonstrated that p70S6K1 is a novel angiogenic mediator for Ang1-induced endothelial responses. Notably, modulation of p70S6K1 activity has significant effects on basal endothelial cell behaviors in addition to the effects on Ang1-induced responses. Furthermore, Ang1 induces p70S6K1 activation through PI3K and MAPK signaling pathways, which can also be initiated by many other angiogenic factors, such as basic fibroblast growth factor (bFGF) and VEGF. Therefore, p70S6K1 may influence angiogenesis induced by other angiogenic factors as well. To the best of our knowledge, this is the first direct evidence that p70S6K1 is a mediator of angiogenesis. Limited recent studies suggested that p70S6K1 might regulate angiogenesis because rapamycin inhibits VEGFstimulated HUVEC proliferation (7), and suppresses tumor angiogenesis in animal models(8). However, rapamycin targets the p70S6K1 upstream kinase mTOR, which has other downstream effectors such as 4EBP1(9). The rapamycin analog CCI-779 has been evaluated in phase I phase 
II studies for cancer treatment (10). Inhibition of mTOR showed very evident anti-cancer activity, but the noticeable toxic effects remain a problem $(9 ; 10)$. The toxicity of mTOR inhibitors may be due to the inhibition of multiple mTOR downstream effectors. Based on our findings, we propose that selective targeting of p70S6K1 might be a more attractive strategy for anti-cancer and anti-angiogenic therapy, because it may achieve similar therapeutic effects with less serious toxicity as compared to mTOR inhibitors.

Another important focus of this dissertation research is tumor angiogenesis. Compelling evidence has implicated COX-2 as a critical mediator of tumor development and progression, primarily by inducing tumor angiogenesis $(11 ; 12)$. Increased COX-2 expression is frequently detected in many human cancers especially colorectal cancer $(11 ; 13)$. However, the precise factors and molecular mechanisms regulating $C O X-2$ gene expression in human ovarian cancer remain largely unknown. In this study, we showed that IGF-1 significantly upregulates COX-2 expression and $\mathrm{PGE}_{2}$ biosynthesis in human ovarian cancer cells. We further demonstrated that IGF-1 activates PI3K, MAPK, and PKC signaling cascades, which were differentially involved in the transcriptional and posttranscriptional regulation of COX-2 expression induced by IGF-1. The significance of this finding is highlighted by recent epidemiological observations that elevated levels of IGF-1 are associated with the risk of ovarian cancer development (14-17). Our data suggest that the role of IGF-1 in ovarian carcinogenesis and progression may depend on the activation of COX-2-related events.

Tumor angiogenesis involves complex interactions between multiple types of cells, including cancer cells, endothelial cells, fibroblasts, inflammatory cells, and immune cells. Among these cells, cancer cells and vascular endothelial cells are the key players in tumor angiogenesis. Recently, PI3K/Akt pathway was found to be up-regulated in tumor-derived 
endothelial cells (18). However, there is no direct evidence about the functional significance of endothelial PI3K/Akt signaling in tumor angiogenesis in vivo. To address this question, we developed a chicken chorioallantoic membrane (CAM) tumor model system based on a recently reported nude mouse model (19), in which human cancer cells were co-transplanted with human microvascular endothelial cells by using a biodegradable sponge as a scaffold. In this model system, tumor angiogenesis and growth will be predominantly determined by the direct interactions between cancer cells and the implanted human endothelial cells within the defined space of the biodegradable sponge. We found that while inhibition of PI3K or Akt activity in endothelial cells had significantly inhibitory effects, upregulation of endothelial PI3K or Akt activity exerted stimulatory effects on tumor angiogenesis and tumor growth in vivo. These data suggest that PI3K/Akt pathway in tumor associated endothelial cells might be a good target for designing novel anti-angiogenic therapy of cancer. By using the same model, we showed that PI3K/Akt signaling in tumor cells is similarly important for angiogenesis and tumor growth in vivo. Taken together, we demonstrated the important roles of PI3K/Akt signaling pathway in the two key cellular compartments for tumor angiogenesis, suggesting that targeting PI3K/Akt signaling in both tumor cells and endothelial cells may be more effective to control tumor angiogenesis and tumor progression.

Cancer chemoprevention is defined as the use of natural or synthetic compounds to prevent, suppress, or reverse the development of human cancer (20). Natural products from plants have been expected to be the major sources for developing safer and more effective chemopreventive agents. Resveratrol (trans-3,4,5'-Trihydroxystibene) is a representative of such products that has been shown recently to function as a cancer chemopreventive agent by influencing various aspects of carcinogenesis (21). It is noteworthy that no toxicity reports have 
been published with respect to resveratrol in animals even at very high doses $(3,000 \mathrm{mg} / \mathrm{kg}$ diet for 120 days in rats) (21). In this study, we demonstrated for the first time that resveratrol dramatically inhibited HIF-1 $\alpha$ and VEGF expression in human ovarian cancer cells (22), providing a novel molecular mechanism for the anticancer effects of resveratrol. This finding suggests a potential anti-angiogenic activity of resveratrol. Indeed, several recent studies clearly showed that inhibition of tumor growth by resveratrol was associated with significant suppression of tumor angiogenesis in animal models $(23 ; 24)$.

In summary, the work presented in this dissertation investigated the role of PI3K/Akt pathway in various aspects of angiogenesis. The data from this research provide direct evidence that the PI3K/Akt downstream target p70S6K1 is a novel angiogenic mediator in Ang1-induced angiogenesis. The work also demonstrated that, in human ovarian cancer cells, PI3K/Akt pathway, along with other parallel signaling events, regulates IGF-1-induced expression of COX-2, which is an important player in tumor-induced angiogenesis. We developed a novel chicken chorioallantoic membrane (CAM) tumor model system in which human cancer cells were co-transplanted with microvascular endothelial cells by using a biodegradable sponge as a scaffold. By utilizing this model, we demonstrated that PI3K and Akt activities in both endothelial and tumor cells contribute equally to tumor angiogenesis and tumor growth. Finally, we showed that the chemopreventive agent resveratrol potently inhibits HIF-1-mediated VEGF expression in human ovarian cancer cells, which is partly due to its inhibitory effect on PI3K/Akt pathway. These findings confirm the pivotal roles of PI3K/Akt pathway in various aspects of angiogenesis, suggesting that the PI3K/Akt pathway might be a potential target for angiogenesisbased therapy. 


\section{References}

1. Babaei S, Teichert-Kuliszewska K, Zhang Q, Jones N, Dumont DJ, Stewart DJ. Angiogenic actions of angiopoietin-1 require endothelium-derived nitric oxide. Am J Pathol 2003 Jun;162(6):1927-36.

2. Kim I, Kim HG, So JN, Kim JH, Kwak HJ, Koh GY. Angiopoietin-1 regulates endothelial cell survival through the phosphatidylinositol 3'-Kinase/Akt signal transduction pathway. Circ Res 2000 Jan 7;86(1):24-9.

3. Kim I, Kim HG, Moon SO, Chae SW, So JN, Koh KN, et al. Angiopoietin-1 induces endothelial cell sprouting through the activation of focal adhesion kinase and plasmin secretion. Circ Res 2000 May 12;86(9):952-9.

4. Jones N, Master Z, Jones J, Bouchard D, Gunji Y, Sasaki H, et al. Identification of Tek/Tie2 binding partners. Binding to a multifunctional docking site mediates cell survival and migration. J Biol Chem 1999 Oct 22;274(43):30896-905.

5. Harfouche R, Hassessian HM, Guo Y, Faivre V, Srikant CB, Yancopoulos GD, et al. Mechanisms which mediate the antiapoptotic effects of angiopoietin-1 on endothelial cells. Microvasc Res 2002 Jul;64(1):135-47.

6. Fujikawa K, de AS, I, Jain SK, Presman E, Christensen RA, Varticovski L. Role of PI 3kinase in angiopoietin-1-mediated migration and attachment-dependent survival of endothelial cells. Exp Cell Res 1999 Dec 15;253(2):663-72.

7. Yu Y, Sato JD. MAP kinases, phosphatidylinositol 3-kinase, and p70 S6 kinase mediate the mitogenic response of human endothelial cells to vascular endothelial growth factor. J Cell Physiol 1999 Feb;178(2):235-46.

8. Tsutsumi N, Yonemitsu Y, Shikada Y, Onimaru M, Tanii M, Okano S, et al. Essential Role of PDGFR \{alpha\}-p70S6K1 Signaling in Mesenchymal Cells During Therapeutic and Tumor Angiogenesis In Vivo: Role of PDGFR \{alpha\} During Angiogenesis. Circ Res 2004 May 14;94(9):1186-94.

9. Janus A, Robak T, Smolewski P. The mammalian target of the rapamycin (mTOR) kinase pathway: its role in tumourigenesis and targeted antitumour therapy. Cell Mol Biol Lett 2005;10(3):479-98.

10. Dutcher JP. Mammalian Target of Rapamycin Inhibition. Clin Cancer Res 2004 Sep 15;10(18):6382S-6387.

11. Dannenberg AJ, Subbaramaiah K. Targeting cyclooxygenase-2 in human neoplasia: rationale and promise. Cancer Cell 2003 Dec;4(6):431-6. 
12. Chun KS, Surh YJ. Signal transduction pathways regulating cyclooxygenase-2 expression: potential molecular targets for chemoprevention. Biochem Pharmacol 2004 Sep 15;68(6):1089-100.

13. Romano M, Claria J. Cyclooxygenase-2 and 5-lipoxygenase converging functions on cell proliferation and tumor angiogenesis: implications for cancer therapy. FASEB J 2003 Nov;17(14):1986-95.

14. Kalli KR, Conover CA. The insulin-like growth factor/insulin system in epithelial ovarian cancer. Front Biosci 2003 May 1;8:d714-d722.

15. Lukanova A, Lundin E, Toniolo P, Micheli A, Akhmedkhanov A, Rinaldi S, et al. Circulating levels of insulin-like growth factor-I and risk of ovarian cancer. Int J Cancer 2002 Oct 20;101(6):549-54.

16. Dal ML, Augustin LS, Franceschi S, Talamini R, Polesel J, Kendall CW, et al. Association between components of the insulin-like growth factor system and epithelial ovarian cancer risk. Oncology 2004;67(3-4):225-30.

17. Lukanova A, Lundin E, Micheli A, Akhmedkhanov A, Rinaldi S, Muti P, et al. Risk of ovarian cancer in relation to prediagnostic levels of C-peptide, insulin-like growth factor binding proteins-1 and -2 (USA, Sweden, Italy). Cancer Causes Control 2003 Apr;14(3):285-92.

18. BUSSOLATI BENE, DEAMBROSIS ILAR, RUSSO SIMO, DEREGIBUS MC, CAMUSSI GIOV. Altered angiogenesis and survival in human tumor-derived endothelial cells. FASEB J 2003 Jun 1;17(9):1159-61.

19. Nor JE, Peters MC, Christensen JB, Sutorik MM, Linn S, Khan MK, et al. Engineering and characterization of functional human microvessels in immunodeficient mice. Lab Invest 2001 Apr;81(4):453-63.

20. Smith JJ, Tully P, Padberg RM. Chemoprevention: a primary cancer prevention strategy. Semin Oncol Nurs 2005 Nov;21(4):243-51.

21. BHAT KPL, PEZZUTO JM. Cancer Chemopreventive Activity of Resveratrol. Ann NY Acad Sci 2002 May 1;957(1):210-29.

22. Cao Z, Fang J, Xia C, Shi X, Jiang BH. trans-3,4,5'-Trihydroxystibene Inhibits HypoxiaInducible Factor 1 alpha\} and Vascular Endothelial Growth Factor Expression in Human Ovarian Cancer Cells. Clin Cancer Res 2004 Aug 1;10(15):5253-63.

23. Tseng SH, Lin SM, Chen JC, Su YH, Huang HY, Chen CK, et al. Resveratrol Suppresses the Angiogenesis and Tumor Growth of Gliomas in Rats. Clin Cancer Res 2004 Mar 15;10(6):2190-202.

24. Garvin S, Ollinger K, Dabrosin C. Resveratrol induces apoptosis and inhibits angiogenesis in human breast cancer xenografts in vivo. Cancer Lett 2006 Jan 8;231(1):113-22. 


\section{Appendix: Detailed Methods}

\section{Adenovirus preparation}

Recombinant adenoviruses were made by using the AdEasy system (generously provided by Dr. Bert Vogelstein at Johns Hopkins University). Briefly, the cDNA constructs were subcloned into the shuttle vector pAdTrack-CMV, the shuttle plasmids was then linearized with Pme I. The Pme I-digested shuttle plasmid was transformed into electrocompetent Adeasier-1 cells (E. coli BJ5183 cells pretransformed with adenoviral backbone vector) by electroporation. Pick up smallest colonies that potentially contain the recombinant adenoviral plasmid. Perform minipreps using the conventional alkaline lysis method, and restriction digest DNA with Pac I to confirm correct recombinants. Retransform of the correct recombinant miniprep DNA into DH10B E Coli cells. Plasmids are purified by CsCl-banding. Linearize the recombinant adenoviral plasmids with Pac I, perform standard transfection of 293 cells with Lipofectamine. Virus production was monitored by checking GFP expression. Scrape cells off flasks with a rubber policeman about one week post-transfection. Release viruses by performing four cycles of freeze/thaw/vortex. Use the crude virus supernatant to infect 293 cells, collect cells and prepare virus as described above. Perform two more rounds of infection to amplify the virus. Infect the cells of interest with the virus, and perform Western blotting to confirm the effectiveness of the recombinant adenoviruses. To prepare high titer viral stock, Infect 15 to 2010 -cm plates of 293 cells with the virus sup at a multiplicity of infection (MOI) of 5 to 10 PFU per cell. When all cells have rounded up and about half of the cells 
are detached (usually at 3 to 4 days post infection), harvest and combine all the cells. Prepare virus and purify the virus stock by cesium chloride gradient centrifugation. Viral titers were determined by using the BD Adeno- $\mathrm{X}^{\mathrm{TM}}$ Rapid Titer Kit (BD Biosciences Clontech, Mountain View, CA) per the manufacturer's instructions. Briefly, 293 cells were infected with serial dilutions of viral supernatant for $24 \mathrm{~h}$, and virus infection was determined by monitoring the expression of Adenoviral protein hexon with immunohistochemical staining.

\section{Endothelial tube formation assay}

Matrigel (Becton Dickinson) capillary-tube-formation assay was performed to study in vitro angiogenesis. Briefly, human endothelial cells (HUVEC or HMVEC cells) were grown to about $80 \%$ confluence. The cells washed twice with $1 \times \mathrm{PBS}$ and serum-starved in basal medium overnight (about $16 \mathrm{~h}$ ). Cells were trypsinized and resuspended in basal medium at a concentration of $1 \times 10^{5}$ cells $/ \mathrm{ml}$. $100 \mu \mathrm{l}(10,000$ cells/well $)$ of the cell suspension was seeded in a 96-well tissue culture plate which had been evenly coated with growth factor-reduced Matrigel (BD Labware, Bedford, MA). Seeded cells were incubated at $37^{\circ} \mathrm{C}$ in a $5 \% \mathrm{CO}_{2}$ incubator for $12 \sim 24 \mathrm{~h}$. Tube structures was examined under phase-contrast microscopy and photographed using an Olympus imaging system (Olympus, Thornwood, NY, USA). Tube formation was quantified by calculating the average tube length per high power field $(200 \times)$ from five randomly selected fields. 


\section{Biodegradable sponge fabrication}

The bioabsorbable polymer scaffolds were prepared following a particulate leaching technique. Briefly, PLGA (85\% d,1-lactide/15\%glycolide, Medisorb, Cincinnati, Ohio) was dissolved in chloroform to yield a solution of 5\% polymer. The solution was loaded into a Teflon dishes packed with sodium chloride particles which was sieved to a size between 250 and $500 \mu \mathrm{m}$. The solvent was allowed to evaporate and the salt was leached by immersing the films in distilled water with several changes. Sponges were subsequently coated with polyvinyl alcohol (PVA, Aldrich Chem. Co., Milwaukee, WI) by immersing them for $16 \mathrm{~h}$ in an aqueous solution containing $10 \mathrm{mg} / \mathrm{mL}$ of PVA in PBS. The sponges were removed from the solution, dried, and were cut to $6 \times 6 \times 1 \mathrm{~mm}$ in size. The day before transplantation, sponges were disinfected by soaking in $100 \%$ ethanol for 2 hours, followed by washing twice in PBS.

\section{Survival surgery to co-transplant human endothelial and cancer cells in nude mice to study tumor angiogenesis}

Just before transplantation, $0.9 \times 10^{6}$ endothelial cells were mixed with $0.1 \times 10^{6}$ A2780 ovarian cancer cells by resuspending in a 1:1 mixture of basal medium and growth factorreduced Matrigel (BD Labware, Bedford, MA). The cell mixture was absorbed into a piece of PLGA sponge. The sponge was incubated for 30 minutes at $37^{\circ} \mathrm{C}$ to allow for gelation of the Matrigel. Female nude mice (3 to 4 weeks old, CB.17. nude, Taconic, Germantown, NY) were anesthetized with pentobarbital ( $0.05 \mathrm{mg} / \mathrm{g}$ body weight). A 0.5 
cm-long dorsal incision was made, and two sponges were implanted subcutaneously on the right and left flank regions of each mouse. 21 days after transplantation, mice were euthanized and the implants were retrieved, immediately measured with calipers, and weighed in an electronic balance. The tumor tissues were fixed overnight in Bouin's solution and processed for histological examination. The care and treatment of experimental animals was in accordance with West Virginia University Animal Care and Use Committee Policy for Survival Surgery on Rodents.

\section{Co-transplantation of human endothelial and cancer cells in chicken chorioallantoic membrane (CAM) to study tumor angiogenesis}

Fertilized chicken eggs (standard pathogen free grade; SPAFAS, Preston, CT) were incubated for $7 \mathrm{~d}$ at $37^{\circ} \mathrm{C}$ in a humidified atmosphere. An artificial air sac was created over the well-formed chicken chorioallantoic membrane $(\mathrm{CAM})$. A $1.0 \times 1.0$-cm square window was cut in the shell over the artificial air sac and sealed with Scotch ${ }^{\circledR}$ tape. On the next day, a piece of PLGA sponge loaded with cell mixture was put on the exposed $\mathrm{CAM}$. The eggshell window was resealed and the embryo was maintained at $37^{\circ} \mathrm{C}$ in a humidified atmosphere. 11 days after implantation, the eggshell window was opened and the remaining eggshell was removed to retrieve the implants. The tumor was trimmed to remove attached CAM tissues and was immediately measured with calipers, and weighed in an electronic balance. The tumor tissues were fixed overnight in Bouin's solution and processed for histological examination. 


\section{Immuonohistochemical Staining of CD31 and quantification of tumor angiogenesis}

Microvessels inside tumor tissues were visualized by immuonohistochemical staining of the vascular endothelial marker CD31. Tissue sections were deparaffinized and rehydrated following standard protocol. Antigen retrieval was performed by heating the tissue section in a microwave oven to $89^{\circ} \mathrm{C}$ for $10 \mathrm{~min}$ in $\mathrm{BD}$ Pharmingen ${ }^{\mathrm{TM}}$ Retrievagen A solution $\left(\mathrm{pH}\right.$ 6.5). The sections were then incubated at $4^{\circ} \mathrm{C}$ overnight with a $1: 40$ diluted monoclonal mouse antihuman CD31 antibody (Clone JC/70A, DakoCytomation California Inc., Carpinteria, CA). Sections were incubated with appropriate secondary antibodies, and visualization of the complex was accomplished using an $\mathrm{ABC}$ staining kit (Santa Cruz Biotechnology, Santa Cruz, CA). The sections were counterstained with haematoxylin, dehydrated and mounted. The same procedure without primary antibody was included as a negative control.

Tumor angiogenesis was quantified by calculating the microvessel density (MVD). Since microvessels are distributed heterogeneously throughout the tumor, two to four sections from each tumor were scanned under low-power magnification (x40) to identify areas of highest CD31-positive vessel density (hot-spots). Then 5 high-power fields (400x) were randomly chosen from each section to count for the number of CD31positive microvessels. All of the areas in which cells were stained with the endothelial cell marker CD31 were considered as a microvessel in spite of their size or morphology. Data were collected by two independent observers without knowledge of which tumors were viewed. MVD was defined as the total number of microvessels per 200x field (mean $\pm \mathrm{SE})$. 


\section{Immunoblotting}

The cells were washed once with ice-cold phosphate-buffered saline (140 mM NaCl, 3

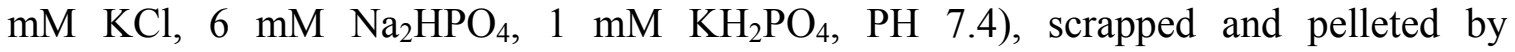
centrifugation. Whole cell extracts were prepared by incubating the cells on ice for 15 min in a modified radioimmune precipitation buffer $(100 \mathrm{mM}$ Tris, $100 \mathrm{mM} \mathrm{NaCl}, 5 \mathrm{mM}$ EDTA, 1\% Triton X-100, 1\% deoxycholate acid, 0.1\% SDS, 2 mM phenylmethylsulfonyl fluoride, $1 \mathrm{mM}$ sodium orthovanadate, $2 \mathrm{mM}$ DTT, $20 \mu \mathrm{g} / \mathrm{ml}$ leupeptin $20 \mu \mathrm{g} / \mathrm{ml}$ pepstatin $20 \mu \mathrm{g} / \mathrm{ml}, \mathrm{PH}$ 7.4). Cell lysates were clarified by centrifugation at $15000 \mathrm{rpm}$ for $15 \mathrm{~min}$. Protein concentrations of the lysates were determined using a protein assay reagent (Bio-Rad). 25 50 $\mu \mathrm{g}$ of protein samples were fractionated by $8-10 \%$ SDS-PAGE, transferred to a nitrocellulose membrane (Schleicher \& Schuell Bisciences, Keene, NH), and subjected to immunoblotting analysis. Primary antibodies were appropriately diluted in a blocking buffer (1× TBS-T: $20 \mathrm{mM}$ Tris, PH 7.4, $137 \mathrm{mM} \mathrm{NaCl,} \mathrm{0.1 \%} \mathrm{Tween-20)}$ containing $5 \%$ nonfat dry milk or $5 \%$ bovine serum albumin. The blots were blocked in $1 \times$ TBS-T buffer containing 5\% nonfat dry milk for $2 \mathrm{~h}$ at room temperature, followed by incubation with the appropriately diluted primary antibodies overnight at $4^{\circ} \mathrm{C}$. Immunoreactivity was visualized with horseradish peroxidase-conjugated secondary antibodies and enhanced chemiluminescence (PerkinElmer Life Sciences, Boston, MA). 


\section{PKC kinase activity assay}

Protein samples were prepared by lysing the cells in a PKC extraction buffer $(50 \mathrm{mM}$ HEPES, pH 7.5, $150 \mathrm{mM} \mathrm{NaCl}, 0.1 \%$ Tween 20, 1 mM EDTA, $2.5 \mathrm{mM}$ EGTA, 10\% glycerol) supplemented with protease inhibitors $(10 \mu \mathrm{g} / \mathrm{ml}$ of aprotinin, $10 \mu \mathrm{g} / \mathrm{ml}$ of leupeptin, $0.1 \mathrm{mM}$ phenylmethylsulfonyl fluoride) and phosphatase inhibitors ( $1 \mathrm{mMNaF}$, $0.1 \mathrm{mM} \mathrm{Na}_{3} \mathrm{VO}_{4}$ ). $200 \mu \mathrm{g}$ of the cellular extracts was diluted to $500 \mu \mathrm{l}$ in $1 \times \mathrm{PBS}$. PKC proteins were immunoprecipitated with $2 \mu \mathrm{g}$ of the anti-phospho-PKC (pan) antibody (beta II, Ser660, Cell Signaling Technology, Beverly, MA). The kinase activity assay was performed in $40 \mu 1$ of PKC reaction buffer (20 mM HEPES, pH 7.5, $10 \mathrm{mM} \mathrm{MgCl}_{2}$, $1 \mathrm{mM}$ dithiothreitol, $2.5 \mathrm{mM}$ EGTA, $1 \mathrm{mM} \mathrm{NaF}, 0.1 \mathrm{mM} \mathrm{Na}_{3} \mathrm{VO}_{4}, 10 \mu \mathrm{M}$ ATP)

containing $1 \mu \mathrm{g}$ of the substrate myelin basic protein and $5 \mu \mathrm{Ci}$ of $\left[\gamma_{-}{ }^{32} \mathrm{P}\right] \mathrm{ATP}$. The reactions were performed at $30^{\circ} \mathrm{C}$ for $20 \mathrm{~min}$, and terminated by adding SDS-PAGE sample buffer. Reaction products were analyzed by SDS-PAGE and visualized by autoradiography. The radioactive bands were excised and quantified by liquid scintillation counting. The activity of PKC is expressed as counts per min per $200 \mu \mathrm{g}$ of protein. 


\section{Curriculum Vitae \\ Zongxian Cao}

Department of Microbiology, Immunology, and Cell Biology

West Virginia University School of Medicine

2095 Health Sciences North, PO Box 9177

Morgantown, WV 26506

Email: zcao@hsc.wvu.edu

\section{EDUCATION:}

Doctor of Philosophy, Microbiology, Immunology, \& Cell Biology, May 2006

West Virginia University, Morgantown, WV (08/2001 05/2006)

Dissertation: PI 3-kinase/Akt signaling pathway and angiogenesis

Master of Science, Medicine, 1999

Peking University Health Sciences Center (formerly, Beijing Medical University), Beijing, P. R. China (09/1996 07/1999)

Thesis: Genetic alterations of p53 gene and its relationship with the expression of MDM2 oncogene in human hepatocellular carcinoma (HCC)

Bachelor of Science (MD equivalent), Clinical Medicine, July 1993

Shandong Medical University, Ji’nan, P. R. China (09/1988 07/1993)

\section{CLINICAL EXPERIENCE:}

Surgeon in general surgery: Yantai Yuhuangding Hospital, Medical School of Qingdao University, P. R. China, 08/1993 08/1996; 07/1999 08/2001

\section{TEACHING EXPERIENCE}

Graduate teaching assistant, January May 2003. Medical Microbiology.

\section{HONORS, AWARDS, \& PROFESSIONAL MEMBERSHIPS:}

- Travel Award, $5^{\text {th }}$ Ovarian Cancer Research Symposium, Seattle, WA. 2004

- Graduate Student Travel Award, School of Medicine, West Virginia University. 2005

- Associate member, American Association of Cancer Research (AACR). 
PROFESSIONAL PRESENTATIONS:

\section{Oral presentations:}

- p70S6K modulates the angiogenic effects of angiopoietin-1. Angiogenesis in Cancer and Vascular Disease-The 2006 Miami Nature Biotechnology Winter Symposium, Miami, FL. February 4-8, 2006

- PI 3-kinase/Akt signaling and angiogenesis. Graduate student seminar, department of Microbiology, Immunology, \& Cell Biology, WVU. 2002-2006 (Annually)

\section{Poster presentations:}

- Inhibitory effect of resveratrol on HIF-1 $\alpha$ and VEGF expression in human ovarian cancer cells. $5^{\text {th }}$ Ovarian Cancer Research Symposium-Emerging Controversies in Ovarian Cancer Research \& Treatment, Seattle, WA. September 9-10, 2004

- p70S6K modulates the angiogenic effects of angiopoietin-1. Angiogenesis in Cancer and Vascular Disease-The 2006 Miami Nature Biotechnology Winter Symposium, Miami, FL. February 4-8, 2006

- Insulin-like growth factor-1 upregulates cyclooxygenase-2 expression in human ovarian cancer cells. 97 ${ }^{\text {th }}$ AACR Annual Meeting, Washington, DC. April 1-5, 2006.

\section{RECENT PUBLICATIONS:}

1. Zongxian Cao, Jing Fang, Chang Xia, Xianglin Shi, Bing-Hua Jiang. 2004. trans-3,4,5'Trihydroxystibene Inhibits Hypoxia-Inducible Factor $1 \alpha$ and Vascular Endothelial Growth Factor Expression in Human Ovarian Cancer Cells. Clin Cancer Res 10: 5253-63.

2. Jing Fang, Chang Xia, Zongxian Cao, Jenny Z. Zheng, Eddie Reed and Bing-Hua Jiang. 2005. Apigenin inhibits VEGF and HIF-1 expression via PI3K/AKT/p70S6K1 and HDM2/p53 pathways. FASEB $\boldsymbol{J}$ 19:342-53.

3. Jing Fang, Zongxian Cao, Yi Charlie Chen, Eddie Reed, and Bing-Hua Jiang. 2004. 9- $\beta$ D-Arabinofuranosyl-2-fluoroadenine Inhibits Expression of Vascular Endothelial Growth Factor through Hypoxia-Inducible Factor-1 in Human Ovarian Cancer Cells. Mol Pharmacol 66: 178-86.

4. Ying Peng, Bing-Hua Jiang, Pai-Hao Yang, Zongxian Cao, Xianglin Shi, Marie C. M. Lin, Ming-Liang He, and Hsiang-fu Kung. 2004. Phosphatidylinositol 3-Kinase Signaling Is Involved in Neurogenesis during Xenopus Embryonic Development. J Biol Chem 279: 28509-14.

5. Chang Xia, Qiao Meng, Zongxian Cao, Xianglin Shi, Bing-Hua Jiang. Regulation of angiogenesis and tumor growth by p110 Alpha and AKT1 via VEGF expression. Journal of Cell Physiol 209(1): 56-66. 